\title{
Search for New Membrane Active Substances: synthesis of 3-tropanols with alkyl, alkenyl and alkenynyl group at the bridgehead
}

Ramalinga Murty Dharanipragada
West Virginia University

Follow this and additional works at: https://researchrepository.wvu.edu/etd

Part of the Organic Chemistry Commons

\section{Recommended Citation}

Dharanipragada, Ramalinga Murty, "Search for New Membrane Active Substances: synthesis of 3-tropanols with alkyl, alkenyl and alkenynyl group at the bridgehead" (1985). Graduate Theses, Dissertations, and Problem Reports. 10148.

https://researchrepository.wvu.edu/etd/10148

This Dissertation is protected by copyright and/or related rights. It has been brought to you by the The Research Repository @ WVU with permission from the rights-holder(s). You are free to use this Dissertation in any way that is permitted by the copyright and related rights legislation that applies to your use. For other uses you must obtain permission from the rights-holder(s) directly, unless additional rights are indicated by a Creative Commons license in the record and/ or on the work itself. This Dissertation has been accepted for inclusion in WVU Graduate Theses, Dissertations, and Problem Reports collection by an authorized administrator of The Research Repository @ WVU.

For more information, please contact researchrepository@mail.wvu.edu. 
Dharanipragada, Ramalinga Murty

SEARCH FOR NEW MEMBRANE ACTIVE SUBSTANCES: SYNTHESIS OF 3. TROPANOLS WITH ALKYL, ALKENYL AND ALKENYNYL GROUP AT THE BRIDGEHEAD

University

Microfilms

International 300 N. Zeeb Road, Ann Arbor, M148106 


\section{PLEASE NOTE}

The negative microfilm copy of this dissertation was prepared and inspected by the school granting the degree. We are using this film without further inspection or change. If there are any questions about the content, please write directly to the schooi.

\section{INFORMATION TO USERS}

The following explanation of techniques is provided to help clarify markings or notations which may appear on this reproduction.

1. The sign or "target" for pages apparently lacking from the document photographed is "Missing Page(s)". If it was possible to obtain the missing page(s) or section, they are spliced into the film along with adjacent pages. This may have necessitated cutting through an image and duplicating adjacent pages to assure complete continuity.

2. When an image on the film is obliterated with a round black mark, it is an indication of either blurred copy because of movement during exposure, duplicate copy, or copyrighted materiais that should not have iccin filmed. For blurred pages, a good image of the page can be found in the adjacent frame. If copyrighted materials were deleted, a target note will appear listing the pages in the adjacent frame.

3. When a map, drawing or chart, etc., is part of the material being photographed, a definite method of "sectioning" the material has been followed. It is customary to begin filming at the upper left hand comer of a large sheet and to continue from left to right in equal sections with small overlaps. If necessary, sectioning is continued again-beginning below the first row and continuing on until complete.

4. For illustrations that cannot be satisfactorily reproduced by xerographic means, photographic prints can be purchased at additional cost and inserted into your xerographic copy. These prints are available upon request from the Dissertations Customer Services Department.

5. Some pages in any document may have indistinct print. In all cases the best available copy has been filmed.

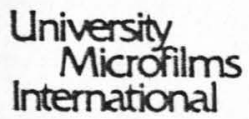


SEARCH FOR NEW MEMBRANE ACTIVE SUBSTANCES:

SYNTHESIS OF 3-TROPANOLS WITH ALKYL, ALKENYL AND ALKENYNYL GROUP AT THE BRIDGEHEAD

DISSERTATION

Submitted To The College of Arts and Sciences of

West Virginia University

In Partial Fulfillment of The Requirement For The Degree of Doctor of Philosophy

by

Ramalinga Murty Dharanipragada, M.S.

Morgantown

West Virginia 


$$
\begin{aligned}
& \text { PHys SCl. UB. } \\
& \omega \\
& 378.7543 \\
& \text { Chem. } \\
& \text { D } 5365 \\
& \text { C. } 2
\end{aligned}
$$

my mother on the occasion of her sixtieth birthday and to the memory of my father. 


\section{ACKNOWLEDGEMENTS}

It is my pleasure to thank my research advisor, Dr. G. Fodor for sharing his expertise on tropane alkaloids with me. I particularly would like to thank him for giving me the opportunity to co-author several review articles on the chemistry of tropane alkaloids. My stay with him has been a learning experience.

I would like to thank two of my teachers, Drs. W. R. Moore and D. W. H. MacDowe11, who "baptised" me into organic chemistry. I would like to thank the other members of my committee Drs. N. S. Dalal and J. P. O'Donnell for their cooperation. I thank Dr. R. Wang for several "chalk-fest" sessions which proved very useful.

Several people in Dr. Fodor's research group deserve my gratitude. I thank Mrs. Jyothsna Venkat for years of warm friendship. Her help in proof-reading this manuscript is deeply appreciated. I thank Dr. J. Case and the late Dr. J. Butterick for refining my techniques in the laboratory. I thank Drs. R. Arnold and K. Fang for their friendship and pleasant company. I chank Dr. R. Sussangkarn and Dr. Hansie Mathelier for their cooperation in the laboratory. I thank Ms. Krystal Berry for her help with some of the drawings.

Several undergraduate students have contributed to the success of this project. I would like to thank Mr. Craig Abshire, Mr. Dale Carpenter, Ms. Karen Clark, Mr. Sam Colombo, 
Mr. Mark Herman, Mr. Jeff Jackson, Mr. Tony Piscopio, Mr. Ely J. Salon, Mr. Stan Wasilewski, and Mr. Robyrt Yepundich for their contributions in terms of maintaining a steady supply of some of the key intermediates. Tony Piscopio was instrumental in the preparation of en-yne Wittig salts.

Over the years, I had the privilege to assist more than 700 students in the undergraduate chemistry laboratories. These students have helped me to strengthen the foundations of my chemistry. I thank the department of chemistry for giving me such an opportunity and also for uninterrupted financial support all these years.

Several friends among the staff of the chemistry department have made me feel at home. They helped me find a home "away from home". Particular mention should be made of Mr. Forrest Ferrell whose sense of humor, fatherly advice and warm friendship kept me sane from time to time. I thank Mrs. Georgetta Cobun, Mrs.

Siobhan Byrne, Mrs. Marleen Dewitt, Mrs. Dorothy Nagy, Ms. Eloise McNair, Ms. Miche 11 Cobun, Ms. Debbie Koon, Mrs. Bev Matheny, Mr. Mike Naugle, Mr. Bob Victor, Mr. Carl Wise, and Mr. Sherman Adams for their cooperation and cheerful disposition at all times.

At this point I would like to reminisce and thank a lot of my friends whose friendship I value very much. I acknowledge Mr. Jamshed Bapasola, Mr. Bobby Adams, Dr. Mahendra Suryan, Dr. Sham Nikam, Dr. Jagadeesh Moodera, Mrs. Sharada Shenvi Labadie, Mrs. Shahin Ravangard, Mr. Jalil Shojae, Mr. Wee Lerdthusnee, Mrs. Malvina Marcano, Ms. Sujitra Dhumrongvaraporn, 
Mr. Hongbum $\mathrm{Kim}$, Ms. Nancy Crowley, Ms. Donna Carmesi and Ms. Stephanie Ware for their friendship. I thank my roommate Mr. Vijay Waghray for putting up with me all these years.

I thank my cousins Dr. Babu Paidipaty and Dr. Sudha Paidipaty of Detroit for the good times I had with them every Christmas.

I thank Mrs. Duana Nacarate for typing this manuscript. She impressed me with her professionalism, speed and her ability to decipher my handwriting, which is no easy task.

There have been times, while in the process of trying to run, I was unable to walk, and I did many "moonwalks" in the chemical sense; with none of the reactions proceeding in the desired direction. I thank God many of the problems have been solved towards the end.

Finally the most important person I would like to thank is my frield Alex who defined friendship in her own special way. When she talks I listen. No matter where I go, her friendship, affection and love will always be cherished. 
TABLE OF CONTENTS

Page

TITLE PAGE .................... i

DEDICATION .................... ii

ACKNOWLEDGEMENTS ................... ii

TABLE OF CONTENTS .................... vi

LIST OF FIGURES .................... $x 11$

1. INTRODUCTION AND LITERATURE SURVEY ........... 1

2. STATEMENT OF THE PROBLEM............... 8

3. SYNTHETIC STRATEGY ................ 9

4. RESULTS AND DISCUSSION ............... 11

Part A - Construction of Tropane Skeleton . . . . . 11

4.1.1 Building Blocks ............. 11

4.1.2 Synthetic Efforts Towards Recoaldehyde 26 . 13

4.1.3 Hydrogenation of $\underline{32}$.......... 17

4.1.4 Robinson Condensation ........ 18

4.1.5 Mechanism of Robinson Condensation..... 20

4.1.6 Synthesis of related Tropinones ...... 20

4.1.7 Stereoselective Reduction of $( \pm)$ 1-Methoxymethyl-3-tropanone $(17)$........ 24

4.1.8 Configuration of $\mathrm{C}-3$ Hydroxyl of 43 ... 25

4.1.9 Structure Determination of 43-Chemical Methods 26

4.1.10 Protection of $\mathrm{C}-3$ Hydroxyl in $43 . . . . .31$

4.1.11 Improvement of Yields of 60 : Use of $4-\mathrm{N}, \mathrm{N}-$ Dimethylaminopyridine (DMAP) as Acetylation Catalyst............ . . 32

4.1.12 Reasons for Improved Yields - Mechanisa of DMAP Action ... . . . . . . . . 33

4.1.13 Cleavage of Methyl Ether of $60 . . . . . .35$

4.1.14 Structure Determination of the Monoacetate 55. 39 
Part B - Elaboration of the Side Chain by Wittig Route . . . . . . . . . 41

4.2.1 Search for Oxidizing Agent......... 41

4.2.2 Dimethylsulfoxide-Dicyclohexylurea Oxidation . 43

4.2.3 Structure of the Tropan-1-Aldehyde (56) Spectral Data ... . . . . . . . 45

4.2.4 Chemical Proof for the Structure of Aldehyde 56 . . . . . . . . . . 46

4.2.5 Mechanism of DMSO-DCC Oxidation ....... 46

4.2.6 Constraints of the oxidation ....... 47

4.2.7 DMSO-Acetic Anhydride as Oxidants . . . . 47

4.2.8 Mechanism of Oxidation ......... 51

4.2.9 Possible Mechanism for Acetate Formation . . 52

4.2.10 Oxidation using DMSO/Pyridine- $\mathrm{SO}_{3}$. . . . 54

4.2.11 Oxidation using DMSO- $\mathrm{P}_{2} \mathrm{O}_{5}$......... 55

4.2.12 DMSO-Thionyl Chloride .......... 56

4.2.13 Swern Oxidation: DMSO-Oxalyl Chloride Complex as Oxidizing Agent . . . . . . . . 56

4.2.14 Mechanism of DMSO-Oxalyl Chloride Oxidation . 58

4.2.15 Wittig Reaction: Extension of the Side Chain. 60

4.2.16 Structure Determination of 1-Pentenyl-38tropanol.............. 63

4.2.17 Interpretation of Mass Spectra of 1-Pentenyl3B-Tropanol . . . . . . . . . . 64

4.2.18 Removal of Acetate by Transesterification . . 67

4.2.19 Stereochemistry of Wittig Olefination . . . 68

4.2.20 Mechanism of Wittig Reaction........ 69

4.2.21 Attempted Preparation of Crystalline Salts of 14 .............. 71

4.2.22 Chemical Confirmation of Structure of Alkene 14 .............. . 72

4.2.23 Reduction of Alkene 14 to $( \pm)$ 1-n-Pentyl-3Btropanol (15) ............ 72

4.2.24 Attempted Removal of $\mathrm{N}-\mathrm{CH}_{3}$ of 1-Penteny $1-38-$ tropanol

Part C - Scope and Limitations of the Wittig Route . . 80

4.3.1 Retrosynthesis Analysis of Skipped En-yne 136. 80

4.3.2 Comparison of Scheme 99 and Scheme $100 . . .83$ 
4.3.3 Attempted Condensation of Aldehyde 56 with ylide 139 .............

4.3.4 Alternate Approaches to Skipped En-yne Sidechain .......... . . 88

4.3.5 Preparation of Wittig Salt $149 . \ldots . . . .88$

4.3.6 Attempted Preparation of $\mathrm{H}-\mathrm{C} \equiv \mathrm{C}-\mathrm{CH}_{2} \mathrm{CH}_{2} \mathrm{PPh}_{3} \mathrm{Br} 49 \quad 89$

4.3.7 Attempted Preparation of Phosphonium Tosylate 158 ............ 91

4.3.8 One Step Preparation of 4-Bromo-1-butyne... 94

4.3.9 Wittig Condensation Leading to En-yne $\underline{151}$. . 96

4.3.10 Studies on Aldehyde Homologation....... 98

Part D - Attempted Organometallic Route to 1-Alkyl Tropanols ............ 103

4.4.1 Attempted Preparation of Bromide 176 . . . 103

4.4.2 Attempted Preparation of Chloride 177 . . 105

4.4.3 Preparation of Mesylate 180 . . . . . 107

4.4.4 Attempted Carbon-Carbon Bond Formation using Mesylates ............... 112

4.4.5 Formation of Sulfones - Steric Factors Raise their Ugly Heads... . . . . . . 113

4.4.6 Preparation of Iodide 193 ........ 115

4.4.7 Mechanism of Formation of Iodide . . . . . 117

5. SUMMARY ........................ 121

6. EXPERIMENTAL . . . . . . . . . . . . 123

Instrumentation .................. 123

Solvents................. 124

Reagents . . . . . . . . . . . . . 124

General Remarks . . . . . . . . . . . 127

Preparations.................. 127

6.1 Preparation of Furfuryl methyl ether $(\underline{31}) . .127$

6.2 Preparation of 2,5-Dimethoxy 2-methoxymethyl$2,5$-dihydrofuran ( 32$)$......... 129

6.3 Preparation of Raney Nickel $\mathrm{W}-2 \ldots . . . . .130$

6.4 Preparation of 2,5-Dimethoxy-2-methoxymethyl tetrahydrofutan (34).................. 131

$6.5( \pm) 1-$ Methoxymethyl-3-tropanone $(\underline{17}) \ldots . . .132$ 
6.6 Preparation of 1-Methoxymethy1-3B-tropanol (43). 134

6.7 Preparation of 1-Methoxymethyl pseudotropine hydrochloride (45).......... . . 135

6.8 Preparation of 1-Methoxymethyl-3B-acetoxytropane Hydrochloride $(60)$. . . . . . . . 136

6.9 Preparation of 1-Hydroxymethyl-3B-acetoxytropane (55)................ . . 137

6.10 Preparation of Tetraphenyl borate salt of 3B-Hydroxymethy 1-38-ace toxytropane .... 138

6.11 Preparation of Methyl-2-furoate (27) . . . . 141

6.12 Preparation of 1-Hydroxymethyl-3B-tropanol (52). 142

6.13 Swern Oxidation of 1-Hydroxymethyl-3Bacetoxytropane (55) to 38-acetoxytropane-1aldehyde (56) .........

6.14 Chemical conformation of structure of $3 B-$ acetoxytropane-1-aldehyde $(56)$ by reduction to 1 -hydroxymethy 1-3B-ace toxytropane (55) ....

6.15 Pfitzner-Moffatt Oxidation of 1-hydroxymethyl$3 B$-ace toxytropane

6.16 Attempted Oxidation of 55 using dimethyl sulfoxide in presence of acetic anhydride. Preparation of 1-acetoxymethy 1-3B-acetoxy tropane $(86)$

6.17 Preparation of Sulfur Trioxide-Pyridine Complex.

6.18 Oxidation of 1 -Hydroxymethyl-3B-acetoxytropane by Dimethyl Sulfoxide in Presence of PyridineSulfur Trioxide Complex . . . . . . . . .

6.19 Preparation of n-Butyl triphenyl phosphonium bromide ( 98 )

6.20 Wittig condensation of aldehyde 56 , with n-butylidene triphenylphosphorane: Preparation of 1-pentyl-3B-hydroxytropane (14)...... 150

6.21 Preparation of 1 -(1-Penteny 1$)$-3-acetoxytropane (103) ..................... 152

6.22 Deacetylation of 1 -(1-penteny 1$)-38$-acetoxytropane 153

6.23 Addition of n-Butyllithium to $3 B$-Acetoxytropane1-aldehyde ............ 154

6.24 Preparation of Potassium Azo Dicarboxylate . . 155

6.25 Attempted Diimide Reduction of Alkene 14... . 155

6.26 Preparation of ( \pm ) $1-n$-amyl-3B-tropanol (15).. 155

6.27 Preparation of $(+) 1-n$-amyl-3B-tropanol hydrochloride $(\underline{122})$.......... 156

6.28 Preparation of 4-Trimethylsilyl but-3yn-1-01 . . 156 
6.29 Tosylation of 4-trimethylsilyl but-3yn-1-ol . . 158

6.30 Displacement of Tosylate 146 by Iodide . . . 158

6.31 Preparation of Triphenyl (1-Trimethyl silyl but-3-yn1) phosphonium iodide (138) ..... 159

6.32 Preparation of 3-Butynyl cosylate . . . . . 160

6.33 Preparation of 1-Bromo-3-butyne (152) . . . . 160

6.34 Attempted improvement of yields of $\mathrm{PBr}_{3}$ reaction: use of $\mathrm{LiBr}$ as co-reactant . . . . . . . 162

6.35 Preparation of 1-Bromo-3-butyne using Carbon Tetrabromide and Triphenylphosphine ..... 163

6.36 Attempted Preparation of 1-Bromo-3-butyne by utilizing $\mathrm{N}$-bromosuccinimide/triphenyl phosphine as brominating reagents

6.37 Preparation of triphenyl(but-3-yn1) phosphonium bromide 149

6.38 Attempted preparation of triphenyl(but-3-ynl) phosphonium tosylate ........ 165

6.39 Attempted Wittig condensation of neopentyl aldehyde 56 with triphenyl (1-trimethylsilyl but-3-ny 1 ) phosphonium iodide $(\underline{138})$. . . 166

6.40 Wittig reaction of triphenyl (3-butynylidene) phosphorane (150) with 38-acetoxytropane-1aldehyde $(56)$........... 169

6.41 Aldehyde homologation - attempted Wittig reaction of neopentyl aldehyde 56 with methoxymethylene triphenylphosphorane

6.42 Successful homologation of aldehyde 56 to $1-(3 B-a c e t o x y t r o p a n e)$ acetaldehyde wittig reaction using 2 eq of potassium butoxide as base

6.43 Cleavage of enol ethers 173 and 174 with boron

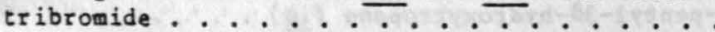

6.44 Attempted Preparation of 1-chloromethyl-3Bacetoxytropane $(\underline{177})$.......... 175

6.451 -Methanesu 1 fony $10 x y m e t h y 1-3 B$-acetoxytropane (180)

6.46 Conversion of acetoxy mesylate 180 into 1 -methane sulfonyloxymethyl-3B-tropanol (181)

6.47 Hydrogenolysis of mesylate 180 into 1 -methyl38-tropanol $(\underline{183})$.......... 178

6.48 Attempts to couple 1 -mesyloxymethy $1-3 B-$ acetoxytropane (186) with allyl magnesium bromide

6.49 Attempted coupling of mesylate 180 with ethyl magnesium bromide 
6.50 Attempted coupling of mesylate 180 with ethyl magnesium bromide using $\mathrm{Li}_{2} \mathrm{CuCl}_{4}$ as catalyst . 180

6.51 Attempted coupling of mesylate 180 with di n-butyl copper lithium ........... 181

6.52 Preparation of di-n-butyl methyl carbinol . . 182

6.53 Conversion of mesylate $\underline{180}$ into iodide $\underline{193} \cdot$. 183

6.54 Artempted Coupling of Allylmagnesium bromide with 1 -Iodomethyl-3B-acetoxytropane . . . . 184

REFERENCES . . . . . . . . . . . . . 186

APPENDIX . . . . . . . . . . . . . . . . . 196

ABSTRACT . . . . . . . . . . . . . . 285

VITA .................. 286

APPROVAL PAGE ..................... 288 


\section{LIST OF FIGURES}

Figure

Page

${ }^{1}$ H NMR spectrum of 1 -methoxymethylfuran (31) . 198

Infrared spectrum of 1-methoxymethyl furan (31) * 199

$1_{H}$ NMR spectrum of 1-methoxymethyl-2,5dimethoxy-2,5-dihydrofuran (32)

Infrared spectrum of 1-methoxymethyl-2,5dimethoxy-2,5-dihydrofuran (32) ..... 202

5 1 1 B MMR spectrum of 1-methoxymethyl-2,5dimethoxytetrahydrofuran (34) ....... 204

6 Infrared spectrum of 1-methoxymethyl-2,5dimethoxytetrahydrofuran (34) ...... 205

${ }^{1}$ H NMR spectrum of 1 -methoxymethyl tropane

3-one $(17)$.............. 207

8 Infrared spectrum of 1-methoxymethyl tropane 3-one $(17)$. . . . . . . . . . 208

$1_{\text {B NMR spectrum of } 1 \text {-methoxymethyl }}$ 38 -hydroxytropane (43) ......... 210

Infrared spectrum of 1 -methoxymethyl $3 B$-hydroxytropane $(\underline{43})$. . . . . . . . . 211

111 H NMR spectrum of 1 -methoxymethy 1 38 -acetoxytropane hydrochloride $(60)$. . . . 213

12 Infrared spectrum of 1-methoxymethyl 38 -acetoxytropane hydrochloride $(60) \ldots 214$

131 H NMR spectrum of 1-methoxymethyl 3B-acetoxytropane .......... 216

141 1H NMR spectrum of 1-hydroxymethyl 3B-ace toxytropane (55) ......... 218

15 Infrared spectrum of 1-hydroxymethyl

38 -ace toxytropane (55)......... 219

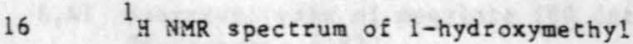
38 -hydroxytropane $(52) . . . . . . .$.

17 Infrared spectrum of 1-hydroxymethy 1

$3 B$-hydroxycropane $(\underline{52})$..........

$1_{H}$ NMR spectrum of $3 B$-acetoxytropane

1 -aldehyde ( $\underline{56})$ 
19 Infrared spectrum of $3 B$-acetoxytropane 1-aldehyde $(56)$. . . . . . . . 225

201 H NMR spectrum of 1-acetoxymethyl 38 -acetoxytropane $(86)$......... 227

$21{ }_{\mathrm{H}}^{1} \mathrm{NMR}$ spectrum of $1-(1-$ penteny 1$)-38-$ acetoxytropane $(103)$. . . . . . . . 229

22 1 ${ }_{\text {H }}$ NMR spectrum of 1 -(1-pentenyl $)-38-$ hydroxytropane $(14)$. Solvent: $\mathrm{CDCl}_{3} . . .231$

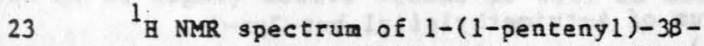
hydroxytropane (14). Solvent: $\mathrm{CDCl}_{3}+\mathrm{D}_{2} \mathrm{O}$. 232

24 Infrared spectrum of 1 -( 1 -penteny 1$)-3 \beta-$ hydroxytropane $(14)$.......... 233

$25{ }^{13} \mathrm{C}$ NMR spectrum of $1-(1-$ penteny 1$)-3 B-$ hydroxytropane $(14)$.......... 234

Mass spectrum of 1 -(1-penteny 1$)-3$ hydroxytropane (14)............. . . 235

271 H NMR spectrum of 1 -pentenyl 3 -hydroxytropane (15).............. . . 237

281 H NMR spectrum of 1 -pentenyl $3 B$-hydroxytropane hydrochloride (122)

Mass spectrum of 1 -pentenyl 38 -hydroxytropane hydrochloride (122)

${ }^{1}$ g NMR spectrum of $1-(1-$ hydroxypentyl $)-38-$ hydroxytropane (118).

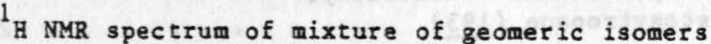
of 1-(2-methoxyvinyl)-3B-acetoxytropane $(173+174)$. . . . . . . . . . . 244

${ }^{1}$ H NMR spectrum of $1-(3 \beta$-hydroxytropany 1$)$ acetaldehyde (164)

${ }^{1}$ H NMR spectrum of 1-bromo-3-butyne (152) ... 248

Infrared spectrum of 1-bromo-3-butyne (152) . 249

${ }^{1}$ H NMR spectrum of 4-butynyl triphenyl phosphonium bromide (149) 
Infrared spectrum of 1 - (1-penten-4-yny 1$)-3 \beta-$ ace toxytropane $(151)$......... 256

Mass spectrum of $1-(1-$ penten-4-yny 1$)-3 B-$ ace toxytropane $(151)$......... 257

${ }^{1}$ H NMR spectrum of $4-t$ rimethylsilyl but $-3 y n-1-01$

Infrared spectrum of 4-trimethylsilyl but-3yn-1-ol

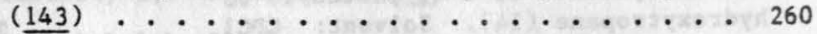

${ }^{1}$ H NMR spectrum of 4-trimethylsilyl but-3yn-1tosylate $(146) . . . . . . . . . .262$

Infrared spectrum of 4-trimethylsilyl but-3yn-1tosylate $(\underline{146}) . . . . . . . .263$

${ }^{1}$ H NMR spectrum of 1-Iodo-4-trimethylsilyl-3-

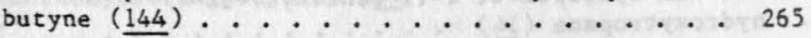

Infrared spectrum of 1-Iodo-4-trimethylsilyl-3butyne $(144) . . . . . . . . .266$ ${ }^{1}$ H MMR spectrum of 3-butynyl 1-tosylate (153) . 268

47 1 1 M MR spectrum of 1-methanesulfonyloxymethyl $3 \beta$-acetoxytropane $(\underline{180})$......... 270

48 Infrared spectrum of 1-methanesulfonyloxymethyl $3 B$-ace toxytropane $(\underline{180})$......... 271

491 H NMR spectrum of 1 -methanesulfonyloxymethyl 3 B-hydroxytropane $(\underline{181})$........ 273

501 H NMR spectrum of 1 -iodomethyl 38 -acetoxytropane $(\underline{193})$........ 275

51 Infrared spectrum of 1-iodomethyl 38 -acetoxytropane $(193)$........ 276

521 H NMR spectrum of Di-n-butyl methyl carbinol $(\underline{185}) \ldots . . . . .278$

53 Infrared spectrum of Di-n-butyl methyl carbinol (185)............ 279

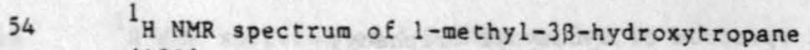
(183) .............. 281

$551_{H}$ NMR spectrum of allyl mechylsulfone (186a) . 283 56 Infrated spectrum of allyl methylsulfone (186a). 284 


\section{INTRODUCTION AND LITERATURE SEARCH}

In recent years, witkop and coworkers have isolated 1,2 several structurally unique alkaloids from the colombian frog belonging to the genera Dendrobates. These alkaloids, which occur in the defensive skin s, :etions of the frog have been found to be highly active venoms as well as mucosal tissue irritants towards both mammals and reptiles. Among them are three important alkaloids histrionicotoxin, isodihydrohistronicotoxin and octahydrohistronicotoxin.

1a Histrionicotoxin

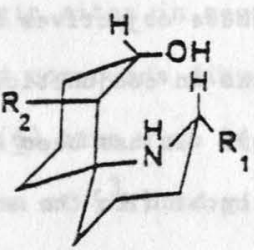

$$
\begin{aligned}
& 1 \\
& R_{1}=-\mathrm{CH}_{2}-\stackrel{\mathrm{C}=\mathrm{C}}{\mathrm{H}} \underbrace{\mathrm{H}}_{\mathrm{C} \equiv \mathrm{C}-\mathrm{H}}
\end{aligned}
$$

$$
R_{2}=-C=C_{C}^{-H}
$$

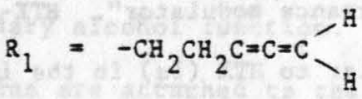

1 b Isodihydrohistronicotoxin

H $\mathrm{H}$

$$
R_{2}=-C=C-C \equiv C-H
$$

1c Octahydrohistrionicotoxin

$$
\begin{aligned}
& \mathrm{R}_{1}=-\mathrm{CH}_{2} \mathrm{CH}_{2} \mathrm{CH}_{2} \mathrm{CH}=\mathrm{CH}_{2} \\
& \mathrm{R}_{2}=-\mathrm{CH}_{2} \mathrm{CH}_{2} \mathrm{CH}=\mathrm{CH}_{2}
\end{aligned}
$$

1d Perhydrohistrionicotoxin

$$
\begin{aligned}
& \mathrm{R}_{1}=-\mathrm{CH}_{2} \mathrm{CH}_{2} \mathrm{CH}_{2} \mathrm{CH}_{2} \mathrm{CH}_{3} \\
& \mathrm{R}_{2}=-\mathrm{CH}_{2} \mathrm{CH}_{2} \mathrm{CH}_{2} \mathrm{CH}_{3}
\end{aligned}
$$


The $C_{19}$ alkaloids histrionicotoxin (abbreviated as HTX) 1 a and gephyrotoxin (2) (Dendrobates histrionicus) share common cis enyne side chains, while pumiliotoxin-C ( 3 ) (Dendrobates Pumilio) and gephyrotoxin (2) are both elaborated cis-decahydroquinolines. Both histrionicotoxin (1 $\underline{\text { a }}$ ) (HTX) and its semisynthetic derivative perhydrohistrionicotoxin ( $(1 \mathrm{~d})\left(\mathrm{H}_{12}{ }^{-H T X}\right)$ have attracted considerable interest from the standpoint of total synthesis, and while a total synthesis of HTX is yet to be accomplished, several different approaches to the construction of $\mathrm{H}_{12}-\mathrm{HTX}(\underline{1 \mathrm{~d}})$ have been reported. ${ }^{3}$ The attention given to these objectives stems from their unique properties as neurotoxins in conjunction with the scarcity of $\operatorname{HTX}\left(c a .200 \mu g\right.$ per frog). It has been shown ${ }^{4 b}$ that both $\operatorname{HTX} \underline{\mathrm{la}}$ and $\mathrm{H}_{12}-\mathrm{BTX}$ Id selectively bind to the aceryl choline receptor and interrupt transsynaptic transmission of neuromuscular impulses. Both $\underline{1 \mathrm{a}}$ and $\underline{1 \mathrm{~d}}$ block postsynaptic membrane depolarization while not interfering with acetylcholine binding. It has been postulated ${ }^{4 a}$ that these toxins prevent membrane depolarization by reversible binding to the receptor ion channel or "ion conductance modulator". $\operatorname{arX}-12$ (1d) has biological activity similar to HTX (1a) in the in vitro assay in nerve muscle preparation of frogs and therefore provides a biochemical standard.

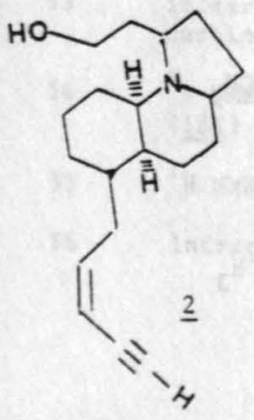<smiles>CCC[C@@H]1CC[C@@H]2C(C)CCC[C@H]2N1</smiles> 
Histrionicotoxin $\operatorname{HIX}(\underline{\mathrm{la}})$ appears to act quite similarly to its completely reduced form $\mathrm{HTX}-12$ (1d). This alkaloid reduces the sensitivity of denervated skeletal-muscle to repetitive applications of acetylcholine and blocks the increase in ionic conductance resulting from co ination of acetylcholine with its own receptor. In addition, HTX specifically inhibits the increase of potassium conductance that normally occurs during an action potential.

Perhydrohistrionicotoxin has been shown to inhibit muscarinic cholinergic sites in neuroblastoma cells. ${ }^{4 c}$ The structurally related compounds dihydro-adaline, (4), granatan-3 $\alpha-01$ (5), grantan-38-ol (ㅁ) have also been tested for their receptor affinity. Inhibition of $\left[{ }^{3} \mathrm{H}\right]$ scopolamine binding was studied by carrying out displacement experiments with $\left[{ }^{3} \mathrm{H}\right]$ scopolamine as the labelled ligand. Fifty percent inhibition of $\left[{ }^{3} \mathrm{H}\right]$ scopolamine binding was obtained by either 70 M H $\mathrm{H}_{12} \mathrm{HTX}, 250$ M

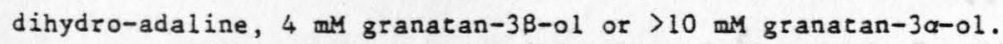
All these compounds have similar bicyclic structural elements with a secondary amino and a secondary alcohol function. While in $\mathrm{H}_{12} \mathrm{HTX}$, two aliphatic side chains are attached to the ring system, dihydro-adaline has only one aliphatic side chain, and the granatanols have none. Thus, the observed order of receptor affinity suggests that liphophilic side chains contribute to the receptor binding of these compounds.

As can be seen from molecular models, the amino and hydroxyl groups of HTX ( 1 a ) and dihydro-adaline ( 4 ) are in very similar and 
close conformational arrangements, permitting a hydrogen bond interaction. The hydroxyl group of granatan-38-ol ( $\underline{6})$ has the same conformation as in dihydro-adaline whereas, in granatan-3 $\alpha-01$ (5) it points in the opposite direction and cannot interact with the amino -rnup. Since granatan-3 $\alpha-01$ ( $\underline{5}$ ) has a lower affinity to the receptor than granatan-38-ol (6), a certain orientation of the hydroxyl group, probably in relation to the amino group, appears to be important for causing receptor blockade.

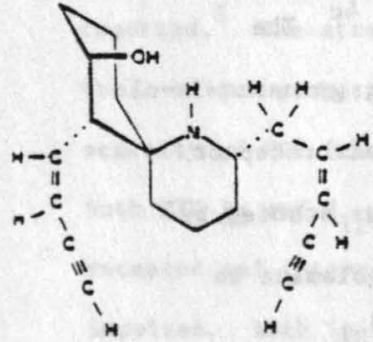

$\underline{1 \mathrm{a}}$
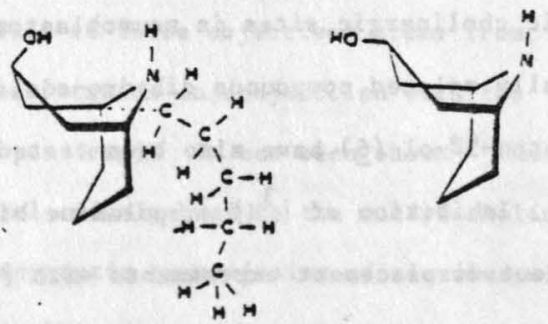

$\underline{4}$ $\underline{5}$

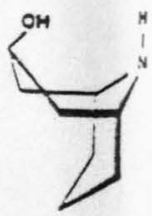

Adaline 7, isolated ${ }^{5}$ from the defensive secretion of European ladybug Adalia bipunctata, has a secondary amino and hydroxyl moieties and an amyl side chain. It has insect antifeeding properties. Several groups ${ }^{6}$ have accomplished the total synthesis of adaline.

An elegant route to racemic adaline, using an intramolecular nitrone cyclo-addition has been achieved by Gössinger and witkop, affording adaline in $30 \%$ overall yield in eight steps from N-hydroxy-piperidine ${ }^{6 a}$ (Scheme 1 ).

An alternative approach by $\mathrm{H} 11^{6 \mathrm{~b}}$, using double Michael 
Scheme 1

$\int_{0}^{0}$
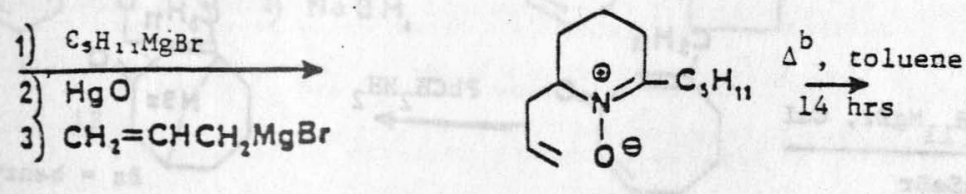

8
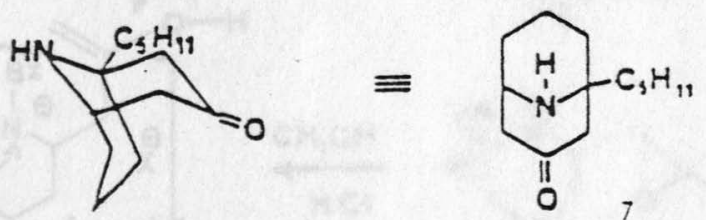

(ध) ADALINE 
addition of benzylamine to 3-alkyl-2,7-cyclooctadienones lead to racemic adaline (Scheme 2). Asymetric induction was achieved by using (+)- $\alpha-$ methyl benzylamine (Scheme 3 ).

\section{Scheme 2}

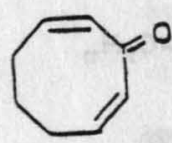

1. $\mathrm{C}_{5} \mathrm{H}_{11} \mathrm{MgBr}, \mathrm{CuI}$

2. $\mathrm{PhSeBr}$

3. $\mathrm{H}_{2} \mathrm{O}_{2}$, pyridine

11

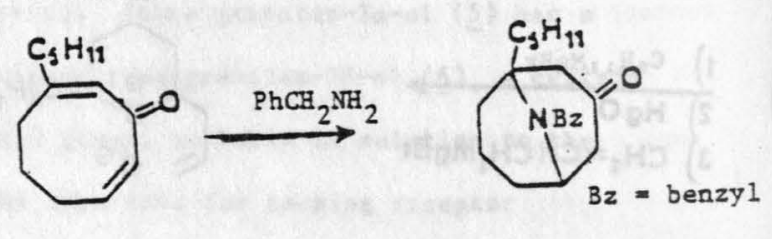

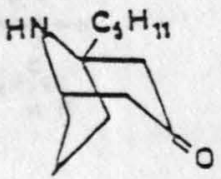

$\equiv$

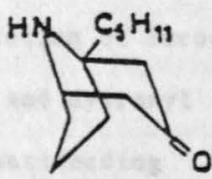

\section{$R(-)$ ADALINE}

A biomimetic synthesis of adaline has been accomplished by Hussen $^{6 \mathrm{~d}}$ and coworkers. The key step of their synthetic route was an intramolecular Mannich reaction of the intermediate iminium-enol $13^{\prime}$ derived from the enamine equivalents, aminonitrile 13 (Scheme 4 ). 


\section{Scheme 4}

(1)

1) $8 z B r$

12

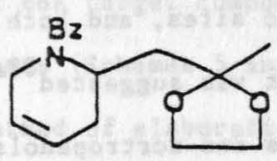

2) $\mathrm{NaBH}_{4}$

$\overbrace{B 2}^{\text {II }}$

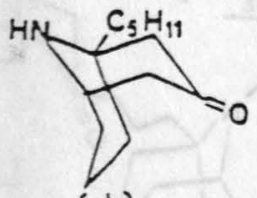

(士) ADALINE

$$
\begin{aligned}
\mathrm{Bz} & =\mathrm{CH}_{2} \mathrm{C}_{3} \mathrm{H}_{3} \\
\mathrm{R}= & \mathrm{CH}_{3} \quad \text { (a) } \\
& \mathrm{n} \mathrm{C}_{5} \mathrm{H}_{11} \quad \text { (b) }
\end{aligned}
$$

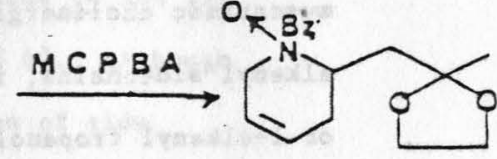

$\left.\left(\mathrm{CF}{ }_{3} \mathrm{CO}\right)_{2}\right)$

$\mathrm{KCN}$

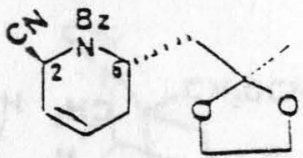

(1) $H_{2} / P d$

(2) $L D A / R X$

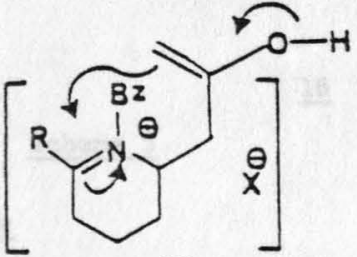

$\mathrm{CH}_{2} \mathrm{OH}$ $+\mathrm{HCl}$

13

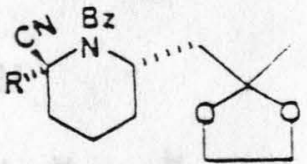




\section{STATEMENT OF THE PROBLEM}

Since histrionicotoxin (1a) and dihydroadaline (4) inhibit muscarinic cholinergic sites, and both of them have alkyl or alkenyl sidechains, it was suggested 88 a that synthesis of 1 -alkyl or 1-alkenyl tropanols and nortropanols (which would be expected to have similar conformational arrangement as $\underline{1 a}$ and $\underline{4}$ ) might be profitable in order to explore structure activity relationships. The target compounds are:
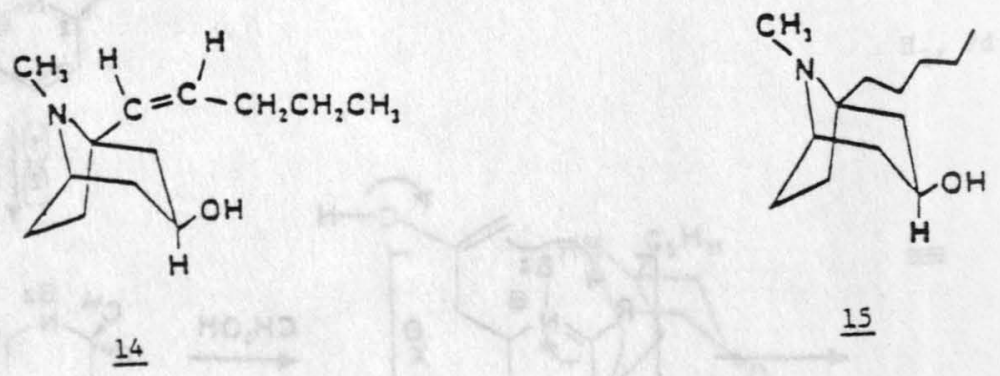

\section{5}

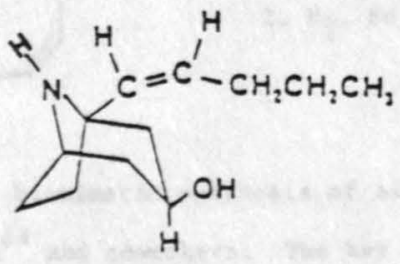

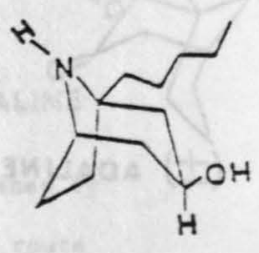

207 


\section{SYNTHETIC STRATEGY}

A retrosynthetic analysis of the target compounds 14 and 15 would suggest two conceivable routes (Schemes 5 and 6 ). Although different in nature (as to the method of elaboration of side chain), both these routes share a common precursor such as 1-carbomethoxy-3-tropanone $(\underline{16})$ or 1-methoxymethy 1-3-tropanone (17).

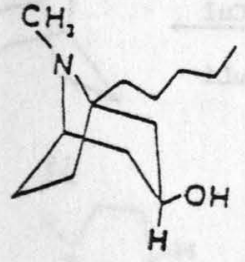

13

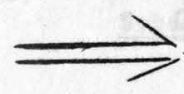

16

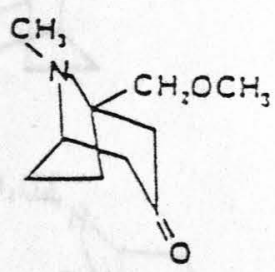

17

Scheme 5

\subsection{Route I: Wittig Route}

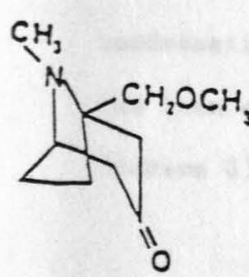

17

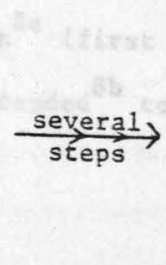

OR

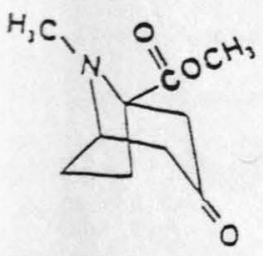

16

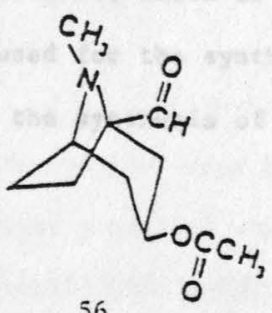

56

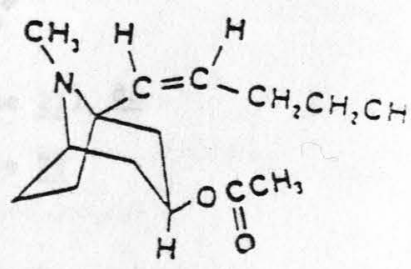

103

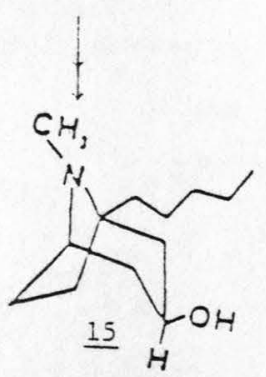




\section{Scheme 6}

\subsection{Route II: Organometallic Route}

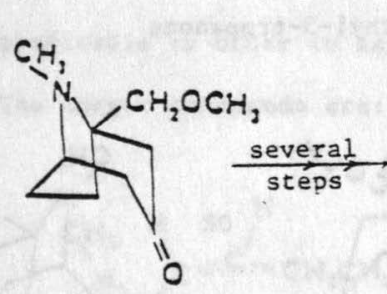

$\underline{17}$

OR

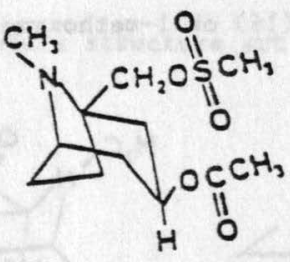

18

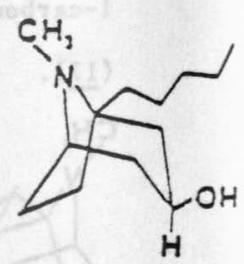

$\underline{15}$

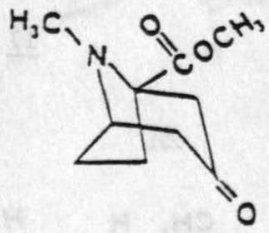

16 


\section{RESULTS AND DISCUSSION}

Part A. Construction of the Tropane Skeleton

\subsubsection{Building Blocks}

A classical way to build a tropane skeleton ${ }^{7}$ is by the condensation of succinic dialdehyde $\underline{18}$, methylamine hydrochloride 19 and acetone dicarboxylic acid 20 (Scheme 7 ).

\section{$\underline{\text { Scheme }}^{8 a}$}<smiles>O=CCCC=O</smiles>

$\underline{18}$

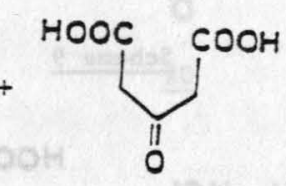

$\underline{20}$

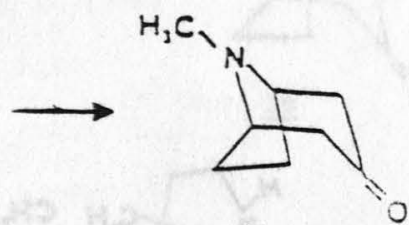

$\underline{21}$

This "one pot" procedure, known as the Robinson condensation $^{8 a}$ (first used for the synthesis of tropinone 21), has been extended $8 \mathrm{~b}$ to the synthesis of 1 -methyltropinone 23 (Scheme 8). 


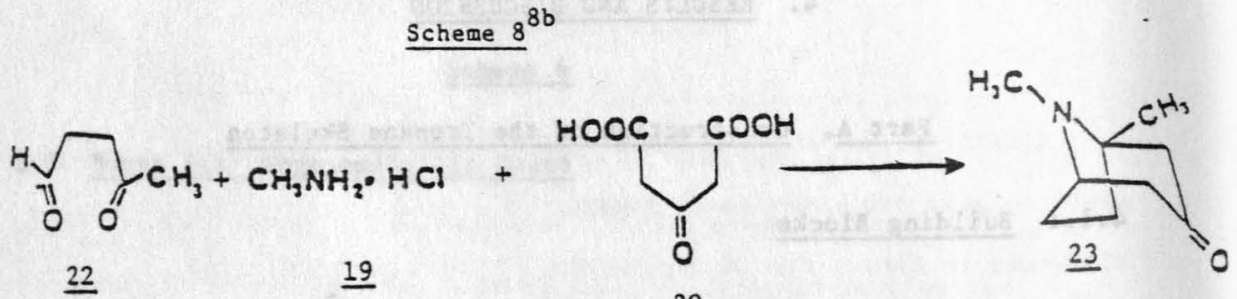

20

Unfortunately, generalization of this method to higher

homologues ${ }^{9}$ seemed to be difficult, owing to the problems in

synthesizing the key intermediates and to the diminished

reactivity of long-chain keto aldehydes (Scheme 9).

Scheme 9

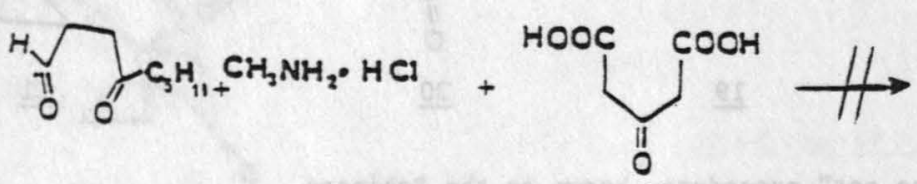

$\underline{24}$

19

$\underline{20}$

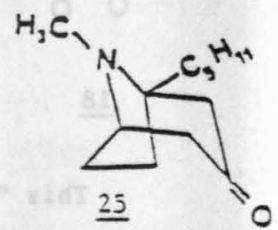

Therefore a more intricate study seemed desirable.

A search of literature showed that 1-carbomethoxy-3-tropanone

(16) and 1-methoxymethyl-3-tropanone (17) have been synthesized

by Kebrle and Karter. ${ }^{10}$ We envisioned that either of these

compounds could be elaborated to our synthetic targets $\underline{14}$ and $\underline{15}$

by methods outlined in our retrosynthesis analysis (Schemes 5 and 6).

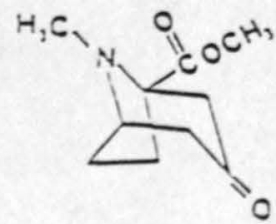

$\underline{16}$

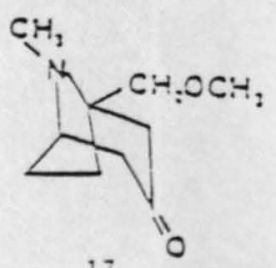

17 
1-Carbomethoxy-3-tropanone $(\underline{16})$ has been synthesized by Karrer ${ }^{10}$ from the ketoaldehyde 26 , methylamine hydrochloride (19) and acetone dicarboxylic acid $(\underline{20})$. When keto aldehyde $\underline{33}$ was used in place of 26,1 -methoxymethyl-3-tropanone (17) was obtained (Scheme 10).

\section{Scheme 10}<smiles>CC(=O)C(=O)CCC=O</smiles>

26

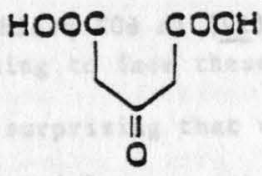

20

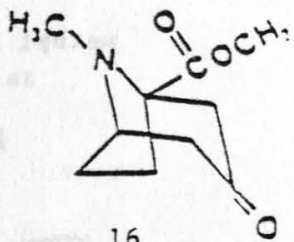

16<smiles>CCC1(CC)CCC2CCCC1N2C</smiles>

\subsubsection{Synthetic Efforts Towards Retoaldehyde 26:}

2,5-Dimethoxydihydrofurans have been utilized as syntheric precursors of keto aldehydes. Rarrer ${ }^{10}$ obtained keto aldehyde 26 on hydrolysis of 2,5-dimethoxy-2-carbomethoxy tetrahydrofuran 28 (Scheme 11). 
<smiles>COC(=O)C1(OC)CCC(O)O1</smiles>

28

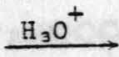

26

We planned to synthesize the tetrahydrofuran derivative $\underline{28}$ using Rarrer's procedure. 10 Thus 2 -furoic acid was esterified using absolute methanol and a cat. amount of sulfuric acid to give methyl 2-furoate (27) in $60 \%$ yield (Scheme 12).

\section{Scheme 12}

$\int_{\mathrm{COOH}}+$ abs. $\mathrm{CH}_{3} \mathrm{OH}+$ conc. $\mathrm{H}_{2} \mathrm{SO}_{4}$ (cat.) $\frac{\Delta^{b}}{24 \mathrm{hrs}}$<smiles>COC(=O)c1ccco1</smiles>

In our hands, attempted electrolytic methoxylation of 27 gave the desired dimethoxy dihydrofuran $\underline{29}$ in only $10-15 \%$ yield (Scheme 13). We could never obtain the reported ${ }^{11 \text { a }}$ yields of $68 \%$.

\section{Scheme 13}

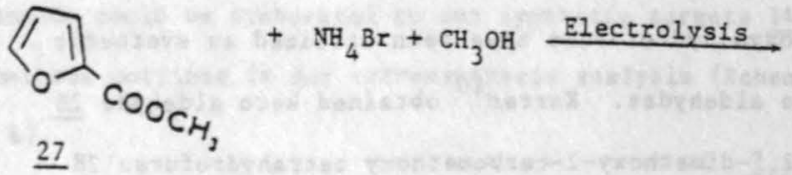

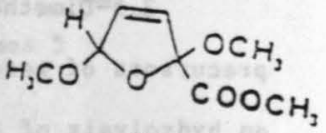

29

Even a chemical variation of this method involving 
displacement using methanol did not improve our yields

(Scheme 14).

Scheme 14

${ }_{\mathrm{COO}_{\mathrm{CH}_{3}}}+\mathrm{Br}_{2} \stackrel{-10^{\circ} \mathrm{C}}{\mathrm{COOCH}_{3}}$

27<smiles>COC1C=CC(C=O)(OC)O1</smiles>

29

Although it was very disheartening to face these setbacks at that time, in retrospect, it is not surprising that we obtained poor yields, since an electron-withdrawing group like the carbomethoxy would reduce the electron density on the furan ring and would render it less susceptible to electrophilic attack by bromine.

Since such serious problems were encountered in synthesizing $\underline{29}$ (and in turn obtaining $\underline{26}$ and $\underline{16}$ ), we abandoned all hopes of making this compound and turned our attention to the synthes is of 1-methoxymethyl-3-tropanone (17)). We speculated (correctly as it turned out) that the precursors to 17 , namely the dihydrofuran derivative $\underline{32}$ and keto aldehyde $\underline{33}$ would be more easily accessible.<smiles>COCC1(OC)C=CC(OC)O1</smiles>

$\underline{32}$

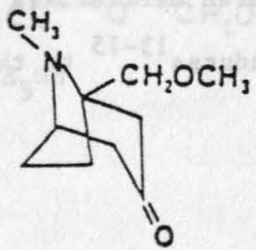<smiles>COCC(=O)CCC=O</smiles>

$\underline{33}$ 
Thus furfuryl alcohol ( $\underline{30}$ ) was methylated by methyl iodide following Tollens' procedure ${ }^{12}$ (Scheme 15).

\section{Scheme $15^{12}$}

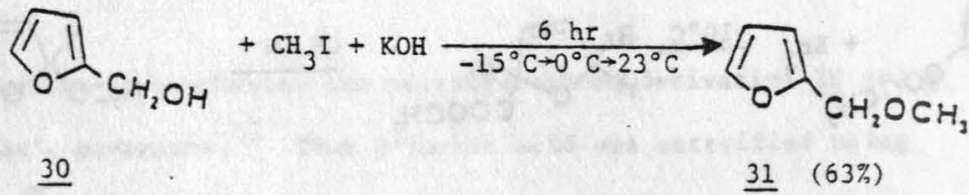

Electrophilic addition of bromine to 2-methoxymethylfuran (31), followed by nucleophilic displacement of the resulting bromide by methanol gave 2,5-dimethoxy-2-methoxymethyl2,5 -dihydrofuran (32) in $66 \%$ yield (Scheme 16).

\section{Scheme 16}

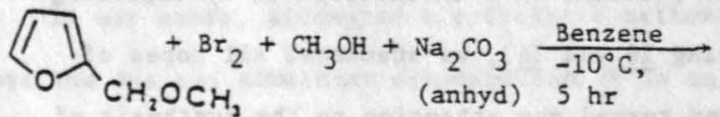
$\underline{31}$<smiles>COCC1(OC)C=CC(OC)O1</smiles>

32

To our knowledge this is the first chemical synthesis of 32 by this procedure (the previous methods ${ }^{10}$ were electrochemical). Furan and several other furan derivatives (but not 31 ) have been converted by similar procedures ${ }^{13-15}$ to the corresponding dimethoxydihydrofurans. 


\subsubsection{Hydrogenation of 32 :}

In the literature $11,13,14$ hydrogenation of dihydrofurans of type $\underline{32}$ has been accomplished by using catalytic amounts of Raney nickel $(\mathrm{W}-2)$ at $1700-2000 \mathrm{psi}$ and/or heating to $80^{\circ} \mathrm{C}$ (Scheme 17).

\section{Scheme 17}

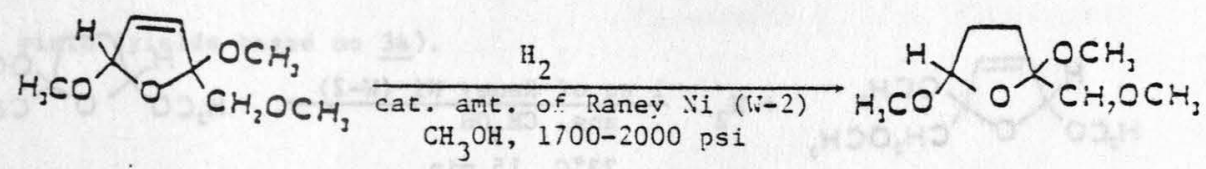
32

As these conditions appeared too drastic to us, we tried to find a different catalyst that would allow the same hydrogenation at much milder conditions. Unfortunately using $\mathrm{PtO}_{2}$ or $\mathrm{Pd} / \mathrm{black}$ at 1-2 atmospheres (16-32 psi) and carrying out the reduction at room temperature resulted in hydrogenolysis of methoxy group (Scheme 18).

\section{Scheme 18}<smiles>COCC1(OC)C=CC(OC)O1</smiles><smiles>COCC1CCC(O)O1</smiles> 
Finally, after several trials, we found that by increasing the amount of Raney nickel ( 1 equivalent of Raney nickel by weight to 1 equivalent of $\underline{32}$ ), the hydrogenation can be carried out under very mild conditions (1-2 atm, 20\%) without any hydrogenolysis (Scheme 19).

\section{Scheme 19}

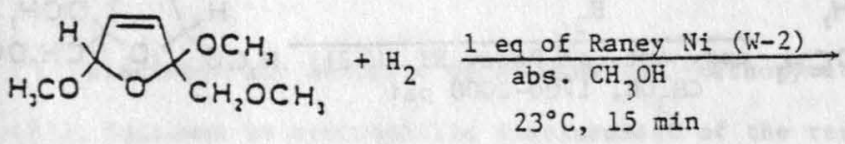

32<smiles>COCC1(OC)CCC(OC)O1</smiles>

$34(85-90 \%)$

Under these conditions, the uptake of hydrogen was sufficiently rapid. In fact, even using 0.5 equivalent of Raney nickel would maintain a sufficient rate of hydrogenation.

\subsubsection{Robinson condensation:}

The hydrolysis of the above-hydrogenated product 34 to the keto aldehyde $\underline{33}$ was achieved by heating it with $1 \mathrm{~N}$ hydrochloric acid at $75^{\circ} \mathrm{C}$ for 20 min (Scheme 20 ).

Scheme 20<smiles>COCC1(OC)CCC(OC)O1</smiles>

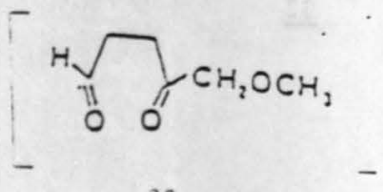


The resulting ketoaldehyde 33 was cooled rapidly to $10^{\circ} \mathrm{C}$ and condensed with acetonedicarboxylic acid and methylamine hydrochloride in water at room temperature for two days in the presence of sodium citrate as buffer. The reaction was carried out at $\mathrm{pH} 5$. At the end, the pH was adjusted to 10 and the reaction mixture was heated to $60^{\circ} \mathrm{C}$ to effect decarboxylation of the intermediate keto acid 35 (Scheme 21). The desired product, 1-methoxymethyl-3-tropinone (17) was thus obtained in 55-60\% yield (yields based on 34 ).

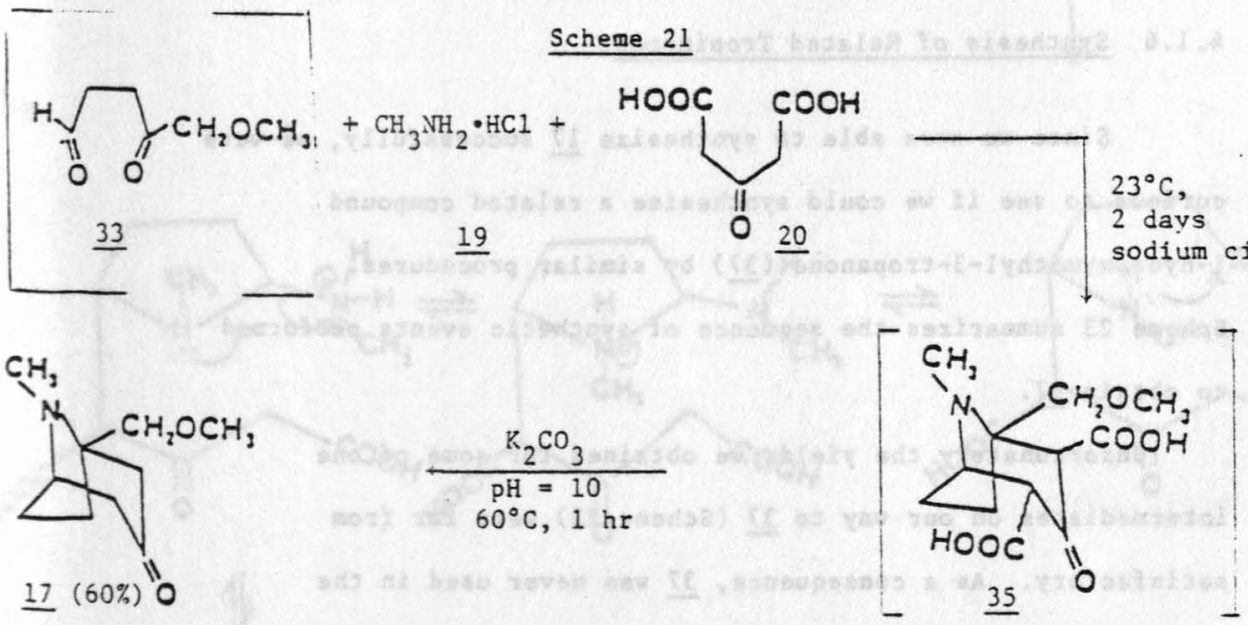

Our yields of 17 are $15-20 \%$ higher than Karrer's yields. 10

We believe that the improved yields are due to the use of sodium citrate as a buffer. 16 


\subsubsection{Mechanism of Robinson Condensation:}

The mechanism of Robinson condensation has been elucidated by Paquette. ${ }^{17}$ It is sumarized in Scheme 22 .

Paquette's mechanism explains the formation of 3-tropanone (36). We can safely assume that the same mechanism operates for the formation of 1-methoxymethyl-3-tropanone (17) from the keto aldehyde 33 , methylamine hydrochloride $(\underline{19})$ and acetone dicarboxylic acid 20 (Scheme 22).

\subsubsection{Synthesis of Related Tropinones:}

Since we were able to synthesize 17 successfully, we were curious to see if we could synthesize a related compound 1-hydroxymethy 1-3-tropanone (37) by similar procedures. Scheme 23 summarizes the sequence of synthetic events performed to obtain 37 .

Unfortunately the yields we obtained for some of the intermediates on our way to $\underline{37}$ (Scheme 23) were far from satisfactory. As a consequence, $\underline{37}$ was never used in the subsequent steps of our synthesis.

Instead compound $\underline{17}$ was carried on for further synthetic elaborations. 

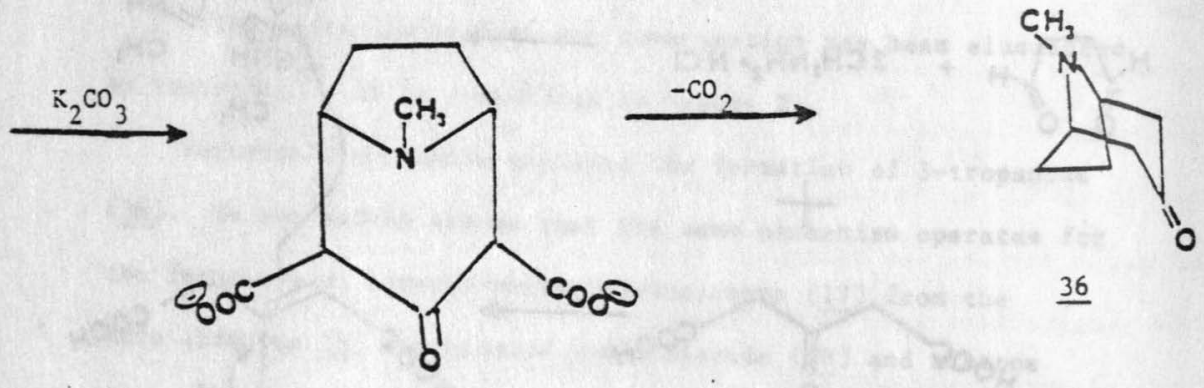

36 
Scheme 23

$\int_{\mathrm{CH}_{2} \mathrm{OH}}+\mathrm{Br}_{2}+\mathrm{CH}_{3} \mathrm{OH}+\mathrm{Na}_{2} \mathrm{CO}_{3} \frac{\text { Benzene }}{-10^{\circ} \mathrm{C}, 5 \mathrm{hr}}$

30

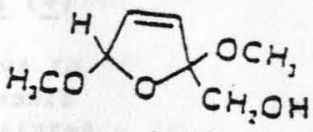

$38(27 \%)$

$\mathrm{H}_{2}, 1-2 \mathrm{~atm}$ Raney Nickel $\mathrm{CH}_{3} \mathrm{OH}, 23^{\circ} \mathrm{C}$

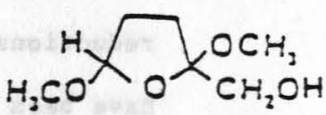

$\underline{39}(05-90 \%)$

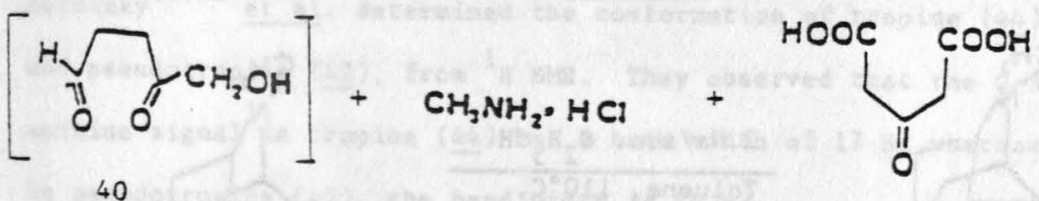

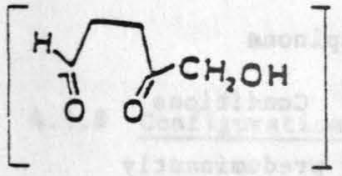

40

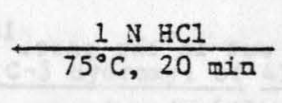

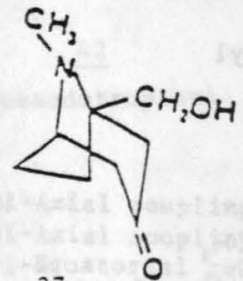

37

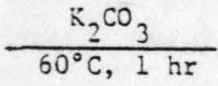

(25\%)

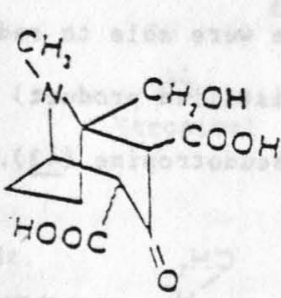

41 


\subsubsection{Stereoselective Reduction of}

\section{(+) 1-Methoxymethyl-3-tropanone (17):}

Since the cotifiguration of the $c-3$ hydroxyl is equatorial

(B) in our target compounds $\underline{14}$ and $\underline{15}$, we needed to adopt

conditions that would reduce the carbonyl of 17

stereospecifically to the B-hydroxy group.

Several studies on the stereochemistry of tropinone

reductions have been carried out in the past. ${ }^{18,19}$ Conditions

have been developed ${ }^{19}$ (Scheme 24 ) whereby one gets predominantly the $B$ isomer (thermodynamically controlled) or predominantly the $\alpha$ isomer (kinetically controlled).

Scheme $24^{19}$

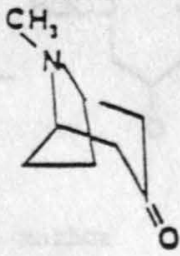

36

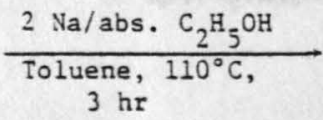

$3 \mathrm{hr}$

By using known ${ }^{19}$ procedures (Scheme 25) for such reactions,

we were able to reduce ketone 17 in $90 \%$ crude yield ( $70 \%$

distilled product) exclusively to $( \pm) 1$-methoxymethyl pseudotropine (43).

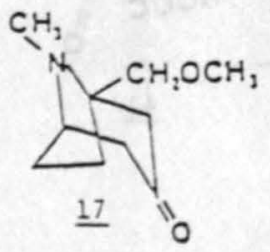

\section{Scheme 25}

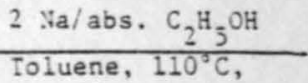

12 hr

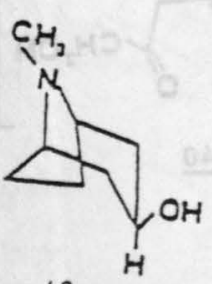

42 
The crude compound was sufficiently pure (no impurities could be seen in "H NMR) and could be used "as is" in the subsequent steps. The loss of yields on distillation is due to the partial decomposition of the compound at higher temperatures (b.p. $105^{\circ} \mathrm{C}$ at $0.4 \mathrm{~mm}$ ). One could avoid distillation altogether and purify the compound by column chromatography (basic alumina).

\subsubsection{Configuration of C-3 Hydroxyl of 43 :}

The configuration of the hydroxyl group was determined to be equatorial ( $\beta$ ) based on ${ }^{1}$ H NMR. This conclusion was based on the coupling constant of the $C-3$ axial hydrogen with the axial hydrogens of $C_{2}$ and $C_{4}$ (base width $=40 \mathrm{~Hz}$ ). Fodor, Katrizky 20,21 et al. determined the conformation of tropine (44) and pseudotropine (42), from ${ }^{1} \mathrm{H}$ NMR. They observed that the $\mathrm{C}-3$ methine signal in tropine (44) has a band width of $17 \mathrm{~Hz}$ whereas in pseudotropine (42), the band width is $40 \mathrm{~Hz}$.

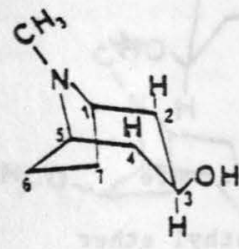

$\underline{42}$

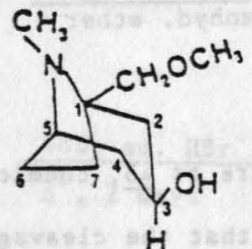

43

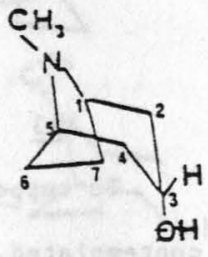

44

(tropine)

(pseudotropine)

Axial-Axial coupling of $\mathrm{C}-3$ hydrogen in 42 is $10.2 \mathrm{~Hz}$. Axial-Axial coupling of $\mathrm{C}-3$ hydrogen in $\overline{43}$ is $10 \mathrm{~Hz}$. Axial-Equatorial coupling of $\mathrm{C}-3$ hydrogen in 44 is $5 \mathrm{~Hz}$. 
Since the band width for the $\mathrm{C}-3$ hydrogen in 43 is close to the band width for $\mathrm{C}-3$ hydrogens in 42 , we can assume that both 43 and $\underline{42}$ have the same configuration at $c-3$.

\subsubsection{Structure Determination of 43 - Chemical Methods:}

Since 43 was one of the key intermediates, we felt the need for an unequivocal determination of its structure. The hydrochloride salt of this amine was prepared by bubbling dry hydrogen chloride gas through an ethereal solution of 43 (Scheme 26). The elemental analysis of the corresponding crystalline hydrochloride salt 45 was satisfactory.

\section{Scheme 26}

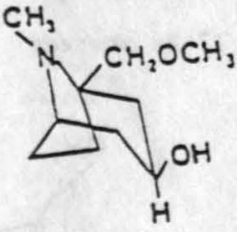

43

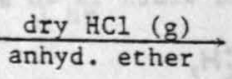

To support the structure of 43 , chemical reactions were contemplated. It was felt that the cleavage of the methyl ether would be a good start.

Ethers have been cleaved by $48 \%$ aqueous hydrobromic acid. Sperber ${ }^{22}$ cleaved the neopentyl amino ethyl ether 46 to the corresponding hydroxy derivative 47 in $95 \%$ yield by using this reagent (Scheme 27). 
Scheme 27<smiles>COCC(O)(CN(C)C)c1ccccc1</smiles>

46

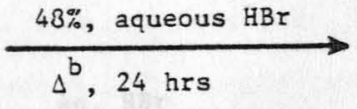

Scheme 28

$\mathrm{H}_{3} \mathrm{CO}\left(\mathrm{CH}_{2}\right)_{12} \mathrm{OCH}_{3} \frac{\mathrm{aq} \text {. } \mathrm{HBr}}{\Delta^{\mathrm{b}}, 2 \text { days }} \mathrm{Br}\left(\mathrm{CH}_{2}\right)_{12} \mathrm{Br}$

48

49

Among tropanes, Fodor ${ }^{24}$ et al. cleaved 6B-methoxytropine

(50) to the corresponding diol 51 (Scheme 29).

\section{Scheme 29}

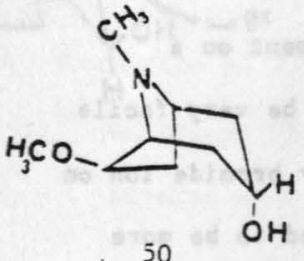

50

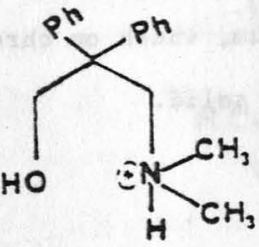

47

Nineham ${ }^{23}$ cleaved the primary dimethyl ether 48 to the corresponding dibromide 49 by the same method (Scheme 28 ).

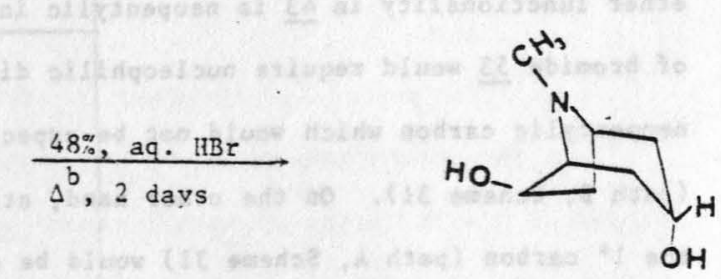

$\underline{51}$

Following Fodor's procedure ${ }^{24}$, the methyl ether 43 was cleaved to the diol $\underline{52}$ by refluxing in $48 \%$ aqueous hydrogen bromide for two days and neutralizing the resulting hydrobromide 
salt with sodium carbonate (Scheme 30 ). The diol $\underline{52}$ was obtained as a gum, which on chromatography over basic alumina gave a yellow solid.

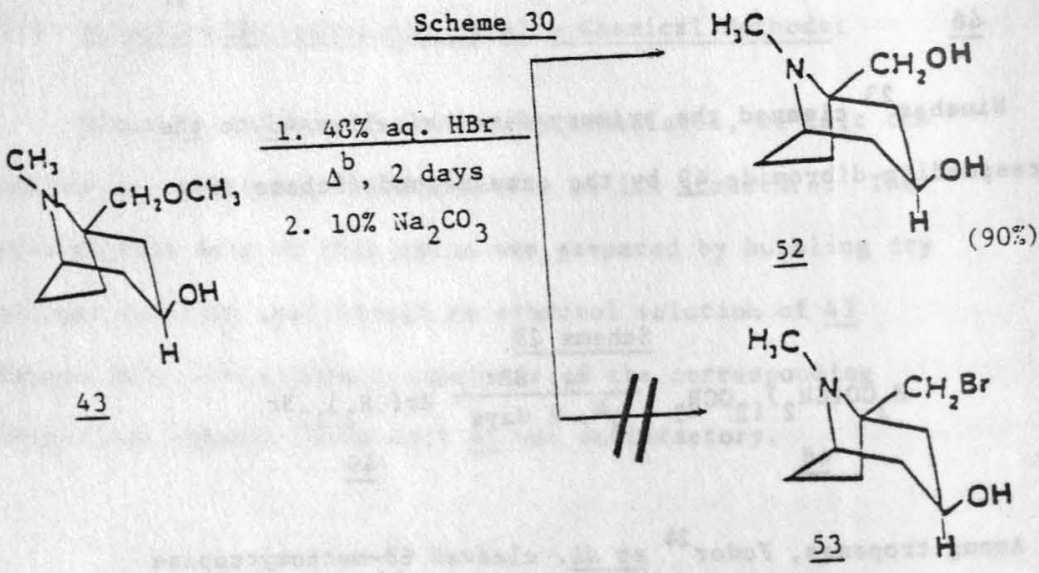

It did not come as a surprise that diol $\underline{52}$ was formed exclusively and the bromide 53 was not formed at all. The reason for such immediate acceptance of this result is that the methyl ether functionality in $\underline{43}$ is neopentylic in nature and formation of bromide 53 would require nucleophilic displacement on a neopentylic carbon which would not be expected to be very facile (path B, Scheme 31). On the other hand, attack by bromide ion on the $1^{\circ}$ carbon (path A, Scheme 31 ) would be expected to be more easy and that happens to be the prefered path for the reaction. The evidence for the transformation of $\underline{43}$ into diol $\underline{52}$ was obtained from the ${ }^{1}$ H NMR spectra of these compounds. The sharp singlet for the wethoxy group at $\delta 3.3\left(\mathrm{CH}_{2} \mathrm{OCH}_{3}\right)$ in 43 was absent 


\section{Scheme 31}

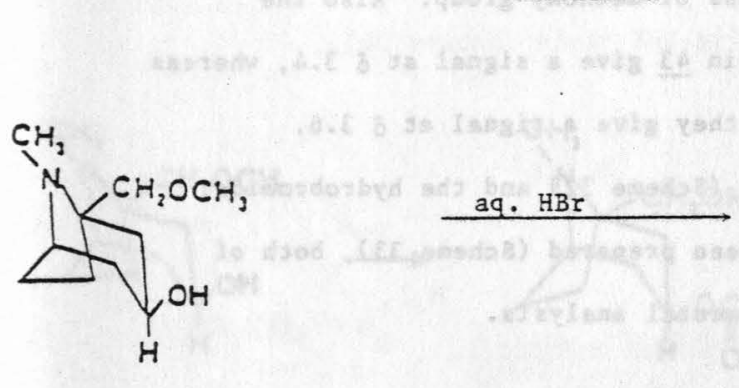

43
$Q_{B r}$

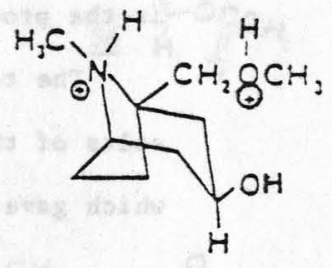

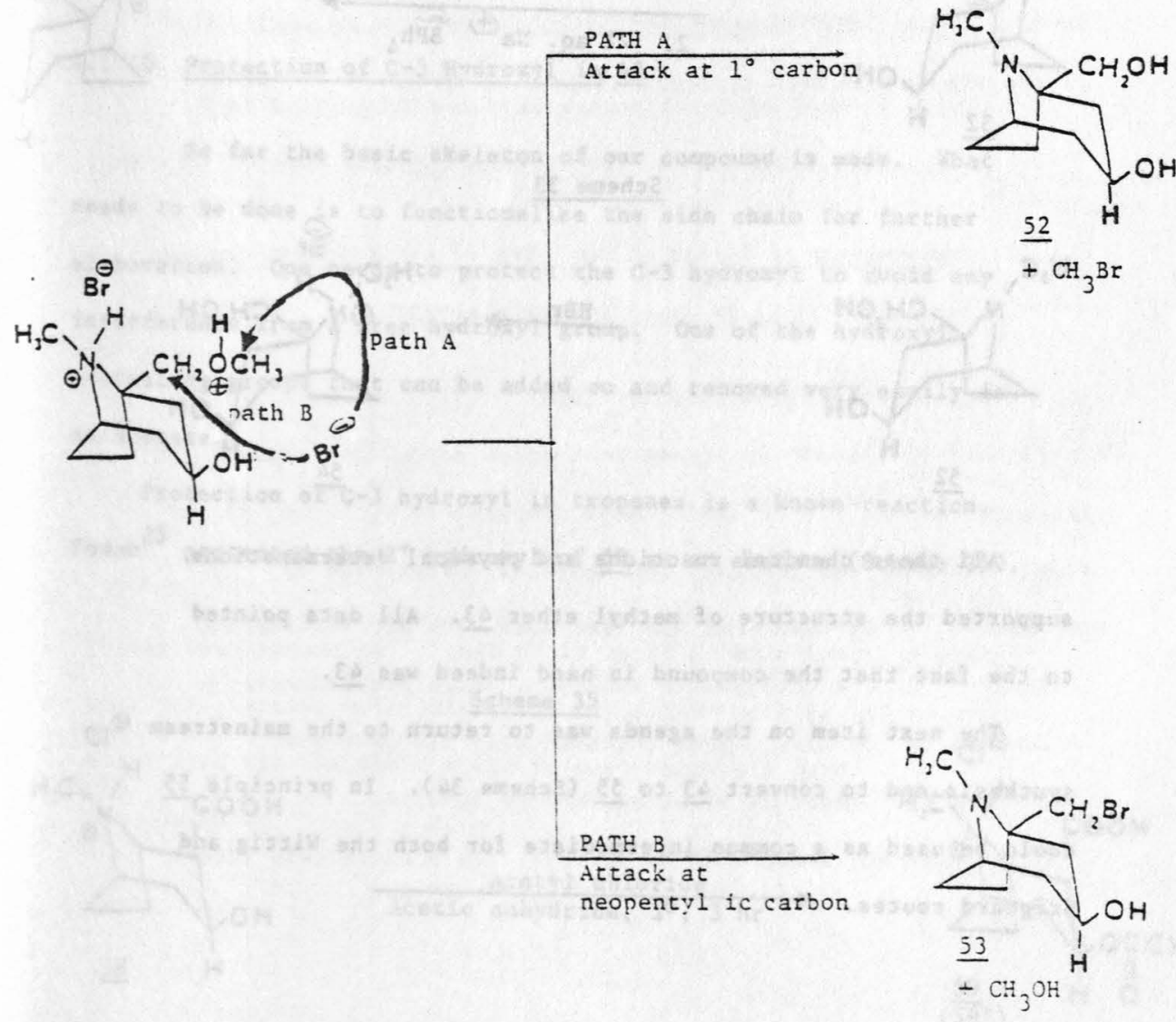


in case of $\underline{52}$ indicating loss of methoxy group. Also the methylene protons $\mathrm{CH}_{2} \mathrm{OCH}_{3}$ in $\underline{43}$ give a signal at $\delta 3.4$, whereas in the product $\left.\underline{52}_{\left(\mathrm{CH}_{2}\right.} \mathrm{OH}\right)$, they give a signal at $\delta 3.6$.

The tetraphenyl borate (Scheme 32 ) and the hydrobromide salts of the diol 52 have been prepared (Scheme 33 ), both of which gave satisfactory elemental analysis.

\section{Scheme 32}

Opin.

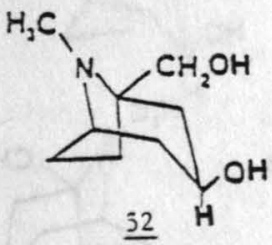

1. dil. $\mathrm{HCl}$
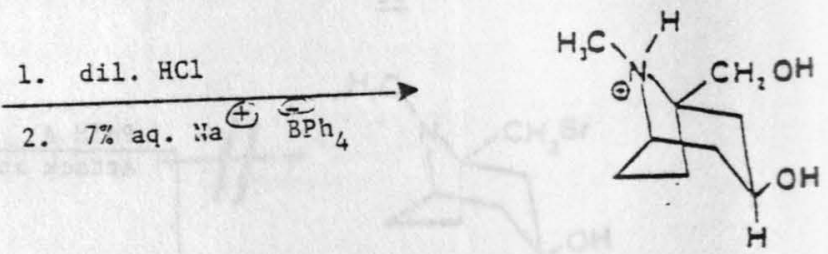

\section{Scheme 33}

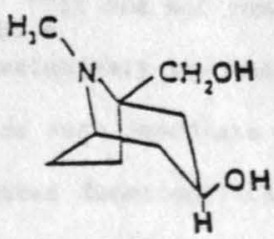

52

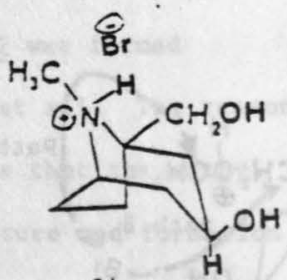

54

All these chemical reactions and physical determinations supported the structure of methyl ether 43 . All data pointed to the fact that the compound in hand indeed was 43 .

The next item on the agenda was to recurn to the mainstream synthesis and to convert $\underline{43}$ to $\underline{55}$ (Scheme 34 ). In principle $\underline{55}$ could be used as a common intermediate for both the wittig and Grignard routes. 


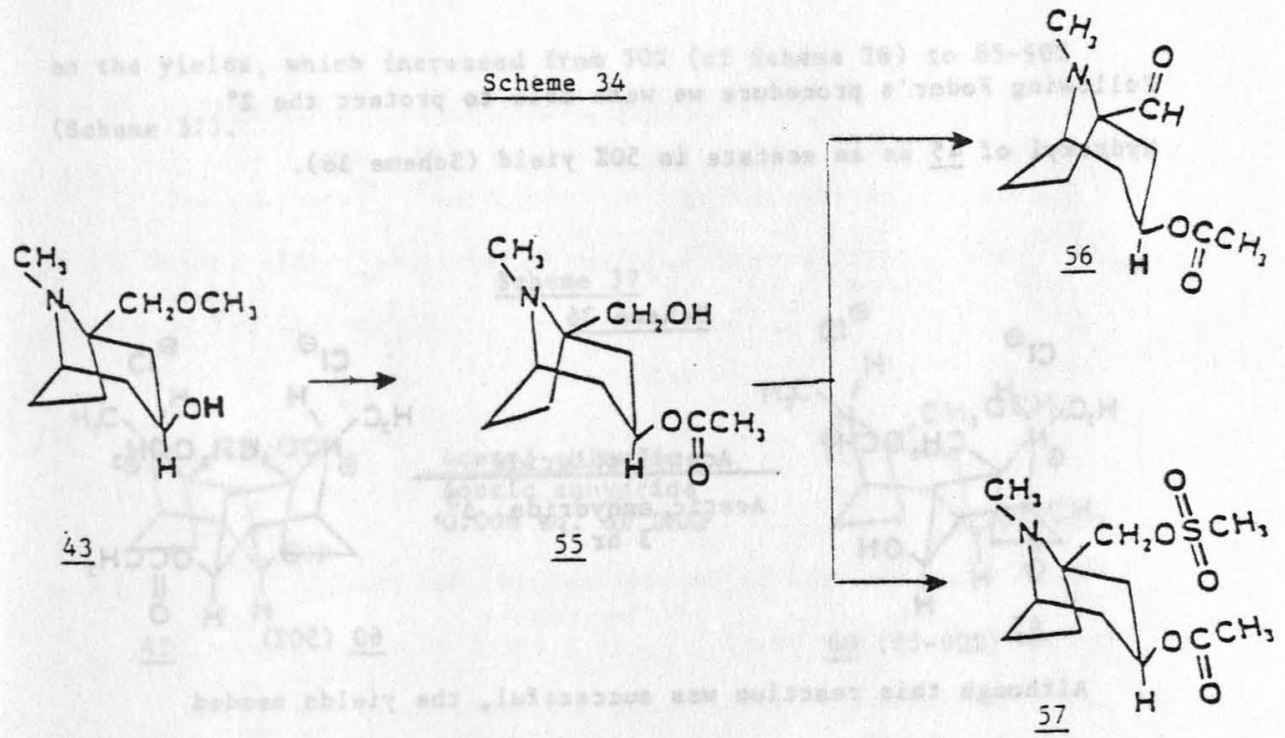

\subsubsection{Protection of C-3 Hydroxyl in 43 :}

So far the basic skeleton of our compound is made. What needs to be done is to functionalize the side chain for further elaboration. One needs to protect the $c-3$ hydroxyl to avoid any interference from a free hydroxyl group. One of the hydroxyl protecting groups that can be added on and removed very easily is an acetate.

$$
\text { Protection of } \mathrm{C}-3 \text { hydroxyl in tropanes is a known reaction. }
$$
Fodor 25 protected the $2^{\circ}$ hydroxyl of 58 as an acetate (Scheme 35 ).

\section{Scheme 35}
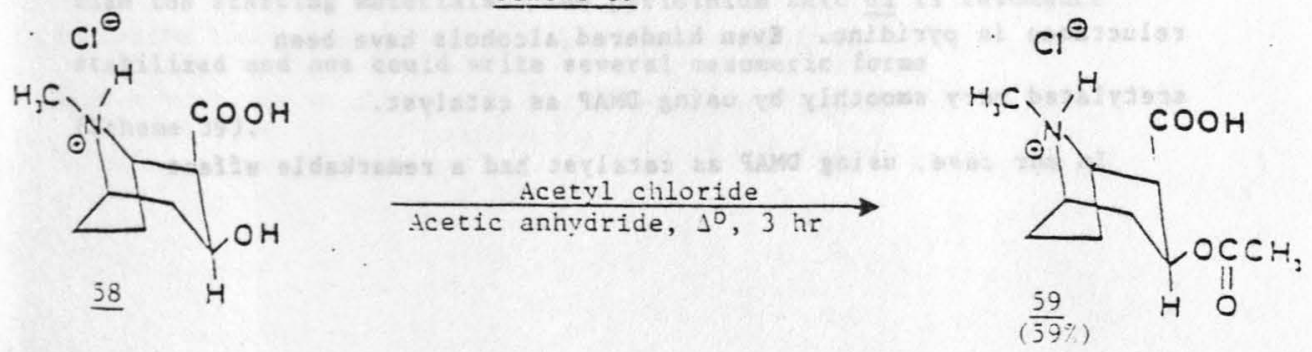
Following Fodor's procedure we were able to protect the $2^{\circ}$ hydroxyl of 45 as an acetate in $50 \%$ yield (Scheme 36 ).

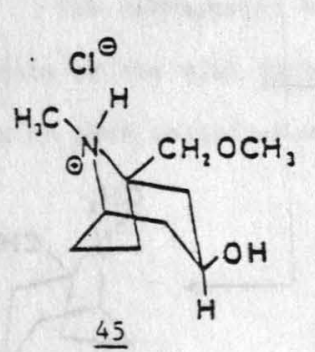

Although this reaction was successful, the yields needed of the yields has been accomplished.

4.1.11 Improvement of Yields of 60 : Use of 4-N, N-Dimethylaminopyridine (DMAP) as Acetylation Catalyst:

4-N,N-Dime thylamino pyridine (DMAP), (61), has been introduced to organic synthesis as a super acylation catalyst by Steglich and Höfle $e^{26}$ in 1969. When compared to pyridine, it was found that DMAP can increase the rates of acetylation by $10^{4}$ times. Since then DMAP has been used with ever-increasing frequency ${ }^{27,29}$ for acetylation reactions which proceed with reluctance in pyridine. Even hindered alcohols have been acetylated very smoothly by using DMAP as catalyst.

In our case, using DMAP as catalyst had a remarkable effect 
on the yields, which increased from 50\% (cf Scheme 36) to 85-90\% (Scheme 37).

\section{Scheme 37}

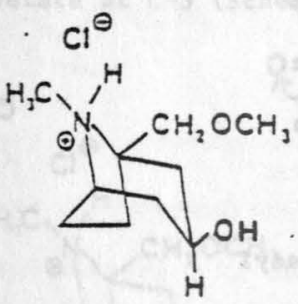

45

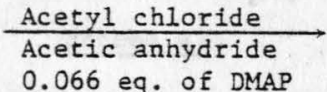

$0.066 \mathrm{eq}$. of DMAP

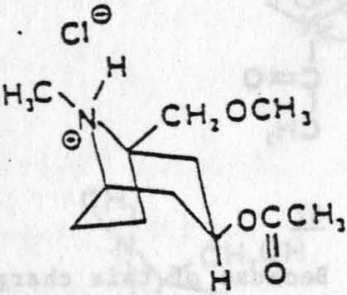

$60(85-90 \%)$

\subsubsection{Reasons for Improved Yields - Mechanism of DMAP Action:}

When treated with acetic anhydride, DMAP forms a stable

N-acyl pyridinium salt 62 (Scheme 38 ).

\section{Scheme 38}<smiles>CN(C)c1ccncc1</smiles>

DMAP

61<smiles>CC(=O)OC(C)=O</smiles>

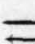
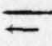

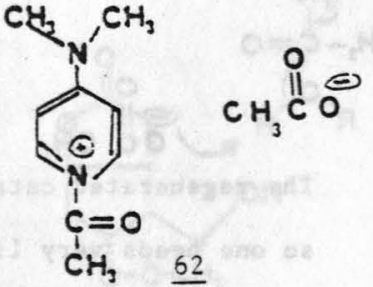

It has been estimated 28 , that 62 is ca $25 \mathrm{~kJ} /$ mole lower in energy than the starting materials. The pyridinium salt $\underline{62}$ is resonance stabilized and one could write several mesomeric forms (Scheme 39). 
Scheme 39

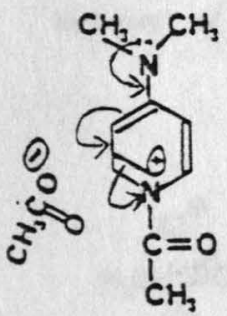

62
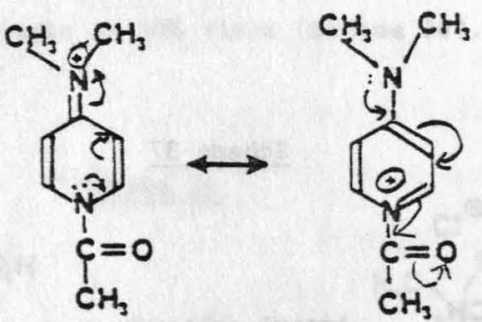

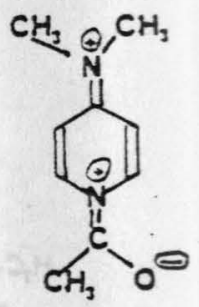

Because of this charge delocalization, the $\mathrm{N}$-acyl

4-dialkylamino pyridinium salt 62 is present as a loosely-bound ion pair, thus greatly facilitating nucleophilic attack on the activated acyl group with general base catalysis by the neighboring acetate group (Scheme 40 ).

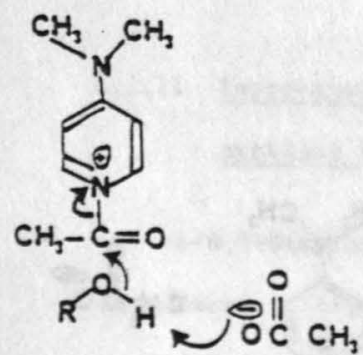

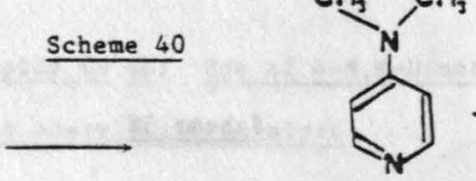

\section{DMAP}

Regenerated catalyst

The regenerated catalyst repeats its action over and over again, so one needs very little (ca. 0.05 eq. of cat to 1 eq. of $R-O H$ ) of the catalyst. 


\subsubsection{Cleavage of Methyl Ether of 60 :}

The next problem we had to address was selective cleavage of the methyl ether functionality in 60 without affecting the acetate at $\mathrm{C}-3$ (Scheme 41$)$.

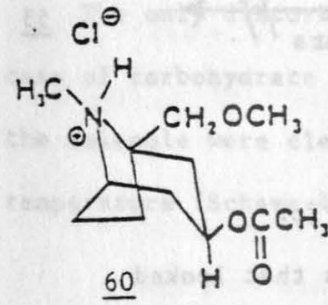

\section{Scheme 41}
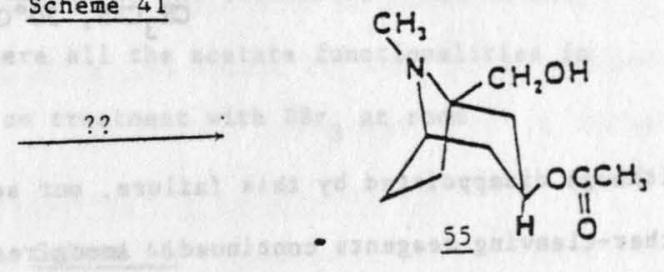

Recently, Corey ${ }^{30}$ converted the methyl ether 63 into the alcohol 64 by using two equivalents of iodotrimethylsilane, generated in situ from chlorotrimethylsilane and sodium iodide (Scheme 42).

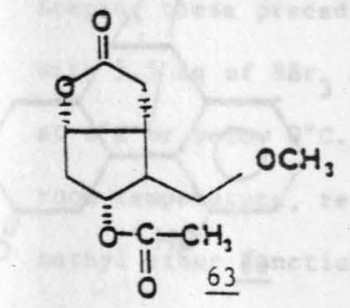

\section{Scheme 42}

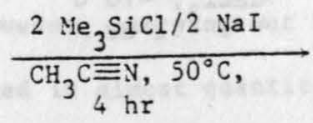

Following Corey's procedure, 60 was treated with freshly generated iodotrimethylsilane. Heating this mixture either in acetonitrole or in chloroform led to complete recovery of starting material (Scheme 43 ). 
Scheme 43
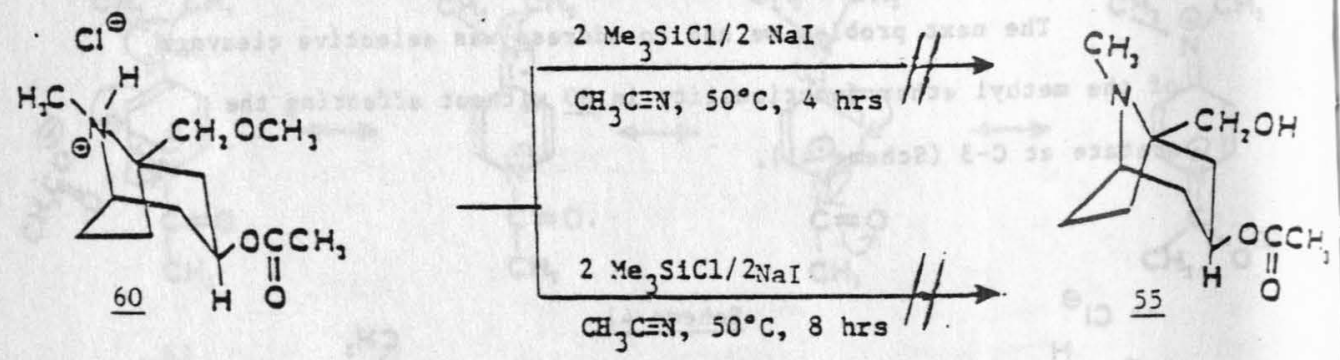

Although disappointed by this failure, our search for ether-cleaving reagents continued. Among reagents that looked promising for the problem at hand, boron tribromide caught our attention. Brossi ${ }^{31}$ cleaved the arylmethylether 65 into the phenol 66 by treating with a thirty-fold excess of boron tribromide in chloroform at $-70^{\circ} \mathrm{C}$ (Scheme 44 ).

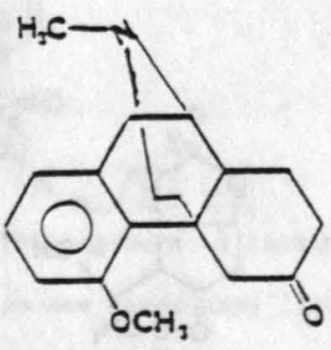

65

\section{Scheme 44}

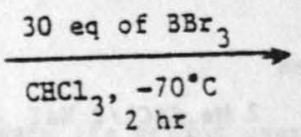

Corey $^{32}$, in his first synthesis of prostaglandins, cleaved

the wethyl ether in 63 by treating with excess $\mathrm{BBr}_{3}$ at $0^{\circ} \mathrm{C}$

(Scheme 45), without affecting the acetate functionality. 


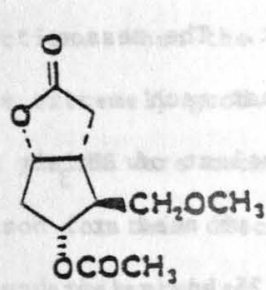

$\underline{63}$
Scheme 45

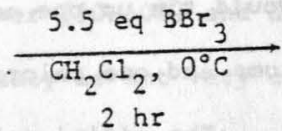

$2 \mathrm{hr}$

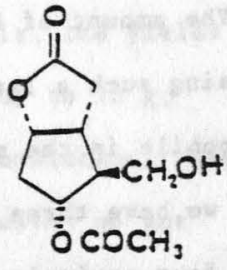

$64(90 \%)$

The only disturbing example in the literature ${ }^{33}$ was in the case of carbohydrate 67 where all the acetate functionalities in the molecule were cleaved on treatment with $\mathrm{BBr}_{3}$ at room temperature (Scheme 46).

\section{Scheme 46}

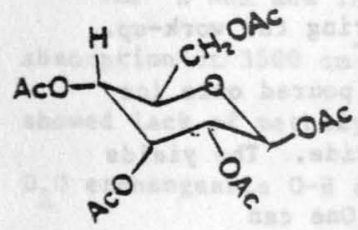

67

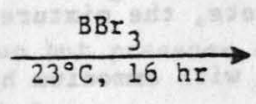

68

Keeping these precedents in mind, methyl ether 60 was treated with 5.5 eq of $\mathrm{BBr}_{3}$ at $0^{\circ} \mathrm{C}$. Unfortunately there was no reaction at $0^{\circ} \mathrm{C}$ or below $0^{\circ} \mathrm{C}$. However, carrying out the same reaction at room temperature, resulted in almost quantitative cleavage of methyl ether functionality (Scheme 47 ) and the acetate was untouched.

Scheme 47
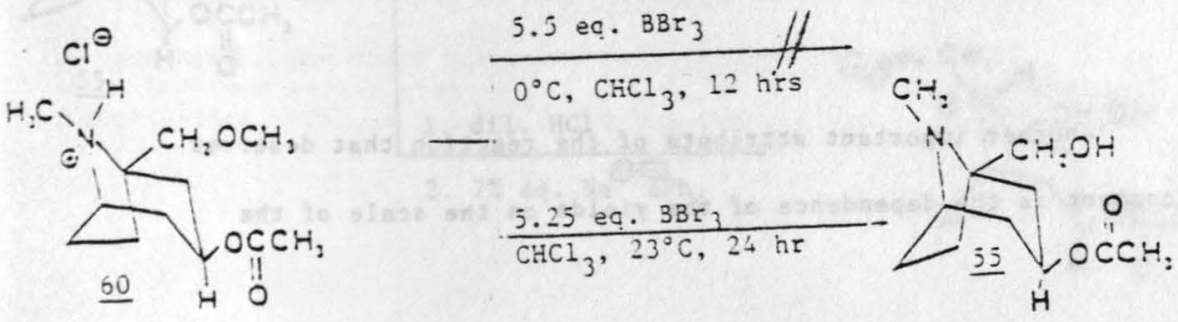
The amount of $\mathrm{BBr}_{3}$ used deserves some comment. The reason for using such a large excess of the reagent is that each nucleophile in the molecule would tie up one equivalent of $\mathrm{BBr}_{3}$. Since we have three oxygen atoms and one chloride, we need at least four equivalents of $\mathrm{BBr}_{3}$. The additional 1.25 equivalents was to make sure that we have enough reagent.

The best aspect of this reaction is that the acetate was untouched in our case (cf Scheme 46), although we carried out the reaction at room temperature (Scheme 47 ).

The yields and ease of isolation of product seemed to depend a lot on the method of work-up. The best yields were obtained when concentrated ammonium hydroxide was used during the work-up. After the reaction was complete, the mixture was poured onto ice and the pH was brought to 11 with ammonium hydroxide. The yields dropped when the pH was taken to 12 and beyond. One can speculate that at higher hydroxide ion concentrations, the acetate would be attacked resulting in the formation of the water-soluble diol $\underline{52}$ (Scheme 48 ).

\section{Scheme 48}
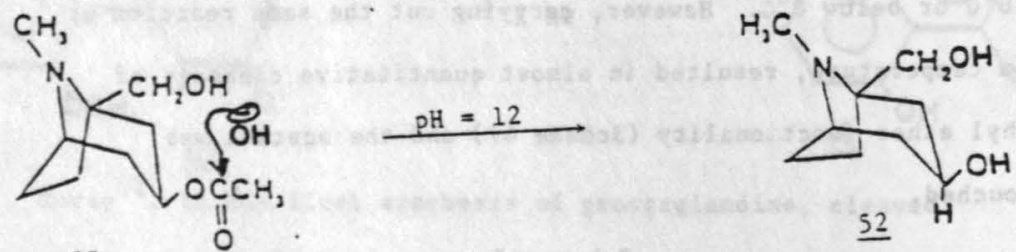

$\underline{55}$

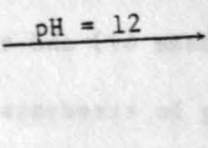

Another important attribute of the reaction that deserves 
reaction. When the reaction was done on a $5 \mathrm{~g} \mathrm{scale,} \mathrm{the} \mathrm{yields}$ were extremely good. However, when it was scaled up to $10 \mathrm{~g}$, the yields were much lower $(50-60 \%)$ and highly inconsistent. The reason for this discrepancy is not very clear. However we got around this problem by carrying out three or four sets of reactions at the same time on a 5 scale and combining the product from all the sets.

\subsubsection{Structure Determination of the Monoacetate 55:}

The ${ }^{1} H$ NMR and IR of $\underline{55}$ were as expected. $\underline{55}$ had an IR absorption at $3500 \mathrm{~cm}^{-1}$ indicating OH functionality. ${ }_{\mathrm{H}}^{\mathrm{H}} \mathrm{NR}$ showed lack of methoxy group but presence of $\mathrm{CH}_{2} \mathrm{OH}(\delta 3.5)$ and $\mathrm{D}_{2} \mathrm{O}$ exchangeable $\mathrm{O}-\mathrm{H}$ at $\delta 4.5$.

The hydrochloride and tetraphenylborate salts of $\underline{55}$ have been prepared and both of them gave satisfactory elemental analyses (Scheme 49 ).

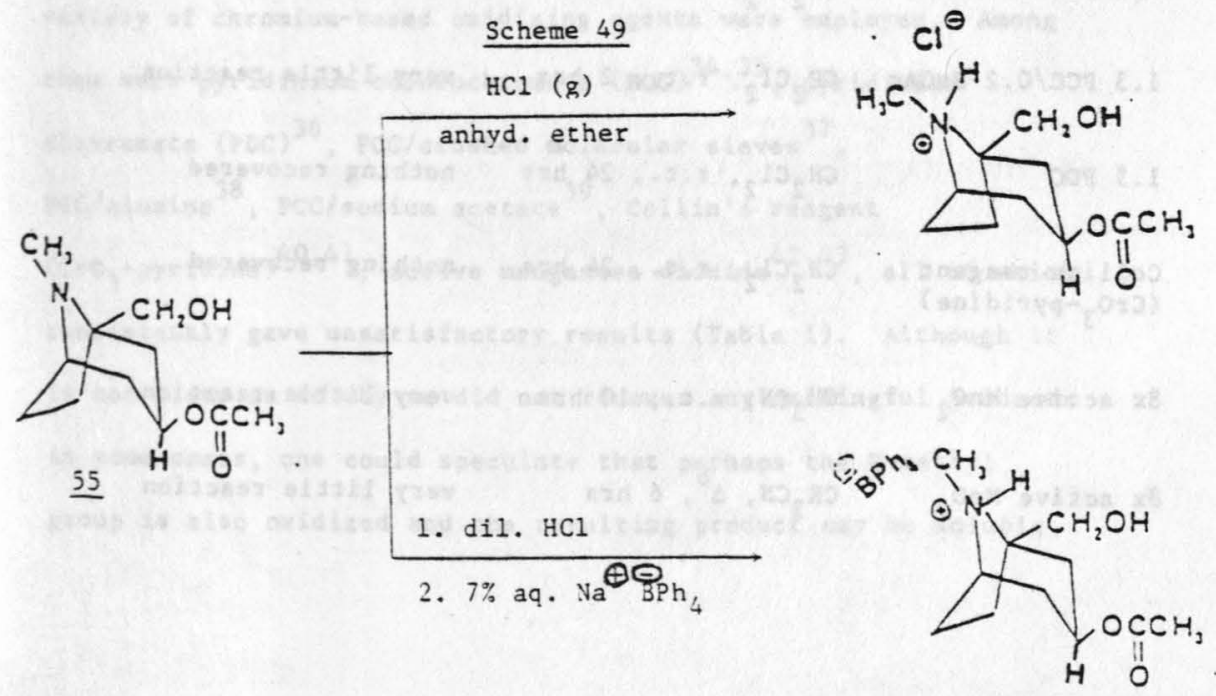




\section{TABLE I}

STARTING MATERIAL:

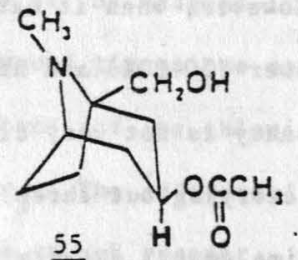

$\underline{\text { Reagents }}$

\section{$1.5 \mathrm{PCC}$}

4 PCC

1.5 PCC

1.2 PCC

\section{$1.5 \mathrm{PCC} / \mathrm{crushed}$} mol. sieves

$1.6 \mathrm{PCC} /$ alumina

1.3 $\mathrm{PCC} / 0.2 \mathrm{NaOAC}$

\section{$1.5 \mathrm{PDC}$}

Collins reagent ( $\mathrm{CrO}_{3}$-pyridine)

$8 \mathrm{x}$ active $\mathrm{MnO}_{2}$

$8 \mathrm{x}$ active $\mathrm{MnO}_{2}$
Conditions

$\mathrm{CH}_{2} \mathrm{Cl}_{2}, \mathrm{t.t}, 5 \mathrm{hrs}$

$\mathrm{CH}_{2} \mathrm{Cl}_{2}$, r.t., 24 hrs

$\mathrm{CHCl}_{3}, \Delta^{b}, 24$ hrs

$\mathrm{CH}_{2} \mathrm{Cl}_{2}, \Delta^{\mathrm{b}}, 1 \mathrm{hr}$

$\mathrm{CH}_{2} \mathrm{Cl}_{2}, \mathrm{r} \cdot \mathrm{t} ., 2 \mathrm{hrs}$

$\mathrm{CH}_{2} \mathrm{Cl}_{2}$, r.t., 2 hrs

$\mathrm{CH}_{2} \mathrm{Cl}_{2}, \mathrm{r} \cdot \mathrm{t} ., 2 \mathrm{hrs}$

$\mathrm{CH}_{2} \mathrm{Cl}_{2}$, r.t., 24 hrs

$\mathrm{CH}_{2} \mathrm{Cl}_{2}$, r.t., $24 \mathrm{hrs}$

$\mathrm{CH}_{3} \mathrm{CN}, \mathrm{r}, \mathrm{t}, 10 \mathrm{hrs}$

$\mathrm{CH}_{3} \mathrm{CN}, \Delta^{\mathrm{b}}, 6 \mathrm{hrs}$

\section{Result}

no reaction

no reaction

nothing recovered

nothing recovered

nothing recovered

nothing recovered

very little reaction

nothing recovered

nothing recovered

very little reaction

very little reaction 
Part B. Elaboration of the Side Chain by Wittig Reaction

The successful synthesis of the diol monoacetate 55 has been a break-through as far as our methodology was concerned. We considered it to be a very versatile intermediate. Successful oxidation of the hydroxyl group would give aldehyde 56 (Scheme 50), which sets the stage for Wittig reaction.

\section{Scheme 50}
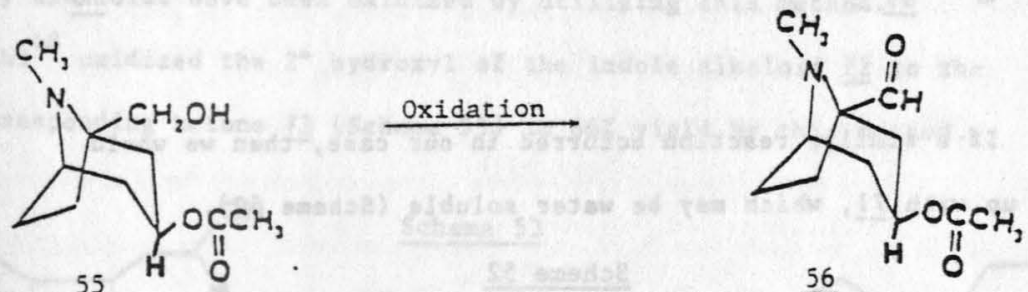

\subsubsection{Search for Oxidizing Agent:}

Our search started with transition metal oxidants. A variety of chromium-based oxidizing agents were employed. Among them were pyridinium chlorochromate (PCC) $)^{34,35}$, pyridinium dichromate $(P D C)^{36}$, PCC/crushed molecular sieves ${ }^{37}$, PCC/alumina ${ }^{38}$, PCC/sodium acetate ${ }^{39}$, Collin's reagent $\left(\mathrm{CrO}_{3} \text {-pyridine }\right)^{40,41}$, active manganese dioxide ${ }^{42,43}$, all of which consistently gave unsatisfactory results (Table I). Although it is not clear as to why we did not recover any meaningful products in some cases, one could speculate that perhaps the $\mathrm{N}$-methyl group is also oxidized and the resulting product may be soluble 
in water. This speculation is based on an analogy in the literature, where an $N$-methyl was oxidized to an $N$-formyl group by Collins' reagent in the laboratories of Corey ${ }^{44,45}$ (Scheme 51).

\section{Scheme 51}

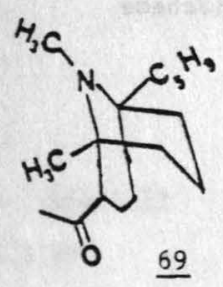

$$
\frac{\text { Collin's Reagent }}{23^{\circ} \mathrm{C}, 72 \mathrm{hr}}
$$

If a similar reaction occurred in our case, then we would end up with 71 , which may be water soluble (Scheme 52).

\section{Scheme 52}
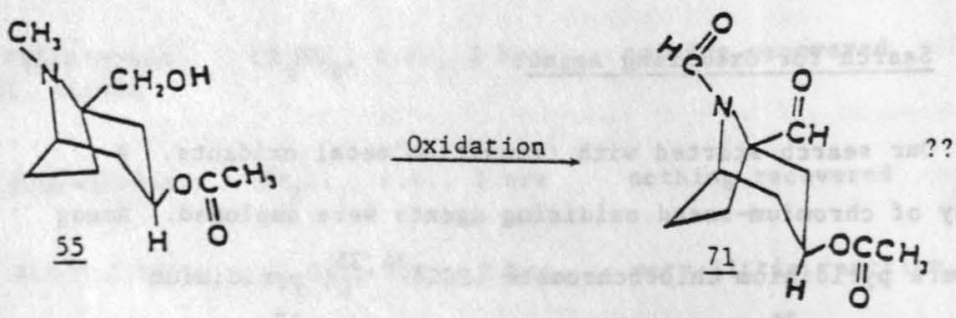

The next type of oxidizing agent we have looked at are those that utilized dimethyl sulfoxide (DMSO) as an oxidant. 


\subsubsection{Dimethylsulfoxide-Dicyclohexylurea Oxidation:}

Dimethylsulfoxide has been used very widely as an oxidizing agent, in organic synthesis. It has been used with various electrophiles which activate the DMSO. One of the first activators used was dicyclohexylcarbodiimide (DCC). ${ }^{46}$ This oxidation now known as Pfitzner-Moffatt oxidation, 47 is carried out by using DMSO and DCC in the presence of 1.5 molar equivalents of anhydrous phosphoric acid or trifluoroacetic acid. Many alkaloids have been oxidized by utilizing this method. Büchi ${ }^{48}$ oxidized the $2^{\circ}$ hydroxyl of the indole alkaloid 72 to the corresponding ketone 73 (Scheme 53 ) in $66 \%$ yield by this method.

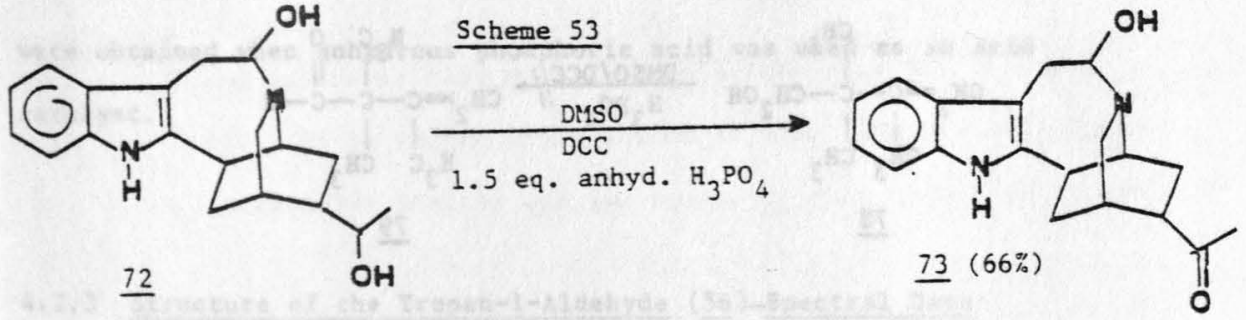

Even neopentyl alcohols (such as the one we have at hand) have been oxidized, to the corresponding aldehydes. Djerassi ${ }^{49}$ oxidized $\Delta^{12}$-oleanol $\underline{74}$ to the corresponding aldehyde $\underline{75}$ (Scheme 54).

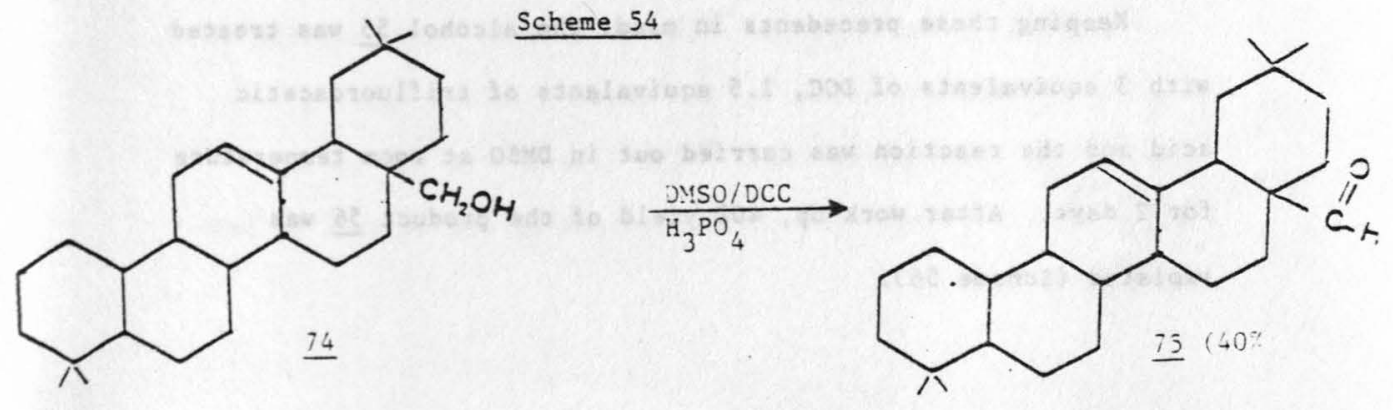


Weisner ${ }^{50}$ oxidized the tricyclic compound $\underline{76}$ to aldehyde $\underline{77}$ (Scheme 55-A).

\section{Scheme 55-A}<smiles>OCC12C=CC(CC1)c1ccccc12</smiles>

$\underline{76}$

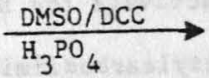

$77(77 \%)$

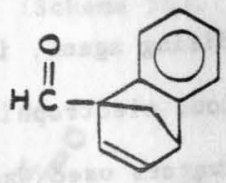

We have found only one reported example 51 where such an oxidation failed in case of a neopentyl alcohol 78 (Scheme 55-B).

\section{Scheme $55-B$}<smiles>[CH2-]C(C)(C)C(C)(C)CO</smiles>

78

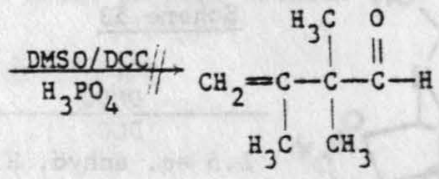

79

From these examples one can conclude that neopentyl alcohols can be oxidized by this method as long as they are held by a bicyclic system $(e . g . \underline{74}, \underline{76})$. This observation was very encouraging to us, since the compound we planned to oxidize, 55 , happened to be a neopentyl alcohol held by a bicyclic system.

Keeping these precedents in mind, the alcohol $\underline{55}$ was treated with 3 equivalents of $D C C, 1.5$ equivalents of trifluoroacetic acid and the reaction was carried out in DMSO at room temperature for 2 days. After work-up, $40 \%$ yield of the product $\underline{56}$ was isolated (Scheme 56). 
Scheme 56

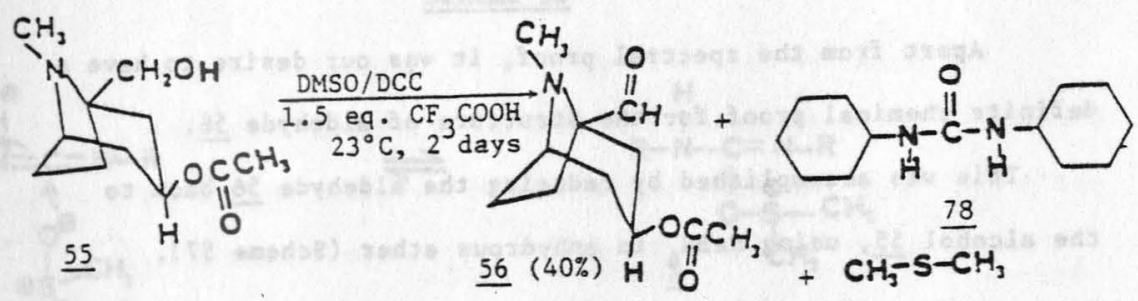

The work-up of the reaction was simplified by the possibility of freeing the product from excess DCC and dicyclohexylurea by extraction of the amine salt into water followed by regeneration of the free base.

The yields could be improved to $50 \%$ (and the reaction was cleaner) when 1.5 equivalents of 2,2-dichloropropionic acid were used instead of trifluoroacetic acid. Very poor yields (20\%) were obcained when anhydrous phosphoric acid was used as an acid catalyst.

\subsubsection{Structure of the Tropan-1-Aldehyde (56)-Spectral Data:}

The ${ }^{1} H$ NMR of aldehyde $\underline{56}$ showed a sharp singlet for the aldehyde proton $-\mathrm{C}-\mathrm{H}$ at $\delta 9.5$. The IR spectra showed absence of hydroxyl, which proved that the alcohol was oxidized. 


\subsubsection{Chemical Proof for the Structure of Aldehyde 56:}

Apart from the spectral proof, it was our desire to have a definite chemical proof for the structure of aldehyde 56 .

This was accomplished by reducing the aldehyde 56 back to the alcohol 55, using $\mathrm{NaBH}_{4}$ in anhydrous ether (Scheme 57).

\section{Scheme 57}
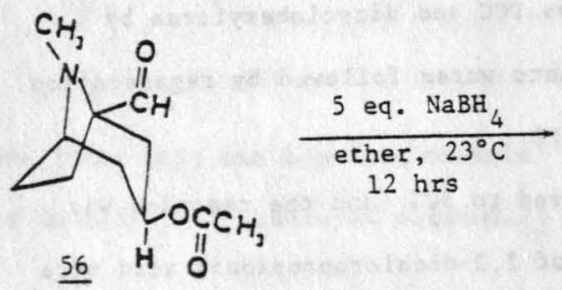

The ${ }^{1}$ H NMR spectrum of product from this reduction was superimposable with that of an authentic sample of $\underline{55}$. This result confirmed that $\underline{56}$ indeed was the desired aldehyde.

4.2.6 Mechanism of DMSO-DCC Oxidation ${ }^{47,52}$ :

The mechanism of this oxidation involves formation of intermediate A (Scheme 58) by nucleophilic attack of DMSO on the carbodilmide, followed by reaction of this species with the alcohol. A major part of the driving force for the reaction is derived from the conversion of the carbodilmide to urea $\underline{D}$, with formation of an amide carbonyl. The role of the DCC is to activate DMSO towards nucleophilic attack by the alcohol on DMSO. 
47

Scheme 58<smiles>[R]N=C([O-])N[R]</smiles><smiles>C1=CC=C1</smiles>

A<smiles>[R]N=C(N[R])OS(C)(C)C</smiles><smiles>[R]C(C)O</smiles><smiles>[R]COS1(C)CCCCC1ON=C(N[R])O[R]</smiles>

B<smiles>[R]COS(=C)C</smiles>

$+$<smiles>[R]NC(=O)N[R]</smiles>

D

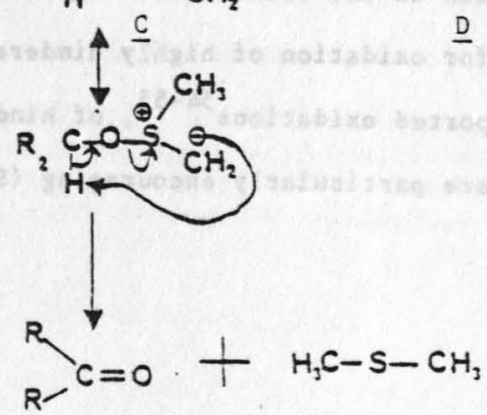




\subsubsection{Constraints of the Oxidation:}

Although the reaction worked well, separation of the product from the byproduct dicyclohexylurea involved tedious chromatography. To avoid it, we looked for other DMSO based oxidizing agents. What followed was a systematic experimental investigation of a variety of DMSO based oxidizing agents as to their potential to effect clean oxidation of our neopentyl alcohol $\underline{55}$ to the corresponding aldehyde $\underline{56}$.

\subsubsection{DMSO-Acetic Anhydride as Oxidants:}

Following their work on the application of the DMSO-DCC method to the oxidation of the indole alkaloids, Albright and Goodman $^{53}$ have developed a very useful alternative reaction using DMSO and acetic anhydride. The advantage of this reaction is that the byproduct from the reaction is predominantly acetic acid, which can be removed by aqueous extraction together with DMSO. Another feature that makes this method attractive is a suggestion in the literature ${ }^{46}$ that DMSO-AC ${ }_{2} \mathrm{O}$ oxidations are we 11 suited for oxidation of highly hindered alcohols.

Reported oxidations ${ }^{54-55}$, of hindered primary alcohols 80 and $\underline{82}$ are particularly encouraging (Scheme 59). 


\section{Scheme 59}

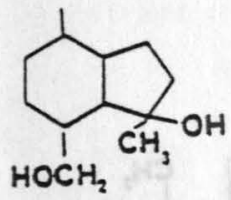

80

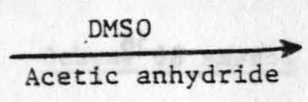

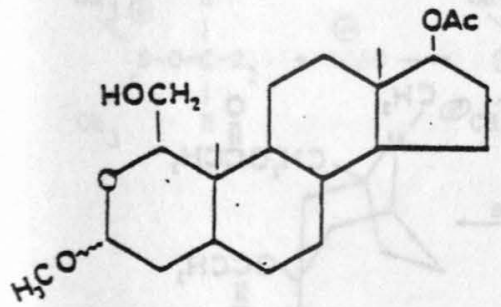

82
81

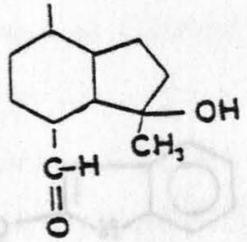

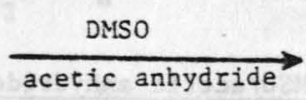

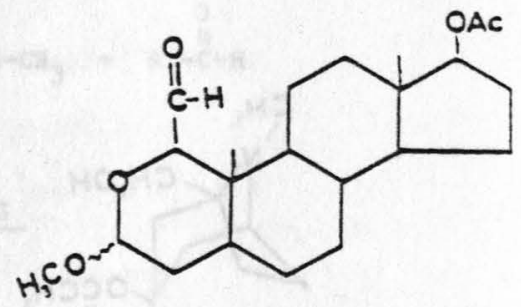

83 
In the alkaloid area, the reported ${ }^{56}$ oxidation of neopentyl indole alkaloid $\underline{84}$ to the aldehyde $\underline{85}$ (Scheme 60 ) raised our hopes of accomplishing a similar oxidation in our case too.

Scheme $60^{56}$

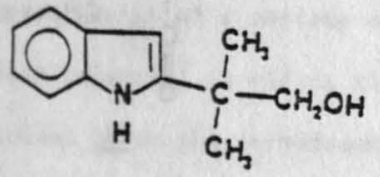

84

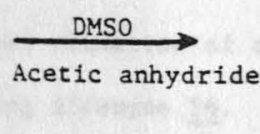

$\overrightarrow{\text { Acetic anhydride }}$

.

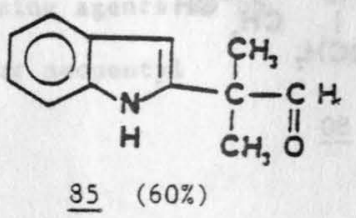

$35(60 \%)$

Adopting a similar procedure to our case and treating 55 with DMSO and acetic anhydride at room temperature for $40 \mathrm{hrs}$ gave, to our total disbelief, the corresponding diacetate 86 as the exclusive product (Scheme 61).

\section{Scheme 61}

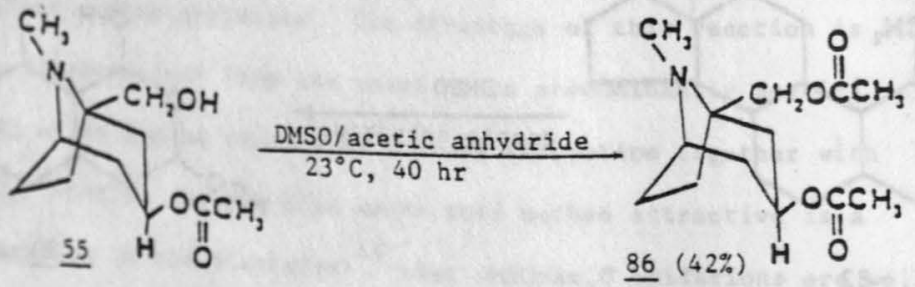

To understand this anomalous result, we have to look at the supposed aechanistic pathway by which DMSO-AC ${ }_{2} \mathrm{O}$ oxidations occur. 


\subsubsection{Mechanism of Oxidation:}

Scheme 62 describes the mechanism of DMSO-Ac ${ }_{2} \mathrm{O}$ oxidation.

\section{Scheme 62}

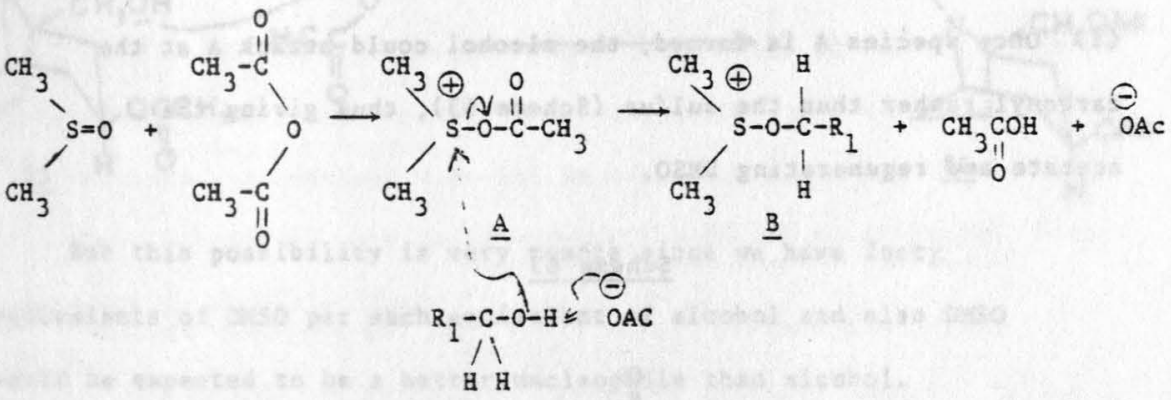

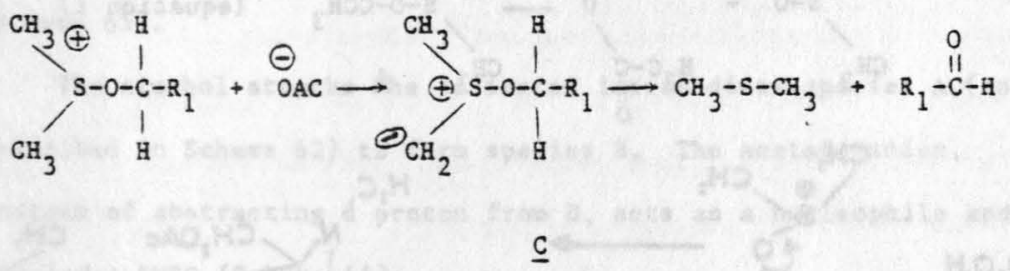

The first step is attack of sulfoxide on acetic anhydride to form species $A$, which is very susceptible to nucleophilic attack by the alcohol to give species $B$, which on loss of proton to acetate anion gives $\underline{C}$. The species $\underline{C}$, collapses to the aldehyde and dimethyl sulfide. 


\subsubsection{Possible Mechanism for Acetate Formation:}

Since in our case, acetate formation (instead of oxidation) took place, it is obvious that at least some of the events described in Scheme 62 did not occur. We can speculate on how the diacetate 86 could have formed in this reaction. In principle, we can postulate three different pathways.

(i) Once species $A$ is formed, the alcohol could attack A at the carbonyl rather than the sulfur (Scheme 63 ), thus giving the acetate and regenerating DMSO.

\section{Scheme 63}
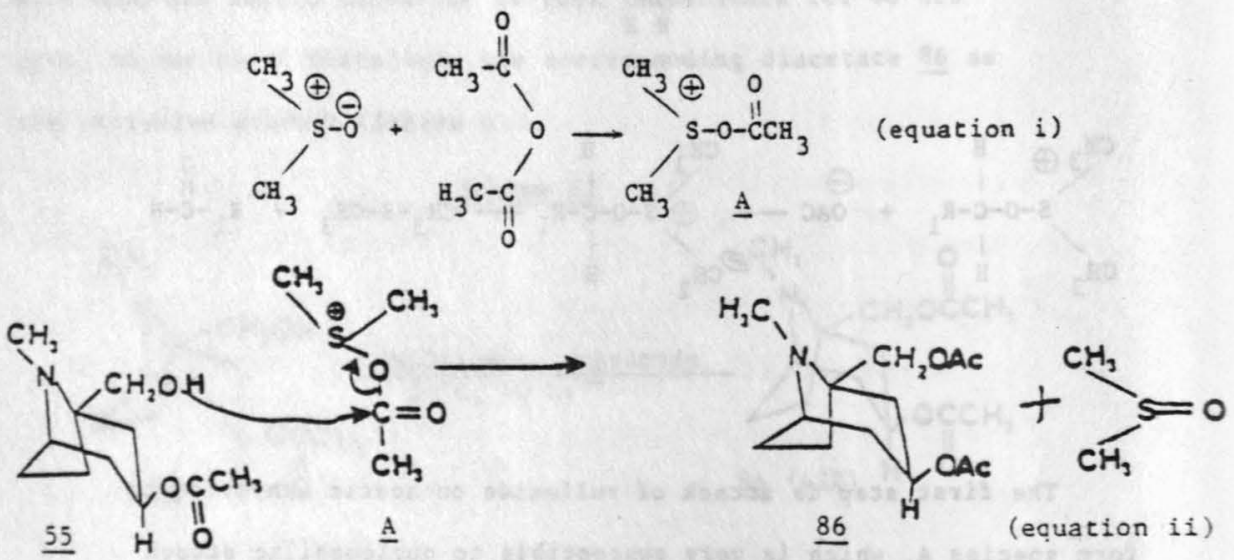

We can justify such an attack by the alcohol in the above scheme (equation $\mathrm{i} i$ ) on the carbonyl rather than the sulfur by contending that the carbonyl group is sterically less hindered than the sulfur.

(ii) The second possible pathway would be competitive 
nucleophilic attack by the alcohol on acetic anhydride

(Scheme 64).

\section{Scheme 64}
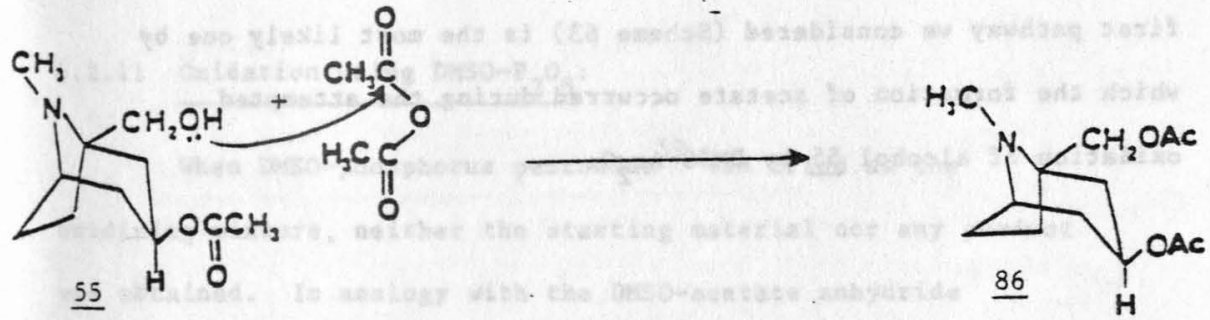

But this possibility is very remote since we have forty

equivalents of DMSO per each equivalent of alcohol and also DMSO

would be expected to be a better nucleophile than alcohol.

(iii) The third path one can imagine would be as follows

(Scheme 65).

The alcohol attacks the activated intermediate species A (as described in Scheme 62) to form species B. The acetate anion, instead of abstracting a proton from B, acts as a nucleophile and displaces DMSO (Scheme 65).

\section{Scheme 65}
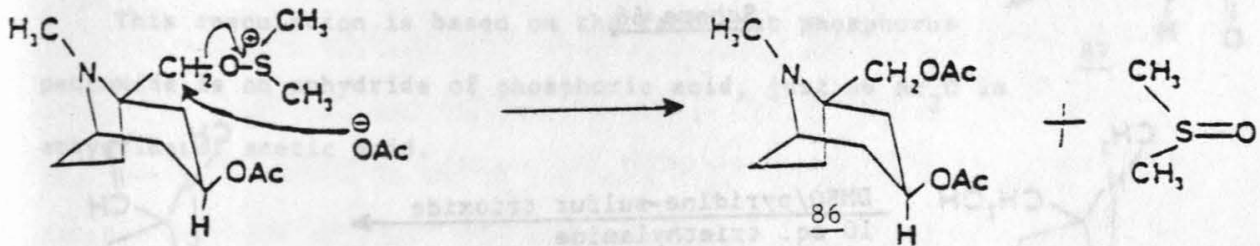

This possibility can also be ruled out with some degree of confidence because nucleophilic displacement on a neopentylic 
carbon would not be expected to go with such ease (considering the fact that the reaction was done at room temperature) and especially by a poor nucleophile like acetate anion.

From these three possibilities we can conclude that the first pathway we considered (Scheme 63 ) is the most likely one by which the formation of acetate occurred during the attempted oxidation of alcohol 55 by DMSO-Ac 2 O.

\subsubsection{Oxidation using DMSO/Pyridine- $\mathrm{SO}_{3}$ :}

Parikh and Doering 57 have shown that the pyridine complex of sulfur trioxide provides excellent activation of DMSO in the presence of triethylamine. The oxidation is usually performed by the addition of the pyridine-50 ${ }_{3}$ complex ${ }^{58}$ (three molar equivalents) to a DMSO solution of the alcohol and triethylamine (ten molar equivalents) at room temperature. This method has been applied to several steroidal alcohols.

Applying Doering's procedure 57 , to our case resulted in the oxidation of alcohol $\underline{55}$ to the aldehyde $\underline{56}$ in $35 \%$ yield (Scheme 66).

\section{Scheme 66}
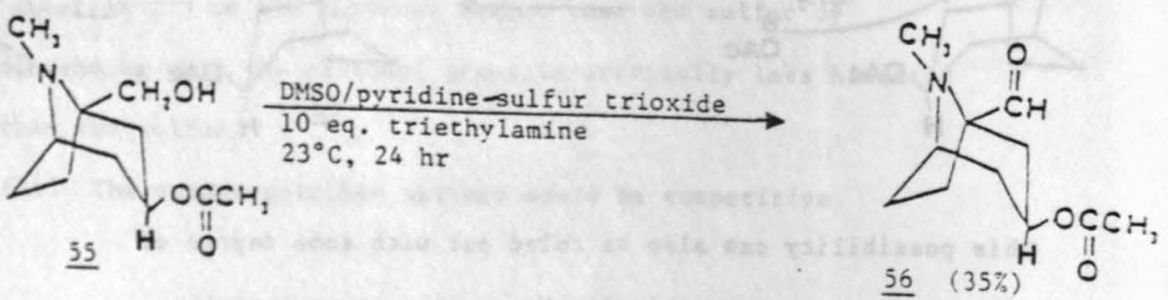
This method did not provide us with any substantial advantages over other methods we attempted. So our search for a better oxidant continued.

4.2.11 Oxidation using DMSO-P ${ }_{2} \mathrm{O}_{5}$ :

When DMSO-phosphorus pentoxide ${ }^{59}$ was tried as the oxidizing mixture, neither the starting material nor any product was obtained. In analogy with the DMSO-acetate anhydride reaction (Scheme 61), one could speculate that a water-soluble phosphate is probably formed (Scheme 67).

\section{Scheme 67}

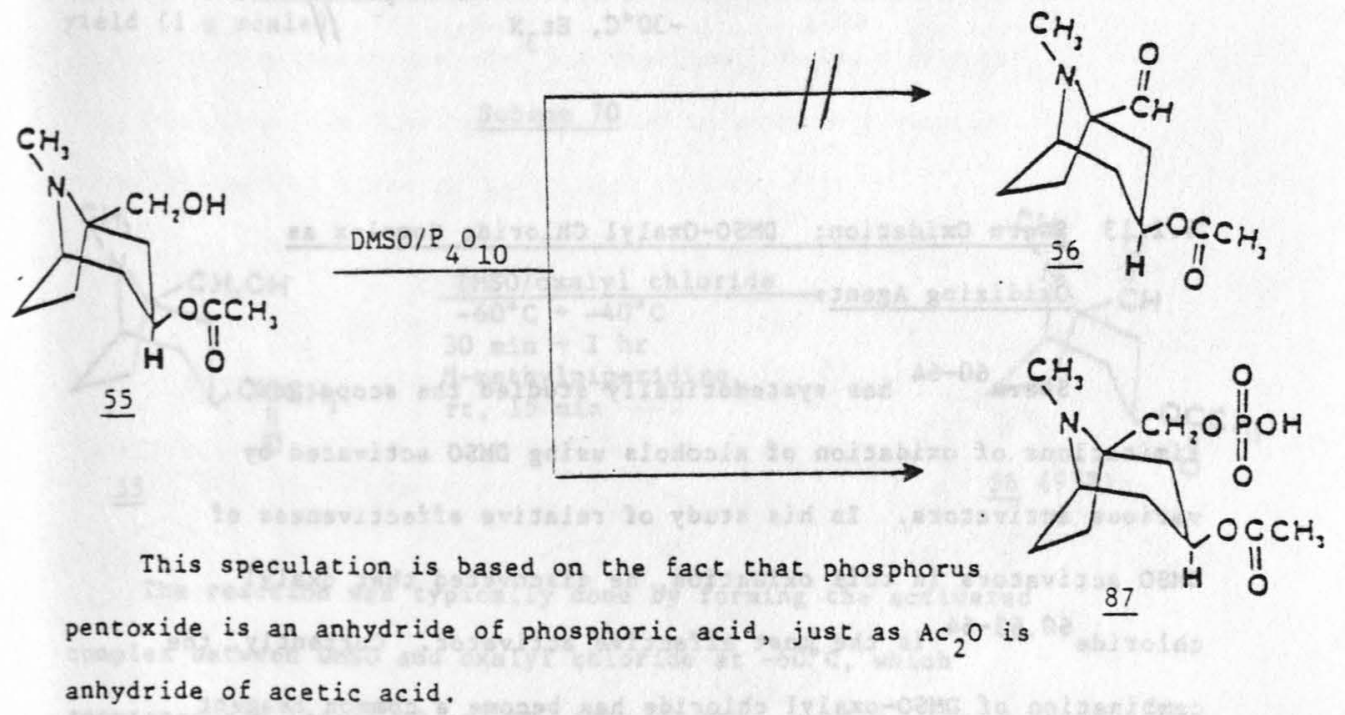




\subsubsection{DMSO-Thionyl Chloride:}

When DMSO- $\mathrm{SOCl}_{2}$ mixture ${ }^{60}$ or DMSO-trifluoroacetic

anhydride mixture $e^{61,62}$ were used as oxidizing agents, alcohol 55

was recovered unchanged (Scheme 68).

Scheme 68

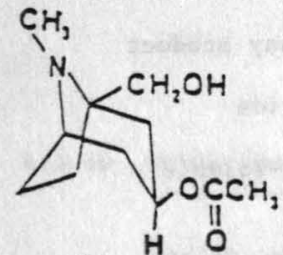

$\underline{55}$

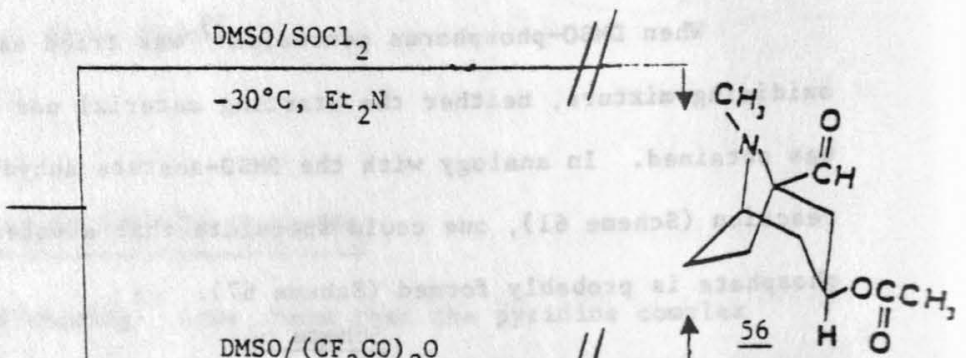

$\frac{\mathrm{DMSO} /\left(\mathrm{CF}_{3} \mathrm{CO}\right) 2^{\mathrm{O}}}{-30^{\circ} \mathrm{C}, \mathrm{Et}_{3} \mathrm{~N}}$

\subsubsection{Swern Oxidation: DMSO-Oxalyl Chloride Complex as}

\section{Oxidizing Agent:}

$$
\text { Swern }{ }^{60-64} \text { has systematically studied the scope and }
$$

limitations of oxidation of alcohols using DMSO activated by

various activators. In his study of relative effectiveness of

DMSO activators in this oxidation, he discovered that oxalyl

chloride $60,63-64$ is the most effective activator. Currently, the

combination of DMSO-oxalyl chloride has become a common reagent

in the organic laboratory. Also known as Swern oxidation, this

method has three advantages: (i) no over-oxidation occurs; (ii) 
even hindered alcohols such as neopentyl alcohol 88 (Scheme 69) can be oxidized very smoothly to the corresponding aldehydes; (iii) the formation of unwanted side-products is minimal.

\section{Scheme 69}

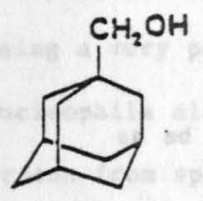

$\underline{88}$

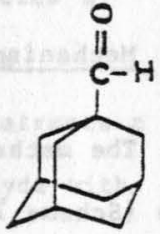

89

Following Swern's procedure ${ }^{60}$ (Scheme 70 ) our neopentyl alcohol $\underline{55}$ was oxidized to the aldehyde $\underline{56}$ very smoothly in $95 \%$ yield ( 1 g scale).

\section{Scheme 70}

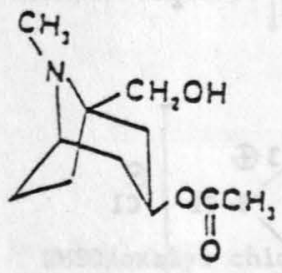

$\underline{55}$

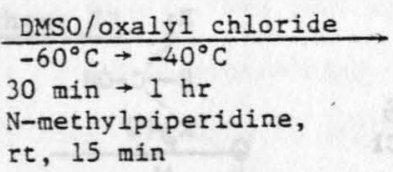

$\mathrm{N}$-methylpiperidine, t, 15 min

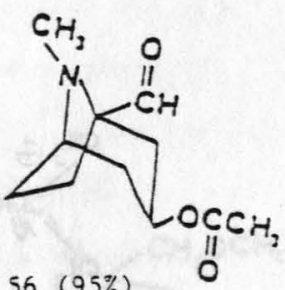

$56(95 \%)$

The reaction was typically done by forming the activated complex between DMSO and oxalyl chloride at $-50^{\circ} \mathrm{C}$, which spontaneously looses $\mathrm{CO}$ and $\mathrm{CO}_{2}$ (Scheme 71). Addition of alcohol to this reactive species, followed by treatment with a base like triethylamine or $\mathrm{N}$-methylpiperidine and warming to room 
temperature, followed by basic $\left(\mathrm{NH}_{4} \mathrm{OH}, \mathrm{pH}=10-11\right)$ aqueous extractive work-up gave the crude aldehyde (which was essentially pure for all practical purposes) in $95 \%$ yield.

\subsubsection{Mechanism of DMSO-0xalyl Chloride Oxidation:}

The mechanism of Swern oxidation is believed to be as follows (Scheme 71).

\section{Scheme 71}

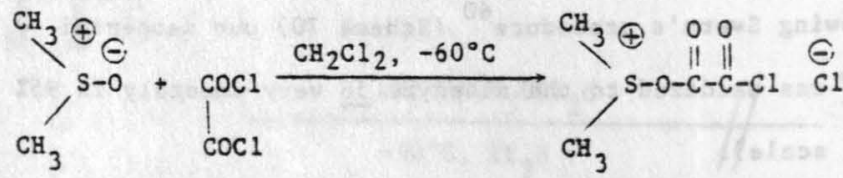

$\underline{A}$ $-\mathrm{CO}_{2},-\mathrm{CO}$<smiles>[C+]C</smiles><smiles>[C-]1CCCC1</smiles>

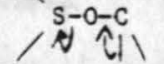<smiles>C1CCCC1</smiles><smiles>[R2]CCNCC</smiles>
C1<smiles>[R1]C(C)O</smiles><smiles>C[Si](C)(C)Cl</smiles>

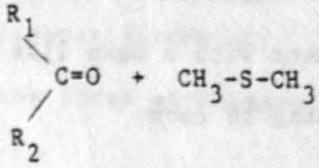

$R_{1}=$ alkyl or $\mathrm{H}$ 
The mechanism of this oxidation deserves some comment. DMSO reacts with oxalyl chloride even at $-60^{\circ} \mathrm{C}$ and forms species $\underline{A}$, which spontaneously loses one mole each of carbon monoxide and carbon dioxide (the loss of these gases can be observed if the escaping gases are bubbled through mineral oil). Species B, being a very powerful electrophile, is attacked by the nucleophile alcohol and forms species $C$. The base abstracts a proton from species $C$, thus forming the desired aldehyde with extrusion of dimethyl sulfide. Overall the alcohol is oxidized to the aldehyde and DMSO is reduced to dimethyl sulfide.

An observation we made during the oxidation of our alcohol 55 is that the yields dropped down to $85 \%$ when the reaction was done on a large scale $(5 \mathrm{~g})$. Also $\mathrm{N}$-methylpiperidine seems to be the most suitable base for the reaction. Using a highly hindered base like 2,6-lutidine seemed to promote formation of methylthiomethyl ether as by-product (Scheme 72).

\section{Scheme 72}
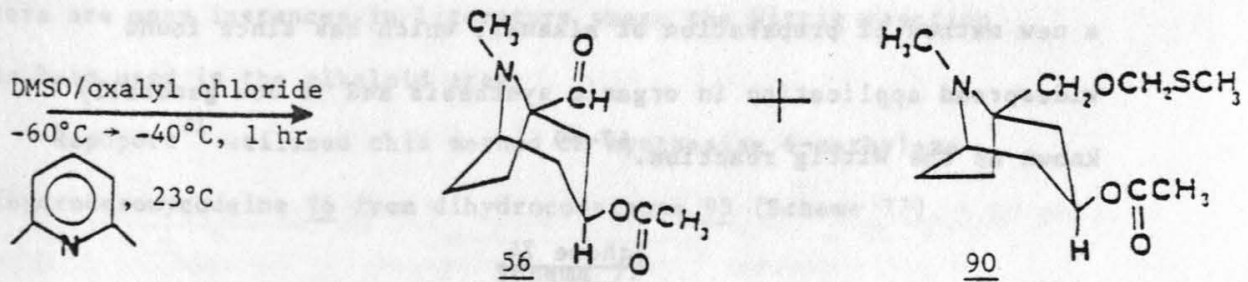

The product 90 should be coming from Pummerer rearrangement ${ }^{65-66}$ of species C (Scheme 73). 


\section{Scheme 73}

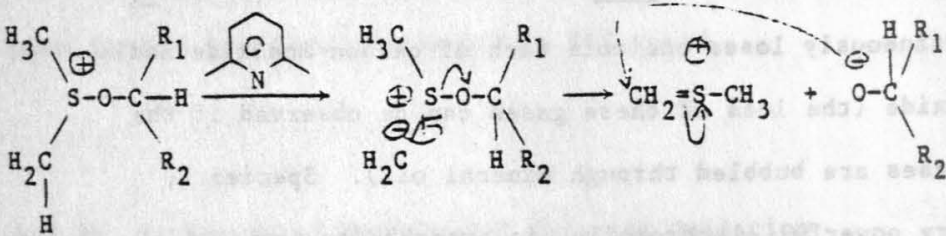

$\underline{\mathrm{C}}$

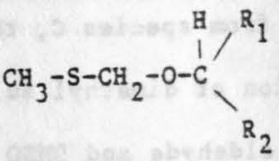

\subsubsection{Wittig Reaction: Extension of the Side Chain:}

In 1953 , wittig ${ }^{70}$ observed that when methyltriphenylphosphonium bromide (91) was treated with phenyllithium, an ylide 92 was formed that could react with benzophenone to give triphenylphosphine oxide ( $\underline{94})$ and 1,1-diphenylethylene (93) in 84\% yield (Scheme 74 ). This discovery led to the development of a new method of preparation of alkenes, which has since found widespread application in organic synthesis and is now generally known as the Wittig reaction. $67-69$

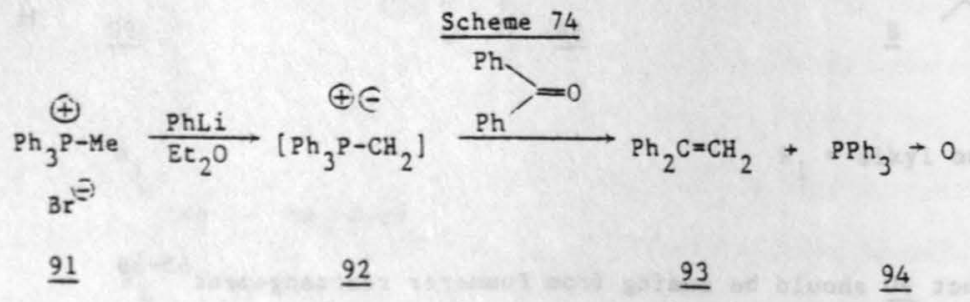


One could generalize this reaction in the following way (Scheme 75).

\section{Scheme 75}

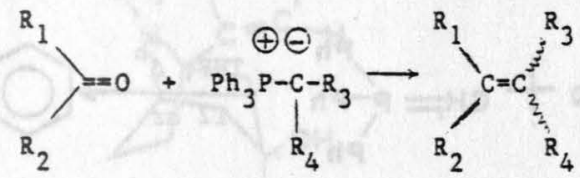

A similar Wittig reaction on our aldehyde 56, in principle should give access to a variety of compounds (Scheme 76).

\section{Scheme 76}
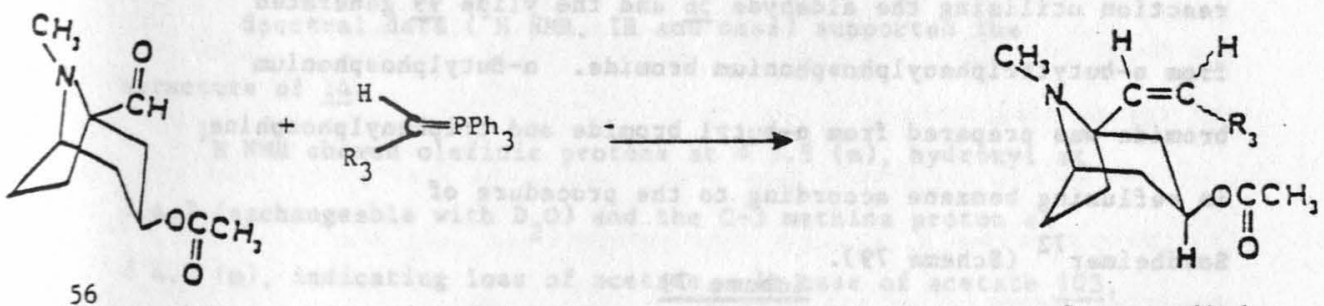

$R_{3}=n-a 1 k y l$.

There are many instances in literature where the Wittig reaction has been used in the alkaloid area.

$$
\text { Rapoport }{ }^{71} \text { utilized this method to synthesize } 6 \text {-methylene }
$$

dihydrodesoxycodeine 96 from dihydrocodeinone 95 (Scheme 77).

\section{Scheme 77}

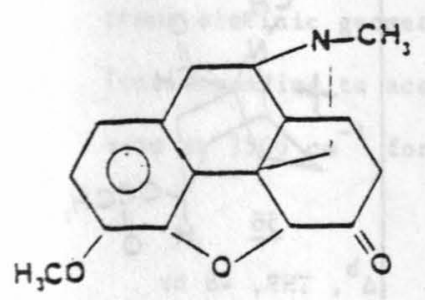

$\underline{95}$

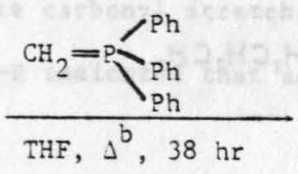

THF, $\Delta^{b}, 38$ hr

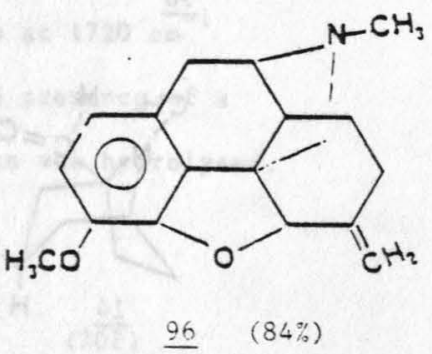

$96 \quad(84 \%)$ 
In the indole series, neopentyl aldehyde 85 was converted 56 to the olefin 97 (Scheme 78 ).

\section{Scheme 78}<smiles>CC(C=O)(C=CC(C)(C)c1cc2ccccc2[nH]1)C=P(c1ccccc1)(c1ccccc1)c1ccccc1</smiles>
85

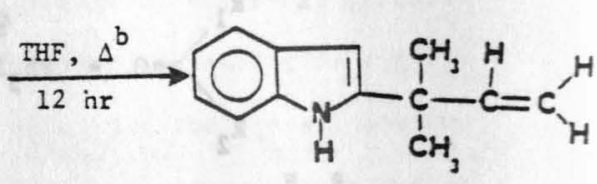

$97(60 \%)$

Keeping these analogies in mind, we carried out the wittig reaction utilizing the aldehyde $\underline{56}$ and the ylide 99 generated from n-butyltriphenylphosphonium bromide. n-Butylphosphonium bromide was prepared from n-butyl bromide and triphenylphosphine in refluxing benzene according to the procedure of Sondhe imer ${ }^{72}$ (Scheme 79 ).

\section{Scheme 79}

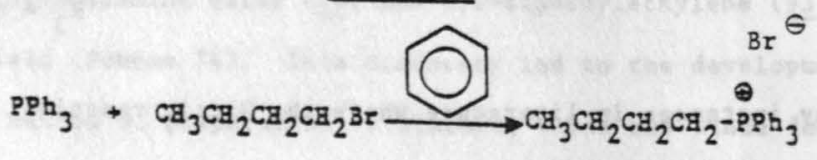

$$
\mathrm{Br}{ }^{\ominus}
$$

1.6 eq $\mathrm{CH}_{3} \mathrm{CH}_{2} \mathrm{CH}_{2} \mathrm{CH}_{2}-\stackrel{\oplus \mathrm{Ph}_{3}}{1.5} \stackrel{\text { eq } \mathrm{a}-3 \mathrm{uLi}}{\longrightarrow} 1.5$ eq $\left[\mathrm{CH}_{3} \mathrm{Ca}_{2} \mathrm{Ca}_{2} \mathrm{CH}=\mathrm{PPh}_{3}\right]$

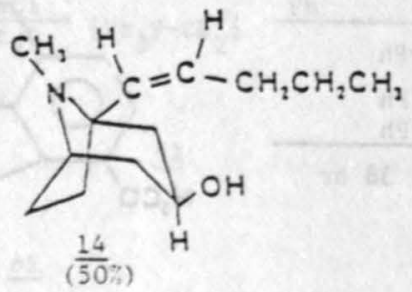

99<smiles>C=CC</smiles>

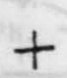

$\int_{\mathrm{H}}^{\mathrm{C}} \mathrm{CH}_{3}^{\mathrm{C}}$ 
It was very pleasing to find that the desired compound 14 was formed as a single product to the exclusion of the trans isomer $\underline{100}$.

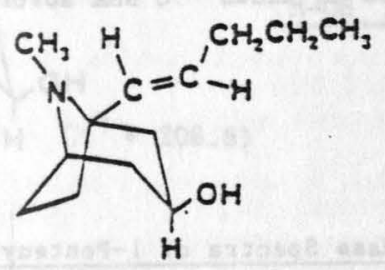

100

\subsubsection{Structure Determination of 1-Pentenyl-3B-tropanol:}

Spectral data ( ${ }^{1} \mathrm{H}$ NMR, IR and mass) supported the structure of $\underline{14}$.

${ }^{1}$ H NMR showed olefinic protons at $\delta 5.5(\mathrm{~m})$, hydroxyl at $\delta 4.7$ (exchangeable with $\mathrm{D}_{2} \mathrm{O}$ ) and the $\mathrm{C}-3$ methine proton at $\delta 4.0$ (m), indicating loss of acetate. In case of acetate 103 , the same proton gives a signal at $\delta 5.0(\mathrm{~m})$. This is a clear indication that the compound underwent deacetylation during the reaction. The coupling constant for vinylic protons was about $6 \mathrm{~Hz}$, indicating cis relationship between the olefinic protons. Infrared absorption at $685 \mathrm{~cm}^{-1}$ also supported cis olefinic geometry. There was no absorption at $965 \mathrm{~cm}^{-1}$ corresponding to trans olefinic geometry. Absence of absorption at $1720 \mathrm{~cm}^{-1}$ (corresponding to acetate carbonyl stretch) and presence of a band at $3500 \mathrm{~cm}^{-1}$ for $0-\mathrm{H}$ indicated that acetate was hydrolysed. 
${ }^{13} \mathrm{C}$ NMR showed 13 signals corresponding to 13 different carbon atoms in the compound. If there were any trans alkene present, it would have showed more than 13 peaks. The assignment of ${ }^{13} \mathrm{C}$ NMR signals was based on known ${ }^{13} \mathrm{C}$ NMR absorption signals for tropanes. ${ }^{74}$

\subsubsection{Interpretation of Mass Spectra of 1-Penteny1-38-Tropanol:}

The mass spectrum of the compound 14 showed molecular ion $\left(\mathrm{M}^{+}\right.$) peak at 208.8 (mol. wt. of $\underline{14}=209$ ). Several years ago Fodor ${ }^{75}$ and Djerassi studied the mass spectra of tropine and several other tropane alkaloids. The fragmentation pattern of our compound 14 fell in line with Fodor's study. Scheme 81 shows the various fragments.

Two surprising events came about during the Wittig reaction:

(i) the conversion of acetate into hydroxyl and (ii) the exclusive formation of cis olefin.

The reaction of acetates with wittig reagents has precendence in 1 iterature. Sondheimer ${ }^{76}$ found that 7 -keto chloesteryl acetate $\underline{101}$ on treatment with excess methylene triphenyl phosphine in refluxing THF produced 7-methylenecholesterol 102 (Scheme 80).

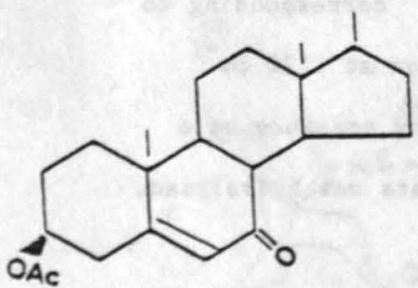

$\underline{101}$

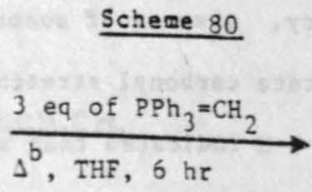

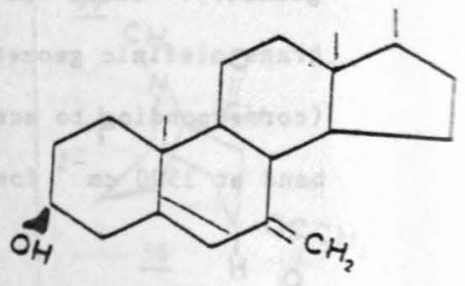

102 


\section{Scheme 81}
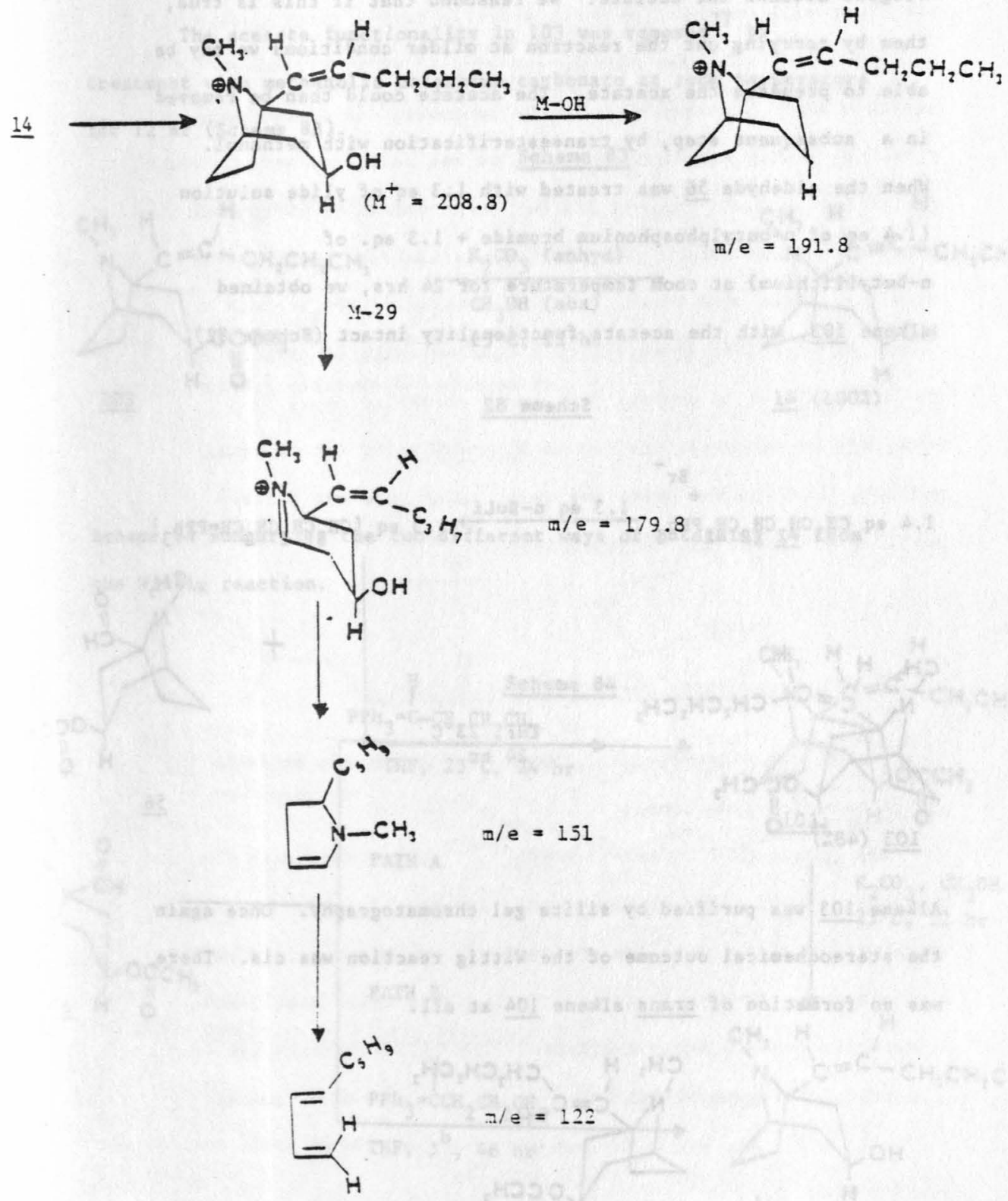
Under these vigorous conditions (refluxing THF), the Wittig reagent attacks the acetate. We reasoned that if this is true, then by carrying out the reaction at milder conditions we may be able to preserve the acetate. The acetate could then be removed in a subsequent step, by transesterification with methanol.

When the aldehyde $\underline{56}$ was treated with 1.3 eq of ylide solution ( 1.4 eq of n-butylphosphonium bromide +1.3 eq. of n-butyllithium) at room temperature for $24 \mathrm{hrs}$, we obtained alkene 103 , with the acetate functionality intact (Scheme 82).

\section{Scheme 82}

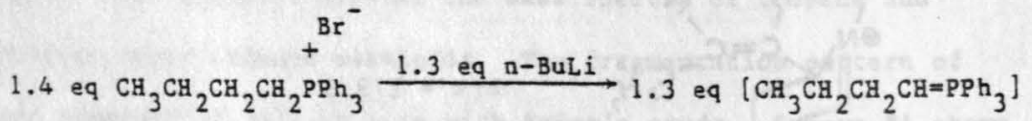<smiles>CC/C=C\C1CCC2CCC1N2C</smiles>
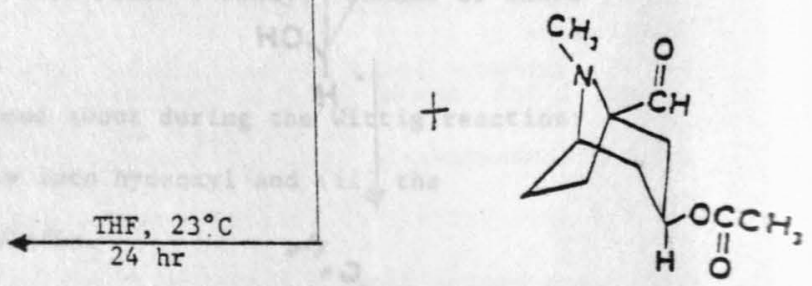

$\underline{56}$

Alkene 103 was purified by silica gel chromatography. Once again the stereochemical outcome of the wittig reaction was cis. There was no formation of trans alkene $\underline{104}$ at all.

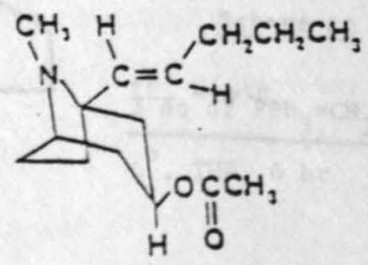




\subsubsection{Removal of Acetate by Transesterification:}

The acetate functionality in 103 was removed ${ }^{77}$ by treatment with methanolic potassium carbonate at room temperature for $12 \mathrm{hr}$ (Scheme 83).

\section{Scheme 83}

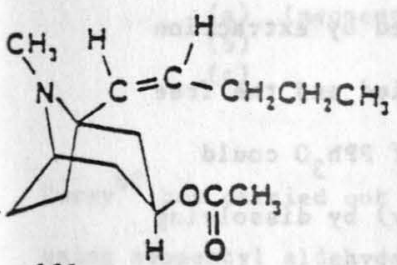

103

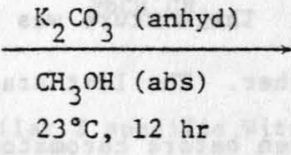

Scheme 84 summarizes the two different ways of obtaining 14 from the Wittig reaction.

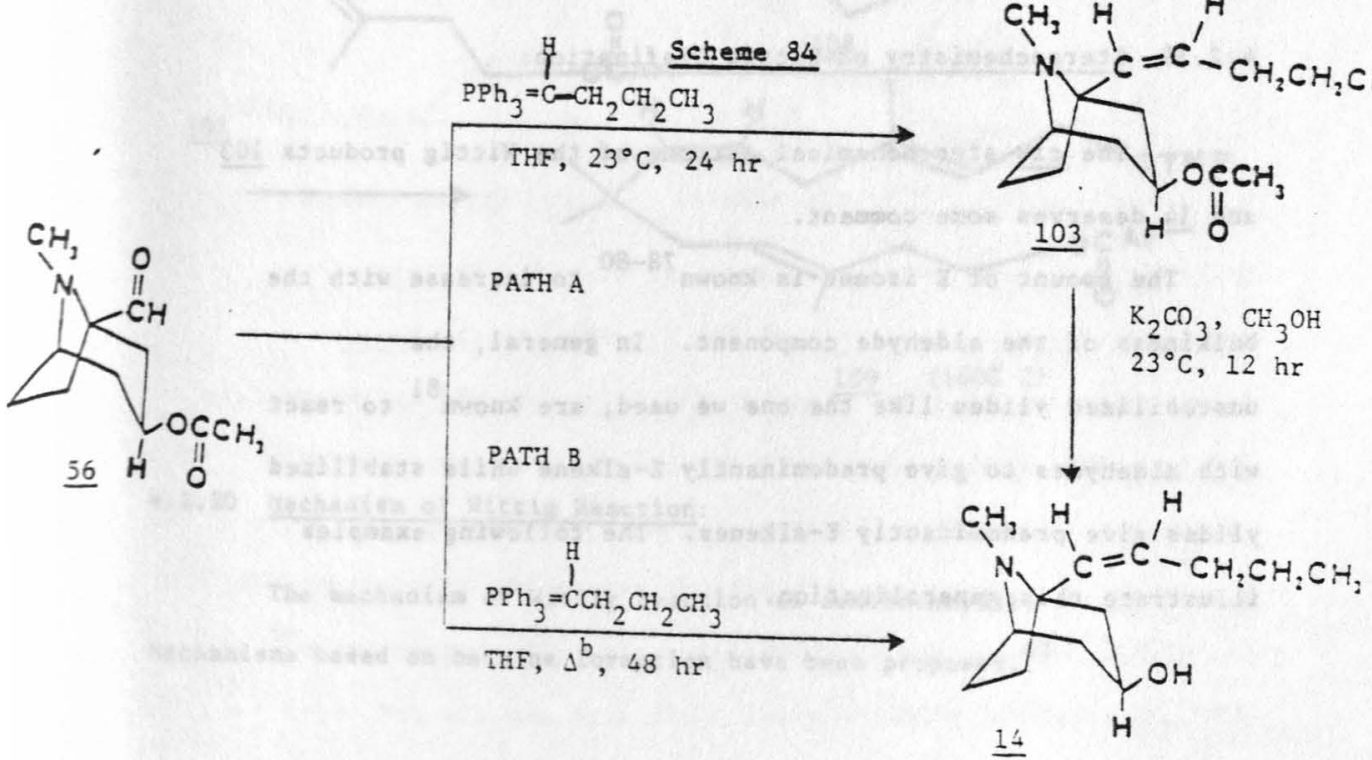


We found that path $A$ is a much cleaner path than path $B$. There were less side products to worry about in path A than in path B. In both cases, the work-up was simplified by virtue of having a basic nitrogen atom in the molecule. In either case, after the Wittig reaction, the mixture was acidified and the nonbasic side products (mainly $\mathrm{PPh}_{3} \mathrm{O}$ ), were removed by extraction with benzene and ether. The mixture was basified and the free amine extracted with ether. The last traces of $\mathrm{PPh}_{3} \mathrm{O}$ could easily be separated (even before chromatography) by dissolving the crude alkene in pentane (triphenyl phosphine oxide is insoluble in pentane), cooling to $0^{\circ} \mathrm{C}$, filtering and removing pentane. The residue which was essentially pure was further purified by silica gel chromatography.

\subsubsection{Stereochemistry of Wittig Olefination:}

The cis stereochemical outcome of the wittig products $\underline{103}$ and 14 deserves some comment.

The amount of $Z$ isomer is known ${ }^{78-80}$ to increase with the bulkiness of the aldehyde component. In general, the unstabilized ylides like the one we used, are known ${ }^{81}$ to react with aldehydes to give predominantly $z$-alkene while stabilized ylides give predominantly E-alkenes. The following examples ${ }^{74}$ illustrate this generalization. 


\section{Scheme 85}

$$
\begin{aligned}
& \mathrm{Br}^{-} \quad \mathrm{H}
\end{aligned}
$$

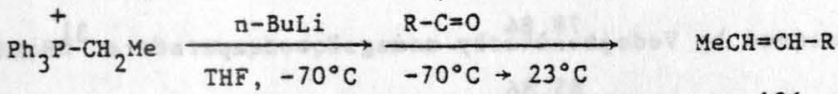

$$
\begin{aligned}
& \underline{105} \underline{\mathrm{R}} \underline{\mathrm{Z}: \mathrm{E}} \\
& \begin{array}{llr}
\text { (a) (neopentyl) } & \mathrm{Me}_{3} \mathrm{C} & 99: 1 \\
\text { (b) } & \mathrm{Ph} & 2: 1 \\
\text { (c) } & \mathrm{PhCH}_{2} \mathrm{CH}_{2} & 7: 3
\end{array}
\end{aligned}
$$

Corey $^{82}$ has carried out a similar $\mathrm{Z}$ specific Wittig reaction by using neopentyl aldehyde 107 (Scheme 86).

\section{Scheme 86}

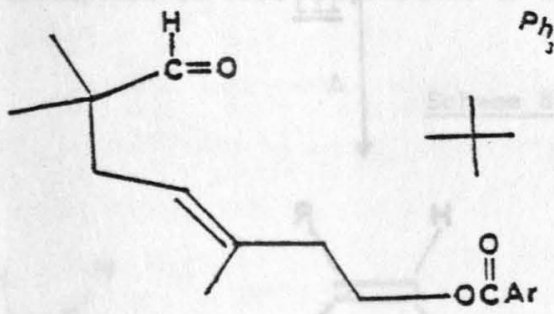

107

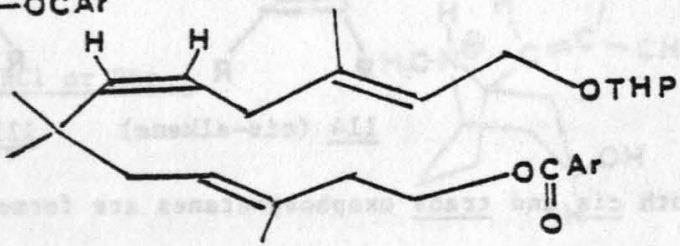

$109 \quad(100 \%$

2)

\subsubsection{Mechanism of Wittig Reaction:}

The mechanism of Wittig reaction is controversial.

Mechanisms based on betaine formation have been proposed. ${ }^{83}$ 
However, there is no experimental evidence for betaines. There are other mechanisms based on oxaphosphetanes. Oxaphosphetanes have been observed by Vedejs ${ }^{78,84}$ by using low-temperature ${ }^{31}$ p NMR spectroscopy. Very recent $1 y^{85,86}$ evidence has been presented for cis- and trans-oxaphosphetanes by Marayanoff who resolved the corresponding ${ }^{31}$ P NMR signals. The following mechanistic pathway is proposed by Maraynoff (Scheme 87 ).

\section{Scheme 87}
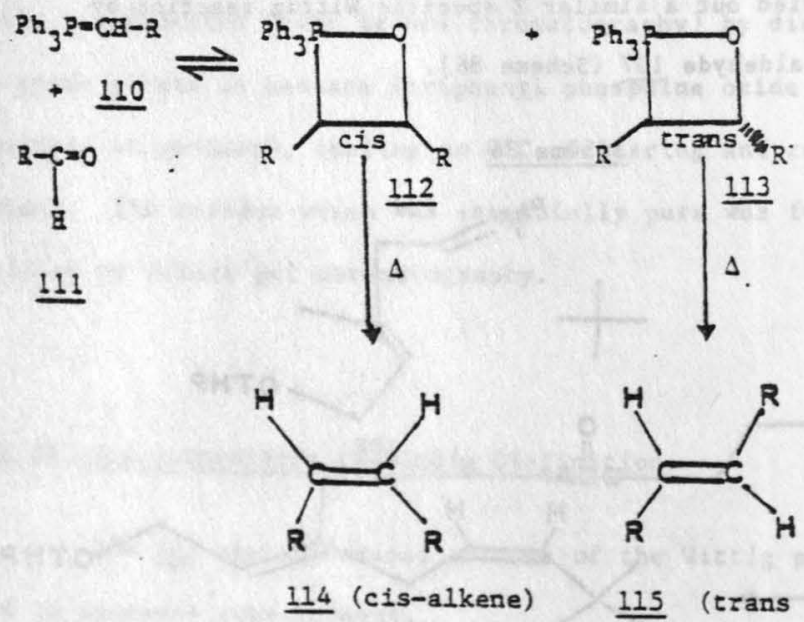

115 (trans alkene)

Both cis and trans oxaphosphetanes are formed. The cis oxaphosphetane $\underline{112}$ gives $\underline{\mathrm{cis}}$ olefin $\underline{114}$ whereas the trans oxaphosphetane $\underline{113}$ gives trans olefin $\underline{115}$. The cis oxaphosphetane 112 is formed faster than the trans. The cis oxaphosphetane decomposes faster than the trans. The cis and trans oxaphosphetanes could equilibrate via reversible interconversion of oxaphosphetanes and starting materials. The current view 85 is that the relative stereochemical preference for cis and trans 
olefins in the Wittig reaction may be dictated not by what happens during the reaction of aldehydes and ylides but by what can happen to the oxaphosphetanes afterwards.

\subsubsection{Attempted Preparation of Crystalline Salts of 14:}

\section{All attempts at preparing crystalline derivatives of 14} have failed. Treating 14 with hydrochloric or hydrobromic acids gave oily salts which could never be crystallized. A white crystalline tetraphenylborate salt could be prepared but it decomposed at room temperature in $24 \mathrm{hr}$ (Scheme 88 ).

\section{Scheme 88}

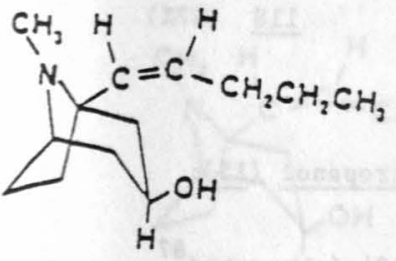

$\underline{14}$

\section{$\mathrm{HCl}$ or $\mathrm{HBr}$}<smiles>CCC=CC1CCCC2CC(O)CC1N2C</smiles>

14

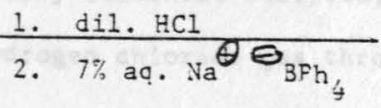

Decomposed

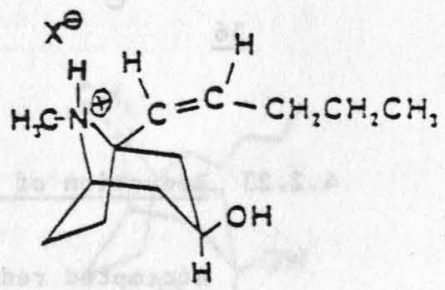

116 (oils) a. $\mathrm{X}=\mathrm{Cl}^{-}$

b. $\mathrm{X}=\mathrm{Br}{ }^{-}$

$\theta_{\mathrm{B}}$<smiles>CC/C=C\C1CCCC2CCCC1[NH+]2C</smiles> 
4.2.22 Chemical Confirmation of Structure of Alkene 14:

To confirm chemically that the product from the Wittig

reaction (Scheme 79) is not just an addition product of

n-butyllithium to the aldehyde $\underline{56}$, an alternate reaction was

done. Pure aldehyde $\underline{56}$ was refluxed with 6 equivalents of

n-butyllithium (Scheme 89 ). The resulting product was identified by ${ }^{1} \mathrm{H}$ NMR as $\underline{118}$.

\section{Scheme 89}

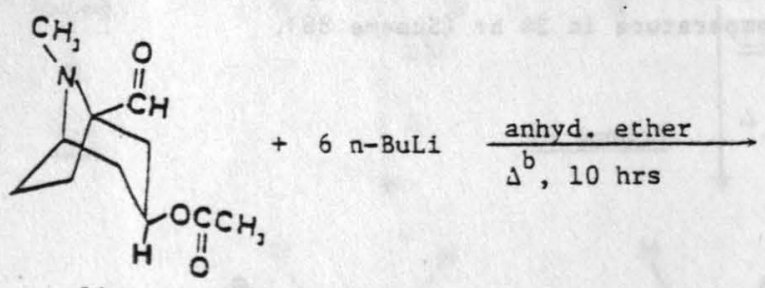

$\underline{56}$

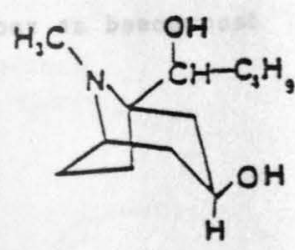

$\underline{118}(47 \%)$

\subsubsection{Reduction of Alkene 14 to $( \pm)$ 1-n-Pentyl-3B-tropanol (15):}

Attempted reduction of olefin $\underline{14}$ by diimide $\underline{121}$ (generated ${ }^{87}$

in situ from potassium azo-dicarboxylate ${ }^{88}$ and acetic acid)

resulted in complete recovery of starting material (Scheme 90). 


\section{Scheme 90}

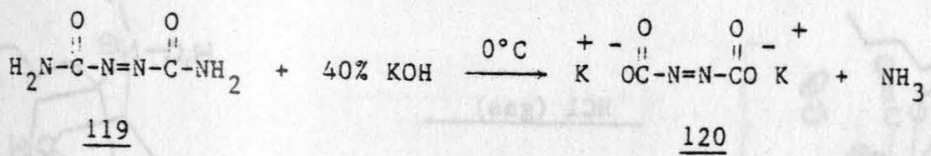

$$
\stackrel{\mathrm{K}}{\mathrm{OC}-\mathrm{N}=\mathrm{N}-\mathrm{CO}} \stackrel{\mathrm{K}}{\mathrm{O}}+\mathrm{CH}_{3} \mathrm{COOH} \longrightarrow[\mathrm{HN}=\mathrm{NH}]
$$

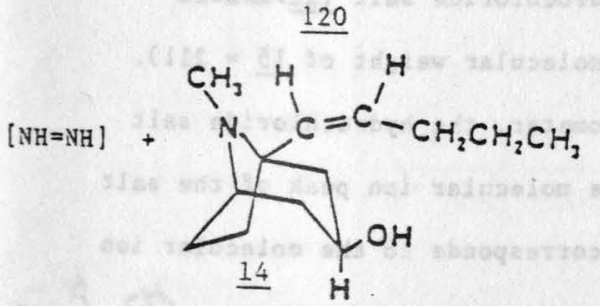

However successful reduction of 14 to the saturated amine 15 was accomplished by catalytic hydrogenation over Raney Nickel $(W-2)$ (Scheme 91).

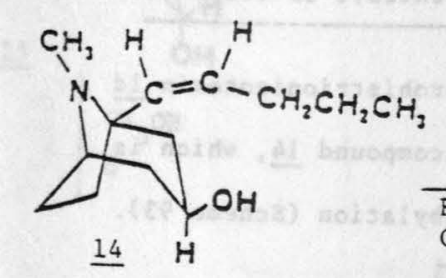

Scheme 91
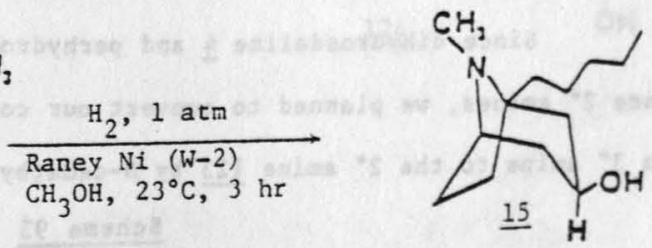

${ }^{1}$ H NMR of 15 showed lack of unsaturation which proved that the reduction was successful. A crystalline hydrochloride salt of 15. which gave a satisfactory elemental analysis, was prepared $^{89}$ by bubbling hydrogen chloride gas through an echereal solution of 15 . 
Scheme 92

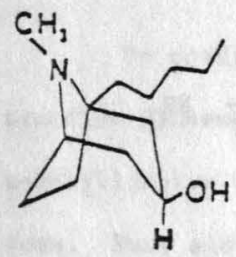

15

\section{$\mathrm{HCl}$ (gas)}

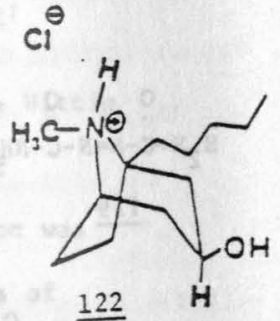

122

The mass spectrum of the hydrochloride salt 122 showed molecular ion peak $\mathrm{M}^{+}$at 210.8 (molecular weight of $15=211$ ). When injected in the mass spectrometer, the hydrochloride salt 122 loses one mole of $\mathrm{HCl}$ and the molecular ion peak of the salt corresponds to $\mathrm{M}^{+}-36.5$, which corresponds to the molecular ion peak of free base 15 .

\subsubsection{Attempted Removal of $\mathrm{N}-\mathrm{CH}_{3}$ of 1-Pentenyl-3B-Tropanol:}

Since dihydroadaline $\underline{4}$ and perhydrohistrionicotoxin $1 \mathrm{~d}$ are $2^{\circ}$ amines, we planned to convert our compound 14 , which is a $3^{\circ}$ amine to the $2^{\circ}$ amine $\underline{123}$ by $\mathrm{N}$-demethylation (Scheme 93 ).

\section{Scheme 93}<smiles>CCC=CC1CCCC2CC(O)C1N2C</smiles>

14

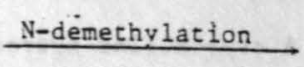

123

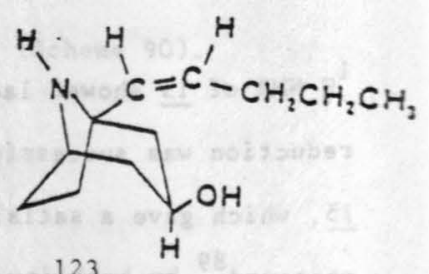

H

In the tropane series, a variety of amine demethylation

procedures have been developed. Most of these involve treatment 
Scheme $94^{93}$
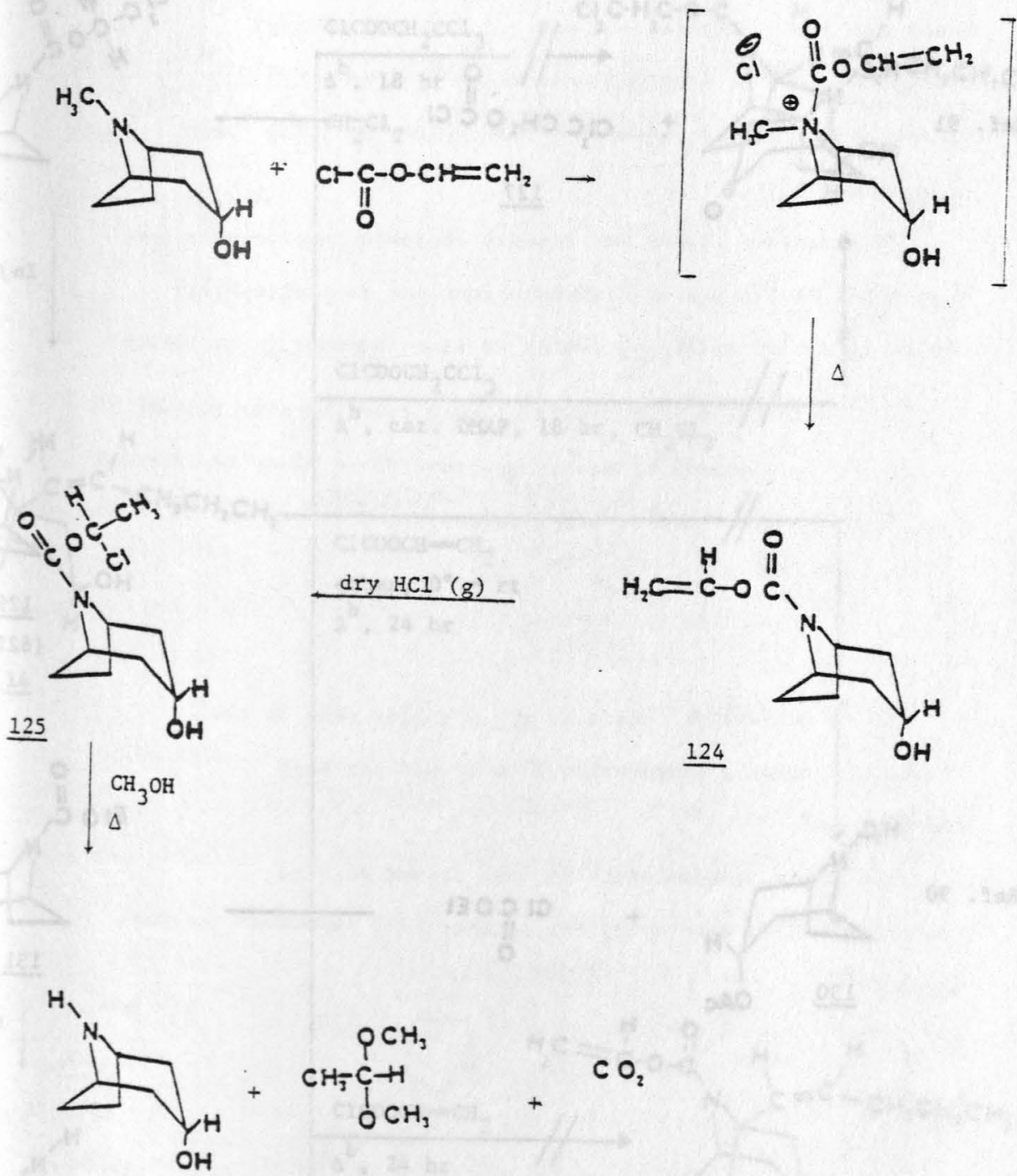
Scheme 95
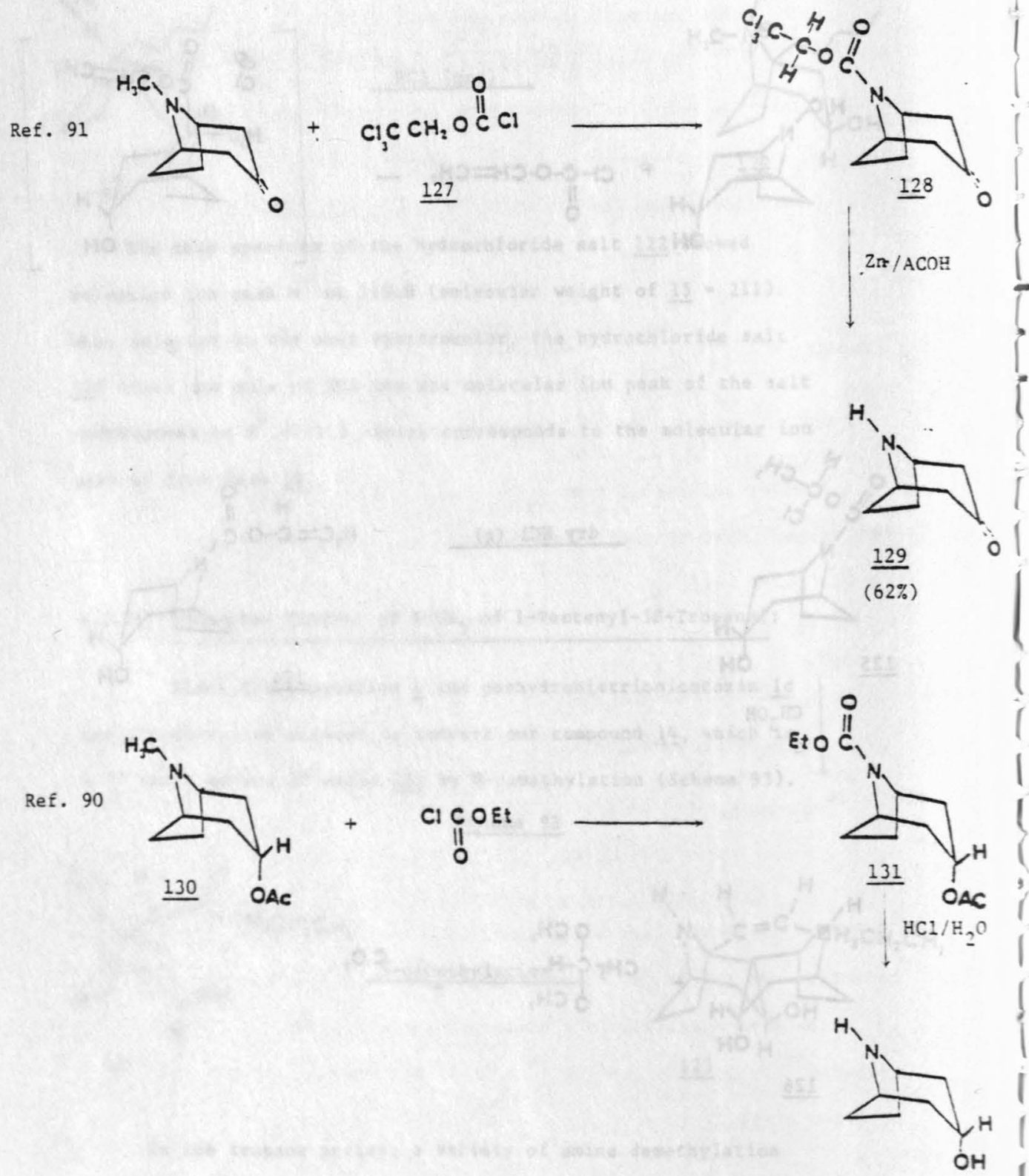


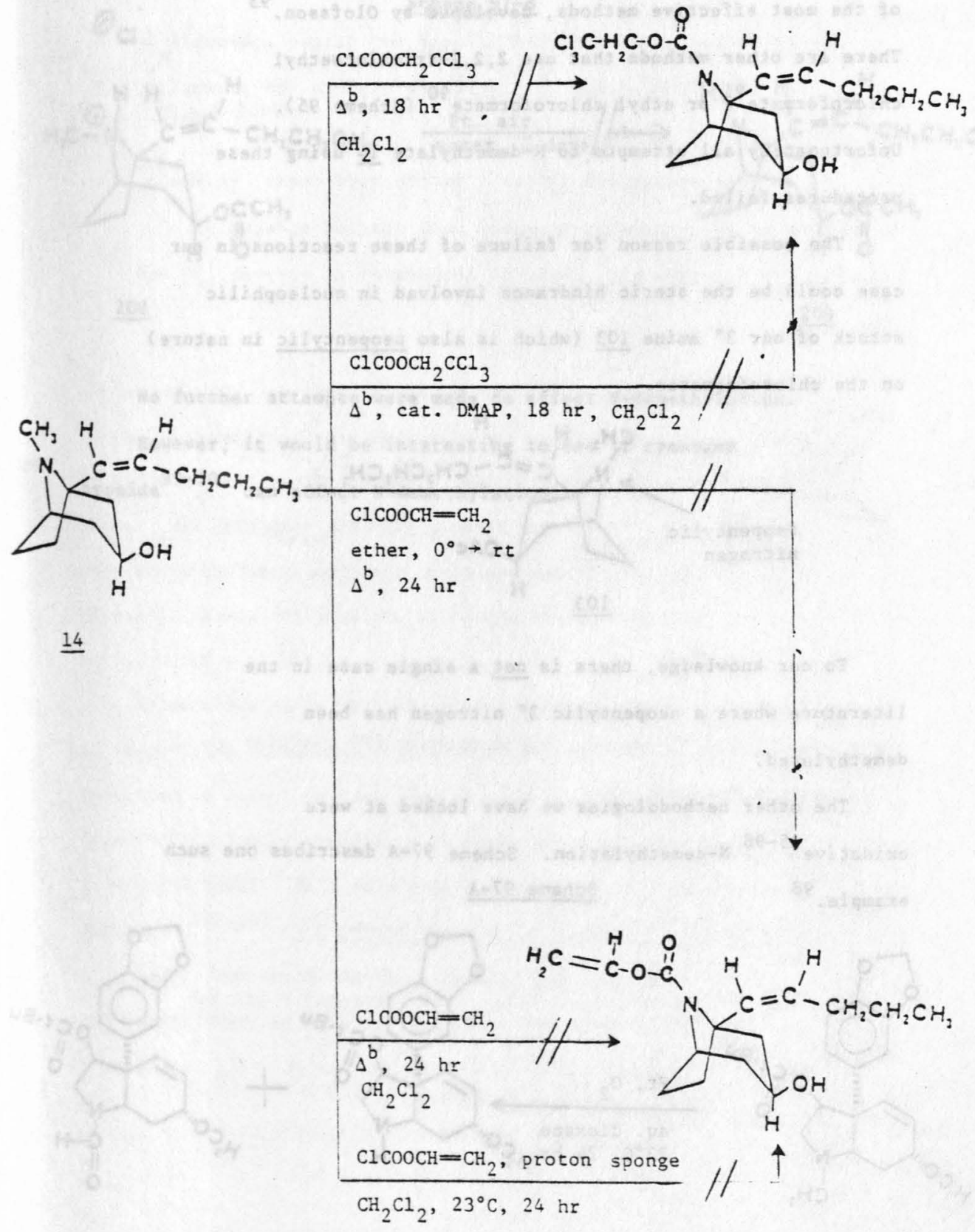


of $3^{\circ}$ amine with acylating agents. ${ }^{90-94}$ Scheme 94 describes one of the most effective methods, developed by 0lofsson. ${ }^{93}$

There are other methods that use 2,2,2-trichloroethyl chloroformate 91 or ethyl chloroformate 90 (Scheme 95 ). Unfortunately all attempts to $\mathrm{N}$-demethylate $\underline{14}$ using these procedures failed.

The possible reason for failure of these reactions in our case could be the steric hindrance involved in nucleophilic attack of our $3^{\circ}$ amine 103 (which is also neopentylic in nature) on the chloroformates.

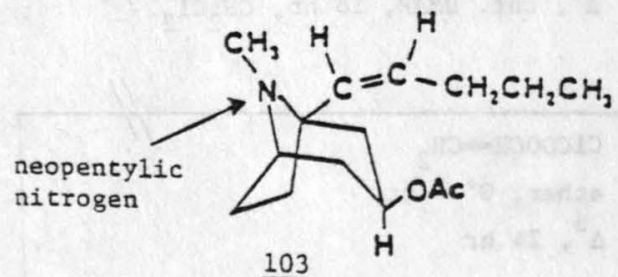

To our knowledge, there is not a single case in the literature where a neopentylic $3^{\circ}$ nitrogen has been demethylated.

The other methodologies we have looked at were oxidative ${ }^{95-98} \mathrm{~N}$-demethylation. Scheme 97-A describes one such example. ${ }^{98}$ Scheme $97-\mathrm{A}$<smiles>CN1CC(OC(=O)O)[C@@]2(c3ccc4c(c3)OCO4)C=C[C@H](O)CC12</smiles>

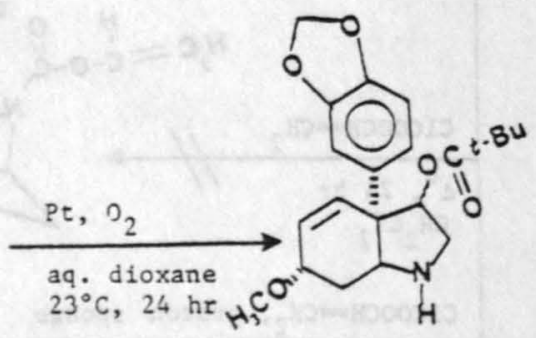<smiles>O=CC1CN(C=O)C2C[C@H](O)C=C[C@@]12c1ccc2c(c1)OCO2</smiles> 
To our chagrin this methodology did not work in our case (Scheme 97-B).

Oci

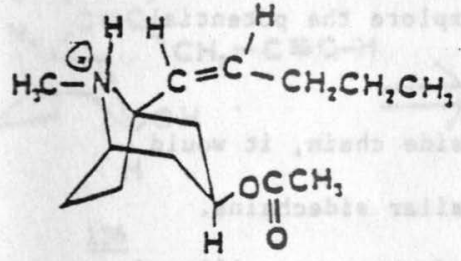

203

\section{Scheme 97-B}
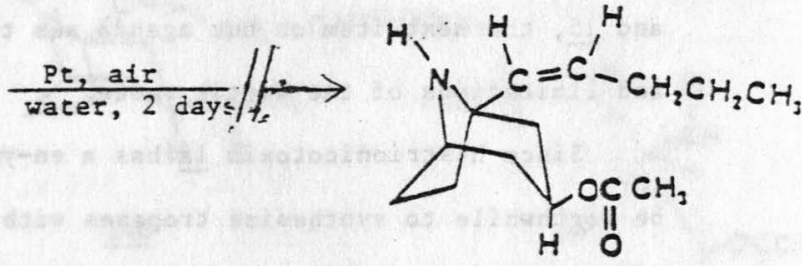

209

No further attempts were made to effect $\mathrm{N}$-demethylation.

However, it would be interesting to see if cyanogen bromide $99-101$ can effect $\mathrm{N}$-demethylation. 
Part C. Scope and Limitations of the Wittig Route

Having succeeded in the synthesis of our target compounds 14 and 15 , the next item on our agenda was to explore the potential and 1 imitations of the Wittig route.

Since histrionicotoxin 1 a has a en-yne side chain, it would be worthwhile to synthesize tropanes with similar sidechains. Aldehyde $\underline{56}$, in principle, could be elaborated to en-ynes $\underline{136}$ and 137.

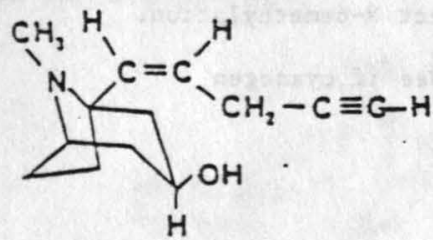

136<smiles>C#C/C=C\CC1(C)CCCC2CC1CCN2C</smiles>

137

136 has a skipped en-yne side chain whereas $\underline{137}$ contains a conjugated en-yne side chain.

\subsubsection{Retrosynthesis Analys is of Skipped En-yne 136:}

Scheme 98 depicts a possible retro synthetic route for 136 . 
Scheme 98

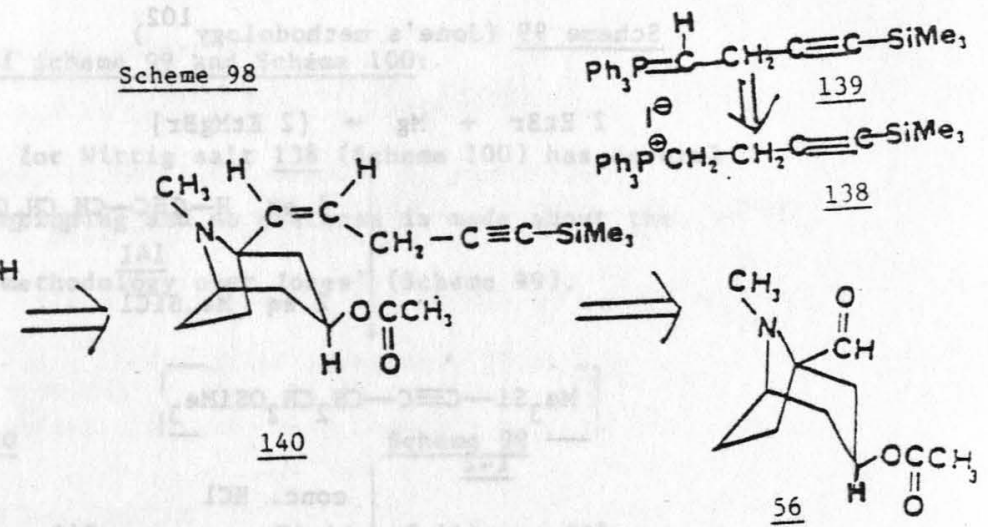

Wittig salt 138 was synthesized by Jones 102 in modest yields. Scheme 99 describes Jones methodology.

The overall yields of Wittig salt $\underline{138}$ were $27 \%$ over three steps. The step that definitely needs improvement is the first step where the trimethylsilyl acetylene derivative 143 was prepared. Jones followed the procedure of Shostakovski 103 and obtained $39 \%$ yield of this compound.

It occurred to us that the reason for low yields could lie in (low-yield) formation of ethylmagnesium bromide which was generated in situ. We used commercially available ethylmagnesium bromide (Aldrich, 2 M solution in tetrahydrofuran) and obtained 143 in $91 \%$ yield. This is a major improvement over Jones' procedure. 102,103

Apart from improving the yields of 143 , we completely renovated Jones' methodology and developed a new protocol for Wittig salt 138: Scheme 100 describes our methodology. 
Scheme 99 (Jone's methodology ${ }^{102}$ )

$$
\begin{aligned}
& 2 \mathrm{EtBr}+\mathrm{Mg} \rightarrow[2 \mathrm{EtMgBr}] \\
& 1 \text { eq } \mathrm{H}-\mathrm{C} \equiv \mathrm{C}-\mathrm{CH}_{2} \mathrm{CH}_{2} \mathrm{OH} \\
& 141 \\
& 2 \text { eq } \mathrm{Me}_{3} \mathrm{SiCl} \\
& \mathrm{Me}_{3} \mathrm{Si}-\mathrm{C} \equiv \mathrm{C}-\mathrm{CH}_{2} \mathrm{CH}_{2} \mathrm{OSiMe}_{3} ! \\
& \mathrm{Me}_{3} \mathrm{Si}-\mathrm{C} \equiv \mathrm{C}-\mathrm{CH}_{2} \mathrm{CH}_{2} \mathrm{OH} \\
& 143(39 \%)
\end{aligned}
$$

$$
\begin{aligned}
& \mid \begin{array}{l}
(\mathrm{PhO})_{3}^{\mathrm{P}} \mathrm{PeI} \\
\mathrm{CH}_{2} \mathrm{Cl}_{2} \text {-DMF }
\end{array} \\
& \mathrm{Me}_{3} \mathrm{Si}-\mathrm{C} \equiv \mathrm{C}-\mathrm{CH}_{2} \mathrm{CH}_{2} \mathrm{I} \quad \text { (purified by chromarography) } \\
& 144(72 \%) \\
& \mathrm{PPh}_{3} \\
& \text { EtOH, } \Delta^{b}, 68 \mathrm{hr}
\end{aligned}
$$

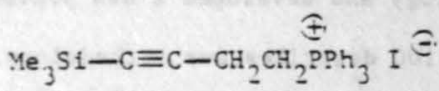

$$
\begin{aligned}
& \underline{138} \quad(95 \%)
\end{aligned}
$$




\subsubsection{Comparison of Scheme 99 and Scheme 100:}

Our protocol for Wittig salt 138 (Scheme 100) has several advantages worth mentioning and no pretense is made about the superiority of our methodology over Jones' (Scheme 99).

\section{Scheme 100}

1. Yields of $\underline{143}$ are $91 \%$

2. Yields of iodide $\underline{144}$ are $89 \%$ Yields of iodide $\underline{144}$ are $72 \%$ (based on 143)

3. Iodide 144 purified by distillation

4. Isolation of Wittig salt is very easy; since the reaction was done in benzene, the wittig salt separates out from the reaction as the reaction proceeds.

\section{Scheme 99}

Yields of 143 are $39 \%$
Iodide 144 purified by tedious chromatography

The reaction done in ethanol in which the wittig salt is somewhat non-trivial. soluble. Isolation is

5. Overall yields of Wittig salt Overall yields of Wittig salt 138 are $77 \%$ (based on 141 ). $\quad 138$ are $27 \%$ (based on 141 ).

\subsubsection{Attempted Condensation of Aldehyde 56 with ylide 139:}

It was gratifying to develop a synthetic methodology for Wittig salt 138 . The next task was to utilize it in the wittig 
Scheme 100 (our methodology)

$$
\begin{aligned}
& \mathrm{HO}-\mathrm{CH}_{2} \mathrm{CH}_{2}-\mathrm{C} \equiv \mathrm{C}-\mathrm{H} \frac{2 \text { eq } \mathrm{EtMgBr}}{2 \text { eq } \mathrm{Me}_{3} \mathrm{SiCl}}\left[\mathrm{Me}_{3} \mathrm{SiOCH}_{2} \mathrm{CH}_{2}-\mathrm{C} \equiv \mathrm{C}-\mathrm{SiMe}_{3}\right] \\
& 141 \\
& \begin{array}{ccc}
\mathrm{Me}_{3} \mathrm{Si}-\mathrm{C} \equiv \mathrm{C}-\mathrm{CH}_{2} \mathrm{CH}_{2} \mathrm{PPh}_{3} & \frac{\mathrm{PPh}_{3}}{\text { benzene }} & \mathrm{Me}_{3} \mathrm{Si}-\mathrm{C} \equiv \mathrm{C}-\mathrm{CH}_{2} \mathrm{CH}_{2} \mathrm{I} \\
\underline{138}(95 \%) & \Delta^{\mathrm{b}}, 68 \mathrm{hr} & \frac{144}{(90 \%)}
\end{array} \\
& \text { conc. } \mathrm{HCl} \\
& \text { EtOH- }{ }_{2} \mathrm{O}, 23^{\circ} \mathrm{C}, 1 \mathrm{hr} \\
& \mathrm{HOCH}_{2} \mathrm{CH}_{2}-\mathrm{C} \equiv \mathrm{C}-\mathrm{SiMe}_{3} \\
& \underline{143}(91 \%) \\
& 1.1 \text { eq TsC1 } \\
& \text { pyridine, } 0^{\circ} \mathrm{C}, 2 \mathrm{hr} \\
& \mathrm{Me}_{3} \mathrm{Si}-\mathrm{C} \equiv \mathrm{C}-\mathrm{CH}_{2} \mathrm{CH}_{2} \mathrm{OTS} \\
& \underline{146}(98 \%) \\
& 5.5 \text { eq } \mathrm{NaI} \\
& \text { Acetone } \\
& \Delta^{\mathrm{b}}, 48 \mathrm{hr}
\end{aligned}
$$


condensation as planned in Scheme 98.

The ylide 139 could be generated by a variety of bases (Scheme 102). However, to our total dismay, it proved very intransigent as far as addition to the aldehyde was concerned (Scheme 103). Every attempt at effecting the Wittig condensation resulted only in recovery of unreacted aldehyde. Ylide 139 is known to add to unhindered aldehydes very smoothly even at $0^{\circ} \mathrm{C}$ (Scheme 101).

\section{Schere 101}

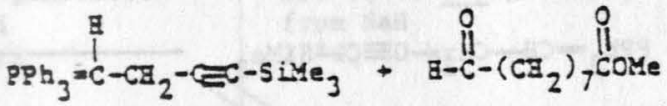

\section{9}
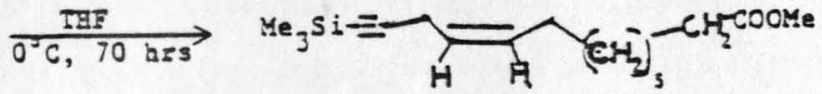

$148(80 \%)$

We can attribute the lack of reactivity of ylide $\underline{139}$ in our case to the neopentylic nature of our aldehyde. This is in contrast to the reactivity of ylide 99 , generated from n-butyltriphenylphosphonium bromide which added very smoothly to aldehyde 56 (see Scheme 79). It is surprising that the bulky trimethylsilyl group (which was absent in ylide 99 , but present in ylide 139 ), although remote from the reaction site, apparently hampers the reactivity of ylide 139 , by imposing severe steric restraints. 
Scheme 102

$\mathrm{I}^{\ominus} \Theta$

$$
\begin{gathered}
\mathrm{PPh}_{3}-\mathrm{CH}_{2} \mathrm{CH}_{2}-\mathrm{C} \equiv \mathrm{C}-\mathrm{SiMe}_{3} \\
\underline{138}
\end{gathered}
$$

NaH/THF

1 hr at $0^{\circ} \mathrm{C}$

2 hr at $23^{\circ} \mathrm{C}$

KOtbu/THF

$1 \mathrm{hr}$ at $0^{\circ} \mathrm{C}$

$\mathrm{PPh}_{3}=\mathrm{CH}-\mathrm{CH}_{2}-\mathrm{C} \equiv \mathrm{C}-\mathrm{SiMe}_{3}$

$2 \mathrm{hr}$ at $23^{\circ} \mathrm{C}$

139

n BuLi $-78^{\circ} \mathrm{C} \rightarrow-40^{\circ} \mathrm{C}$ $-40^{\circ} \mathrm{C}, 5$ hrs 


\section{Scheme 103}

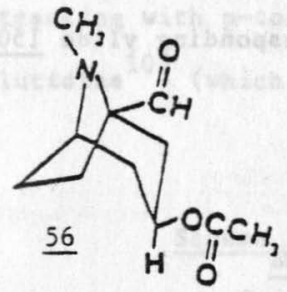

2 eq of 132 generated from a $\overline{\mathrm{BuL} i}$ $-10^{\circ} \mathrm{C}, 40 \mathrm{hrs}$ $0^{\circ} \mathrm{C}, 2$ hrs
1.1 eq of 139 generated from $\mathrm{NaH}$ $23^{\circ} \mathrm{C}, 60 \mathrm{hr}$
1.1 eq of 139 generated from KOtbu $23^{\circ} \mathrm{C}, 60 \mathrm{hr}$

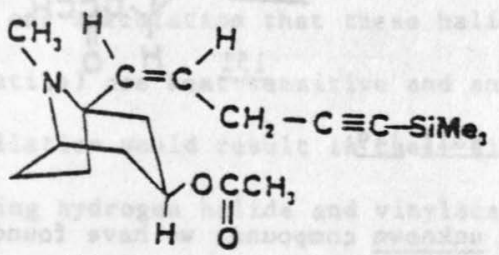




\subsubsection{Alternate Approaches to Skipped En-yne Sidechain:}

At this point, we postulated that replacing the bulky trimethylsilyl group by a much smaller group like hydrogen would increase the reactivity of the corresponding ylide 150 and give access to en-yne 151 (Scheme 104).
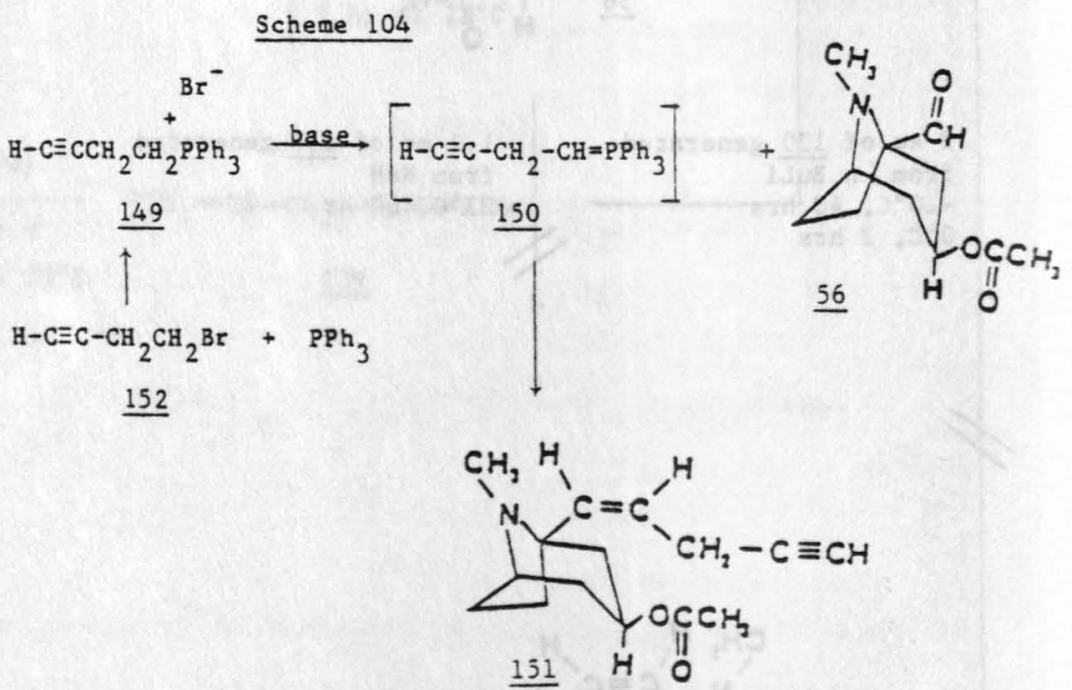

\subsubsection{Preparation of Wittig Salt 149 :}

Wittig salt $\underline{149}$ is an unknown compound; we have found no report of it in the literature. It can, in principle, be prepared from bromide $\underline{152}$ and triphenyl phosphine. This synthetic plan demanded a steady and facile supply of bromide $\underline{152}$. 
4.3.6 Attempted Preparation of $\mathrm{H}-\mathrm{C} \equiv \mathrm{C}-\mathrm{CH}_{2} \mathrm{CH}_{2} \mathrm{PPh}_{3} 49$ :

3-Butyn-1-01 was converted ${ }^{104}$ to its tosylate 153

(Scheme 105) by treating with p-toluenesulfonyl chloride in presence of 2,6-lutidine 105 (which acts as solvent as well as proton (rap).

\section{Scheme 105}

$$
\begin{aligned}
& \mathrm{H}-\mathrm{C} \equiv \mathrm{C}-\mathrm{CH}_{2} \mathrm{CH}_{2} \mathrm{OH}+\mathrm{PTsCl} \frac{2,6 \text {-Lutidene }}{\text { r.t., } 24 \text { hrs }} \mathrm{H}-\mathrm{C} \equiv \mathrm{C}-\mathrm{CH}_{2} \mathrm{CH}_{2} \mathrm{OTS} \\
& 141 \\
& 153(81 \%)
\end{aligned}
$$

Tosylate 153 was purified by silica gel chromatography.

A variety of attempted nucleophilic displacements of this tosylate by chloride, bromide or iodide ions failed to give the corresponding halides (Scheme 106). It is surprising that none of these reactions worked in our hands. 106

It is our speculation that these halides (which seem to be highly volatile) are heat-sensitive and any attempted (Scheme 107) distillation would result in their disintegration into corresponding hydrogen halide and vinylacetylene (bp $15^{\circ} \mathrm{C}$ ).

$$
\begin{aligned}
& \text { Scheme } 107 \\
& \mathrm{H}-\mathrm{C} \equiv \mathrm{C}-\mathrm{CH}_{2} \mathrm{CH}_{2} \mathrm{Cl} \stackrel{\Delta}{\longrightarrow} \mathrm{H}-\mathrm{C} \equiv \mathrm{C}-\mathrm{CH}=\mathrm{CH}{ }_{2}+\mathrm{HCl} \\
& \mathrm{H}-\mathrm{C} \equiv \mathrm{C}-\mathrm{CH}_{2} \mathrm{CH}_{2} \mathrm{Br} \stackrel{\Delta}{\longrightarrow} \mathrm{H}-\mathrm{C} \equiv \mathrm{C}-\mathrm{CH}=\mathrm{CH}_{2}+\mathrm{HBr} \\
& \mathrm{H}-\mathrm{C} \equiv \mathrm{C}-\mathrm{CH}_{2} \mathrm{CH}_{2} \mathrm{I} \stackrel{\mathrm{I}}{\longrightarrow} \mathrm{H}-\mathrm{C} \equiv \mathrm{C}-\mathrm{CH}=\mathrm{CH}_{2}+\mathrm{HI}
\end{aligned}
$$


Scheme 106

$\mathrm{NaI}$, Acetone

$23^{\circ} \mathrm{C}, 18 \mathrm{hr}$, aq. work-up

NaI, Acetone

$23^{\circ} \mathrm{C}, 18 \mathrm{hr}$, non-aq work-up

$\mathrm{H}-\mathrm{C} \equiv \mathrm{C}-\mathrm{CH}_{2} \mathrm{CH}_{2} \mathrm{OTs}$

LiBr, Acetone /f $\mathrm{H}-\mathrm{C} \equiv \mathrm{C}-\mathrm{CH}_{2} \mathrm{CH}_{2} \mathrm{Br}$

$23^{\circ} \mathrm{C}, 12 \mathrm{hr} \quad 152$

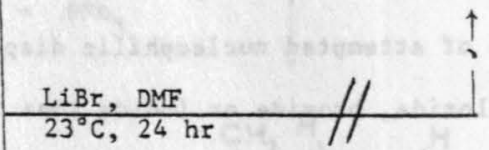

$\frac{\mathrm{LiCl}, \text { DMF-Ether }}{23^{\circ} \mathrm{C}, 24 \mathrm{hr}} \mathrm{H}-\mathrm{C} \equiv \mathrm{C}-\mathrm{CH}_{2} \mathrm{CH}_{2} \mathrm{Cl}$

L1C1, DMF, $\triangle$

$1 \mathrm{hr}$

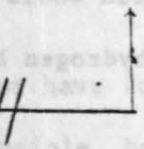

1. LiCl, DMF-ether

$\frac{23^{\circ} \mathrm{C}, 24 \mathrm{hr}}{\mathrm{PPh}_{3}, \Delta^{\mathrm{b}}} / \mathrm{H}-\mathrm{C} \equiv \mathrm{C}-\mathrm{CH}_{2} \mathrm{CH}_{2} \stackrel{\mathrm{PPh}}{\mathrm{Cl}} \Theta$ 
4.3.7 Attempted Preparation of Phosphonium Tosylate 158:

There are few instances $107-110$ in literature where phosphonium ylides are generated from alkyl phosphonium tosylates. Scheme 108 represents one such example.
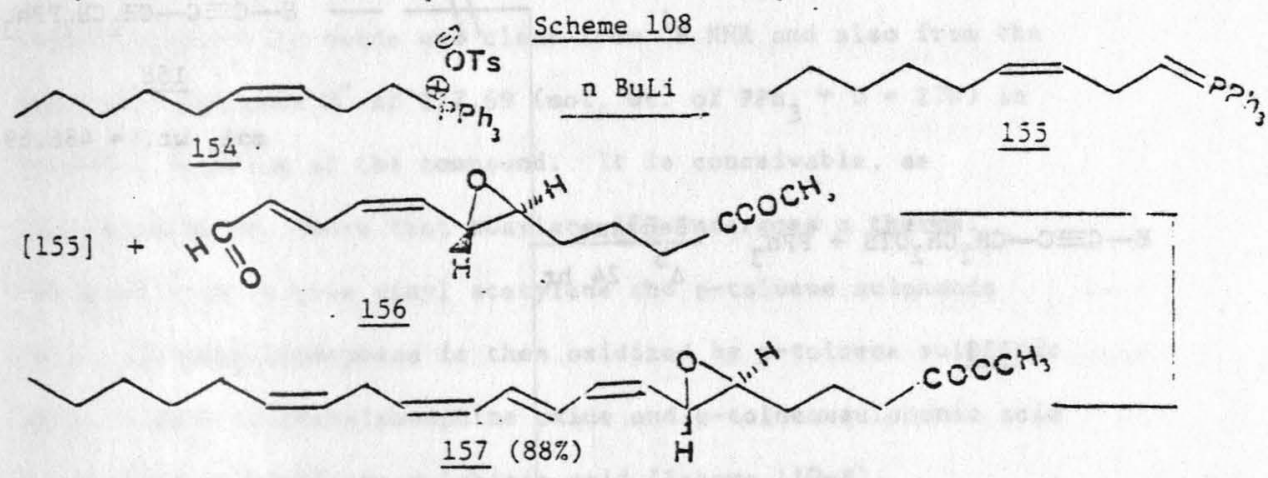

Since we had seemingly insurmountable problems in the preparation of bromide $\underline{152}$ (and in turn Wittig salt $\underline{149}$ ), we planned to take recourse to 4-butynyltriphenylphosphonium tosylate (158), an unknown compound in literature. The phosphonium salt $\underline{158}$ could be visualized as a precursor to ylide 150 (Scheme 109).

$$
\begin{aligned}
& \text { Scheme } 109 \\
& \text { อิ) }
\end{aligned}
$$

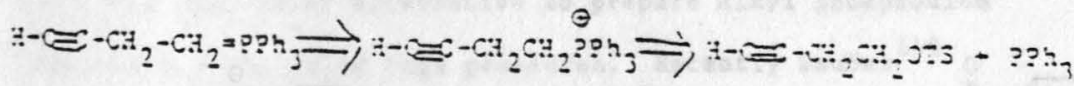

$$
\begin{aligned}
& 150 \\
& 158
\end{aligned}
$$


Scheme 110-A

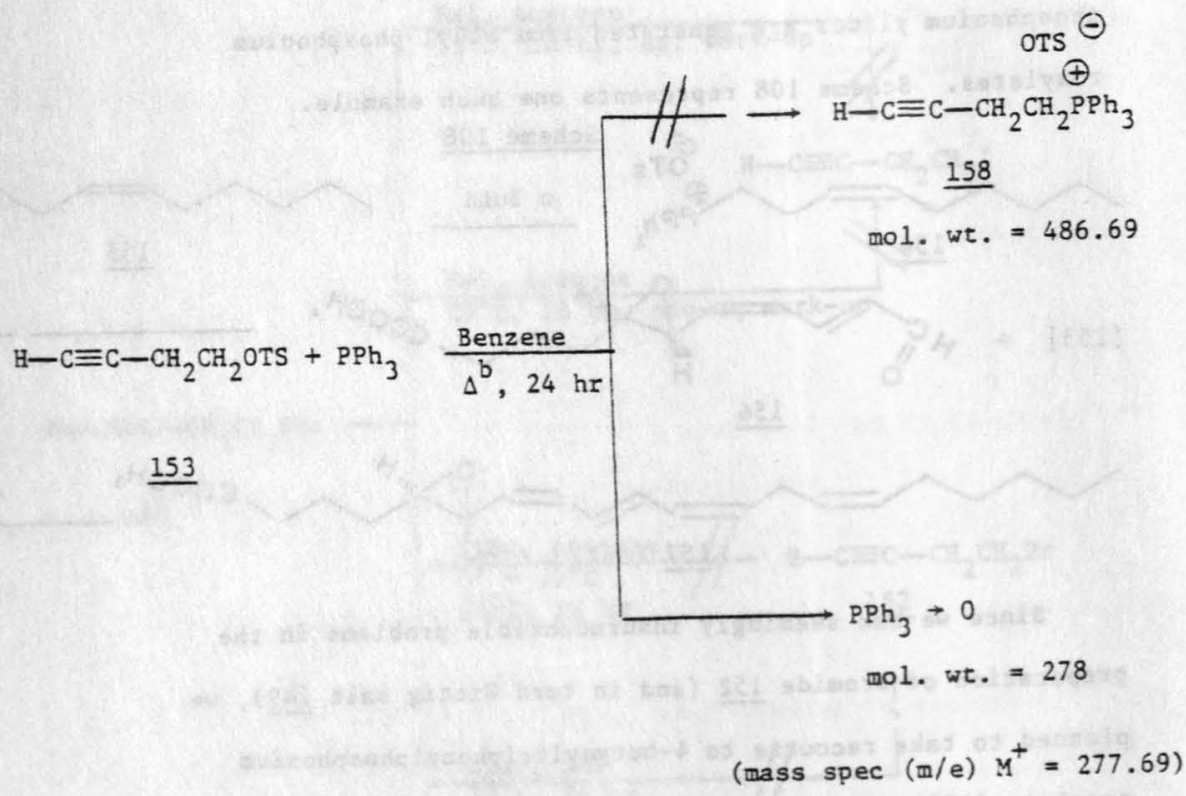

Scheme 110-B

$\mathrm{H}-\mathrm{C} \equiv \mathrm{C}-\mathrm{CH}_{2} \mathrm{CH}_{2} \mathrm{OTS} \stackrel{\Delta}{\longrightarrow} \mathrm{H}-\mathrm{C} \equiv \mathrm{C}-\mathrm{CH}=\mathrm{CH}_{2}+\mathrm{H}_{3} \mathrm{C}-{ }_{\mathrm{O}}^{\mathrm{II}}-\mathrm{OH}$

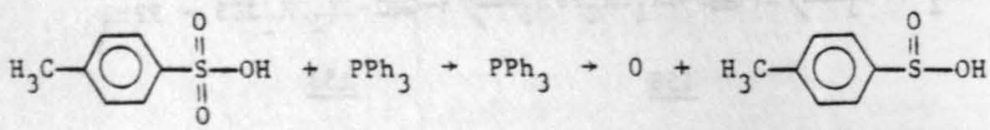


Refluxing tosylate 153 with triphenylphosphine in benzene, to our total surprise and disappointment gave (as the only identified product) triphenylphosphoxide but none of the desired, Wittig salt 158 (Scheme 110-A). The structure of the product triphenylphosphine oxide was clear from ${ }^{1}$ H NMR and also from the molecular ion peak $\mathrm{M}^{+}$at 277.69 (mol. wt. of $\mathrm{PPh}_{3} \rightarrow 0=278$ ) in the mass spectrum of the compound. It is conceivable, as suggested by Dr. Moore that tosylate $\underline{153}$ undergoes a thermal decomposition to give vinyl acetylene and p-toluene sulphonic acid. Triphenylphosphene is then oxidized by p-toluene sulphonic acid to give triphenylphosphine oxide and p-toluenesulphonic acid is reduced to p-toluene sulphinic acid (Scheme 110-B).

There is one instance in literature 111 where triphenylphosphine oxide was isolated when octyl tosylate was refluxed with triphenyl phosphine (Scheme 111).

$$
\begin{gathered}
\frac{\text { Scheme } 111}{\mathrm{PPh}_{3}+\mathrm{CH}_{3}\left(\mathrm{CH}_{2}\right)_{6} \mathrm{CH}_{2} \mathrm{OTs} \rightarrow \mathrm{PPh}_{3}=0} \\
\underline{159}
\end{gathered}
$$

The only other alternative to prepare alkyl phosphonium tosylates is by using high pressures. Recently Dauben 112 developed conditions to prepare alkyl phosphonium tosylates (and mesylates) by using high pressures at ambient temperatures (Scheme 112). 
Scheme 112

\section{ดิMs}

$\overbrace{160} \underset{1}{16 P_{3}} \frac{1}{\mathrm{CH}_{3} \mathrm{CN}}$<smiles>CCCC[Pb]</smiles>

$161 \theta$

$\mathrm{C}_{9} \mathrm{H}_{3} \mathrm{CH}_{2} \mathrm{OTs} \stackrel{\mathrm{PPh}}{\rightarrow} \frac{15 \mathrm{~K} \text { bars }}{\mathrm{CH}_{3} \mathrm{CN}}$

$\mathrm{C}, \mathrm{H}_{3} \mathrm{CH}_{2} \stackrel{\ominus}{\mathrm{P}} \mathrm{Ph}_{3}$

$\underline{162}$

163

We could not attempt these conditions since we didn't have Dauben's high-pressure apparatus. But, if possible, it certainly would be interesting to see if the desired Wittig salt 158 could be prepared using Dauben's conditions.

\subsubsection{One Step Preparation of 4-Bromo-1-butyne:}

Since tosylate 153 did not prove useful either in the preparation of 4-bromo-1-butyne 152 or 4 -butynyltriphenylphosphonium tosylate $\underline{158}$, we had to take recourse to procedures that would directly convert 4-butyn-1-01 in one step to 4-bromo-1-butyne, thus bypassing use of tosylate 153 completely (Scheme 113).

$$
\begin{aligned}
& \text { Scheme } 113 \\
& \mathrm{H}-\mathrm{C} \equiv \mathrm{C}-\mathrm{CH}_{2} \mathrm{CH} \\
& 2
\end{aligned}
$$


A variety of reagents were utilized by us in attempts to bring about this transformation. Utilizing carbon tetrabromide-triphenylphosphine mixture ${ }^{113-114}$ gave the desired bromide $\underline{152}$ in $10 \%$ yield along with unidentified olefinic compound(s) (Scheme 114).

\section{Scheme 114}

$\mathrm{H}-\mathrm{C} \equiv \mathrm{C}-\mathrm{CH}_{2} \mathrm{CH} \mathrm{OH}_{2} \frac{\mathrm{CBr}_{4}, \mathrm{PPh}_{3}}{\mathrm{CH}_{2} \mathrm{Cl}_{2}, 23^{\circ} \mathrm{C}} \mathrm{H}-\mathrm{C} \equiv \mathrm{C}-\mathrm{CH}_{2} \mathrm{CH}_{2} \mathrm{Br}+$ olefins $12 \mathrm{hrs}$

141 152

Employing N-bromosuccinimide-triphenylphosphine mixture 115 gave none of the desired compound 152 but only olefinic impurities which were not identified (Scheme 115).

\section{Scheme 115}

$$
\mathrm{H}-\mathrm{C} \equiv \mathrm{C}-\mathrm{CH}_{2} \mathrm{CH}{ }_{2} \mathrm{OH} \frac{\mathrm{NBS}}{\mathrm{THF}, \mathrm{r} \cdot \mathrm{t} \text {. }} \mathrm{H}-\mathrm{C} \equiv \mathrm{C}-\mathrm{CH}_{2} \mathrm{CH}_{2} \mathrm{Br}
$$

141

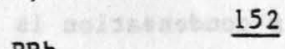

$\mathrm{PPh}_{3}$

However, a $15 \%$ yield of the desired bromide 152 was obtained, Wien phosphorus tribromide ${ }^{104}$ was used (Scheme 116).

\section{Scheme 116}

$$
\mathrm{H}-\mathrm{C} \equiv \mathrm{C}-\mathrm{CH}_{2} \mathrm{CH}_{2} \mathrm{OH}+\mathrm{PBr}_{3} \frac{\text { Pyridine }}{0^{\circ} \mathrm{C}} \mathrm{H}-\mathrm{C} \equiv \mathrm{C}-\mathrm{CH}_{2} \mathrm{CH}_{2} \mathrm{Br}
$$


Attempted improvement ${ }^{116}$ of yields of this reaction by adding lithium bromide did not prove useful (Scheme 117).

\section{Scheme 117}

$$
\begin{gathered}
\mathrm{H}-\mathrm{C} \equiv \mathrm{C}-\mathrm{CH}_{2} \mathrm{CH}{ }_{2} \mathrm{OH}+\mathrm{PBr}_{3} \frac{\mathrm{LiBr},}{2,6 \text { - Iutidene }} \mathrm{H-C} \equiv \mathrm{C}-\mathrm{CH}_{2} \mathrm{CH}_{2} \mathrm{Br} \\
\underline{141} \quad \underline{152}(10 \%)
\end{gathered}
$$

\subsubsection{Wittig Condensation Leading to En-yne 151:}

The bromide 152 obtained from the $\mathrm{PBr}_{3}$ reaction (Scheme 116) was used to generate Wittig salt $\underline{149}$ (Scheme 118). The phosphonium salt, $\underline{149}$ was treated with n-butyllithium to generate glide $\underline{150}$, which was condensed with aldehyde $\underline{56}$. The spectral data were in agreement with the assigned structure for en-yne 151. The mass spectrum showed a moleculat ion peak $\mathrm{M}^{+}$at 247 (calculated molecular weight of $\underline{151}=247$ ).

Although the Wittig condensation is successful in obtaining en-yne 151 , there is a need for improved preparation of the bromide $\underline{152}$ and the wittig salt 149 . No further studies were carried out in that direction. 
Scheme 118

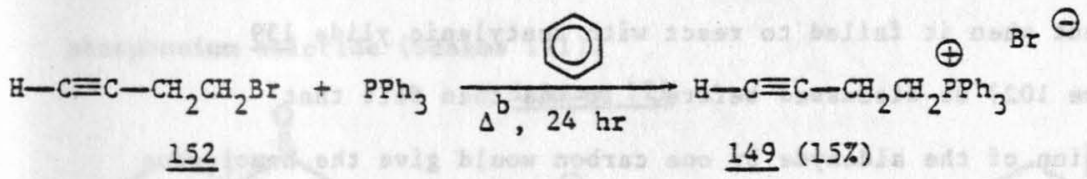

$$
\oplus \theta^{B r}{ }^{\ominus}
$$

$1.3 \cdot \mathrm{q} \cdot \mathrm{H}-\mathrm{C} \equiv \mathrm{C}-\mathrm{CH}_{2} \mathrm{CH}_{2} \mathrm{PPh}_{3} \frac{1.2 \mathrm{eq} \mathrm{a} \mathrm{BuLI}}{0^{\circ} \mathrm{C}, 2 \mathrm{hr}} \mathrm{H}-\mathrm{C} \equiv \mathrm{C}-\mathrm{CH} \mathrm{PH}_{2}-\mathrm{CH}=\mathrm{PPh}_{3}$ $23^{\circ} \mathrm{C}, 2 \mathrm{hr}$

\section{9}

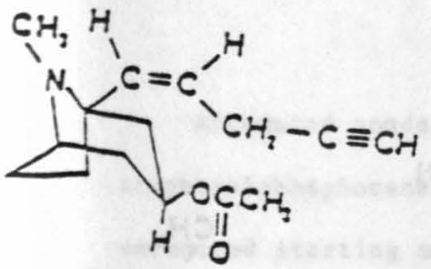




\subsubsection{Studies on Aldehyde Homologation:}

Our neopentylic aldehyde $\underline{56}$ is quite sluggish in its

reactivity compared to unhindered aldehydes. This fact became apparent when it failed to react with acetylenic ylide 139

(Scheme 102) as discussed before. It was then felt that extension of the aldehyde by one carbon would give the homologous aldehyde 164 (Scheme 119), which being unhindered, should be more reactive.

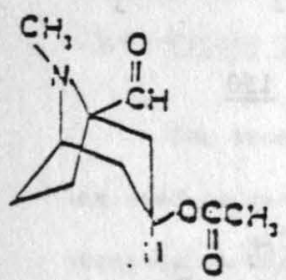

\section{Scheme 119}

Extension

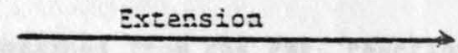

56

Initial attempts at aldehyde homologation utilizing Magnus's 117

reductive nucleophilic acylation procedure did not yield any meaningful product(s) (Scheme 120).

\section{Scheme 120}

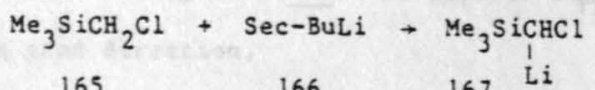

165

166

167

164
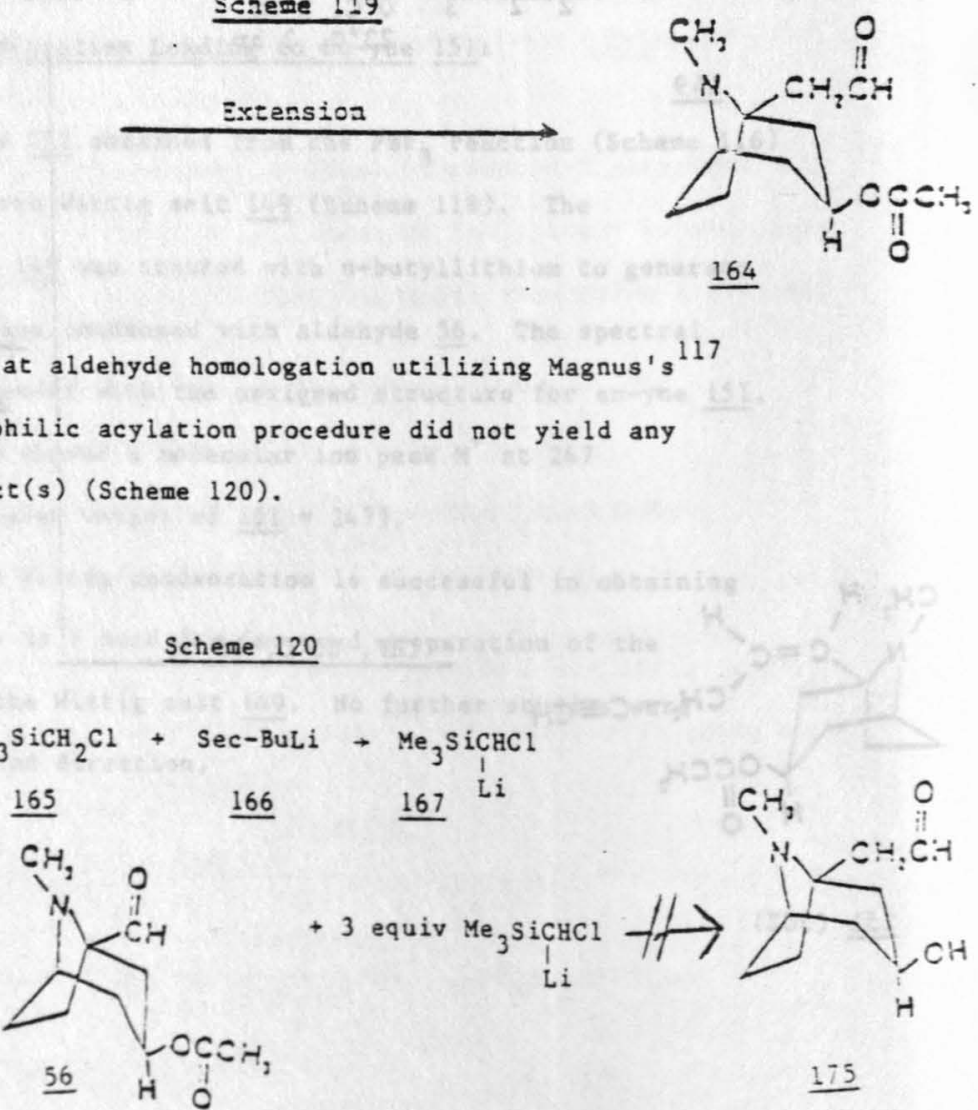

+3 equir $\mathrm{Me}_{3} \mathrm{SiCHCl}_{1}-\mathrm{l}$

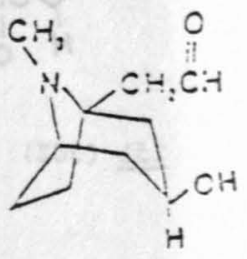


Scheme 122
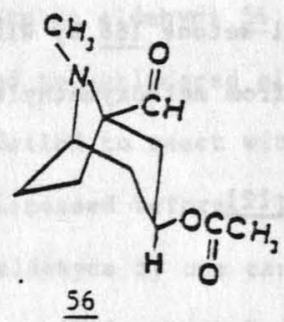

$\mathrm{Cl}{ }^{\Theta}$
1.1 eq $\mathrm{Ph}_{3} \mathrm{P} \mathrm{CH}_{2} \mathrm{OMe}$
1.1 eq $\mathrm{NaH} / \mathrm{DMSO}$
1.1 eq $\mathrm{PPh}_{3}=\mathrm{C}^{-\mathrm{H}}$ OMe

$\mathrm{Cl} \Theta$

171

1.1 eq $\mathrm{Ph}_{3} \mathrm{P} \quad \mathrm{CH}_{2} \mathrm{OMe}$

$\oplus$

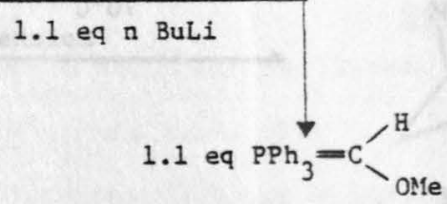

171
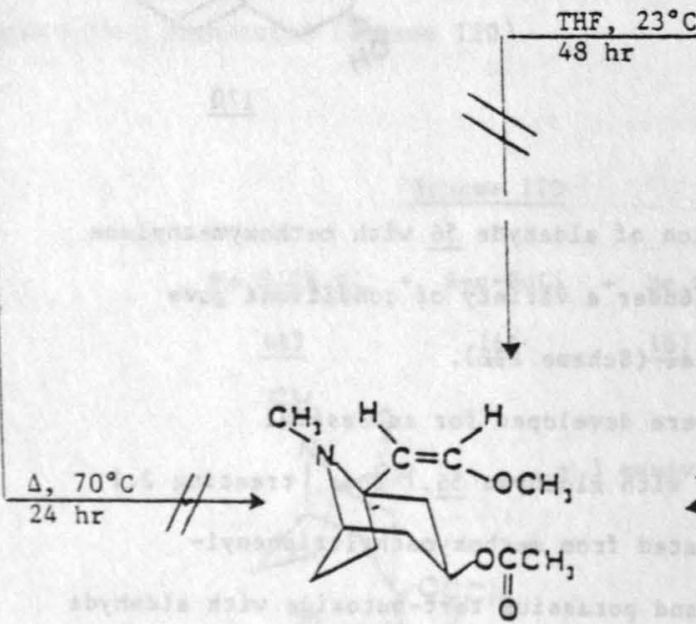

A) $\frac{\mathrm{THF}, \mathrm{s}^{\mathrm{b}}}{48 \mathrm{hr}}$ 
56 at ambient temperature for 3 days resulted in isolation of a mixture of 2 and $E$ enol ethers $\underline{173}$ and $\underline{174}$ respectively

(Scheme 123).

$$
=\mathrm{Cl}_{1} \text { Scheme } 123
$$

$\oplus$

2.1 equiv $\mathrm{Ph}_{3} \mathrm{P} \mathrm{CH}_{2} \mathrm{OMe}+2.1$ equiv KOtBu
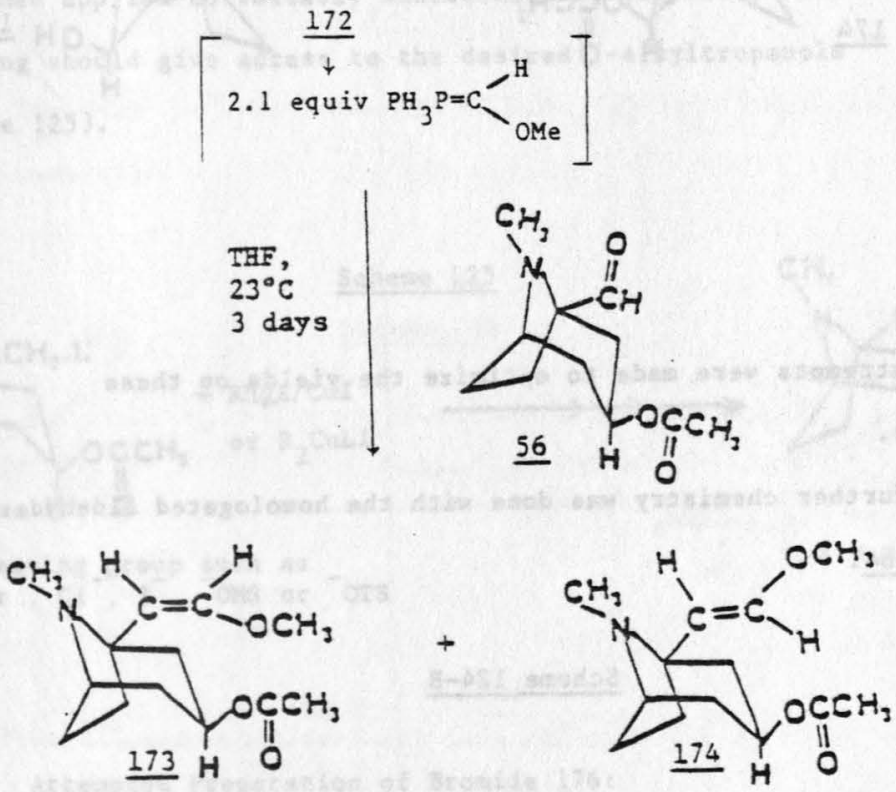

The above mixture of isomers could be hydrolysed to the homologated aldehydes $\underline{164}$ and $\underline{175}$ in poor yields by using either $70 \%$ aqueous perchloric acid (Scheme 124-A) or by treating with a large excess of boron tribromide (Scheme 124-B). 


\section{Scheme 124-A}
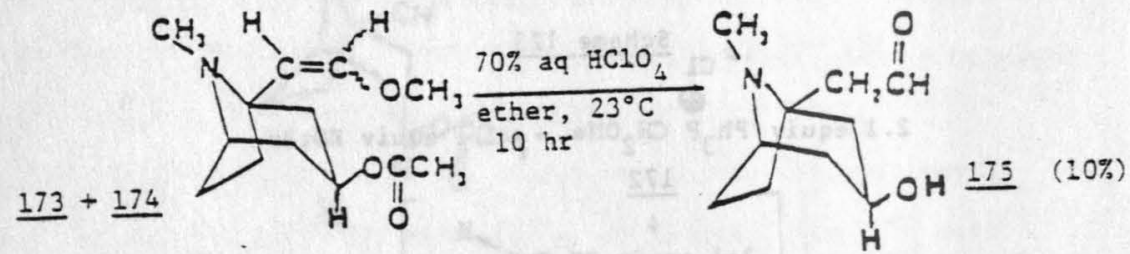

No attempts were made to optimize the yields on these reactions.

No further chemistry was done with the homologated aldehydes $\underline{175}$ and 164.

\section{Scheme $124-B$}
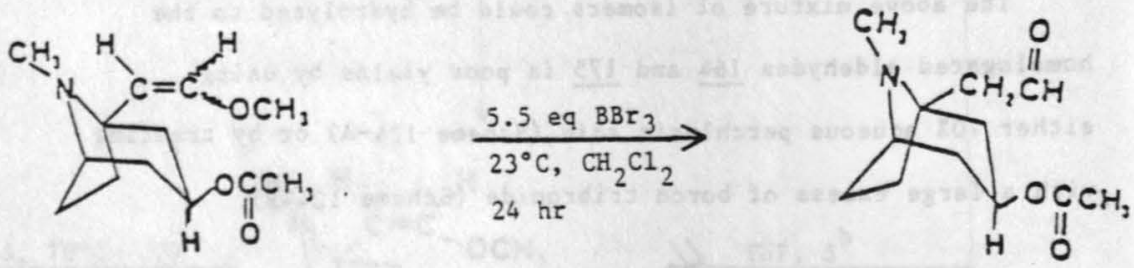


\section{Part D. Attempted Organometallic Route to 1-Alkyl Tropanols}

An alternative route for wittig condensation in carbon-carbon bond formation is coupling of alkyl halides or mesylates with carbon nucleophiles such as cuprate or Grignard reagents. ${ }^{125-137}$

When applied to suitably functionalized tropanes, such coupling should give access to the desired 1-alkyltropanols (Scheme 125).

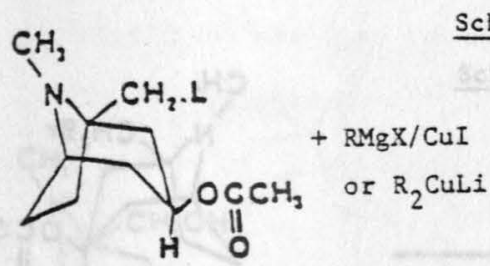

Scheme 125

$L=$ leaving_group such as $\mathrm{Br}^{-}, \mathrm{Cl}^{-}, \mathrm{I}^{-}$, OMS or

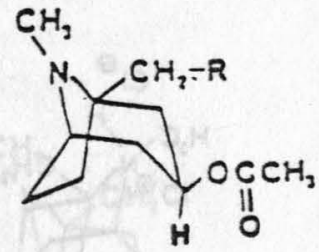

$R=n-a \mid k y l$

\subsubsection{Attempted Preparation of Bromide 176:}

Triphenylphosphine dibromide ${ }^{138-139}$ has been used to

cleave ethers to the corresponding bromides (Scheme 126).

Scheme 126

$$
\mathrm{R}-\mathrm{O}-\mathrm{R}^{\prime}+\mathrm{PPh}_{3} \cdot \mathrm{Br}_{2} \rightarrow \mathrm{R}-\mathrm{Br}+\mathrm{R}^{\prime} \mathrm{Br}+\mathrm{PPh}_{3} \mathrm{O}
$$




\section{Scheme 127}

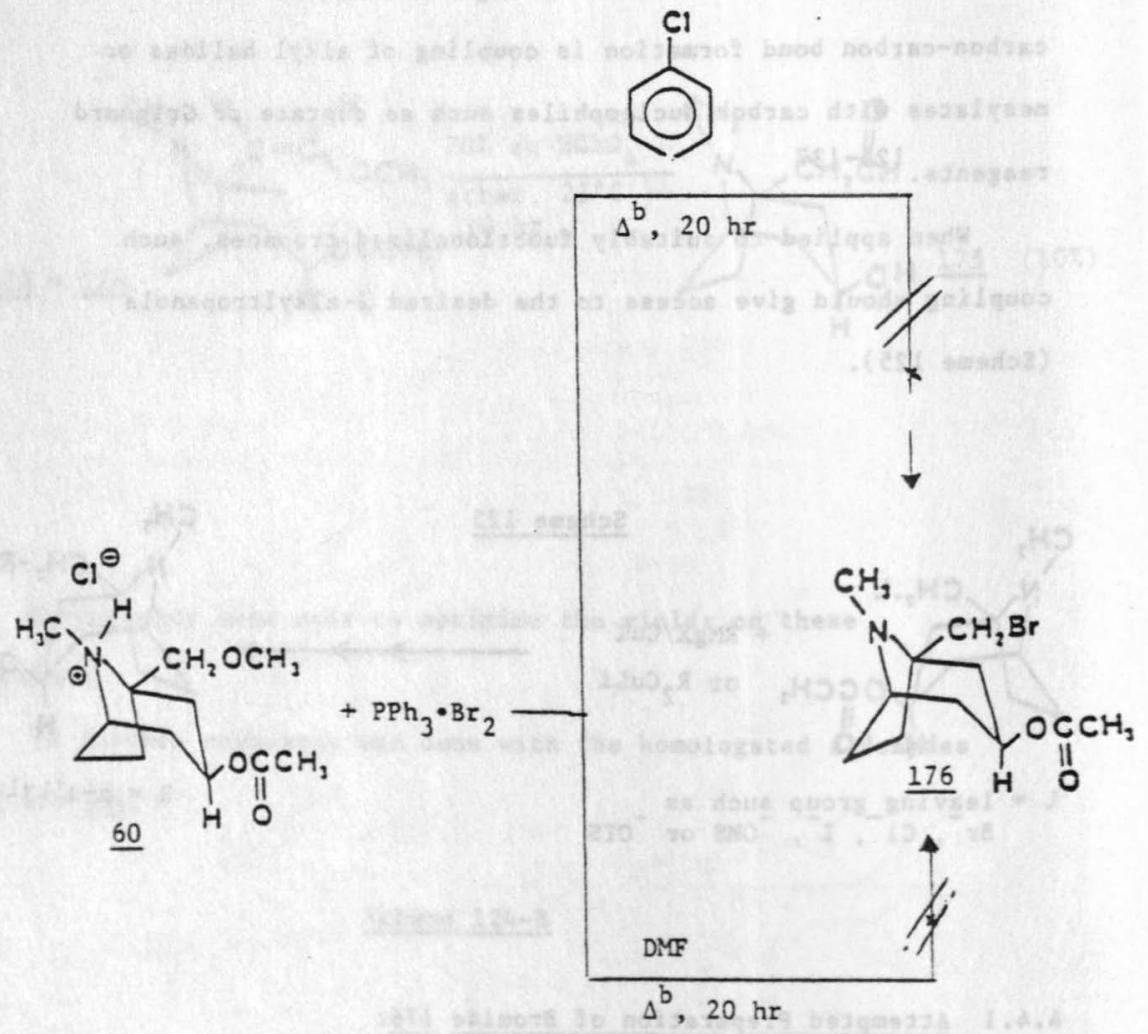


Treatment of methyl ether 60 with this reagent, either in refluxing DMF or chlorobenzene, resulted in only recovery of starting materials and none of the desired bromide 176 was obtained (Scheme 127).

\subsubsection{Attempted Preparation of Chloride 177:}

The next goal was to convert alcohol $\underline{55}$ into the chloride 177 (Scheme 128).

\section{Scheme 128}
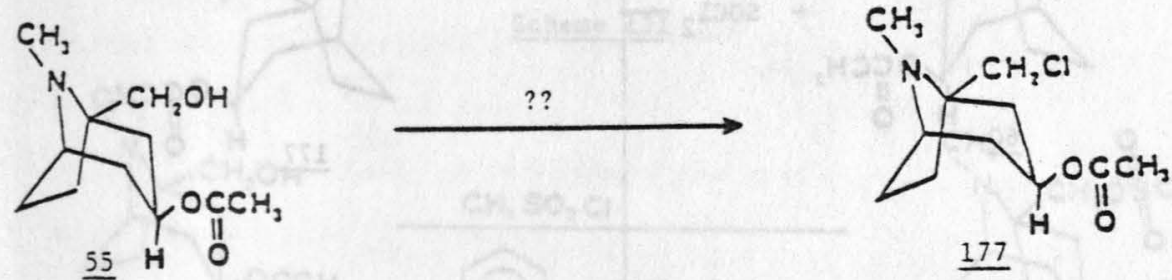

$$
\text { Fodor }{ }^{140} \text { converted diol } \underline{178} \text { into chloride } \underline{179} \text { by using }
$$

thionyl chloride (Scheme 129).

\section{Scheme $129^{140}$}
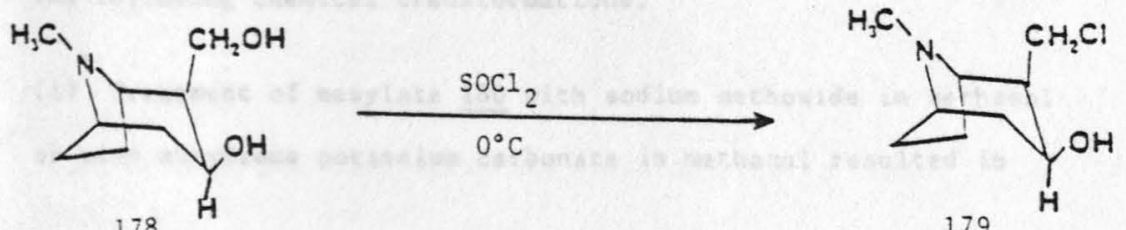


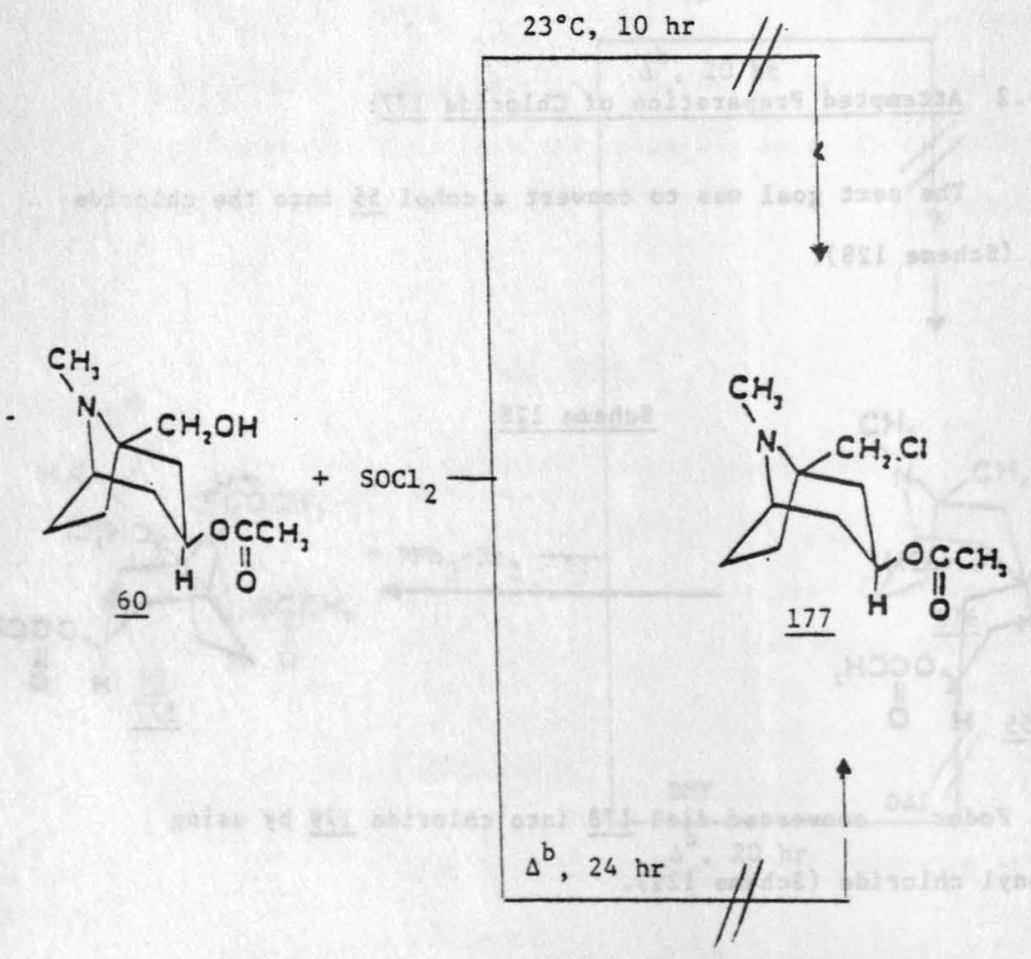


Applying the same procedure to our case did not prove useful (Scheme 130), due to the neopentylic nature of the hydroxy group.

\subsubsection{Preparation of Mesylate 180:}

Since all attempts at converting the neopentyl alcohol $\underline{55}$ into the corresponding halides failed, we turned our attention to the preparation of mesylates. When $\underline{55}$ was treated with methane sulfonyl chloride at room temperature in the presence of $2,6-1$ utidine, mesylate 180 was obtained as a yellow crystalline solid (Scheme 131).

\section{Scheme 131}

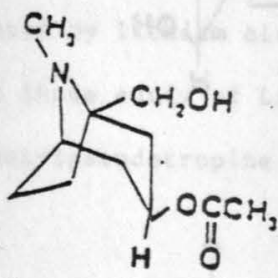

$\underline{55}$

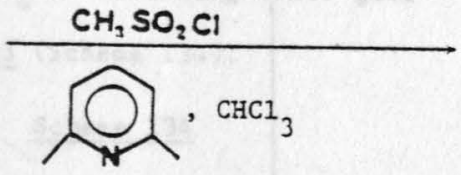

$23^{\circ} \mathrm{C}, 12 \mathrm{hr}$

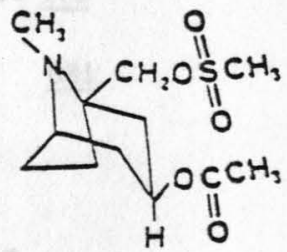

$180(53 \%)$

The spectral data of mesylate 180 were in agreement with the assigned structure. The structure received further support from the following chemical transformations.

(i) Treatment of mesylate 180 with sodium methoxide in methanol or with anhydrous potassium carbonate in methanol resulted in 


\section{Scheme 132}

\section{6 eq $\mathrm{NaOMe}$}

\section{МeOH, $23^{\circ} \mathrm{C}, 24 \mathrm{hr}$}
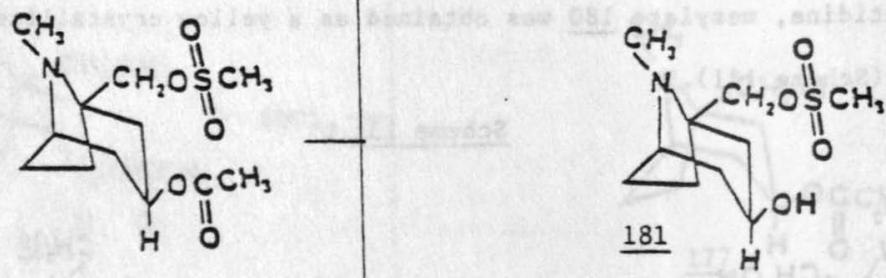

180

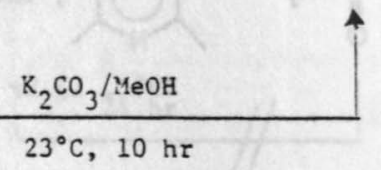


cleavage of acetate, while leaving. the methanesulfonyl group intact (Scheme 132).

In fact, the mesylate 181 was inert to methoxide even in refluxing methanol (Scheme 133).

\section{Scheme 133}

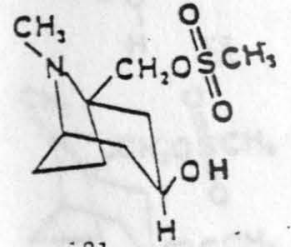

$-81$

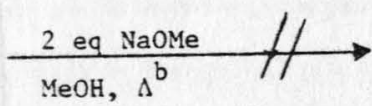

182

(ii) Mesylates and tosylates are known ${ }^{143-144}$ to be easily reduced by lithium aluminum hydride. Reduction of mesylate 180 with three equiv of $\mathrm{LiAlH}_{4}$ in refluxing ether gave 1-methylpseudotropine 133 (Scheme 134 ).

\section{Scheme 134}<smiles>CO[C@H]1CCC[C@H]2CC[C@]1(CS(C)(=O)=O)N2C</smiles>

180

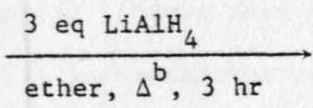

183

These chemical transformations confirmed the structure of mesylate 180 . 
Scheme 135
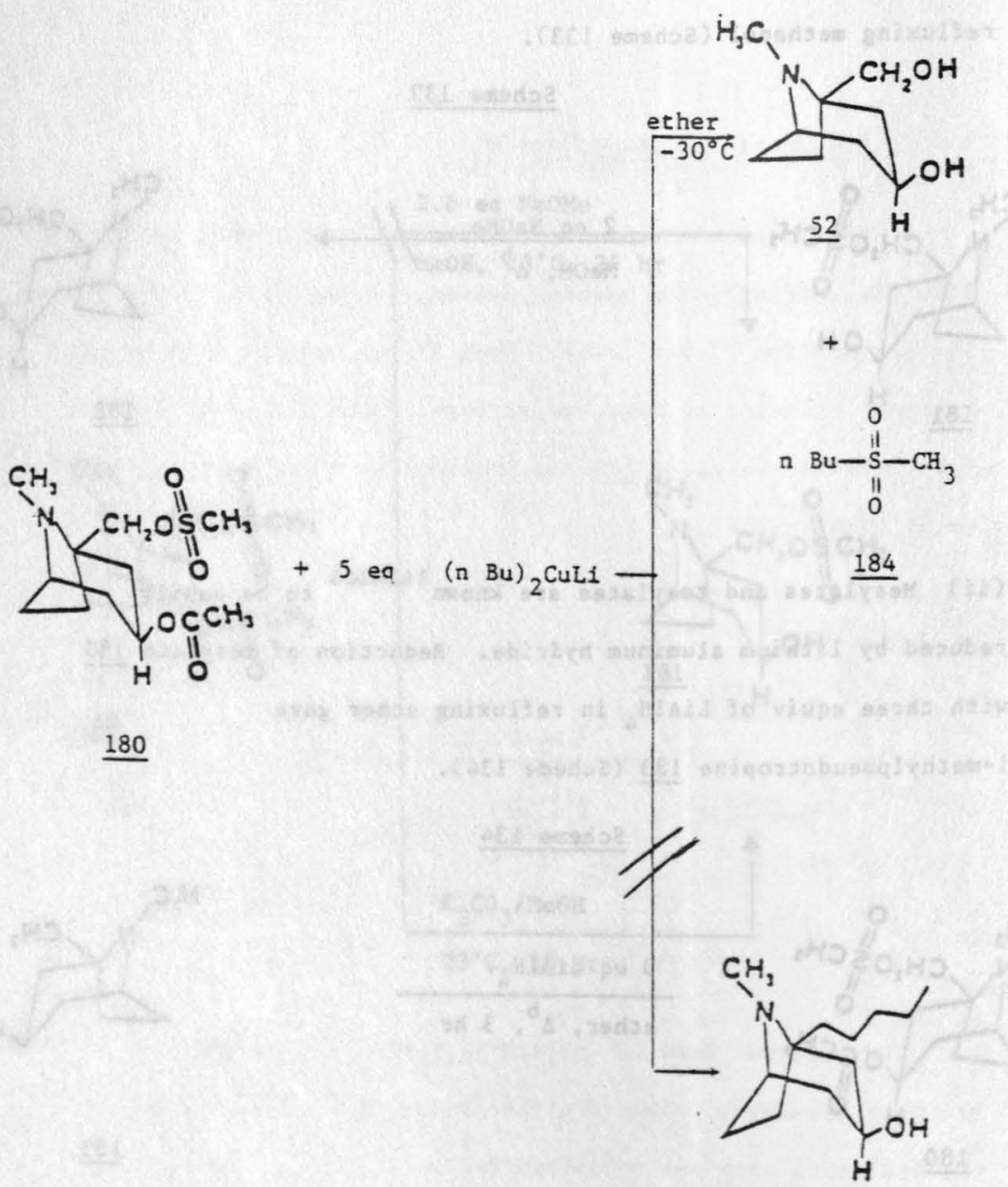


\section{Scheme 136}
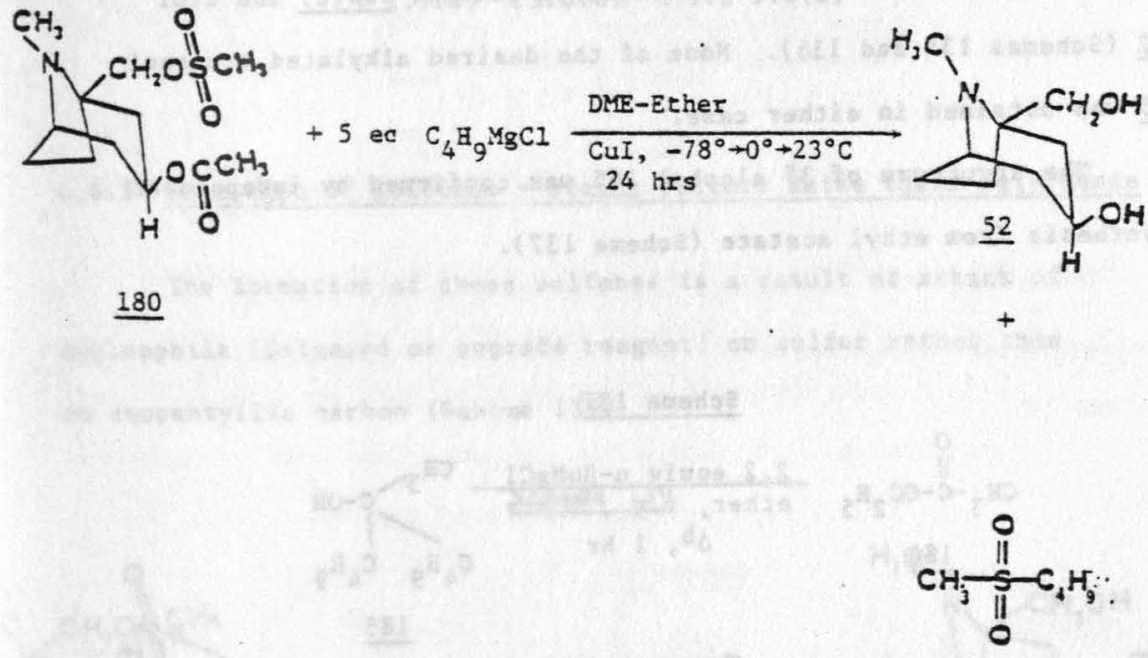

$186 c$

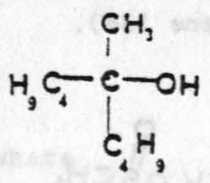


4.4.4 Attempted Carbon-Carbon Bond Formation using Mesylates:

The successful preparation of mesylates $\underline{180}$ and $\underline{181}$ set the stage for carbon-carbon bond formation via Grignard/cuprate coupling.

Unfortunately, treatment of mesylate $\underline{180}$ with either lithium n-butylcuprate or n-butylmagnesium bromide in the presence of cuprous iodide resulted in isolation of sulfone $\underline{186(c)}$ and diol 52 (Schemes 135 and 136). None of the desired alkylated tropanol 15 was obtained in either case.

The structure of $3^{\circ}$ alcohol $\underline{185}$ was confirmed by independent synthesis from ethyl acetate (Scheme 137).

\section{Scheme 137}

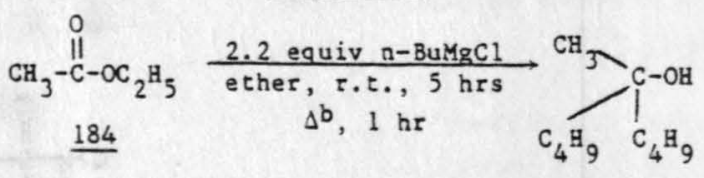

$\underline{185}$

Treatment of mesylate $\underline{181}$ with several Grignard reagents in presence of cuprous iodide gave corresponding sulfones $\underline{186}(\mathrm{a}-\mathrm{c})$ (Scheme 138).

\section{Scheme 138}
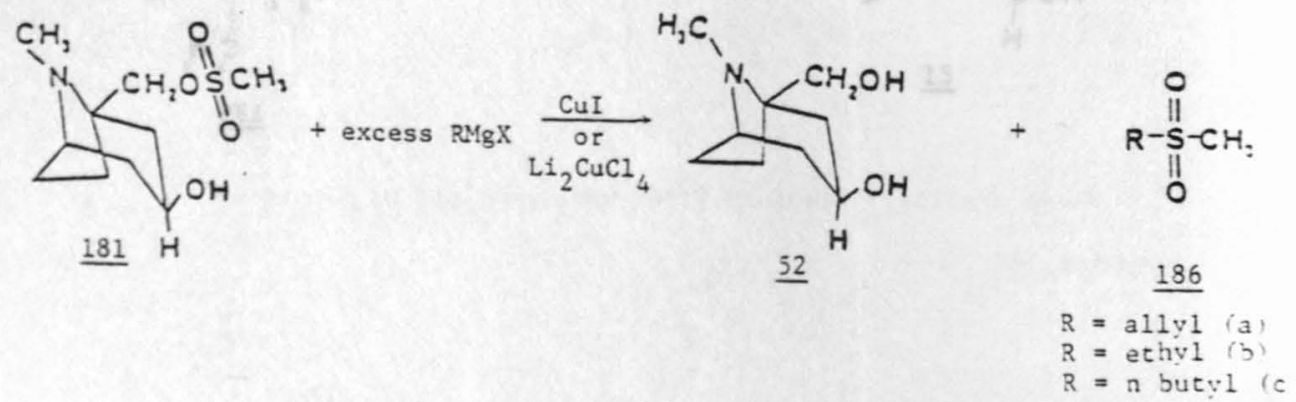
The structure of sulfones $186(a-c)$ was very clear from the ${ }^{1}$ H NMR. For example, in case of alkylmethyl sulfone $186 \mathrm{a}$, the methylene protons next to sulfur gave a signal at $\delta 3.8$ as a doublet, which is typical ${ }^{146}$ of an allyl sulfone.

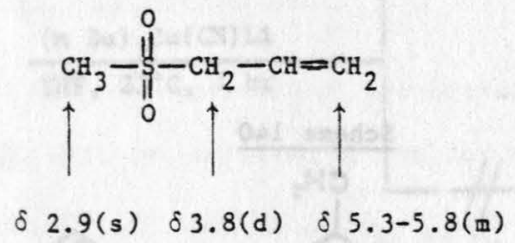

\subsubsection{Formation of Sulfones - Steric Factors Raise their Ugly Heads:}

The formation of these sulfones is a result of attack of aucleophile (Grignard or cuprate reagent) on sulfur rather than on neopentyllic carbon (Scheme 139).

\section{Scheme 139}
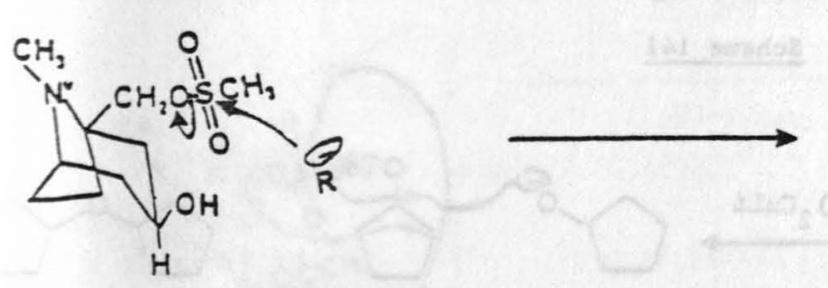

$\underline{181}$

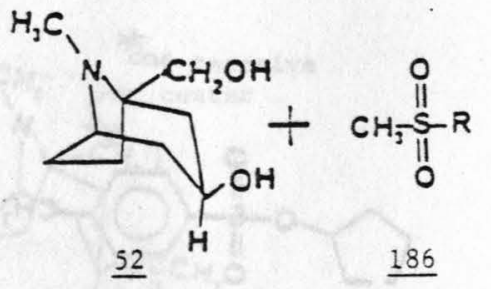

There are two isolated incidents in literature where sulfones are formed in similar reactions. Johnson ${ }^{130}$ and Dutra, during their pioneering study on 
carbon-carbon bond formation via organometallic coupling, found that when cyclopentyl tosylate was treated with lithium dimethyl cuprate, a side product, believed to be dicyclopentyl ether $(\underline{190})$ was obtained in minor amounts (Scheme 140).

\section{Scheme 140}

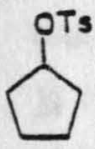

187

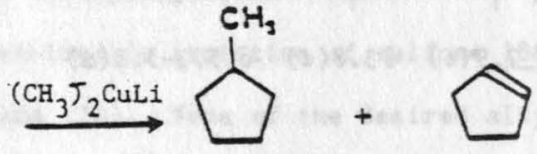

188 (60z)

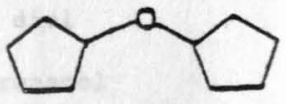

190 $(5-10 \%)$

These authors ${ }^{130}$ proposed the following mechanistic

rationale (involving sulfones) for the formation of ether 190 (Scheme 141).

\section{Scheme 141}
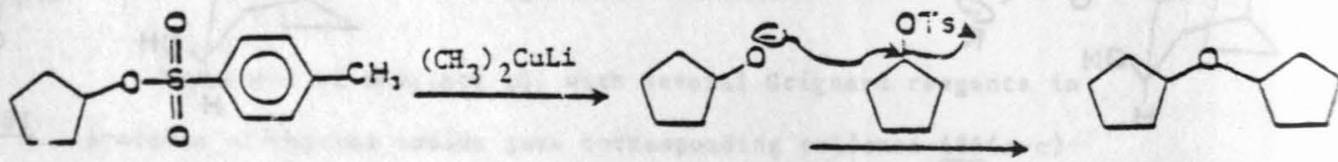

There is another precedent from the recent literature 136

(Scheme 142). 


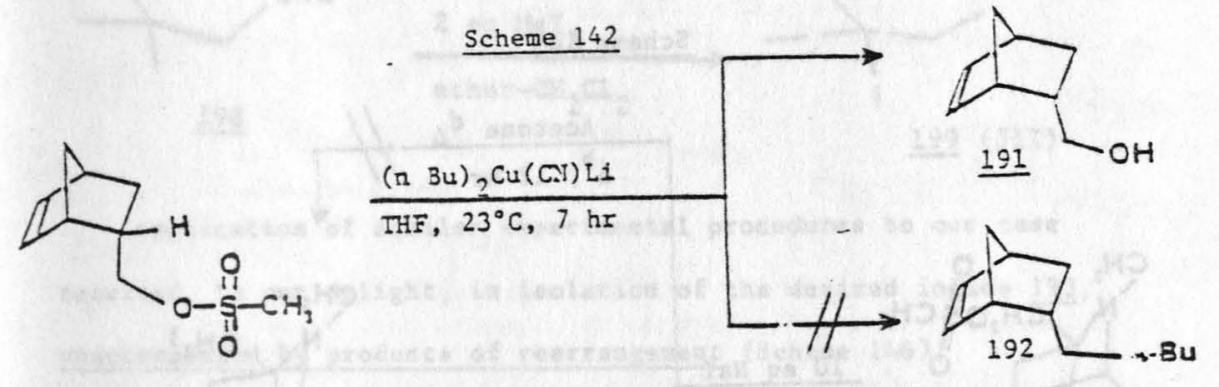

\subsubsection{Preparation of Iodide 193:}

When there are two reactive centers in a molecule, the reaction always occurs at the more reactive site. Such was the case with mesylate 180 , in which sulfur being sterically less hindered was more open (compared to neopentyl carbon) to attack by carbon nucleophiles (Grignard/cuprate reagents).

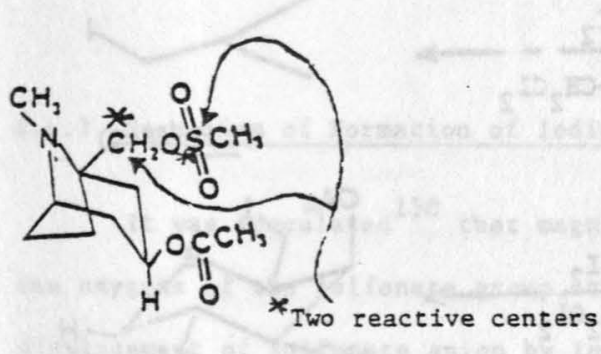

180

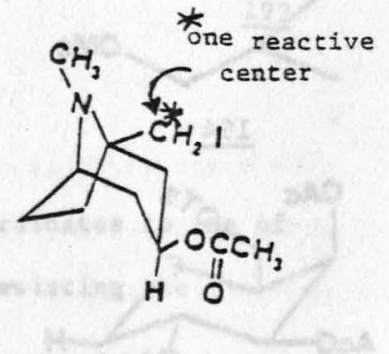

193

To get around this problem, we planned to convert mesylate $\underline{180}$ to iodide 193. 
Attempted preparation of iodide $\underline{193}$ from mesylate 180 by refluxing with sodium iodide failed (Scheme 143).

\section{Scheme 143}

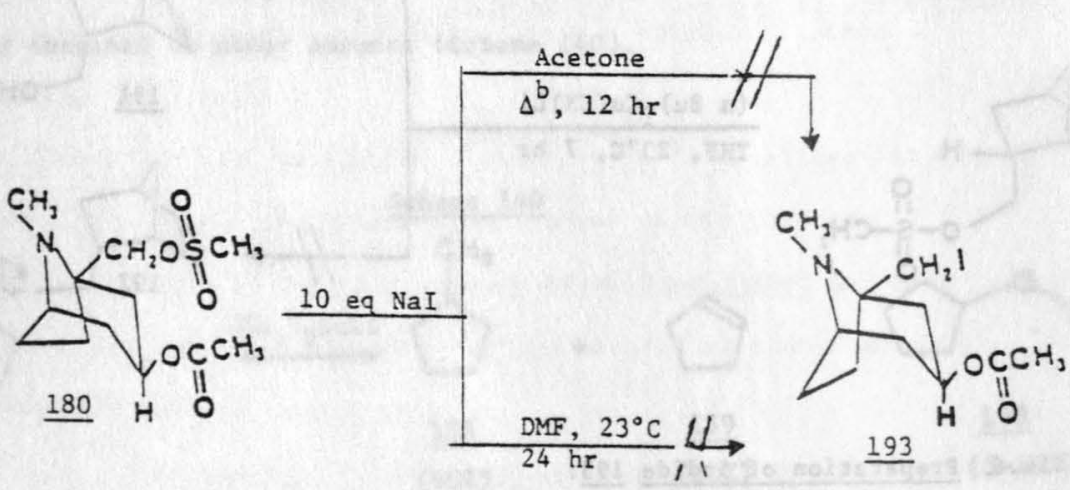

Magnesium iodide $\left(\mathrm{MgI}_{2}\right)$ is known ${ }^{150-151}$ to work in cases where sodium iodide has failed. Scheme 144 represents typical examples.

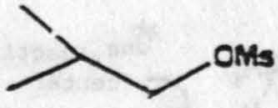

194

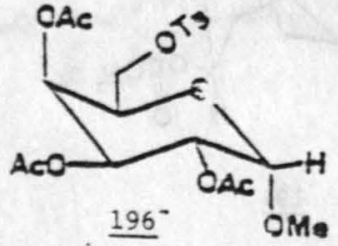

Scheme 144
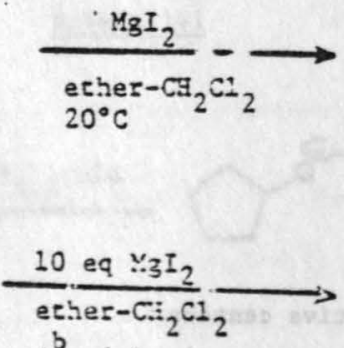

$\Delta^{b}, 4$ hr

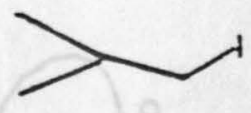

$195(64 \%)$

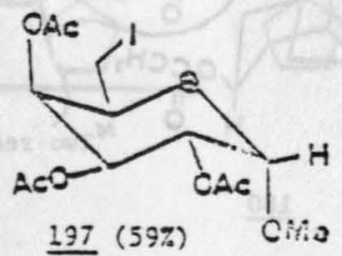

Neopentyl tosylates are known to undergo such substitutions with rearrangement to give $3^{\circ}$ iodides (Scheme 145 ). 


\section{Scheme 145}

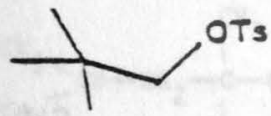

198
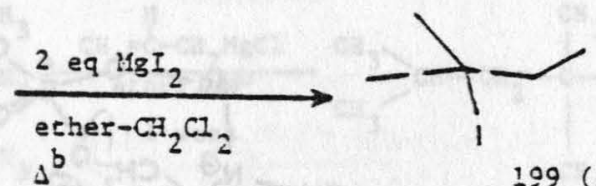

199 (51\%)

Application of similar experimental procedures to our case resulted, to our delight, in isolation of the desired iodide 193 , unaccompanied by products of rearrangement (Scheme 146).

\section{Scheme 146}

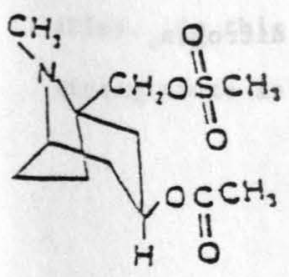

180

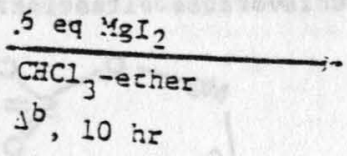

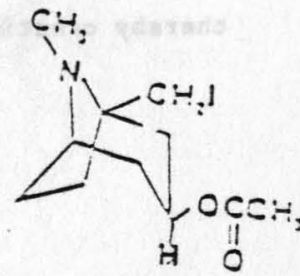

193

\subsubsection{Mechanism of Formation of Iodide:}

It was speculated ${ }^{150}$ that magnesium coordinates to one of the oxygens of the sulfonate group, there by assisting the displacement of sulfonate anion by iodide.

In our case, it is conceivable that magnesium being a bidentate 1 igand, coordinates not only to the oxygen of the sulfonate group but also to the lone pair of nitrogen and forms a seven membered chelate (Scheme 147). 


\section{Scheme 147}

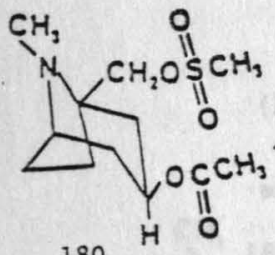

180

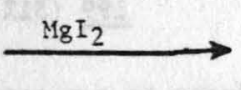

$\mathrm{CH}_{3}$

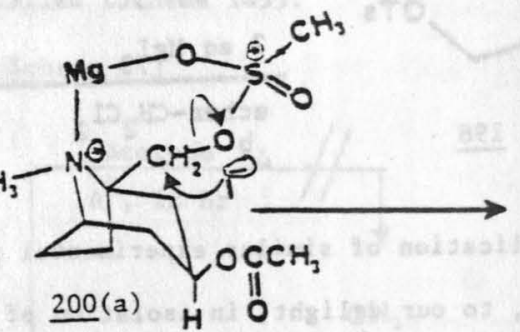

We believe that chelation of nitrogen prevents any

rearrangements, since rearrangement would lead to a $3^{\circ}$ carbonium ion ( $200 \mathrm{~b})$, that would be next to a positively charged nitrogen, thereby creating an unfavorable situation.

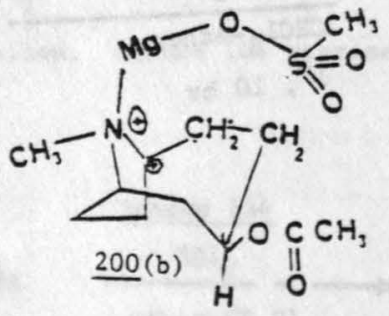

There are examples in literature 134,135 where neopentyl type and other hindered halides have been displaced by carbon nucleophiles. Schemes 148 and 149 represent a few examples.

Scheme $148^{134}$

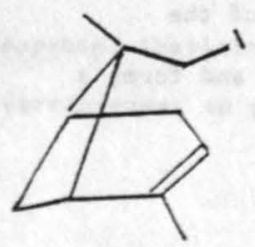

201
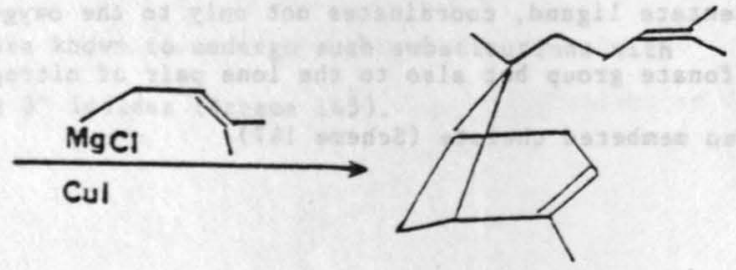

$\underline{202}(80 \%)$ 
Scheme $149^{135}$

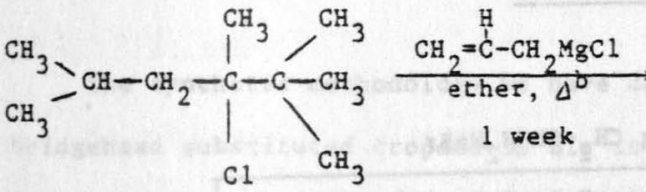
C1<smiles>CCCC(C)(CC(C)C)C(C)(C)C</smiles>

$204(28 \%)$

In our hands, all attempts at carbon-carbon bond formation by displacement of iodide functionality in 193 resulted in complete recovery of starting material (Scheme 150).

At this point it became clear that we have come to a blind alley. So this route was abandoned and we took recourse to the Wittig route as described previously (Chapter 4, Part B). 
Scheme $150^{\circ}$

5 eq $\mathrm{CH}_{2}=\mathrm{CHCH}_{2} \mathrm{MgBr}$

0.1 eq $\mathrm{CuI}, \mathrm{THF}, 23^{\circ} \mathrm{C}, 24 \mathrm{hr}$

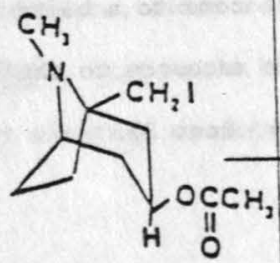

193

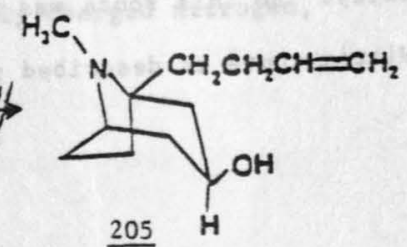

5 eq $\mathrm{CH}_{2}=\mathrm{CHCH}_{2} \mathrm{MgBr}$

1 eq CuI, THF-HMPA $24 \mathrm{hr}$

5 eq $\mathrm{CH}_{2}=\mathrm{CHCH}_{2} \mathrm{MgBr}$

1 eq CuI, DitE
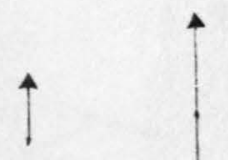

5 eq $\mathrm{CH}_{2}=\mathrm{CHCH}_{2} \mathrm{MgBr}$

0.1 eq CuI, THF, $\Delta^{\text {b/T }}$ $24 \mathrm{hr}$

205
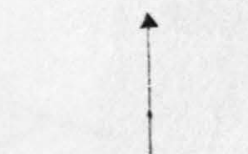
5. SUMMARY

The synthetic methodology we have developed 153,154 for bridgehead substituted tropane-3B-ols is summarized in Scheme 151 . 


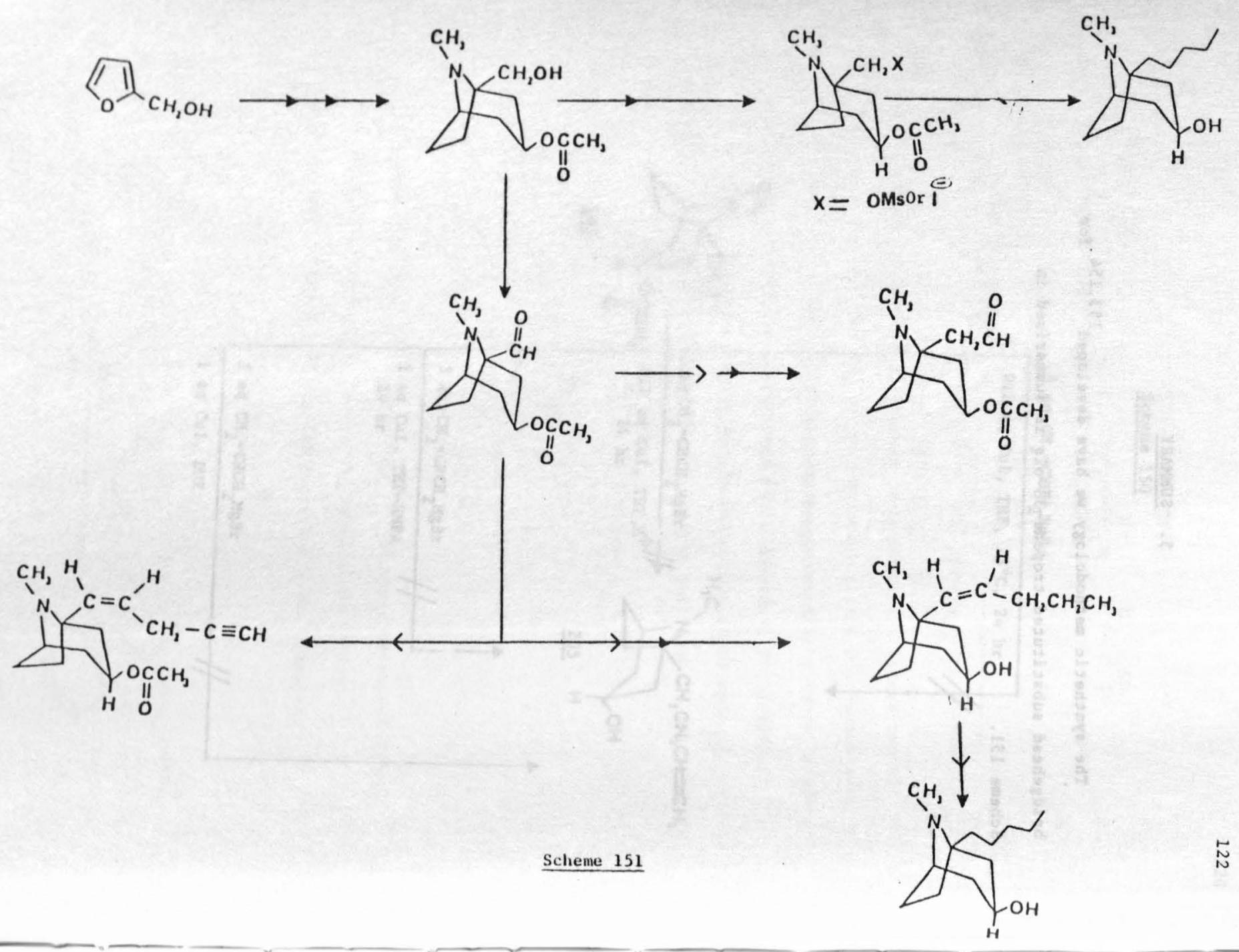




\section{EXPERIMENTAL}

\section{INSTRUMENTATION:}

Melting points were determined on a Electrothermal melting point apparatus. Both melting and boiling points are uncorrected.

Infrared spectra were recorded on a Beckman IR-8, IR-10 or IR-20A spectrophotometers. The absorptions are expressed in wavenumbers $\left(\mathrm{cm}^{-1}\right)$ and were described by the following abbreviations: $v s=$ very strong, $s=$ strong, $m=$ medium, $w=$ weak, $b r=$ broad, and $s h=$ sharp.

${ }^{1}$ H NMR spectra were recorded on a Varian EM-360 (60 MHz) spectrometer. The chemical shifts were expressed in ppm $(\delta)$ and the letter code describes the multiplicities of the resonance signals: $s=$ singlet, $d=$ doublet, $t=$ triplet, $q=$ quartet, $m=$ multiplet. The coupling constants, $J$ are reported in Hertz.

The carbon-13 NMR spectra were taken on a Varian CFT-20 spectrometer at $20 \mathrm{MHz}$. Tetramethylsilane (TMS) was used as internal standard for both ${ }^{1} \mathrm{G}$ NMR and ${ }^{1{ }^{3}} \mathrm{C}$ recordings.

Mass spectra were obtained on Finnigan 4021 mass spectrometer with an INCOS data system. The ionizing voltage was $70 \mathrm{eV}$ unless otherwise indicated in the text.

Elemental analyses were performed by Galbraith Laboratories Inc., Knoxville, Tennessee. All the hydrogenations were carried out on a Parr low-pressure reaction apparatus. 
SOLVENTS:

"Dry" solvents were obtained by distillation from an appropriate drying agent shortly before use.

Tetrahydrofuran (THF) was distilled from $\mathrm{CaH}_{2}$ followed by distillation over $\mathrm{LiAlH}_{2}$ under $\mathrm{N}_{2}$. In some instances, it was distilled under $\mathbb{N}_{2}$ from sodium wetal in the presence of benzophenone ketyl. The distilled THF was stored over $4 \AA$ molecular sieves under $\mathrm{N}_{2}$ atmosphere. Benzene was distilled from sodium metal and stored over sodium wire. Toluene was distilled from $\mathrm{CaH}_{2}$. Anhydrous ether was distilled from $\mathrm{CaH}_{2}$. Dimethyl sulfoxide (DMSO), dimethylformamide and hexamethylphosphoramide were stirred overnight with $\mathrm{NaOH}$ pellets, decanted and distilled twice over $\mathrm{CaH}_{2}$ under high vacuum. They were stored over $3 \AA$ molecular sieves under $\mathrm{N}_{2}$. Glyme and diglyme were distilled over $\mathrm{CaH}_{2}$. Methanol was distilled from magnesium methoxide.

Chloroform and methylene chloride were stirred with anhydrous $\mathrm{CaCl}_{2}$, decanted and distilled over $\mathrm{P}_{4} \mathrm{O}_{10}$. Ethyl acetate was distilled from $\mathrm{P}_{4} \mathrm{O}_{10}$.

\section{REAGENTS :}

The following chemicals were purchased from Fisher Chemical Company and were purified as mentioned.

$$
\begin{aligned}
& \text { Oxalyl chloride was distilled under } \mathrm{N}_{2} \text {. Acetic anhydride } \\
& \text { was distilled under } \mathrm{N}_{2} \text {. Acetyl chloride was used from a freshly }
\end{aligned}
$$


opened bottle. Methanesulfonyl chloride was distilled under vacuum (water aspirator) just before use. Triethylamine, pyridine, N-methylpiperidine and 2,6-lutidine were distilled twice from $\mathrm{CaH}_{2}$ and stored over $3 \AA$ molecular sieves under $\mathrm{N}_{2}$. Chlorotrimethylsilane ( $\mathrm{Me}_{3} \mathrm{SiCl}$ ) was distilled from $\mathrm{CaH}_{2}$ under $\mathrm{N}_{2}$. Lithium bromide, lithium chloride, sodium iodide, cuprous chloride, carbon tetrabromide and phosphorous tribromide were used without purification.

Thionyl chloride was purified by distilling over triphenyl phosphite, according to the procedure of Fieser. ${ }^{152} \mathrm{Li}_{2} \mathrm{CuCl}_{4}$ was prepared according to the procedure of Kochi. ${ }^{153}$

Furfuryl alcohol was distilled prior to use. Methyl iodide was used from a freshly opened bottle. Methylamine hydrochloride was used without any purification. 1-Bromobutane was distilled from $\mathrm{P}_{2} \mathrm{O}_{5}$. Triphenylphosphine $\left(\mathrm{PPh}_{3}\right)$, sulfur trioxide $\left(\mathrm{SO}_{3}\right)$, 2-furoic acid, sodium citrate, sodium tetraphenylborate were used without any purification. p-Toluenesulfonyl chloride was used from a freshly opened bottle. Hydrogen chloride gas was generated from sodium chloride and concentrated sulfuric acid. Hydrogen bromide was used as a $48 \%$ aqueous solution. Perchloric acid $\left(\mathrm{HClO}_{4}\right)$ was used as a $70 \%$ aqueous solution. Sodium hydride (NaH) was purchased as a $59 \%$ suspension in mineral oil and was washed with dry pentane just before use.

The following chemicals were purchased from Aldrich Chemical Company:

Boron tribromide $\left(\mathrm{BBr}_{3}\right)$ was supplied as a $1 \mathrm{M}$ solution in 
dichloromethane.

n-Butyllithium ( $n-B u L i)$ was used as a $1.6 \mathrm{M}$ solution in hexane.

a-Butylmagnesium chloride ( $\mathrm{n}-\mathrm{BuMgCl}$ ) was used as a $2 \mathrm{M}$ solution in diethyl ether.

Allylmagnesium chloride was used as a 2 M solution in tetrahydrofuran.

Ethylmagnes ium bromide (EtMgBr) was used as a $2 \mathrm{M}$ solution in tetrahydrofuran.

Propylmagnesium chloride was used as a 2 M solution in diethyl ether.

Methoxymethyltriphenylphosphonium chloride and potassium t-butoxide were used without purification. Raney nickel was prepared from Aluminum-aickel catalyst according to the procedure of Mozingo. $11 \mathrm{~b}$

Proton sponge $[1,8$-bis(dimethyl amino)napthalene $]$ and dicyclohexylcarbodimide (DCC) were used without purification. Pyridinium chlorochromate ${ }^{34}$ (PCC) and pyridinium dichromate 26 (PDC) were prepared according to the procedure of Corey.

Eastman chromatogram sheets, either silica gel or alumina with fluorescent indicator, were used for thin-layer chromatography (TLC). Spots were detected by visualization under ultraviolet light $(254 \mathrm{~nm})$. Silica gel 60 (Merck) was used for flash vacuum chromatography. Solvents were evaporated on a Buchi Rotavapor $-R$. 
General Remarks:

The symbol r.t. refers to room temperature and $r . b$. refers to round bottom flask. Ether refers to diethyl ether unless otherwise noted. Air- and moisture-sensitive reactions were carried out under on $\mathrm{N}_{2}$ atmosphere. The glassware was flame-dried before use in such reactions. Air-sensitive reagents were transferred either via double ended cannula or by syringes equipped with needles. The solvents were freshly distilled just before use and were transferred to the reaction flask via double ended aeedles under positive pressure of $N_{2}$. The symbol $\Delta^{b}$ refers to heated to reflux.

\section{PREPARATIONS:}

\subsection{Preparation of Furfuryl methyl ether (31):}

In a 1-L three-necked flask equipped with a mechanical stirrer, a reflux condenser and a stopper, 225 mi of furfuryl alcohol (2.6 mol, $255.3 \mathrm{~g}, \mathrm{~d}=1.135$ ) and $162 \mathrm{~mL}$ of iodomethane ( $2.6 \mathrm{~mol}, 369.3 \mathrm{~g}, \mathrm{~d}=2.28$ ) were taken. The mixture was stirred well and cooled in an ice-salt bath to $-10^{\circ} \mathrm{C}$. To this cooled mixture, $148 \mathrm{~g}$ of finely powdered potassium hydroxide pellets ( $2.6 \mathrm{~mol})$ were added in small portions. During the addition, the temperature was maintained below $25^{\circ} \mathrm{C}$. When all the potassium hydroxide had been added, the ice-bach was removed and the mixture stirred for another $6 \mathrm{hr}$ at $23^{\circ} \mathrm{C}$. At the end of this period, 
$200 \mathrm{~mL}$ of ice-cold distilled water was added to the reaction mixture. The aqueous and organic layers were separated. The organic layer was extracted three times with $300 \mathrm{~mL}$ portions of ether each time. The organic extracts were combined, dried (anhyd. $\mathrm{Na}_{2} \mathrm{SO}_{4}$ ) and the solvent evaporated. Distillation of the residual oil at 1 atm (b.p. $130-134^{\circ} \mathrm{C}$ ) gave $192 \mathrm{~g}(66 \%)$ of furfuryl methyl ether, as a colorless liquid.

$\operatorname{MMR}\left(\mathrm{CDCl}_{3}\right): \delta 3.25(\mathrm{~s}, 3 \mathrm{H}), \delta 4.3(\mathrm{~s}, 2 \mathrm{H}), \delta 6.3(\mathrm{~s}, 2 \mathrm{H})$, $\delta 7.4(s, 1 \mathrm{H})$.

IR (neat): $3100,3000,1600,1500,1450,1350,1150,1000$, $950,750 \mathrm{~cm}^{-1}$.

\section{Notes:}

1. Using dimethyl sulfoxide (DMSO) as solvent resulted in only a $4 z$ increase of yields $(66 \rightarrow 70 \%)$.

2. Using anhydrous ether as solvent decreased the yield from $66 \%$ to $50 \%$.

3. When necessary the reaction was scaled up to two times the amounts used in the above procedure without any serious problems.

4. Using NaH/DME gave only $43 \%$ yield of product. 
6.2 Preparation of 2,5-Dimethoxy 2-methoxymethyl-

$\underline{2,5-d i h y d r o f u r a n}(\underline{32})$ :

The procedure by Kebrle and Karrer ${ }^{10}$ has been modified for larger scale work. In a four-necked $1-I$ reaction kettle (equipped with a mechanical stirrer, low-temperature thermometer, drying tube filled with drierite and a dropping funne 1 ) $400 \mathrm{~mL}$ of absolute methanol, $100 \mathrm{~mL}$ of dry benzene, $208 \mathrm{~g}$ of anhydrous sodium carbonate $(2.2 \times 0.892 \mathrm{~mol})$ and $100 \mathrm{~g}$ of 2-methoxymethylfuran $(0.892 \mathrm{~mol})$ were placed. The slurry was cooled to $-15^{\circ} \mathrm{C}$ and stirred. Meanwhile, to 100 mi of absolute methanol $47.4 \mathrm{~mL}$ of bromine ( 0.892 moles) were added dropwise, below $-10^{\circ} \mathrm{C}$. The methanolic bromine solution was then added slowly to the reaction mixture maintained below $-10^{\circ} \mathrm{C}$ in about $2 \mathrm{hr}$. The mixture was stirred for another $5 \mathrm{hr}$. at $-10^{\circ} \mathrm{C}$. Then, $50 \mathrm{~g}$ of anhydrous sodium sulfate was added, the cooling bath was removed and the mixture was stirred for $0.5 \mathrm{hr}$ at room temperature. The salts were filtered off and washed with dry ether and benzene. The filtrate was placed into the reaction kettle and stirred with $50 \mathrm{~g}$ of anhydrous $\mathrm{K}_{2} \mathrm{CO}_{3}$ for $8 \mathrm{hr}$. After filtration, the solvent was evaporated; then a total of $1000 \mathrm{~mL}$ of anhydrous ether was added until no more solids precipitated. After filtration and evaporation a brownish oil was obtained which was distilled at $0.1 \mathrm{~mm}\left(\right.$ bp $45-50^{\circ} \mathrm{C}$ ) to give $111.6 \mathrm{~g}(72 \%)$ of the diastereoisomeric mixture of $( \pm)$ 2-methoxymethyl-2,5dimethoxy-2,5-dihydrofurans as a colorless oil.

$\operatorname{NMR}\left(\mathrm{CDCl}_{3}\right): \delta 3.2(\mathrm{~s}, 2 \mathrm{H}), \delta 3.5-3.8\left(\mathrm{OCH}_{3}\right.$, (several 
singlets, $9 \mathrm{H}), \delta 5.6(\mathrm{~s}, 1 \mathrm{H}), \delta 5.9-6.2(\mathrm{~m}, 2 \mathrm{H}, \mathrm{C}=\mathrm{C}-\mathrm{H})$.

IR (neat): $3000,1640(\mathrm{C}=\mathrm{C}), 1450,1350,850,750 \mathrm{~cm}^{-1}$.

Notes:

1. Bromine reacts with methanol very violently above $0^{\circ} \mathrm{C}$. So the temperature of bromine-methanol solution should always be kept at or below $-10^{\circ} \mathrm{C}$ for safety reasons.

2. Bromine should be added as fast as it is consumed.

3. Before distilling the product, a pinch of an anti-oxidant such as hydroquinone should be added to avoid decomposition of the product.

4. If the product is kept for too long, it becomes yellow. It may be necessary to redistill it prior to use.

\subsection{Preparation of Raney Nickel W-2:}

Raney nickel W-2 was prepared from nickel-aluminium alloy $(50 / 50)$ according to the procedure of Mozingo, ${ }^{11 b}$ as described in Organic Synthesis. It was stored in bottles filled completely with $95 \%$ ethanol. 


\section{Notes:}

1. Raney nickel is extremely pyrophoric when it is dry. So every precaution should be taken while handling it.

2. Even the used catalyst should be stored and disposed of in bottles filled with water.

\subsection{Preparation of 2,5-Dimethoxy-2-methoxymethyl}

tetrahydrofuran (34):

2-me thoxymethy 1-2,5-dimethoxyd ihydrofuran (35 g, $0.201 \mathrm{~mol})$ were dissolved in $100 \mathrm{~mL}$ of absolute ethanol in a Pyrex hydrogenation bottle. $20 \mathrm{~g}$ of Raney nickel were added and the compound was hydrogenated at 2 atm until the calculated amount of hydrogen ( 145 psi) was consumed. The hydrogen uptake was rapid (about 15 min for the total consumption of hydrogen). The catalyst was filtered and the solvent evaporated. Distillation of the residual oil (b.p. $45-48^{\circ} \mathrm{C}$ at $.1 \mathrm{~mm}$ ) gave $32 \mathrm{~g}(90 \%)$ of the expected cyclic acetate ketal of 4-keto-5-methoxypentanol (34).

NMR $\left(\mathrm{CDCl}_{3}\right): \delta 1.9-2(\mathrm{~m}, 4 \mathrm{H}), \delta 3.1-3.3(\mathrm{~m}, 11 \mathrm{H}), \delta 5.0(\mathrm{~m}$, 1H).

IR (neat): $3000,1450,1350,850,720 \mathrm{~cm}^{-1}$. 
Notes:

1. Raney nickel $\mathbf{W}-2$ can be purchased as a suspension in water from Aldrich. However using this commercially available catalyst resulted in slowdown of hydrogenation by at least ten times.

2. Ethyl acetate was a poor solvent for this hydrogenation. The rate was too slow.

3. Using $\mathrm{PtO}_{2}$ or $10 \% \mathrm{Pd} / \mathrm{C}$ resulted in hydrogenolysis of the methoxy groups.

4. The same hydrogenation was done by Clauson-Kaas ${ }^{14}$ at 2000 psi and $100^{\circ} \mathrm{C}$ by using a catalytic amount of Raney nickel.

$6.5( \pm)$ 1-Methoxymethyl-3-tropanone (17):

2,5-dimethoxy-2-methoxymethyltetrahydrofuran $(100 \mathrm{~g}, 0.568$ mol) were dissolved in $550 \mathrm{~mL} 1 \mathrm{~N} \mathrm{HCl}$ and kept at $80^{\circ} \mathrm{C}$ for $20 \mathrm{~min}$. The mixture was rapidly cooled in ice and the ketoaldehyde was used immediately in the Robinson condensation.

In a 3-necked 2-L flask equipped with a mechanical stirrer, reflux condenser, addition funnel, $133 \mathrm{~g}(1.6 \times 0.568 \mathrm{~mol})$ of acetonedicarboxylic acid were added to the solution of the keto-aldehyde and the solution adjusted to $\mathrm{pH}=5$ with solid potassium carbonate very carefully (foam!!) while cooling. Then $600 \mathrm{~mL} 127$ sodium citrate solution followed by $80 \mathrm{~g}$ 
methylammonium chloride $(2.1 \times 0.568 \mathrm{~mol})$ were added. The total volume of the solution was adjusted to $1000 \mathrm{~mL}$ by water. The resulting solution was stirred for $40 \mathrm{~h}$ at room temperature when release of carbon dioxide ceased. At the end the pH was brought to 10 by solid potassium carbonate.

Subsequently the mixture was heated to $60^{\circ} \mathrm{C}$ and cooled down. The volume of the solution was evaporated to $300 \mathrm{~mL}$ and extracted with ether in a continuous liquid-liquid extractor for $24 \mathrm{hr}$. The ethereal extract was dried $\left(\mathrm{Na}_{2} \mathrm{SO}_{4}\right)$ and the solvent removed by evaporation. The resulting crude oil was distilled at $0.4 \mathrm{~mm}$, bp $65-70^{\circ} \mathrm{C}$. Yield $62 \mathrm{~g}(60 \%)$. Light yellowish colored viscous oil. Rebrle and Karrer $^{10}$ reported $40 \%$ yield when no citrate buffer was used.

$\operatorname{NMR}\left(\mathrm{CDCl}_{3}\right): \delta 1.5-2.9(\mathrm{~m}, 11 \mathrm{H}), \delta 3.5\left(\mathrm{~m}, 6 \mathrm{H}, \mathrm{CH}_{2} \mathrm{OCH}_{3}\right.$, $1-$ H).

IR (neat): 3000,1710 (br, $C=0$ ) $, 1450,1410,1350,1200$, $1150,100$.

For analytical purposes the picrate was prepared from 500 mg distilled $\underline{6}$ tropanone $\underline{6}$ and 5 mL of a saturated alcoholic solution of picric acid. Washing with absolute methanol and drying gave a product. m.p. $170-171^{\circ} \mathrm{C}$.

Anal. for $\mathrm{C}_{16} \mathrm{H}_{20} \mathrm{O}_{9} \mathrm{~N}_{4}$ : Caled.: C, 46.60; $\mathrm{H}, 4.89 ; \mathrm{N}, 13.59$. Found: $C, 46.71 ; \mathrm{H}, 4.99$; $\mathrm{N}, 13.52$. 


\section{Notes:}

1. The reported ${ }^{10}$ yield of this compound was only $40 \%$ (sodium citrate was not used as buffer by these workers).

2. If the continuous extraction was not done, the yields dropped down to $42 \%$. This is due to the fact that the product is fairly soluble in water. The carbonyl and the $3^{\circ}$ amine functionalities allow for extensive hydrogen bonding.

\subsection{Preparation of 1-Methoxymethyl-38-tropanol (43):}

In a 3-necked 2-I r.b. flask equipped with a mechanical stirrer, reflux condenser and dropping funnel, a suspension 238 ( $1 \mathrm{~mol}$ ) of $\mathrm{Na}$ in $500 \mathrm{~mL}$ of dry coluene was brought to reflux. A mixture of $85 \mathrm{~g}$ of 1 -methoxymethyltropinone $(0.46 \mathrm{~mol})$ and $21 \mathrm{~mL}$ of absolute ethanol $(1.25 \times 0.46 \mathrm{~mol})$ and $100 \mathrm{~mL}$ of dry toluene was added dropwise, enough to keep the mixture refluxing. The mixture was refluzed for $12 \mathrm{hr}$. At the end of this period, it was cooled in an ice bath. 200 mL of absolute ethanol was added, followed by $200 \mathrm{~mL}$ of water. The organic and aqueous layers were separated. The aqueous layer was extracted with ( $3 \times 200 \mathrm{~mL}$ ) ether. The combined organic layers were washed with saturated sodium chloride solution, dried $\left(\mathrm{Na}_{2} \mathrm{SO}_{4}\right)$, filtered and the solvents evaporated. The resulting brown oil was distilled at $0.4 \mathrm{~mm}\left(\mathrm{~b} \cdot \mathrm{p} \cdot 110-112^{\circ} \mathrm{C}\right)$ to give $75 \mathrm{~g}(90 \%)$ of 
$\operatorname{MMR}\left(\operatorname{CDCl}_{3}\right): \delta 1.5-1.8(\mathrm{~m}, 8 \mathrm{H}), \delta 2.4(\mathrm{~s}, 3 \mathrm{H}), \delta 3.3(\mathrm{~m}$, 6H), $\delta 4.1(\mathrm{~m}, 1 \mathrm{H})$.

IR (film): $3400,1450,1250,1100,1050,900 \mathrm{~cm}^{-1}$.

\section{Notes:}

1. The compound could also be purified by chromatography on silica gel $\left(\mathrm{MeOH}+1 \% \mathrm{Na}_{4} \mathrm{OH}\right)$.

2. During the vacuum distillation, an air-cooled condenser was used. The compound would solidify when a water cooled condenser was used.

3. The gields drop down to $75-80 \%$ if good vacuum (less than 0.5 $\operatorname{mm})$ is unattainable. Reproducibility was better if the vacuum was good.

6.7 Preparation of 1-Methoxymethyl pseudotropine hydrochloride (45):

$10 \mathrm{~g}$ of 43 were $(0.054 \mathrm{~mol})$ dissolved in $200 \mathrm{~mL}$ of absolute ethanol and dry HCl gas was bubbled through the solution until $\mathrm{pH}=2-3$ was reached. Ethanol was evaporated and the resulting solid dried under vacuum for $6 \mathrm{hrs}$. Yield $11.9 \mathrm{~g}(100 \%)$. Anal. Caled. for $\mathrm{C}_{10} \mathrm{H}_{20} \mathrm{NO}_{2} \mathrm{Cl}: \mathrm{C}, 54.77 ; \mathrm{H}, 9.03 ; \mathrm{N}, 6.32 ; 0$, $14.44 ; \mathrm{Cl}, 16.03$. Found: $\mathrm{C}, 54.22 ; \mathrm{H}, 9.00 ; \mathrm{N}, 6.21 ; 0,14.61$; C1, 16.03. 
m.p. $177-179^{\circ} \mathrm{C}$.

\subsection{Preparation of 1-Methoxymethyl-3B-acetoxytropane}

Hydrochloride $(60)$ :

Amine $45(7.00 \mathrm{~g}, 0.032 \mathrm{~mol})$ was dissolved in $125 \mathrm{~mL}$ of freshly distilled acetic anhydride and $50 \mathrm{~mL}$ of acetyl chloride, in a 500 mI r.b. flask. To this magnetically stirred solution, $0.268(0.002 \mathrm{~mol})$ of dimethylaminopyridine (DMAP) was added and the mixture was refluxed overnight. Acetyl chloride and acetic anhydride were removed by evaporation. To the brown oily residue, $20 \mathrm{~mL}$ of acetone was added and the sides of the flask scratched with a glass rod. White crystals were obtained, which were washed with $5 \mathrm{~mL}$ of cold acetone. Yield $7 \mathrm{~g}$ (85\%). m.p. $153-156^{\circ} \mathrm{C}$. $\operatorname{MMR}\left(\mathrm{CDCl}_{3}\right): \delta 2.2-2.5(\mathrm{~m}, 11 \mathrm{H}), \delta 2.9(\mathrm{~s}, 3 \mathrm{H}), \delta 3.3(\mathrm{~s}$, $5 \mathrm{H}), \delta 4.9-5.2(\mathrm{~m}, 1 \mathrm{H})$.

IR $(\mathrm{KBr}): \quad 2900,1720,1370,1240,1020 \mathrm{~cm}^{-1}$.

Anal. Calcd. for $\mathrm{C}_{12} \mathrm{H}_{22} \mathrm{O}_{3} \mathrm{NCl}$ : C, 54.64; $\mathrm{H}, 8.37 ; \mathrm{N}, 5.31$;

C1, $13.47 ; 0,18.21$. Found: C, $54.53 ; \mathrm{H}, 8.52 ; \mathrm{N}, 5.25$;

C1, 13.60; $0,17.99$. 


\section{Notes:}

1. The amount of DMAP needed is only $1 / 15$ of the alcohol.

2. The yields drop down from $85 \rightarrow 50 \%$ if the catalyst (DMAP) is not used.

3. Instead of using HCl salt of the starting amino alcohol 43 , one could use the free base. Since one mole of hydrogen chloride is liberated during the reaction, we still end up with the hydrochloride salt of the acylated amine. However, it is convenient to use the hydrochloride salt of the starting amino alcohol 45 which is a solid rather than the free base which is a syrup.

\subsection{Preparation of 1-Hydroxymethyl-3B-acetoxytropane (55):}

In a 3-necked $500 \mathrm{~mL}$ 5.b. flask equipped with a mechanical stirrer, addition funnel with septum, reflux condenser with a nitrogen inlet, $5 \mathrm{~g}(0.019 \mathrm{~mol})$ of 60 were taken and dissolved in $200 \mathrm{~mL}$ of dry chloroform. $100 \mathrm{ml}$ of $1 \mathrm{M}$ solution of boron tribromide $(5.25 \times 0.019$ mol) in methylene chloride were transferred via cannula to the addition funnel by using a positive pressure of nitrogen. It was added dropwise from the addition funnel to the reaction mixture at $23^{\circ} \mathrm{C}$. The mixture was stirred for $16 \mathrm{hr}$. It was then poured onto crushed ice and less adjusted to pH 11 by ammonium hydroxide solution. The organic 
and aqueous layers were separated. The aqueous layer was extracted with $(2 \times 100 \mathrm{~mL})$ chloroform. The combined organic layers were dried $\left(\mathrm{Na}_{2} \mathrm{SO}_{4}\right)$, filtered and the solvent was evaporated. The crude compound was pure enough for the next step and was used in most cases without any purification. Yield $4 \mathrm{~g}$ (99\%).

However for analytical purposes, a small amount was chromatographed ( $\mathrm{CHCl}_{3}$ as eluent) over silica gel.

${ }_{\text {H }}$ NMR $\left(\mathrm{CDCl}_{3}\right): \delta 1.5-1.9(\mathrm{~m}, 8 \mathrm{H}) ; \delta 2.1(\mathrm{~s}, 3 \mathrm{H}) ; \delta 2.3(\mathrm{~s}$, $3 \mathrm{H}) ; \delta 3.3(\mathrm{~m}, 1 \mathrm{H}), \delta 3.5(\mathrm{~s}, 2 \mathrm{H}) ; \delta 4.4(\mathrm{~s}, 1 \mathrm{H}$, exchangeable with $\left.\mathrm{D}_{2} \mathrm{O}\right) ; \delta 5.1$ (m, $\left.1 \mathrm{H}\right)$.

IR $\left(\mathrm{CDCl}_{3}\right): 3400$ (br, OH), 2950, $1720\left(\mathrm{~s}, 0-\mathrm{CCH}_{3}\right), 1450$, $1300,1200,1020,900,800 \mathrm{~cm}^{-1}$.

\section{Notes:}

1. The reaction does not proceed below room temperature.

2. For optimization of yields, see Table I.

\subsection{Preparation of Tetraphenyl borate salt of 3-Hydroxymethyl-} 38-acetoxytropane:

To a solution of $1 \mathrm{~g}$ of $\underline{55}$ in $30 \mathrm{ml}$ of water diluted hydrochloric acid was added until pH of 2 was reached. A $7 \%$ aqueous solution of a sodium tetraphenyl boron was added 
Table I

\section{OPT IMIZAT ION OF YIELDS}

Amt. of $\mathrm{CH}_{2} \mathrm{OCH}_{3}$ Amt. of $\mathrm{BBr}_{3}$ Conditions

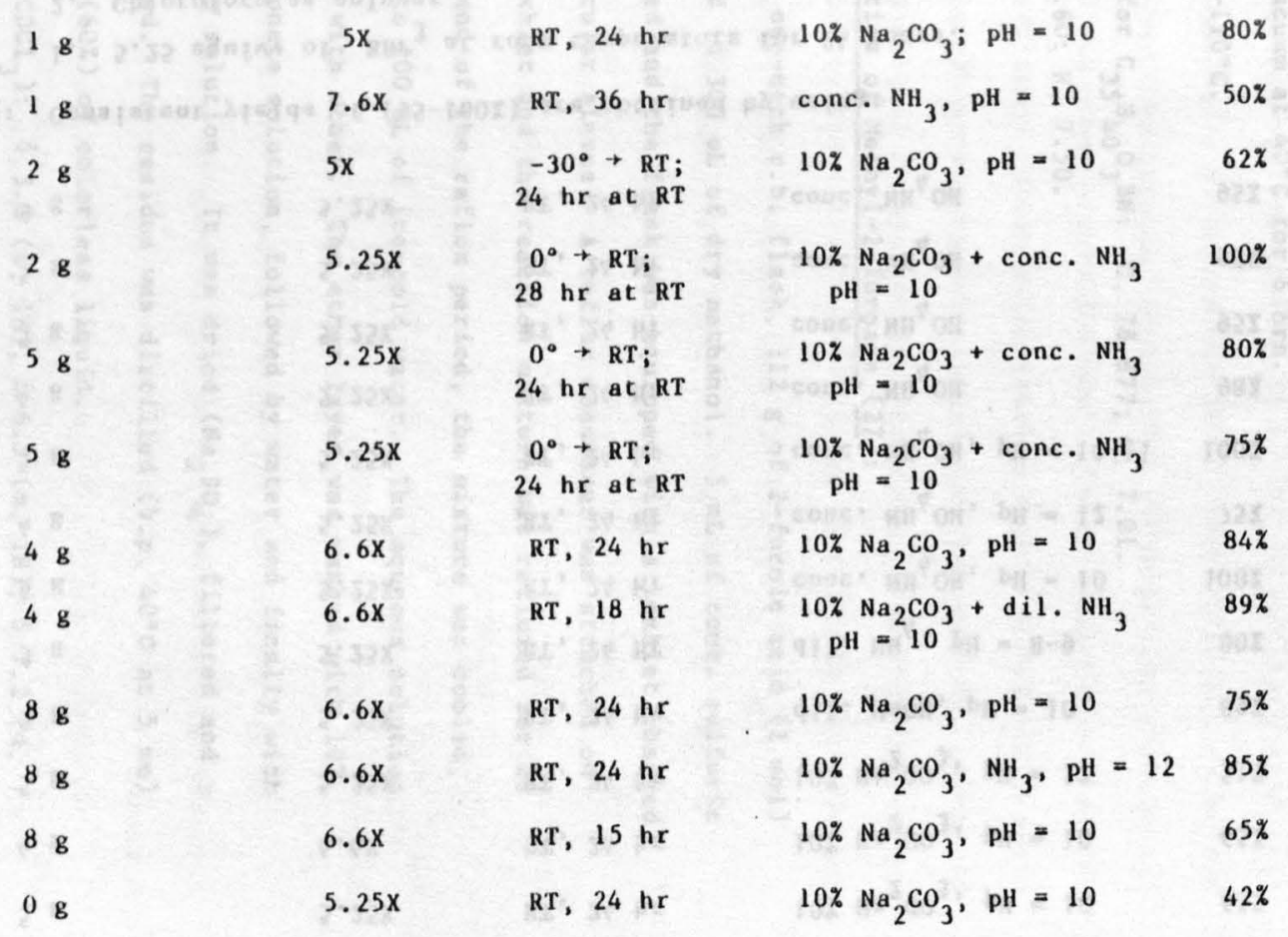




\begin{tabular}{|c|c|c|c|}
\hline 58 & $5.25 x$ & $\mathrm{RT}, 24 \mathrm{hr}$ & $10 \% \mathrm{Na}_{2} \mathrm{CO}_{3}, \mathrm{pH}=10$ \\
\hline 48 & $6.6 x$ & $\mathrm{RT}, 24 \mathrm{hr}$ & $10 \% \mathrm{Na}_{2} \mathrm{CO}_{3}, \mathrm{pH}=10$ \\
\hline $5 \mathrm{~g}$ & $5.25 \mathrm{x}$ & $\mathrm{RT}, 24 \mathrm{hr}$ & $10 \% \mathrm{Na}_{2} \mathrm{CO}_{3}, \mathrm{pH}=12$ \\
\hline $5 \mathrm{~g}$ & $5.25 \mathrm{X}$ & $\mathrm{RT}, 24 \mathrm{hr}$ & dil. $\mathrm{NaOH}, \mathrm{pH}=10$ \\
\hline $5 \mathrm{~g}$ & $5.25 x$ & $\mathrm{RT}, 24 \mathrm{hr}$ & dil. $\mathrm{NH}_{4}, \mathrm{pH}=8-9$ \\
\hline 48 & $5.25 x$ & $\mathrm{RT}, 24 \mathrm{hr}$ & conc. $\mathrm{NH}_{4} \mathrm{OH}, \mathrm{pH}=10$ \\
\hline 48 & $5.25 \mathrm{X}$ & $\mathrm{RT}, 24 \mathrm{hr}$ & conc. $\mathrm{NH}_{4} \mathrm{OH}, \mathrm{pH}=12$ \\
\hline 58 & $5.25 \mathrm{X}$ & RT, $24 \mathrm{hr}$ & conc. $\mathrm{NH}_{4} \mathrm{OH}, \mathrm{pH}=10-11$ \\
\hline 48 & $5.25 x$ & $\mathrm{RT}, 24 \mathrm{hr}$ & conc. $\mathrm{NH}_{4} \mathrm{OH}$ \\
\hline 58 & $5.25 \mathrm{X}$ & RT, $24 \mathrm{hr}$ & conc. $\mathrm{NH}_{4} \mathrm{OH}$ \\
\hline 58 & $5.25 x$ & $\mathrm{RT}, 24 \mathrm{hr}$ & conc. $\mathrm{NH}_{4} \mathrm{OH}$ \\
\hline 58 & $5.25 x$ & $\mathrm{RT}, 24 \mathrm{hr}$ & conc. $\mathrm{NH}_{4} \mathrm{OH}$ \\
\hline
\end{tabular}

Notes: Consistent yields of $(95-100 \%)$ are obtained by using:

1. 5.25 equiv. of $\mathrm{BBr}_{3}$ at room temperature for 24 hours.

2. Chloroform as solvent.

3. Using concentrated $\mathrm{NH}_{4} \mathrm{OH}$ in work up $(\mathrm{pH}=10)$.

4. At higher pH, acetate is hydrolysed. 
dropwise, with cooling and stirring. An immediate precipitation occurred. After the precipitation was complete, the precipitate was filtered on suction, washed well with distilled water and dried under vacuum at $40^{\circ} \mathrm{C}$ for $6 \mathrm{hrs}$.

m.p. $108-110^{\circ} \mathrm{C}$.

Anal. Calcd. for $\mathrm{C}_{35^{\mathrm{H}}}{ }_{40} \mathrm{O}_{3} \mathrm{BN}$ : C, 78.877; $\mathrm{B}, 7.01$.

Found: $\quad$ C, $78.60 ; \mathrm{H}, 7.50$.

\subsection{Preparation of Methyl-2-furoate (27):}

In a 1-I one-neck r.b. flask, $112 \mathrm{~g}$ of 2-furoic acid ( $1 \mathrm{~mol}$ ) were dissolved in $300 \mathrm{~mL}$ of dry methanol. $5 \mathrm{~mL}$ of conc. sulfuric acid were added and the flask was equipped with a soxhlet charged with $3 \AA$ molecular sieves. A reflux condenser was attached on top of the soxhlet and the reaction mixture was refluxed for 20 hrs. At the end of the reflux period, the mixture was cooled, and poured into $200 \mathrm{~mL}$ of ice-cold water. The aqueous solution was extracted with ether. The ether layer was washed with $10 \%$ sodium bicarbonate solution, followed by water and finally with saturated salt solution. It was dried $\left(\mathrm{Na}_{2} \mathrm{SO}_{4}\right)$, filtered and then evaporated. The residue was distilled (b.p. $40^{\circ} \mathrm{C}$ at $5 \mathrm{~mm}$ ) to give $80 \mathrm{~g}(60 \%)$ of colorless liquid.

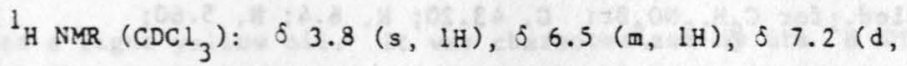
$1 \mathrm{H}), \delta 7.8(\mathrm{~d}, 1 \mathrm{H})$. 


\subsection{Preparation of 1-Hydroxymethy 1-3B-tropanol (52):}

In a l-L r.b. flask equipped with a magnetic stirrer and reflux condenser, $26.0 \mathrm{~g}(0.14 \mathrm{~mol})$ of 1 -methoxymethy $1-3 \beta$-tropanol (43) were dissolved in $160 \mathrm{~mL}$ of $48 \mathrm{z}$ aqueous $\mathrm{HBr}$ and the mixture heated to reflux for $36 \mathrm{hr}$. At the end of this heating period, the mixture was cooled in an ice-bath, neutralized carefully with $10 \%$ sodium hydroxide solution and water was evaporated. To the crude solid $100 \mathrm{~mL}$ of hot acetone added and the insoluble solids filtered. Acetone was evaporated and the crude product was chromatographed on a column of basic alumina. $20 \mathrm{~g}(90 \%)$ of $\underline{52}$ was obtained as a yellow solid.

$\operatorname{NMR}\left(\mathrm{D}_{2} \mathrm{O}\right): \delta 1.5-1.8(\mathrm{~m}, 8 \mathrm{H}), \delta 2.5(\mathrm{~s}, 3 \mathrm{H}), \delta 3.6(3 \mathrm{H})$. IR $\left(\mathrm{CHCl}_{3}\right): 3500$ (br, OH), $3000,1450,1020 \mathrm{~cm}^{-1}$.

The tetraphenylborate salt was prepared using the procedure out 1 ined in section 6.10 .

m.p. $194-196^{\circ} \mathrm{C}$.

Anal. Caled. for $\mathrm{C}_{33} \mathrm{H}_{38} \mathrm{NO}_{2}$ : C, 80.65; $\mathrm{A}, 7.73 ; \mathrm{N}, 2.85 ; 3,2.24$; $0,6.52$. Found: C, 79.85; $\mathrm{A}, 8.03 ; \mathrm{N}, 2.75 ; \mathrm{B}, 2.09 ; 0,7.10$.

The $\mathrm{BBr}$ salt of the diol $\underline{52}$ was prepared by dissolving the compound in $48 \% \mathrm{HBr}$ solution and azeotroping the water with benzene.

Ana1. Calcd. for $\mathrm{C}_{9} \mathrm{H}_{18} \mathrm{NO}_{2} \mathrm{Br}: \mathrm{C}, 43.20 ; \mathrm{H}, 6.4 ; \mathrm{N}, 5.60$;

$\mathrm{Br}, 32.0 ; 0,12.80$. Found: $\mathrm{C}, 43.05 ; \mathrm{A}, 6.6 ; \mathrm{N}, 5.39 ; \mathrm{Br}, 32.6$;

$0,12.65$. 
6.13 Swern Oxidation of 1-Hydroxymethyl-3B-acetoxytropane (55) to $3 \beta$-acetoxytropane-1-aldehyde ( $\underline{56})$ :

A solution of $3.6 \mathrm{~mL}(2.2 \times 0.019 \mathrm{~mol})$ of oxalyl chloride in $50 \mathrm{~mL}$ dichloromethane was placed in a flask equipped with mechanical stirrer, a low-temperature thermometer, a Claisen-adapter with dropping funnels, one containing $6.5 \mathrm{~mL}$ $(4.8 \times 0.0188$ mol $)$ dimethyl sulfoxide diluted with 20 mL methylene chloride and the other containing $4 \mathrm{~g}(0.019$ mol) of 1-hydroxymethyl-3B-acetoxytropane ( 1 a $)$ dissolved in $20 \mathrm{~mL}$ of the same solvent. The flask was cooled to $-60^{\circ} \mathrm{C}$. First the dimethyl sulfoxide solution was added dropwise under nitrogen to the oxalyl chloride solution. The reaction mixture was stirred for additional 30 min at $-60^{\circ} \mathrm{C}$. The methylene chloride solution of 8a was then added dropwise and the solution stirred for additional $1 \mathrm{hr}$ between $40^{\circ} \mathrm{C}$ and $-60^{\circ} \mathrm{C}$. Finally $11 \mathrm{~mL}(5 \times 0.019$ mo1) of $\mathrm{N}$-methylpiperidine were added and the solution stirred for additional $15 \mathrm{~min}$ and the mixture was allowed to warm to $20^{\circ}$. $30 \mathrm{~mL}$ of water added and the $\mathrm{pH}$ adjusted to 11 with dil. ammonium hydroxide solution. The organic and aqueous phases were separated and the aqueous layer extracted 3 times with $100 \mathrm{~mL}$ ) methylene chloride. The combined organic layers were washed with water, by saturated salt solution, dried $\left(\mathrm{Na}_{2} \mathrm{SO}_{4}\right)$. Filtration followed by evaporation of solvent gave $3.8 \mathrm{~g}$ (95\%) of aldehyde 11 as a light yellow oil. It was characterized by its ${ }^{1}$ H NMR and mass spectra.

$\operatorname{NMR}\left(\mathrm{CDCl}_{3}\right): \delta 1.5-1.8(\mathrm{~m}, 8 \mathrm{H}), \delta 2.0(\mathrm{~s}, 3 \mathrm{H}), \delta 2.3(\mathrm{~s}$, 
$\left.3 \mathrm{H}, \mathrm{N}-\mathrm{CH}_{3}\right), \delta 3.3(\mathrm{~m}, 1 \mathrm{H}), \delta 5.1-5.4(\mathrm{~m}, 1 \mathrm{H}, \mathrm{H}-3), \delta 9.7(\mathrm{~s}, 1 \mathrm{H}$, $-\mathrm{C}-\underline{\mathrm{H}})$.

IR (film): $2900,1750,1350,1250,1070,900,720 \mathrm{~cm}^{-1}$.

Mass spectrum: $\mathrm{m} / \mathrm{e} 211.1{\left(\mathrm{M}^{+}\right)}^{+}, 196.1,185.1,168.1,152.1$,

$122.1,111.1,96.1$ (base peaks, $82.1,67.1,55.0$ ).

\section{Notes:}

1. Evaporation of solvent should be carried out in a well ventilated hood.

2. When triethylamine was used in place of $\mathbf{N}$-methylpiperidine, there was evidence for another product, amino sulfide 90. Using 2,6-1utidine increased the amounts of this by-product at the cost of desired aldehyde $\underline{56}$. Thus the most suitable base was determined to be $\mathrm{N}$-methylpiperidine.

3. When the reaction was carried out on a smaller scale ( $1 \mathrm{gm}$ of starting alcohol), the crude yields were found to be much better (95-100z). 
6.14 Chemical conformation of structure of 38 -acetoxytropane

1 -aldehyde ( $\underline{56}$ ) by reduction to 1-hydroxymethyl-38acetoxytropane (55):

To $1.00 \mathrm{~g}$ of the crude aldehyde $\underline{56}$ in $25 \mathrm{~mL}$ of ether were added $2.00 \mathrm{~g}$ of $\mathrm{NaBH}_{4}(0.053 \mathrm{~mol})$ and the mixture was stirred for $12 \mathrm{hr}$ in a $100 \mathrm{~mL} \mathrm{r.b}$. flask at $23^{\circ} \mathrm{C}$. After this time, the solids were filtered, and the pH of the solution was adjusted to 3 by dilute hydrochloric acid. It was then basified with dilute ammonium hydroxide $(\mathrm{pH}=10)$. The water layer was extracted with chloroform. Drying $\left(\mathrm{Na}_{2} \mathrm{SO}_{4}\right)$ and removal of chloroform gave alcohol $\underline{55}$ as the only product.

$\operatorname{MMR}\left(\mathrm{CDCl}_{3}\right): \delta 1.5-1.9(\mathrm{~m}, 8 \mathrm{H}), \delta 2.1(\mathrm{~s}, 3 \mathrm{H}), \delta 2.3(\mathrm{~s}$, $3 \mathrm{H}), \delta 3.3(\mathrm{~m}, 1 \mathrm{H}), \delta 3.5(\mathrm{~m}, 2 \mathrm{H}), \delta 4.9(\mathrm{~s}, 1 \mathrm{H}), \delta 5.0(\mathrm{t}, 1 \mathrm{H})$. IR $\left(\mathrm{CHCl}_{3}\right): 3500$ (br, O-H), 3000, $1450,1020 \mathrm{~cm}^{-1}$.

\section{Notes:}

1. Methanol or any other alcohol was not used deliberately to avoid loss of acetate by trans esterification.

2. Notice the appearance of signals for $\mathrm{CH}_{2} \mathrm{OH}$ at $\delta 3.5$ and disappearance of signals at $\delta 9.5$ corresponding to aldehyde proton in ${ }^{1} \mathrm{H}$ NMR. 


\subsection{Pfitzner-Moffatt oxidation of 1-hydroxymethy 1-3B-}

\section{acetoxytropane:}

Alcohol $55(0.80 \mathrm{~g}, 0.0037 \mathrm{~mol})$ was dissolved in $100 \mathrm{~mL}$

of ethyl acetate in a one necked $100 \mathrm{~mL}$ r.b. flask. Then $25 \mathrm{~mL}$ of dimethyl sulfoxide (DMSO), 2.258 of $(3 \times 0.0037 \mathrm{~mol})$

dicyclohexylcarbodiimide (DCC) and $0.4 \mathrm{~mL}$ of trifuoroacetic acid $(1.5 \times 0.0037 \mathrm{~mol})$ were added. The mixture was stirred at $23^{\circ} \mathrm{C}$ for $48 \mathrm{hr}$. Ethyl acetate was evaporated on rotovap. Dimethyl sulfoxide was removed by vacuum distillation. To the residue 50 $\mathrm{mL}$ of water was added. Ether extraction of the aqueous layer gave dicyclohexyl urea after removal of ether. The water layer was basified with dilute $\mathrm{NH}_{4} \mathrm{OH}(\mathrm{pH}=11)$ and extracted with chloroform. Removal of chloroform gave the aldehyde 56 . Yield $0.3 \mathrm{~g}(40 \%)$.

$\operatorname{MMR}\left(\mathrm{CDCl}_{3}\right): \delta 1.9-2.3(\mathrm{~m}, 11 \mathrm{H}), \delta 2.3(\mathrm{~s}, 3 \mathrm{H}), \delta 3.3(\mathrm{~m}$, 1H), $\delta 4.9-5.3(\mathrm{~m}, 1 \mathrm{H}), \delta 9.6(\mathrm{~s}, 1 \mathrm{H})$.

IR (neat): $2900,1750,1350,1250,1070,900,720 \mathrm{~cm}^{-1}$.

\section{Notes:}

1. The yields could be improved to $50 \%$ when 2,2 -dichloropropionic acid was used in place of trifluoroacetic acid.

2. The product could be purified by silica gel chromatography (acetone as eluent). 
3. The reaction could be done even without using ethyl acetate as solvent.

4. Poor yields were obtained when anhydrous phosphoric acid was used as acid catalyst.

5. It is important that strictly anhydrous conditions be maintained for the success of the reaction.

6.16 Attempted Oxidation of 55 using dimethyl sulfoxide in presence of acetic anhydride. Preparation of 1-acetoxymethyl-38-acetoxy tropane ( 166$)$ :

To $2.00 \mathrm{~g}$ of alcohol $(0.009 \mathrm{~mol}) \underline{55}$ in $28 \mathrm{~mL}$ of dry DMSO, $4.8 \mathrm{~mL}(5.5 \times 0.009 \mathrm{~mol})$ of dry acetic anhydride were added and the mixture stirred at $23^{\circ} \mathrm{C}$ for $40 \mathrm{hr}$. At the end of this period, dimethyl sulfoxide and acetic anhydride were vacuum distilled. Water was added and the mixture made basic with dilute ammonium hydroxide $(\mathrm{pH}=10)$. Extraction by chloroform, followed by drying $\left(\mathrm{Na}_{2} \mathrm{SO}_{4}\right)$ and evaporating the solvent gave $1 \mathrm{~g}$ of diacetate 86 as the only product ( $42 \%$ yield). NMR $\left(\mathrm{CDCl}_{3}\right): \delta 1.5-1.8(\mathrm{~m}, 8 \mathrm{H}), \delta 1.9(\mathrm{~s}, 3 \mathrm{H}), \delta 2.0(\mathrm{~s}$, $3 \mathrm{H}), \delta 2.3(\mathrm{~s}, 3 \mathrm{H}), \delta 3.2(\mathrm{~m}, 1 \mathrm{H}), \delta 4.5(\mathrm{~m}, 1 \mathrm{H})$. 
6.17 Preparation of Sulfur Trioxide-Pyridine Complex ${ }^{58}$ :

In a $250 \mathrm{~mL}$ erlenmeyer flask, cooled in an ice bath $12.3 \mathrm{~mL}$ of sulfur trioxide $(0.3 \mathrm{~mol})$ were dissolved in $40 \mathrm{ml}$ of carbon tetrachloride. To this stirred mixture, $24 \mathrm{~mL}$ of $(0.3 \mathrm{~mol})$ dry pyridine were added slowly. The crystalline product that separated out was collected and washed with $5 \mathrm{~mL}$ of ice cold water to remove traces of pyridine and sulfuric acid. The compound was dried under vacuum for $6 \mathrm{hrs}$. Yield $37 \mathrm{~g}(78 \%)$. ๘.p. $172-175^{\circ} \mathrm{C}$.

\section{Notes:}

1. Sulfur trioxide-pyridine complex is commercially available.

2. Sulfur trioxide used was from a freshly opened bottle.

6.18 0xidation of 1-Hydroxymethyl-3B-acetoxytropane by Dimethyl

Sulfoxide in Presence of Pyridine-Sulfur Trioxide Complex:

To a solution of $2.00 \mathrm{~g}(0.0094 \mathrm{~mol})$ of alcohol $\underline{55}$ in $20 \mathrm{~mL}$ of dry DMSO and $14 \mathrm{~mL}$ of dry triethylamine $(11 \times 0.0094 \mathrm{~mol})$ was added, a solution of $7.5 \mathrm{~g}$ of $\mathrm{py}^{-\mathrm{SO}_{3}}(5 \times 0.0094 \mathrm{~mol})$ complex in 20 al of dry DMSO (exothermic reaction). The mixture was stirred at $23^{\circ} \mathrm{C}$ for $12 \mathrm{hrs}$. After this period, triethyl amine was removed on rotovap and dimethyl sulfoxide by vacuum distillation. 
To the residue, water was added and $\mathrm{pH}$ adjusted to 3 with diluted HC1. Extraction with ethyl acetate removed the side products.

The aqueous layer was basified with dilute ammonium hydroxide $(\mathrm{pH}=10)$ and extracted with chloroform. Evaporation of chloroform gave $0.7 \mathrm{~g}(35 \%)$ of aldehyde 56.

The ${ }^{1} H$ NMR and IR spectra are superimposable with those of aldehyde $\underline{56}$ obtained from previous methods (cf section 6.13).

\subsection{Preparation of n-Butyl triphenyl phosphonium bromide (98):}

In a $100 \mathrm{~mL}$ r.b. flask equipped with a condenser, $10.0 \mathrm{~g}$ of triphenyl ( $0.038 \mathrm{~mol})$ and $30 \mathrm{~mL}$ of 1 -bromobutane $(8 \times 0.038 \mathrm{~mol})$ were dissolved in $10 \mathrm{~mL}$ of dry benzene. The mixture was magnetically stirred and heated to reflux for $8 \mathrm{hr}$. A white solid precipitated out during that time. It was collected on a Buchner funnel. The solid was washed with $20 \mathrm{~mL}$ of dry benzene. It was then dried under vacuum for $6 \mathrm{hr}$ to give $12 \mathrm{~g}(79 \%)$ of white powder. m.p. $233-235^{\circ} \mathrm{C}$.

Mass spectrum $(70 \mathrm{eV}): \mathrm{m} / \mathrm{e} 319.1\left(\mathrm{M}^{+}-\mathrm{HBr}\right), 289.1$ (base peak), $262.1,199.1,183.1,152.1,108.1,91.4,65.0,57.0$. 
6.20 Wittig condensation of aldehyde 56, with

n-butylidene triphenylphosphorane: Preparation of

1-Pentyl-3B-hydroxytropane (14):

A 3-necked flask was equipped with a reflux condenser, a septum, addition funnel and nitrogen adapter, and a stirring bar. $5.45 \mathrm{~g}$ of n-butyl triphenylphosphonium bromide $(1.6 \times 0.008 \mathrm{~mol})$ was dissolved in $25 \mathrm{~mL}$ dry tetrahedrofuran and ultimately $8 \mathrm{~mL}$ of a $1.6 \mathrm{M}$ n-butyllithium solution in tetrahydrofuran ( $1.5 \mathrm{x}$ $0.0085 \mathrm{~mol}$ ) was added dropwise via syringe. A deep red color developed. The mixture was stirred at $20^{\circ}$ for 30 min. It was refluxed for $45 \mathrm{~min}$. Then $1.8 \mathrm{~g}$ of aldehyde $\underline{10}(0.0085 \mathrm{~mol})$ in $25 \mathrm{~mL}$ dry tetrahydrofuran was added dropwise and the mixture refluxed for $40 \mathrm{hr} .10 \mathrm{~mL}$ of water added dropwise at $0^{\circ}$, followed by $10 \mathrm{~mL}$ of dil. hydrochloric acid and the mixture stirred for $30 \mathrm{~min}$. The solvent was evaporated in a rotavapor and the pH was adjusted to 2 with dil. hydrochloric acid. $100 \mathrm{~mL}$ water was added and the water layer was extracted with $500 \mathrm{~mL}$ benzene followed by $500 \mathrm{~mL}$ ether to remove triphenylphosphine oxide. The aqueous layer was made alkaline (pH 10) with dil. ammonium hydroxide and extracted with ether. The ethereal layer was washed with water and saturated sodium chloride solution. Drying ( $\left.\mathrm{Na}_{2} \mathrm{SO}_{4}\right)$, followed by evaporation in vacuo gave $1.78 \mathrm{~g}$ of a crude liquid. This was purified on a column of silica gel. Pure 1-(1-penteny 1$)-3 B$-hydroxytropane $(14)$ was eluted with methanol and $1 \%$ ammonium hydroxide solution. Yield $0.9 \mathrm{~g}(50 \%)$. The TLC of the product 14 gave one spot: Rf $\left(\mathrm{CHCl}_{3}\right): 0.39$. 
$\operatorname{NMR}\left(\mathrm{CDCl}_{3}\right): \delta 0.9\left(\mathrm{t}, 3 \mathrm{H}, \mathrm{CH}_{3}\right), \delta 1.2-2.1(\mathrm{~m}, 12 \mathrm{H}), \delta 2.3$ $\left(\mathrm{s}, 3 \mathrm{H}, \mathrm{N}-\mathrm{CH}_{3}\right), \delta 3.3(\mathrm{~m}, 1 \mathrm{H}), \delta 3.8-4.1(\mathrm{~m}, 1 \mathrm{H}), \delta 4.3$ (br s,

1H, exchangeable with $\left.\mathrm{D}_{2} \mathrm{O}\right), \delta 5.3(\mathrm{~m}, 2 \mathrm{H}, \mathrm{C}=\mathrm{C})$.

IR (film): 3200 (br, OH), 2900,1680 (m), 1400, 1200,675

(cis alkene).

Mass spectrum: m/e $208.9\left(\mathrm{M}^{+}\right), 191.8,179.8,163.8,149.8$

(base peak), $135.8,121.8,109.8,95.8,80.8,67.8,54.8$.

${ }^{13} \mathrm{C}$ NMR $\left(\mathrm{CDCl}_{3}\right): 132.98,131.25,66.0,63.69,60.33,57.28$, $42.58,36.63,34.65,34.08,33.71,30.91,27.55,23.70,18.8$, 13.8 .

Anal. Caled. for $\mathrm{C}_{13}{ }^{\mathrm{H}} 23^{\mathrm{NO}}$ : C, 74.64; $\mathrm{H}, 11.00 ; \mathrm{N}, 6.69$.

Found: $\mathrm{C}, 74.03 ; \mathrm{H}, 10.24 ; \mathrm{N}, 6.69$.

\section{Notes:}

1. The deep red color of the ylide solution starts getting lighter as soon as aldehyde is added. The color change is almost like a titration. At the end of the addition, the solution turns light yellow.

2. Triphenyl phosphine oxide is extremely soluble in benzene. It is advantageous to extract the aqueous layer with as much benzene as possible. Since the amine is in the aqueous layer as an amine salt, which is insoluble in benzene, there is no danger of losing it to benzene or ether.

3. When chloroform was used in the final extraction of the free amine, unidentifable phosphorus-containing side products 
were obtained. However when ether was used, the crude product was essentially pure.

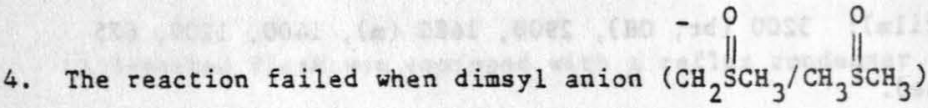
generated from sodium hydride and DMSO was used as base instead of n-butyl lithium. The reason for this failure is not clear.

5. Attempted preparation of crystalline hydrochloride or hydrobromide of the amine $\underline{14}$ gave only oils.

\subsection{Preparation of 1-(1-Penteny 1$)-3$-acetoxytropane (103):}

Same procedure as in 6.20 was used except only 1.4 eq of Wittig salt and 1.3 eq of n-butyl lithium were used for 1 eq of aldehyde. The reaction was carried out at $23^{\circ} \mathrm{C}$ for $40 \mathrm{hr}$. The crude was purified by chromatography on silica gel ( $84 \% \mathrm{CHCl}_{3}+$ $\left.15 \% \mathrm{MeOH}+12 \mathrm{NH}_{4} \mathrm{OH}\right)$ to give $\underline{103}$ as a light yellow colorless liquid. Yield $1.0 \mathrm{~g}(50 \%)$.

$\operatorname{MMR}\left(\mathrm{CDCl}_{3}\right): \delta 0.9(\mathrm{t}, 3 \mathrm{H}), \delta 1.5-2.0(\mathrm{~m}, 15 \mathrm{H}), \delta 2.3(\mathrm{~s}$, $3 \mathrm{H}), \delta 3.3(\mathrm{~m}, 1 \mathrm{H}), \delta 4.9(\mathrm{~m}, 1 \mathrm{H})$, and $55.5(\mathrm{~m}, 2 \mathrm{H})$. 
Notes:

1. The amounts of Wittig salt and n-butyl lithium used are the minimum amounts required for the reaction to go to completion. Using lower amounts ( 1.3 eq Wittig salt and 1.2 eq of n-butyllithium), left some starting aldehyde unreacted.

2. Although the yields were only $50 \%$, the crude product mixture did not show any unreacted aldehyde.

\subsection{Deacetylation of $1-(1$-pentenyl $)-38$-acetoxytropane}

Acetate $103(0.8 \mathrm{~g}, 0.0032 \mathrm{~mol})$ was dissolved in $50 \mathrm{~mL}$ of anhydrous methanol and $4.5 \&(10 \times 0.003 \mathrm{~mol})$ of anhydrous $\mathrm{R}_{2} \mathrm{CO}_{3}$ were added and the mixture stirred at $23^{\circ} \mathrm{C}$ for $10 \mathrm{hr}$. At the end of this period, the solids were filtered, methanol evaporated and pH adjusted to 2 by dilute hydrochloric acid. Then $25 \mathrm{~mL}$ of water was added and the aqueous layer extracted with ether. The water layer was basified with diluted $\mathrm{NH}_{4} \mathrm{OH}$ and extracted with chloroform. Evaporation of chloroform gave a crude oil which was purified by silica gel chromatography (methanol $+1 \% \mathrm{NH}_{4} \mathrm{OH}$ ).

The desired compound was obtained $0.5 \mathrm{~g}(75 \%)$ as a 1 ight yellow oil.

$1_{\mathrm{H} N M R}\left(\mathrm{CDCl}_{3}\right): \hat{0} 0.9(\mathrm{t}, 3 \mathrm{H}), \delta 1.2-2.1(\mathrm{~m}, 12 \mathrm{H})$, ก 2.3 $(\mathrm{s}, 3 \mathrm{H}), \delta 3.3(\mathrm{~m}, 1 \mathrm{H}), \delta 3.8-4.1(\mathrm{~m}, 1 \mathrm{H}), \delta 4.3$ (br s, $1 \mathrm{H}$, 
exchangeable with $\left.\mathrm{D}_{2} \mathrm{O}\right), \delta 5.3(\mathrm{~m}, 2 \mathrm{H})$.

IR (neat): $3200(\mathrm{br}, \mathrm{OH}), 2900,1680$ (m), $1400,1200,600$.

Notes:

The ${ }^{1}$ H NMR and IR spectra of this compound obtained from this two-step procedure were superimposable to the spectra obtained from the one-step procedure.

6.23 Addition of n-Butyllithium to 3B-Acetoxytropane-1-aldehyde.

In a two-necked $100 \mathrm{~mL}$ r.b. flask equipped with a condenser, septum, and magnetic stirrer, $1.2 \mathrm{z}(0.0056 \mathrm{~mol})$ of aldehyde 56 in $50 \mathrm{~mL}$ of ether was dissolved. Then $21.3 \mathrm{~mL}(6 \times 0.0056 \mathrm{~mol})$ of $1.6 \mathrm{M}$ solution of $\mathrm{n}$-butyl lithium in hexane added via syringe. The mixture was heated to reflux under $N_{2}$ for $12 \mathrm{hr}$. Then it was cooled, poured onto ice and made acidic $(\mathrm{pH}=2)$ with diluted BC1. The aqueous layer was extracted with ether $(2 \times 50 \mathrm{~mL})$ to remove non-nitrogenous side products. The aqueous layer was made alkaline with dilute ammonium hydroxide. It was then extracted with chloroform and chloroform evaporated. The residue was dried under vacuum to give $0.6 \mathrm{~g}(47 \%)$ of crude diol 118 .

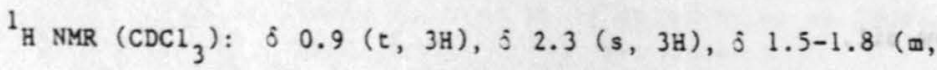
$14 \mathrm{H}), \delta 3.3(\mathrm{~m}, 1 \mathrm{H}), \delta 3.9-4.2(\mathrm{~m}, 2 \mathrm{H})$. 


\subsection{Preparation of Potassium Azo Dicarboxylate:}

This compound was prepared according to the procedure by Curry. ${ }^{88}$

\subsection{Attempted Diimide Reduction of Alkene 14:}

In a three necked $100 \mathrm{~mL}$ r.b. flask equipped with a condenser, $\mathrm{N}_{2}$ adapter, mechanical stirrer, $2.3 \mathrm{~g}$ of potassium azocarboxylate $(3 \times 0.004 \mathrm{~mol})$ were suspended in $10 \mathrm{~mL}$ of absolute methanol. To this slurry, $0.8 \mathrm{~g}$ of alkene 14 in $10 \mathrm{~mL}$ of absolute methanol were added. Then $1.6 \mathrm{~mL}$ of glacial acetic acid was added dropwise. The mixture stirred at r.t. for $14 \mathrm{hrs}$ after which 10 mi of acetic acid and $30 \mathrm{~mL}$ of water were added. The mixture was poured into diluted $\mathrm{NH}_{4} \mathrm{OH}(\mathrm{pH}=11)$. Extraction with ether, followed by drying $\left(\mathrm{Na}_{2} \mathrm{SO}_{4}\right)$ and evaporation the solvent left $0.75 \mathrm{~g}$ ( $90 \%$ recovery) of unreacted starting alkene 14.

6.26 Preparation of $( \pm)$ 1-n-amy1-3B-tropanol $(15)$ :

$$
\text { 1-penteny 1-38-tropanol (14) }(0.75 \mathrm{~g}, 0.0036 \text { mol) was }
$$

dissolved in $50 \mathrm{~mL}$ of absolute methanol and $1 \mathrm{~g}$ of Raney nickel (W-2) was added. The mixture was hydrogenated at 2 atm for 3 hrs. Filtration of the catalyst followed by evaporation of the solvent left $0.7 \mathrm{~g}(93 \%)$ of $( \pm) 1-n$-amyl-3B-tropanol (15) as a 
light yellow oil.

$1_{\mathrm{H} N M R}\left(\mathrm{CDCl}_{3}\right): \delta 0.9(t, 3 \mathrm{H}), \delta 1.5-2.1(\mathrm{~m}, 19 \mathrm{H}), \delta 2.5$ $(\mathrm{s}, 3 \mathrm{H}), \delta 3.4-3.6(\mathrm{~m}, 2 \mathrm{H}), \delta 6.5$ (br $\mathrm{s}, 1 \mathrm{H}$, exchangeable with $\left.D_{2} 0\right)$.

Mass spectrum $(20 \mathrm{eV}): \mathrm{m} / \mathrm{e} 211.2\left(\mathrm{M}^{+}\right), 194.2,182.1,166.1$, $152.1,138.1,126.1,111.1,96.1$ (base peak), $82.0,67.0$.

\subsection{Preparation of $( \pm)$ 1-n-amyl-3B-tropanol hydrochloride $(\underline{122})$ :}

Through the solution of amine (15) in $20 \mathrm{ml}$ of dry chloroform, dry hydrogen chloride gas was bubbled through until the solution was acidic. Evaporation of the solvent left a foam which turned into a fine powder. m.p. $139-142^{\circ} \mathrm{C}$.

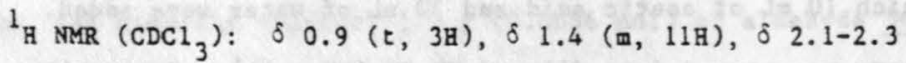
$(m, 8 \mathrm{H}), \delta 2.9$ (d, 3H), $\delta 3.9$ (br m, 1H).

Anal. Calcd. for $\mathrm{C}_{13} \mathrm{H}_{26}$ C1NO: C, 63.03 ; $\mathrm{H}, 10.50, \mathrm{~N}, 5.60$. Found: $\mathrm{C}, 62.20$; H, $10.48 ; \mathrm{N}, 5.53$.

\subsection{Preparation of 4-Trimethylsilyl but-3yn-10l (143):}

In a three-necked 100 mL r.b. flask, equipped with a condenser, $\mathrm{N}_{2}$ adapter, low-temperature thermometer, and a septum, $45 \mathrm{ml}(2 \times 0.045 \mathrm{~mol})$ of ethyl magnesium bromide ( 2 M solution in THF) in $15 \mathrm{~mL}$ of dry tetrahydrofuran was cooled to $-10^{\circ} \mathrm{C}$ with ice-salt bath. $3 \mathrm{~g}(0.043 \mathrm{~mol})$ of 3 -butyn-1-01 was added 
dropwise via syringe. After stirring for $1.5 \mathrm{hr}$ below $0^{\circ} \mathrm{C}$, the cooling bath was removed and the mixture was heated to $50^{\circ} \mathrm{C}$ for 1 $\mathrm{hr}$. It was then stirred at $23^{\circ} \mathrm{C}$ for $12 \mathrm{hr}$. At the end of this period, $80 \mathrm{~mL}$ of saturated ammonium chloride solution was added. Extraction with ether, followed by evaporation of ether left an oily residue, which was stirred with $10 \mathrm{~mL}$ of $95 \%$ ethanol and 3 drops of conc. hydrochloric acid for $1 \mathrm{hr}$. The solution was then extracted with ether, washed with $10 \%$ sodium carbonate solution, dried $\left(\mathrm{Na}_{2} \mathrm{SO}_{4}\right)$ and evaporated. The resulting oil was distilled under vacuum (water aspirator). b.p. $87-89^{\circ} \mathrm{C}$. Yield $5.4 \mathrm{~g}$ (91\%). Clean, colorless oil.

$1_{\mathrm{H} \mathrm{NMR}}\left(\mathrm{CDCl}_{3}\right): \delta 0.9(\mathrm{~s}, 9 \mathrm{H}), \delta 2.3(\mathrm{t}, 2 \mathrm{H}), \delta 3.5(\mathrm{q}$, 2H), $\delta 4.3(t, 1 \mathrm{H})$.

IR (neat): $3400,3000,2100,1410,1250,1170,900,850$, $750 \mathrm{~cm}^{-1}$.

Notes:

1. When Jones procedure 102 was followed the gields dropped down to $50 \%$.

2. Commercially available (Aldrich) ethylmagnesium bromide tends to precipitate out from the tetrahydrofuran solution in the bottle. More tetrahydrofuran was added to the bottle to dissolve the reagent before transferring it to the reaction pot. 
3. When allylmagnesium chloride was used instead of echylmagnesium bromide, the yields dropped down to $84 \%$.

\subsection{Tosylation of 4-trimethylsilyl but-3yn-101:}

Freshly-distilled 4-trimethylsilyl but-3yn-1ol ( 143 ),

$(5.0 \mathrm{~g}, 0.035$ moles) was dissolved in $50 \mathrm{~mL}$ of dry, freshly distilled pyridine in a $100 \mathrm{~mL}$ one-necked r.b. flask. The mixture was stirred and cooled below $0^{\circ} \mathrm{C}$ in ice-salt bath. $7.4 \mathrm{~g}$ $(0.039 \mathrm{~mol})$ of $p$-toluene sulfonyl chloride was added in one portion and the mixture stirred for $2 \mathrm{hr}$ at $0^{\circ} \mathrm{C}$. It was then poured onto $50 \mathrm{~mL}$ of cold water. Extraction with ether followed by washing with $10 z$ sodium carbonate solution and evaporation of ether left crude cosylate $(\underline{146})$ as a colorless oil. It was used in the next step without any purification. Yield $10.1 \mathrm{~g}(98 \%)$.

$1_{\mathrm{H} \operatorname{MMR}}\left(\mathrm{CDCl}_{3}\right): \delta 0.1(\mathrm{~s}, 9 \mathrm{H}), \delta 2.3-2.5(\mathrm{~m}, 5 \mathrm{H}), \delta 4.0(\mathrm{t}$, $2 \mathrm{H}), \delta 7.2(\mathrm{~d}, 2 \mathrm{H}), \delta 7.8(\mathrm{~d}, 2 \mathrm{H})$.

\subsection{Displacement of Tosylate 146 by Iodide:}

Tosylace $\underline{146}(18.6 \mathrm{~g}, 0.063 \mathrm{~mol})$ and $47 \mathrm{~g}(5 \times 0.063 \mathrm{~mol})$ were dissolved in $500 \mathrm{~mL}$ of dry acetone. The mixture was brought to reflux and kept there for $48 \mathrm{hr}$. It was then cooled to $23^{\circ} \mathrm{C}$, acetone evaporated and $300 \mathrm{~mL}$ of water was added. Extraction with methylene chloride followed by drying $\left(\mathrm{CaCl}_{2}\right)$ and 
evaporation gave a crude oil which was distilled under vacuum (b.p. $73^{\circ} \mathrm{C}$ at $0.04 \mathrm{~mm}$ ) to give $14.2 \mathrm{~g}(90 \%)$ of iodide 144 .

${ }^{1} \mathrm{H}$ NMR $\left(\mathrm{CDCl}_{3}\right): \delta 0.1(\mathrm{~s}, 9 \mathrm{H}), \delta 2.5(\mathrm{t}, 2 \mathrm{H}), \delta 3.2(\mathrm{t}, 2 \mathrm{H})$. IR (neat): $3000,2200,1410,1250,1170,900,850,750 \mathrm{~cm}^{-1}$.

Notes:

1. The displacement of the tosylate by iodide occurs very slowly at zoom temperature.

6.31 Preparation of Triphenyl (1-Trimethyl silyl but-3-yn1) phosphonium iodide (138):

Iodide $138(7 \mathrm{~g}, 0.028 \mathrm{~mol})$ in $50 \mathrm{mi}$ of dry benzene was mixed with $7.25 \mathrm{~g}(0.028 \mathrm{~mol})$ of triphenylphosphine and the mixture refluxed for $68 \mathrm{hrs}$. A heavy oily layer separated out. The mixture was cooled, the layers separated and the bottom layer extracted with benzene $(2 \times 50 \mathrm{~mL})$ to remove unreacted starting materials. The bottom layer was dried under vacuum to remove any traces of benzene. Addition of anhydrous ether resulted in a white foam, which was dried on a freeze dryer. It was crushed to a fine powder. m.p. $132-133^{\circ} \mathrm{C}$. Yield $13.9 \mathrm{~g}$ (95\%). 


\subsection{Preparation of 3-Butynyl tosylate:}

A solution of $45.6 \mathrm{~g}(1.2 \times 0.2 \mathrm{~mol})$ of $\mathrm{p}$-toluene sulfonyl chloride in $31 \mathrm{~mL}(1.3 \times 0.1 \mathrm{~mol})$ of $2,6-1$ utidine was placed in a 3-necked $250 \mathrm{~mL}$ r.b. flask equipped with a low-temperature thermometer and $\mathrm{N}_{2}$ adapter. The mixture was cooled in an ice bath. $14 \mathrm{~g}(0.2 \mathrm{~mol})$ of 3 -butyn-1-ol was added dropwise. The ice bath was removed and the mixture stirred magnetically for 18 hr. The mixture was then poured into $100 \mathrm{~mL}$ water. It was then extracted with $300 \mathrm{~mL}$ of ether. The ether layer was then washed with $10 \%$ sulfuric acid (to remove traces of lutidine), followed by $10 \%$ sodium bicarbonate, water and saturated salt solution. Evaporative removal of ether left $38.3 \mathrm{~g}(81 \%)$ of tosylate 158 , which was purified by silica gel chromatography ( $80 \%$ pet. ether * $20 \%$ ethyl acetate).

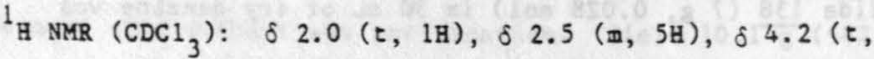
$2 \mathrm{H}), \delta 7.4(\mathrm{~d}, 2 \mathrm{H}), \delta 7.9(\mathrm{~d}, 2 \mathrm{H})$.

For attempted displacement of tosylate $\underline{158}$ by halide ions, see Table II.

\subsection{Preparation of 1-Bromo-3-buryne (152):}

In a 3-necked $250 \mathrm{~mL}$ r.b. flask equipped with a mechanical stirter, low-temperature thermometer, addition funnel with $\mathrm{N}_{2}$ adapter, $35 \mathrm{~g}(0.4993 \mathrm{~mol})$ of but-3yn-101 and $4 \mathrm{~mL}(0.49 \mathrm{~mol})$ of dry pyridine were stirred. The temperature was maintained 


\section{Table II}

Attempted displacement of tosylate 153 by iodide, bromide and chloride

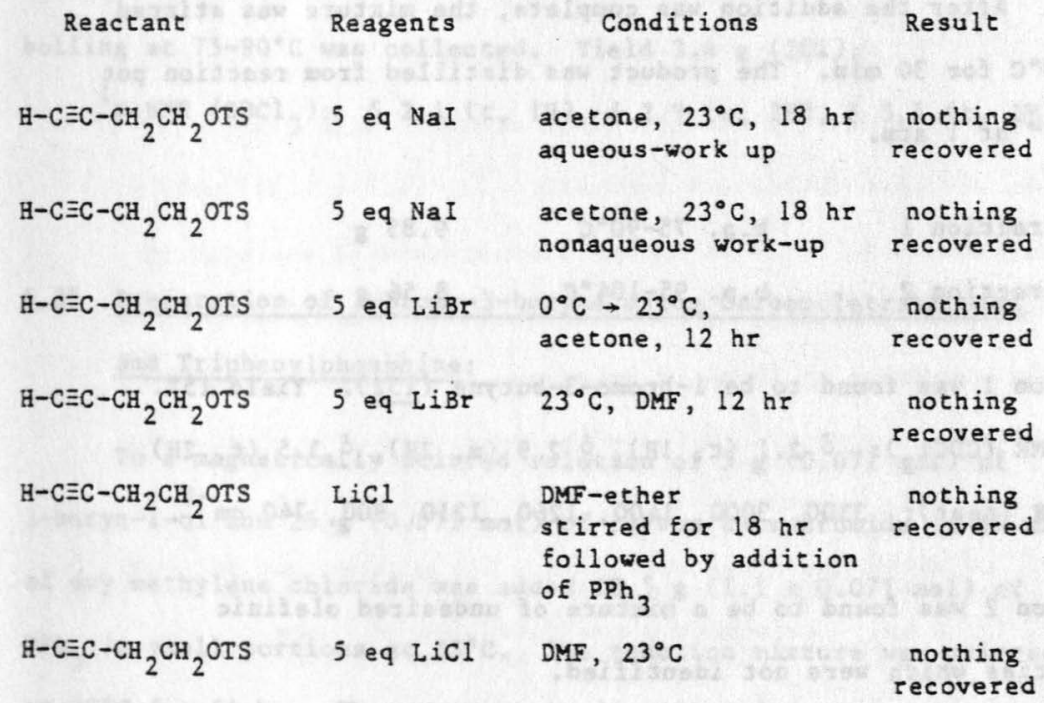


between $-20^{\circ} \mathrm{C}$ and $-10^{\circ} \mathrm{C}$ with acetone/1iq. $\mathrm{N}_{2}$ bath. A solution of $16.6 \mathrm{~mL}(1 / 3 \times 0.49 \mathrm{~mol})$ of $\mathrm{PBr}_{3}$ in $20 \mathrm{~mL}$ of anhydrous ether added dropwise. The temperature was maintained between $-20^{\circ} \mathrm{C}$ and $-15^{\circ} \mathrm{C}$. After the addition was complete, the mixture was stirred at $-20^{\circ} \mathrm{C}$ for $30 \mathrm{~min}$. The product was distilled from reaction pot "as is" at $1 \mathrm{~atm}$.

$\begin{array}{lll}\text { Fraction } 1 & \text { b.p. } 75-90^{\circ} \mathrm{C} & 9.85 \mathrm{~g} \\ \text { Fraction } 2 & \text { b.p. } 95-104^{\circ} \mathrm{C} & 8.56 \mathrm{~g}\end{array}$

Fraction 1 was found to be 1-bromo-3-butyne (152). Yield $15 \%$. $\operatorname{NMR}\left(\mathrm{CDCl}_{3}\right): \delta 2.1(t, 1 \mathrm{H}), \delta 2.9(\mathrm{~m}, 2 \mathrm{H}), \delta 3.5(t, 2 \mathrm{H})$. IR (neat): $3300,3000,1400,1260,1210,900,740 \mathrm{~cm}^{-1}$.

Fraction 2 was found to be a mixture of undesired olefinic impurities which were not identified.

6.34 Attempted improvement of yields of $\mathrm{PBr}_{3}$ reaction: use of $\underline{\mathrm{LiBr}}$ as co-reactant:

In a 3-necked $250 \mathrm{~mL}$ r.b. flask equipped with a mechanical stirter, low-temperature thermometer and $\mathrm{N}_{2}$ adapter, a mixture of $15 \mathrm{~g}(0.21 \mathrm{~mol})$ of 3-butyn-1-01, $20 \mathrm{~mL}$ of anhydrous ether, $18 \mathrm{~mL}$ $(1.5 \times 0.21 \mathrm{~mol})$ of 2,6 -lutidine and $36.8 \mathrm{~g}(2 \times 0.21 \mathrm{~mol})$ of anhydrous lithium bromide was cooled to $-40^{\circ} \mathrm{C}$. Then $10 \mathrm{~mL}(0.5 \mathrm{x}$ $0.21 \mathrm{~mol}$ ) of phosphorous tribromide was added dropwise. The mixture was warmed to $0^{\circ} \mathrm{C}$, stirred at $23^{\circ} \mathrm{C}$ for $2 \mathrm{hr}$ and $0^{\circ} \mathrm{C}$ 
after which 15 mL of 2,6-lutidine were added. The mixture was poured onto water, layers separated. The organic layer was dried over $3 \AA$ molecular sieves and distilled at 1 atm. The fraction boiling at $75-90^{\circ} \mathrm{C}$ was collected. Yield $3.4 \mathrm{~g}(10 \mathrm{z})$.

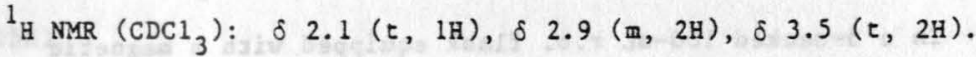

\subsection{Preparation of 1-Bromo-3-butyne using Carbon Tetrabromide} and Triphenylphosphine:

To a magnetically stirred solution of $5 \mathrm{~g}(0.071 \mathrm{~mol})$ of 3-butyn-1-ol and $26 \mathrm{~g}(0.071 \mathrm{~mol})$ of carbon tetrabromide in $50 \mathrm{~mL}$ of dry methylene chloride was added $20.5 \mathrm{~g}(1.1 \times 0.071 \mathrm{~mol})$ of $\mathrm{PPh}_{3}$ in small portions at $23^{\circ} \mathrm{C}$. The reaction mixture was stirred at $23^{\circ} \mathrm{C}$ for $24 \mathrm{hr}$. The product was distilled from the reaction pot.

Fraction $140-60^{\circ} \mathrm{C}$ (mainly methylene chloride)

Fraction $2 \quad 65-85^{\circ} \mathrm{C}$ (fairly pure)

Fraction $390-110^{\circ} \mathrm{C}$ (impure, contains olefinic compounds)

Fraction 2 was redistilled to give $1.5 \mathrm{~g}(15 \%)$ of 1-bromo-3-butyne. b.p. $75-90^{\circ} \mathrm{C}$ at 1 atm.

${ }^{1} \mathrm{H}$ NMR $\left(\mathrm{CDCl}_{3}\right): \delta 2.0(t, 1 \mathrm{H}), \delta 2.9(\mathrm{~m}, 2 \mathrm{H}), \delta 3.5(t$, 2H). 
6.36 Attempted Preparation of 1-Bromo-3-butyne by utilizing

N-bromosuccinimide/triphenyl phosphine as brominating

reagents:

In a 3-necked 100-mi r.b. flask equipped with a magnetic stirter, addition funnel and condenser, $7 \mathrm{~g}(1.1 \times 0.357 \mathrm{~mol})$ of $\mathrm{N}$-bromosuccinimide in 40 mL of dry tetrahydrofuran was stirred under nitrogen. A solution of $10.25 \mathrm{~g}(1.1 \times 0.357 \mathrm{~mol})$ of triphenylphosphine in $20 \mathrm{~mL}$ of anhydrous ether added dropwise. An exothermic reaction occurred with separation of a solid. To this suspension, a solution of $2.5 \mathrm{~g}(0.3566 \mathrm{~mol})$ of 3-butyn-101 in $10 \mathrm{~mL}$ of anhydrous ether was added. The mixture was stirred at $23^{\circ} \mathrm{C}$ for $6 \mathrm{hr}$. The compound was distilled at $1 \mathrm{~atm}$, b.p. $75-88^{\circ} \mathrm{C}$. Yield $2 \mathrm{~g}$.

${ } \mathrm{B}$ NMR indicates this compound to be a mixture of olefins. There was no evidence for acetylinic protons. The structure of the olefin was not determined.

$$
\operatorname{MMR}\left(\mathrm{CDCl}_{3}\right): \delta 1.9(\mathrm{~m}), \delta 3.3(\mathrm{~m}), \delta 5.2-6.9(\mathrm{~m}) \text {. }
$$

\subsection{Preparation of triphenyl(but-3-yn1) phosphonium bromide 149 :}

In a one-necked $250 \mathrm{~mL}$ r.b. flask equipped with a magnetic stirrer and condenser, $9.85 \mathrm{~g}(0.074 \mathrm{~mol})$ of 1-bromo-3-butyne and $29.48(1.5 \times 0.074 \mathrm{~mol})$ of $\mathrm{PPh}_{3}$ were dissolved in $100 \mathrm{~mL}$ of dry benzene. The mixture was heated to reflux for $24 \mathrm{hr}$. Two layers were formed. The top layer was decanted. The heavier 
bottom layer was extracted with $100 \mathrm{~mL}$ of benzene to remove any unreacted starting material. The bottom layer was kept under vacuum. A yellow solid $4.5 \mathrm{~g}(15 \%)$ was obtained.

$1_{\mathrm{H} N M R}\left(\mathrm{CDCl}_{3}\right): \delta 2.0(\mathrm{~m}, 1 \mathrm{H}), \delta 2.8-2.9(\mathrm{~m}, 4 \mathrm{H}), \delta 7.9-8.0$ $(m, 15 \mathrm{H})$.

6.38 Attempted preparation of triphenyl(but-3-ynl) phosphonium tosylate:

In a $250 \mathrm{~mL}$ one-necked $\mathrm{I} . \mathrm{b}$. flask equipped with a magnetic stirrer and condenser $5 \mathrm{~g}(0.026 \mathrm{~mol})$ of but-3-ynl tosylate and $21 \mathrm{~g}(3 \times 0.026 \mathrm{~mol})$ of tripheny 1 phosphine in $100 \mathrm{~mL}$ of benzene were dissolved. The mixture was stirred at $23^{\circ} \mathrm{C}$ for $5 \mathrm{hr}$ and later on heated to reflux for $48 \mathrm{hr}$. Later it was cooled to $23^{\circ} \mathrm{C}$, solvent evaporated. An oil was obtained which was repeatedly washed with anhydrous ether $(500 \mathrm{~mL})$ to give $2.8 \mathrm{~g}$ of a solid which was identified as the phenyl phosphonine oxide based on its melting point, ${ }^{1} \mathrm{H}$ NMR spectrum and mass spectrum. m.p. $153-155^{\circ} \mathrm{C}$.

$\operatorname{NMR}\left(\mathrm{CDCl}_{3}\right): \quad \delta 7.2-7.9(\mathrm{~m})$.

Mass spectrum: m/e $277.69\left(\mathrm{M}^{+}\right), 262.1,201.1,183.0,170.0$, $152.1,128.0,95.0,77.0,55.8$.

The molecular ion 277.69 correspond to triphenyl phosphine oxide $\left(\mathrm{PPh}_{3} \rightarrow 0\right.$, mol. wt. $\left.=278\right)$. 
Notes:

1. Both the ${ }^{1} H M M$ and mass spectrum indicate that the only isolated product is $\mathrm{PPh}_{3} \rightarrow 0$.

2. At no stage during the reaction, there was a separation of two layers. This indicates that the desired phosphonium salt is not formed. One would expect the phosphonium salt to be insoluble in benzene.

6.39 Attempted Wittig condensation of neopentyl aldehyde $\underline{56}$ with triphenyl ( $1-t r i m e t h y l s i l y l$ but-3-ynl) phosphonium iodide (138):

\section{a. Potassium tert-butoxide:}

In a one-necked $50 \mathrm{~mL}$ r.b. flask equipped with a side-arm with septum, $4.5 \mathrm{~g}(1.3 \times 0.007 \mathrm{~mol})$ of tripheny 1 (1-trimethyl silyl but-3-ynl) phosphonium iodide (138) was suspended in $30 \mathrm{~mL}$ of dry tetrahydrofuran and cooled to $0^{\circ} \mathrm{C}$ with an ice bath. To this magnetically stirred suspension, a solution of $1 \mathrm{~g}(1.3 \times 0.07 \mathrm{~mol})$ of potassium butoxide in $10 \mathrm{~mL}$ of dry tetrahydrofuran added via syringe. A brick red color developed very slowly. The mixture was stirred at $0^{\circ} \mathrm{C}$ for $1 \mathrm{hr}$ and at $23^{\circ} \mathrm{C}$ for 2 hrs. To this ylide solution, $1.5 \mathrm{~g}(0.007 \mathrm{~mol})$ of aldehyde $\underline{56}$ in $10 \mathrm{~mL}$ of dry tecrahydrofuran was added via syringe. The mixture stirred at $23^{\circ} \mathrm{C}$ for $80 \mathrm{hr}$. After this period, $20 \mathrm{~mL}$ of 
water was added. Tetrahydrofuran was removed by evaporation. Addition of dilute hydrochloric acid and extraction of the resulting acidic ( $\mathrm{pH}=3$ ) solution with benzene was done to remove non-nitrogenous side products. The aqueous layer was adjusted to $\mathrm{pH} 10$ by dilute ammonium hydroxide and extracted three times with ether. The combined ether layers were dried $\left(\mathrm{Na}_{2} \mathrm{SO}_{4}\right)$ and evaporated to give $1.2 \mathrm{~g}$ of unreacted aldehyde $\underline{56}$ ( $80 \%$ recovery).

Notes:

1. The brick red color of ylide did not change even after $80 \mathrm{hr}$.

\section{b. $\mathrm{NaOH}$ as base:}

In a one-necked $50 \mathrm{~mL}$ r.b. flask equipped with a side arm for septum, $0.37 \mathrm{~g}(1.3 \times 0.007 \mathrm{~mol})$ of $59 \%$ sodium hydride (suspension in mineral oil) was taken. Dry pentane was added and after stirring for a few min., pentane was removed. $30 \mathrm{~mL}$ of dry tetrahydrofuran was added. To this $4.5 \mathrm{~g}$ of phosphonium salt 138 in $30 \mathrm{~mL}$ of dry tetrahydrofuran added dropwise at $0^{\circ} \mathrm{C}$. To this suspension, the aldehyde $\underline{56}$ in $10 \mathrm{~mL}$ of tetrahydrofuran was added via a syringe. The mixture was allowed to warm to $23^{\circ} \mathrm{C}$ and stirred for $60 \mathrm{hr}$. The reaction was worked up in the same way 
as the previous experiment. $1.2 \mathrm{~g}$ ( $80 \%$ recovery) of unreacted aldehyde 56 was recovered from the reaction.

\section{c. n-butyllithium as base:}

In a two-necked $250 \mathrm{~mL} r . \mathrm{b}$. flask with a nitrogen adapter and septum, $10.1 \mathrm{~g}(2.2 \times 0.0095 \mathrm{~mol})$ of Wittig salt 138 in $50 \mathrm{mi}$ of dry tetrahydrofuran was taken. The mixture was cooled to $-78^{\circ} \mathrm{C}$ using acetone/liq. $\mathrm{N}_{2}$ bath. Then $12.4 \mathrm{~mL}(2.1 \mathrm{x}$ 0.0095 mol) of $1.6 \mathrm{M}$-butyl lithium added dropwise via a syringe. The mixture was warmed to $-20^{\circ} \mathrm{C}$ and stirred at $-20^{\circ} \mathrm{C}$ for $5 \mathrm{hr}$. Then $2 \mathrm{~g}(0.0095 \mathrm{~mol})$ of aldehyde $\underline{56}$ in $20 \mathrm{~mL}$ of dry tetrahydrofuran added via syringe. The mixture was stirred at $-15^{\circ} \mathrm{C}$ for $40 \mathrm{hr}$. It was then warmed to $23^{\circ} \mathrm{C}$ and stirred for another $2 \mathrm{hr}$. The reaction was worked up as in the previous experiment. $1.5 \mathrm{~g}$ of unreacted aldehyde $\underline{56}$ ( $75 \%$ recovery) was obtained from the reaction.

\section{Notes:}

1. The deep red color of ylide did not change throughout the length of the reaction.

2. The color disappears only after addition of water. It indicates that the ylide was formed but it did not add to the aldehyde. 
3. If the ylide did not form, butyl lithium would have added to the aldehyde. But the only product isolated was the unreacted aldehyde.

\subsection{Wittig reaction of triphenyl (3-butynylidene) phosphorane (150) with 38-acetoxytropane-1-aldehyde (ㅌ):}

In a 3-necked $250 \mathrm{~mL} r . b$. flask equipped with magnetic stirrer, addition funnel, reflux condenser with $\mathrm{N}_{2}$ adapter, $4.32 \mathrm{~g}(1.3 \times 0.0085 \mathrm{~mol})$ of triphenyl (3-butyny 1) phosphonium bromide in $75 \mathrm{~mL}$ of dry tetrahydrofuran was suspended and cooled to $0^{\circ} \mathrm{C}$. Then $6.3 \mathrm{~mL}(1.18 \times 0.0085 \mathrm{~mol})$ of $1.6 \mathrm{M} \mathrm{n}$-BuLi added dropwise via a syringe. Mixture stirred at $0^{\circ} \mathrm{C}$ for $2 \mathrm{hr}$. It was warmed up to $23^{\circ} \mathrm{C}$ and stirred for another $1 \mathrm{hr}$. A solution of $1.8 \mathrm{~g}(0.008 \mathrm{~mol})$ of aldehyde in $25 \mathrm{~mL}$ of dry tetrahydrofuran added dropwise and the mixture stirred at $23^{\circ} \mathrm{C}$ for $24 \mathrm{hr}$. and worked up to give $0.7 \mathrm{~g}(33 \%)$ of a light yellow liquid. The spectral data are in agreement with the structure of 1-(1-penten-4-yny1)-38-acetoxytropane (151). NMR $\left(\mathrm{CDCl}_{3}\right): \delta 1.8-2.0(\mathrm{~m}, 11 \mathrm{H}), \delta 2.3(\mathrm{~s}, 3 \mathrm{H})$. IR (film): $3300(\mathrm{H}-\mathrm{C} \equiv \mathrm{C}), 3000,2250(\mathrm{C} \equiv \mathrm{C}), 1720\left(0-\mathrm{\| CH}_{3}\right)$, 1250, $1020,900,750 \mathrm{~cm}^{-1}$.

Mass spectrum: m/e $247\left(M^{+}\right)$. 


\subsection{Aldehyde homologation - attempted Wittig reaction of}

neopentyl aldehyde 56 with methoxymethylene

triphenylphosphorane:

a. Dimsylanion $\left(\overline{\mathrm{CH}}_{2} \mathrm{I}-\mathrm{CH}_{3}\right)$ as base:

In a 3-necked $100 \mathrm{~mL}$ r.b. flask equipped with a reflux condenser, $\mathrm{N}_{2}$ adapter and thermometer, a magnetically stirred solution of $0.2 \mathrm{~g}(0.005 \mathrm{~mol})$ of sodium hydride ( $59 \%$ suspension in mineral oil) was washed with dry pentane. Then $5 \mathrm{~mL}$ of dry dimethylsulfoxide (DMSO) was added and the mixture was heated to $55^{\circ} \mathrm{C}$ and kept there under $\mathrm{N}_{2}$ for $40 \mathrm{~min}$. There was evolution of gas $\left(\mathrm{H}_{2}\right)$ and the solution turned green. To this mixture, a solution of $1.72 \mathrm{~g}(0.005 \mathrm{~mol})$ of methoxymethyl triphenyl phosphonium chloride in $10 \mathrm{~mL}$ of dimethylsulfoxide was added dropwise at $55^{\circ} \mathrm{C}$. The mixture was stirred at that temperature for $30 \mathrm{~min}$. and cooled to $23^{\circ} \mathrm{C}$. To this $1 \mathrm{~g}(0.0047 \mathrm{~mol})$ of aldehyde $\underline{56}$ in $10 \mathrm{~mL}$ of dimethylsulfoxide was added dropwise and the mixture stirred at $23^{\circ} \mathrm{C}$ for $24 \mathrm{hr}$. The solvent was removed by vacuum distillation. To the residue $50 \mathrm{~mL}$ of water added. The $\mathrm{pH}$ was brought to 2 with dilute hydrochloric acid. The aqueous layer was extracted with benzene $(2 \times 50 \mathrm{~mL})$ followed by ether $(2 \times 50 \mathrm{~mL})$. The aqueous layer made alkaline $(\mathrm{pH}=10)$ with dilute ammonium hydroxide and extracted with echer. Evaporation of ether gave $0.8 \mathrm{~g}$ ( $80 \%$ recovery) of unreacted aldehyde $\underline{56}$. 
b. n-Butyl lithium as base - reaction at $23^{\circ} \mathrm{C}$ :

In a 3-necked $100 \mathrm{~mL}$ r.b. flask equipped with a reflux condenser, addition funnel and septum, $2.18(1.3 \times 0.0047 \mathrm{~mol})$ of methoxy methyl triphenyl-phosphonium chloride was suspended in $30 \mathrm{~mL}$ of dry THF. Then $3.5 \mathrm{~mL}(1.2 \times 0.0047 \mathrm{~mol})$ of $1.6 \mathrm{Mn}$-BuLi was added via syringe at $23^{\circ} \mathrm{C}$. The mixture was stirred at $23^{\circ} \mathrm{C}$ for $30 \mathrm{~min}$. and heated to reflux for $1 \mathrm{hr}$. It was cooled to $23^{\circ} \mathrm{C}$. Then $1 \mathrm{~g}(0.0047 \mathrm{~mol})$ of aldehyde 56 in $10 \mathrm{~mL}$ of dry tetrahydrofuran added and the solution stirred at $23^{\circ} \mathrm{C}$ for 48 hr. At the end of this period, $20 \mathrm{~mL}$ of water was added. Tetrahydrofuran was evaporated. The solution was made acidic $(\mathrm{pH}=2)$ with diluted hydrochloric acid. The aqueous layer was extracted with benzene $(2 \times 50 \mathrm{~mL})$ followed by ether $(2 \times 50 \mathrm{~mL})$. The aqueous layer was made alkaline $(\mathrm{pH}=10)$ with dilute ammonium hydroxide solution. Extraction with ether and removal of ether gave $0.85 \&$ ( $85 \%$ recovery) of unreacted aldehyde $\underline{56}$.

\section{c. n-Butyl lithium as the base - reaction done at reflux:}

Same procedure as above was followed except the reaction mixture was heated to reflux. Work-up as above yielded unreacted aldehyde $\underline{56}$ as the only product. 


\subsection{Successful homologation of aldehyde 56 to}

$1-(3 B-a c e t o x y t r o p a n e)$ acetaldehyde Wittig reaction using

2 eq of potassium butoxide as base:

In a 3-necked r.b. flask equipped with a reflux condenser, addition funnel, septum and a magnetic stirrer, $5.1 \mathrm{gm}(2.1 \mathrm{x}$ $0.007 \mathrm{~mol}$ ) of methoxy methyl phosphonium chloride was suspended in $50 \mathrm{~mL}$ of dry tetrahydrofuran. A solution of $1.67 \mathrm{~g}(2.1 \mathrm{x}$ 0.007 mo1) of kotbu in 20 mL of dry tetrahydrofuran was added dropwise. The mixture was stirred at $23^{\circ} \mathrm{C}$ for $1 \mathrm{hr}$. A deep red color developed. Then $1.5 \mathrm{~g}(0.007 \mathrm{~mol})$ of aldehyde 56 in $10 \mathrm{~mL}$ of tetrahydrofuran was added dropwise. The color changed from deep red to light yellow. The mixture was stirred at $23^{\circ} \mathrm{C}$ for 72 hrs. After that time, $20 \mathrm{~mL}$ of water was added and tetrahydrofuran evaporated. Work-up as in the previous experiment gave $1.1 \mathrm{~g}$ of crude mixture of gemoetric isomers of 1-(2-methoxyviny 1$)-3 B$-acetoxytropane.

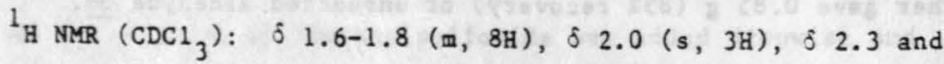
$\delta 2.35(\mathrm{~s}, 3 \mathrm{H}), \delta 3.5$ and $\delta 3.6(\mathrm{~s}, 3 \mathrm{H}), \delta 3.3(\mathrm{~m}, 1 \mathrm{H}), \delta 4.3$ and $5.9(d, 2 \mathrm{H}$ as $\mathrm{J}=8 \mathrm{~Hz}), \delta 4.7$ and $\delta 6.4(\mathrm{~d}, 2 \mathrm{H}$, trans $\mathrm{J}=15 \mathrm{~Hz}$ ).

The crude mixture of enol ethers was used for hydrolysis without any purification. It was dissolved in a solution of $20 \mathrm{~mL}$ of ether + $\mathrm{S} \mathrm{mL}$ of $70 \%$ perchloric acid and stirred at $23^{\circ} \mathrm{C}$ for $10 \mathrm{hrs}$. It was poured onto crushed ice and the resulting solution made alkaline $(\mathrm{pH}=10)$ with dilute ammonium hydroxide. Extraction with ethyl acetate and removal of solvent left $0.14 \mathrm{~g}$ 
( $10 \%$ yield) of crude $1-(3 B$-hydroxytropanyl)acetaldehyde (175). ${ }^{1} \mathrm{H} \operatorname{NMR}\left(\mathrm{CDCl}_{3}\right): \delta 1.2-1.8(\mathrm{~m}, 8 \mathrm{H}), \delta 2.3(\mathrm{~s}, 3 \mathrm{H}), \delta 2.5$ (d, $2 \mathrm{H}), \delta 3.3(\mathrm{~m}, 1 \mathrm{H}) . \delta 3.9(\mathrm{~m}, 1 \mathrm{H})$, and $\delta 9.8(\mathrm{t}, 1 \mathrm{H})$.

Notes:

1. No effort was made to separate the olefins in the wittig condensation. The crude mixture of trans and cis olefins was used in the hydrolys is since both of them yield the same homologated aldehyde.

\subsection{Cleavage of enol ethers 173 and 174 with boron tribromide:}

In a 250 mi 3-necked r.b. flask equipped with a mechanical stirter, condenser and addition funnel, $1 \mathrm{~g}$ of mixture of enol ethers $\underline{173}$ and $174(0.004 \mathrm{~mol})$ was dissolved in $100 \mathrm{~mL}$ of methylene chloride. To this $22 \mathrm{~mL}$ of 1 M solution of boron tribromide $(5.25 \times 0.004 \mathrm{~mol})$ in methylene chloride was added dropwise, at $0^{\circ} \mathrm{C}$. The solution was then warmed up to $23^{\circ} \mathrm{C}$ and stirred for 24 hr at $23^{\circ} \mathrm{C}$. It was then poured onto crushed ice and made alkaline $(\mathrm{pH}=10$ ) with dilute ammonium hydroxide solution. Extraction with chloroform and evaporation of solvent gave $0.18 \mathrm{~g}(20 \%)$ of crude $1-(38$-acetoxytropany 1$)$-acetaldehyde 


\section{Table III}

\section{Attempted $\mathrm{N}$-demethylations}

\begin{tabular}{|c|c|c|}
\hline Reactant & Reagents & Conditions \\
\hline amine $\underline{103}$ & $\begin{array}{l}2,2,2 \text {-trichloroethyl- } \\
\text { chloro formate }\end{array}$ & $\begin{array}{l}\text { benzene, reflux } \\
\text { for } 18 \mathrm{hr} \text { no }\end{array}$ \\
\hline amine $\underline{103}$ & $\begin{array}{l}2,2,2 \text {-trichloroethyl } \\
\text { chloroformate + dimethyl } \\
\text { amino pyridine (DMAP) }\end{array}$ & $\begin{array}{l}\text { benzene, reflux no } \\
\text { for } 18 \mathrm{hr} \text { reaction }\end{array}$ \\
\hline amine 103 & vinyl chloroformate & $\begin{array}{l}\text { ether, reflux } \\
\text { for } 24 \mathrm{hr}\end{array}$ \\
\hline amine $\underline{103}$ & $\begin{array}{l}\text { vinyl chloroformate } \\
+\mathrm{BaO}\end{array}$ & $\begin{array}{l}\text { ether, reflux } \\
\text { for } 24 \text { hr no }\end{array}$ \\
\hline amine 103 & $\begin{array}{l}\text { vinyl chloroformate } \\
+ \text { proton sponge }\end{array}$ & $\begin{array}{l}\text { methylene chloride no } \\
23^{\circ} \mathrm{C}, 24 \mathrm{hr} \text { reaction }\end{array}$ \\
\hline amine 103 & Pt, air 2 & $24 \mathrm{hr}, 23^{\circ} \mathrm{C}$ no \\
\hline
\end{tabular}


6.45 Attempted Preparation of 1-chloromethyl-3B-acetoxytropane $(\underline{177})$ :

In a 100 mi r.b. flask equipped with a reflux condenser and nitrogen in-out let, $1 \mathrm{~g}$ of amino alcohol $\underline{55}(0.005$ mol) was dissolved in 30 mil of distilled thionylchloride. The mixture was stirred under nitrogen at $23^{\circ} \mathrm{C}$ for $10 \mathrm{hr}$. It was heated to reflux for $11 / 2 \mathrm{hr}$ and then cooled to $23^{\circ} \mathrm{C}$. The solvent was evaporated. To the residue $10 \%$ sodium carbonate solution was added until pH adjusted to 10. Extraction with chloroform, followed by drying $\left(\mathrm{Na}_{2} \mathrm{SO}_{4}\right)$ and evaporation of the solvent gave $1 \mathrm{~g}$ of unreacted 1-hydroxymethyl-3B-acetoxytropane (55).

Notes:

1. The lack of reactivity can be attributed to the neopentyllic nature of the hydroxyl group.

2. The same reaction was repeated with the hydrochloride salt of amino alcohol 55 . Refluxing this salt with thionyl chloride for $15 \mathrm{hr}$ and working up as above, resulted in total recovery of starting material.

3. Addition of cat amount of dimethylamino pyridine (DMAP) had no effect on the reaction. 
6.46 1-Methanesulfonyloxymethyl-3B-acetoxytropane (180):

In a $100 \mathrm{~mL}$ one-neck r.b. flask, equipped with a magnetic stirrer, $4.88 \mathrm{~g}$ of 1-hydroxymethyl-3B-acetoxytropane (55) (0.023 mol), $1.9 \mathrm{~mL}$ of freshly distilled methane sulfonyl chloride $(1.1 \times 0.023 \mathrm{~mol}), 2.7 \mathrm{~mL}(0.023 \mathrm{~mol})$ of 2,6 -1utidine were dissolved in $50 \mathrm{~mL}$ of dry chloroform. The mixture was stirred at $20^{\circ} \mathrm{C}$ for $24 \mathrm{hr}$. It was poured onto water. The solution was made alkaline $(\mathrm{pH}=10)$ with dilute ammonium hydroxide solution. The chloroform layer was washed with water and brine. It was dried $\left(\mathrm{Na}_{2} \mathrm{SO}_{4}\right)$, filtered and solvent evaporated. Trituration with petroleum ether and carbon tetrachloride resulted in precipitation of $\underline{180}$ as a solid. Yield $3.5 \mathrm{~g}$ (53\%).

m.p. $89^{\circ} \mathrm{C}-91^{\circ} \mathrm{C}$.

$\operatorname{MMR}\left(\mathrm{CDCl}_{3}\right): \delta 1.5-2(\mathrm{~m}, 8 \mathrm{H}), \delta 2.3(\mathrm{~s}, 3 \mathrm{H}), \delta 3.4(\mathrm{~m}, 1 \mathrm{H})$, $\delta 4.2(\mathrm{~s}, 2 \mathrm{H}), \delta 3.1(\mathrm{~s}, 3 \mathrm{H}), \delta 2.0(\mathrm{~s}, 3 \mathrm{H}), \delta 5.2(\mathrm{q}, 1 \mathrm{H})$. IR $(\mathrm{KBr}): 3000,1720,1360,1170 \mathrm{~cm}^{-1}$.

Anal. Caled. for $\mathrm{C}_{12} \mathrm{H}_{21} \mathrm{NO}_{5} \mathrm{~S}$ : C, 49.48; $\mathrm{A}, 7.25 ; \mathrm{N}, 4.81 ; \mathrm{S}, 10.99$. Found: $\quad C, 49.52 ; \mathrm{H}, 7.33 ; \mathrm{N}, 4.80 ; \mathrm{S}, 10.74$.

Notes:

1. The tosylate was prepared by essentially following the same procedure. However the yields were much lower and reaction was very slow. 
2. Although the isolated yields of the pure compound were only 53\%, there was no evidence for any unreacted starting material in the crude product (absence of $\mathrm{OH}$ at $3400 \mathrm{~cm}^{-1}$ in $I R$ ).

3. It is essential that 2,6-1utidine be used as a proton trap. In the absence of 2,6-1utidine, substantial amounts of unreacted starting material were seen in the crude product mixture.

6.47 Conversion of acetoxy mesylate 180 into 1-methane sulfonyloxymethyl-38-tropanol (181):

In a one-necked $250 \mathrm{ml}$ r.b. flask, equipped with a reflux condenser and nitrogen adapter, $0.52 \mathrm{~g}$ of mesylate $180(0.002$ mol) and $0.24 \mathrm{~g}$ of sodium methoxide $(2.5 \times 0.002 \mathrm{~mol})$ were dissolved in $100 \mathrm{~mL}$ of absolute methanol. The mixture was stirred at $23^{\circ} \mathrm{C}$ for $6 \mathrm{hrs}$ and brought to reflux for $1 \mathrm{hr}$ and cooled. Methanol was evaporated and the residue was poured into ice-water. Extraction with echer followed by drying $\left(\mathrm{Na}_{2} \mathrm{SO}_{4}\right)$ and evaporation of ether gave $0.3 \mathrm{~g}(76 \%)$ of crude deacetylated product.

$\operatorname{NMR}\left(\mathrm{CDCl}_{3}\right): \delta 1.3-1.8(\mathrm{~m}, 8 \mathrm{H}), \delta 2.3(\mathrm{~s}, 3 \mathrm{H}), \delta 3.1(\mathrm{~s}$, $3 \mathrm{H}), \delta 3.3(\mathrm{~m}, 1 \mathrm{H}), \delta 4.2(\mathrm{~m}, 3 \mathrm{H})$. 
Notes:

1. In the NMR, there is no evidence for $\mathrm{OCH}_{3}$ group. The signals for mesylate $(\delta 4.2, \delta 3.1)$ were still present. This lead us to conclude that the mesylate was not displaced.

2. If more stringent conditions are used ( 5 eq. of sodium methoxide, reflux for $48 \mathrm{hrs}$ ), the methoxide ion seems to attack the sulfur of mesylate giving the diol (which is water soluble).

3. Using potassium carbonate/methanol instead of sodium methoxide also resulted in the isolation of 1 -methane sul fony loxymethyl-38-tropanol (181).

\subsection{Hydrogenolys is of mesylate 180 into 1 -methyl-3B-tropanol} (183):

A solution of $0.5 \mathrm{~g}$ of mesylate $180(0.0018 \mathrm{~mol})$ in $50 \mathrm{~mL}$ of anhydrous ether was added to $0.2 \mathrm{~g}(3 \times 0.0018 \mathrm{~mol})$ of 1 ithium alanate at $0^{\circ} \mathrm{C}$ in a $100 \mathrm{~mL} \mathrm{r} . \mathrm{b}$. flask, equipped with a condenser. The mixture was magnetically stirred and warmed to $23^{\circ} \mathrm{C}$, and then heated to reflux for $3 \mathrm{hr}$. It was cooled to $23^{\circ} \mathrm{C}$ and poured onto ice-water. Dilute hydrochloric acid was added to adjust the pH to 3, organic and aqueous layers separated. Aqueous layer was made alkaline $(\mathrm{pH}=10)$ by dilute ammonium hydroxide and extracted with ether. Washing with water followed by sacurated 
salt solution, drying $\left(\mathrm{Na}_{2} \mathrm{SO}_{4}\right)$ and evaporating left $0.2 \mathrm{~g}(74 \%)$

of an oil which proved by ${ }^{1}$ H NMR to be 1 -methyl-3B-tropanol (183). $\operatorname{NMR}\left(\mathrm{CDCl}_{3}\right): \delta 1.1(\mathrm{~s}, 3 \mathrm{H}), \delta 1.5-2(\mathrm{~m}, 8 \mathrm{H}), \delta 2.3(\mathrm{~s}, 3 \mathrm{H})$, $\delta 3.3(\mathrm{~m}, 1 \mathrm{H}), \delta 3.9(\mathrm{~m}, 1 \mathrm{H})$.

Notes:

1. Notice the appearance of signal due to bridgehead methyl group at $\delta 1.1(\mathrm{~s}, 3 \mathrm{H})$. Also the signals due to the mesylate have disappeared. ( $(\delta 4.2, \delta 3.1)$.

6.49 Attempts to couple 1-mesyloxymethyl-3B-acetoxytropane (186) with allyl magnesium bromide:

In a 3 necked $250 \mathrm{~mL}$ r.b. flask equipped with low-temperature thermometer, a reflux condenser, addition funnel, magnetic stirrer, $1.89 \mathrm{~g}(0.0076 \mathrm{~mol})$ of mesylate $\underline{180}$ were dissolved in $50 \mathrm{~mL}$ of dry tetrahydrofuran. $0.72 \mathrm{~g}(1 / 2 \times$ $0.0076 \mathrm{~mol}$ ) of copper(I) iodide were added. At $-30^{\circ} \mathrm{C}, 38 \mathrm{~mL}$ of $1 \mathrm{M}$ solution of allyl magnesium bromide $(9.5 \times 0.0076$ mol $)$ added dropwise and the wixture was stirred at $-30^{\circ} \mathrm{C}$ for $1 \mathrm{hr}$ and then at $23^{\circ} \mathrm{C}$ for $16 \mathrm{hr}$. Work up by adding water and extraction with chloroform gave a residue, $0.49 \mathrm{~g}$ which gave spectral data expected for allyl methyl sulfone.

NMR $\left(\mathrm{CDCl}_{3}\right):$ j $2.9(\mathrm{~s}, 3 \mathrm{H}), \delta 3.8(\mathrm{~d}, 2 \mathrm{H}), 05.3-5.8$ (m, 
$3 \mathrm{H})$.

IR (film): $1640 \mathrm{~cm}^{-1}(\mathrm{C}=\mathrm{C}), 1350 \mathrm{~cm}^{-1}\left(\mathrm{v}, \mathrm{SO}_{2}\right), 1120 \mathrm{~cm}^{-1}$ $\left(\mathrm{v}, \mathrm{SO}_{2}\right)$.

Notes:

1. The ${ }^{1}$ H NMR was compared with that of an authentic ${ }^{1}$ H NMR of allyl phenyl sulfone. This comparison proved that the compound in hand was allyl methyl sulfone.

\subsection{Attempted coupling of mesylate 180 with ethyl magnesium} bromide:

Similar procedure as in section 6.49 was used except ethy 1 magnesium bromide was used in place of allyl magnesium bromide. Work up by similar procedure gave a mixture of compounds which appeared to be ethyl methyl sulfone and methyl diethyl carbinol. $\operatorname{MMR}\left(\mathrm{CDCl}_{3}\right): \delta 1.2-1.5(\mathrm{~m}), \delta 2.3(\mathrm{~m}), \delta 2.8(\mathrm{~s})$.

\subsection{Attempted coupling of mesylate 180 with echyl magnesium} bromide using $\mathrm{Li}_{2} \mathrm{CuCl}_{4}$ as catalyst:

Same procedure as above was obtained except $0.5 \mathrm{~mL}$ of $1 \mathrm{M}$ solution of $\mathrm{Li}_{2} \mathrm{CuCl}_{4}$ in dry THF was used as catalyst, instead of CuI. Work up as above gave similar results. 
Notes:

1. The procedure of Kochi ${ }^{133}$ was used for the preparation of $\mathrm{Li}_{2} \mathrm{CuCl}_{4}$.

6.52 Attempted coupling of mesylate 180 with di a-butyl copper 1ithium:

In a $100 \mathrm{ml}$ 3-necked flask equipped with a $\mathrm{N}_{2}$ adapter and two septums, $1.62 \mathrm{~g}$ of CuI ( $2.5 \times 0.0035$ mol) were taken in $25 \mathrm{~mL}$ of distilled THF. The suspension was cooled to $-40^{\circ} \mathrm{C}$ with ethyl acetate/liq. $N_{2}$ bath. To this magnetically stirred suspension, $6.9 \mathrm{~mL}$ of $2.46 \mathrm{M} \mathrm{n}$-Buli ( $5 \times 0.0035 \mathrm{~mol}$ ) was added dropwise via syringe. The solution turned deep blue. $0.85 \mathrm{~g}(0.0035$ mol) of mesylate 180 in $20 \mathrm{~mL}$ of tetrahydrofuran added dropwise. The mixture was maintained at $-30^{\circ} \mathrm{C}$ for 1 hr and at $23^{\circ} \mathrm{C}$ for another $1 \mathrm{hr}$. Water was added and the end of this period and the aqueous layẹ extracted with chloroform. Removal of $\mathrm{CHCl}_{3}$ left an oil which proved to be methyl butyl sulfone by ${ }^{1}$ H NMR. The other product, diol $\underline{52}$ being soluble in water was never recovered. NMR $\left(\mathrm{CDCl}_{3}\right): \delta 0.9(\mathrm{~m}), \delta 1.3(\mathrm{~m}), \delta 2.5(\mathrm{~m})$ 
182

6.53 Preparation of di-n-butyl methyl carbinol:

In a 3-necked $250 \mathrm{~mL}$ rb. flask equipped with addition funnel (a septum was attached to the addition funnel), condenser, magnetic stirrer, $2 \mathrm{~g}$ of ethyl acetate $(0.0023$ mol) were taken. To the addition funnel $25 \mathrm{~mL}(2.1 \times 0.0023 \mathrm{~mol})$ of n-butyl magnesium chloride ( 2 M solution in ether) was transferred by a cannula. The Grignard reagent was added with stirring at $23^{\circ} \mathrm{C}$, to the ethyl acetate solution. The mixture was refluxed for 3 hr under $\mathrm{N}_{2}$. It was then cooled, poured into $100 \mathrm{~mL}$ of ice-cold water. The $\mathrm{pH}$ was adjusted to 5 with $10 \%$ ammonium chloride solution extracted with ether. Drying $\left(\mathrm{Na}_{2} \mathrm{SO}_{4}\right)$ and evaporation of ether left $3.3 \mathrm{~g}(92 \%)$ of crude di-n-butyl methyl carbinol 135.

$\operatorname{MMR}\left(\mathrm{CDCl}_{3}\right): \delta 0.9(\mathrm{t}), \delta 1.3(\mathrm{~s}), \delta 1.5(\mathrm{~m})$, (all these together integrate for $21 \mathrm{H}), \delta 3.5$ (m, 1H).

IR $\left(\mathrm{CDCl}_{3}\right): 3400$ (br, OH) $2900,1480,1360,1150,1000$, $900 \mathrm{~cm}^{-1}$.

Notes:

1. The only purpose of making this compound was to compare this product with the side products we got during the attempted coupling reaction of mesylate $\underline{180}$ with n-butyl magnesium bromide or n-butyl copper lithium. 


\subsection{Conversion of mesylate 180 into iodide 193 :}

Magnesium iodide was prepared as follows. In a one-neck 50 mL r.b. flask equipped with a reflux condenser, a side arm with septum, $0.62 \mathrm{~g}$ of $\mathrm{Mg}(5 \times 0.0053 \mathrm{~mol})$ in $25 \mathrm{~mL}$ of anhydrous ether was taken. $6.75 \mathrm{~g}$ of $\mathrm{I}_{2}(5 \times 0.0053 \mathrm{~mol})$ was added portion wise. When the brown color of $\mathrm{I}_{2}$ has disappeared, the condenser was removed and replaced by a septum.

In another one-necked $100 \mathrm{~mL} r . b$. flask equipped with a condenser and a sidearm with septum, $1.5 \mathrm{~g}$ of mesylate 180 were dissolved in $25 \mathrm{~mL}$ of chloroform. The magnesium iodide solution was transferred by a double ended needle under a positive pressure of $\mathrm{N}_{2}$. The reaction mixture was refluxed for $24 \mathrm{hr}$. It was then cooled, the solvent evaporated and the residue was adjusted with dilute ammonium hydroxide solution to $\mathrm{pH} 10$ and extracted with chloroform. The organic layer was washed with $5 \%$ sodium bisulfite solution and later with saturated salt solution. Drying ( $\left.\mathrm{Na}_{2} \mathrm{SO}_{4}\right)$ and evaporating the solvent left $0.8 \mathrm{~g}$ of an oil (39\%) which proved to be 1-iodomethyl-38-acetoxytropane 193 . NMR $\left(\mathrm{CDCl}_{3}\right): \delta 1.5-1.8(\mathrm{~m}, 8 \mathrm{H}), \delta 2.0(\mathrm{~s}, 3 \mathrm{H}), \delta 2.3(\mathrm{~s}$, $3 \mathrm{H}), \delta 3.2(\mathrm{~s}, 1 \mathrm{H}), \delta 3.3(\mathrm{~m}, 1 \mathrm{H}), \delta 4.9-5.2(\mathrm{~m}, 1 \mathrm{H})$. IR (film): $2900,1720,1250,1000 \mathrm{~cm}^{-1}$. 
Notes:

1. The mesylate could not be displaced by sodium iodide.

2. Using ether-tetrahydrofuran mixture as solvent system slowed down the reaction. There was some unreacted starting material in the product. It is conceivable that tetrahydrofuran coordinates to magnesium iodide and renders it ineffective.

3. Although the isolated yields of pure iodide were only $39 \%$ when ether-chloroform was used as solvent system, the crude product showed complece absence of starting mesylate.

\subsection{Attempted Coupling of Allylmagnesium bromide with}

\section{1-Iodomethyl-38-acetoxytropane:}

In a $100 \mathrm{~mL}$ 3-necked $\mathrm{r} . \mathrm{b}$. flask equipped with a magnetic stirrer, condenser with $\mathrm{N}_{2}$ adapter, low-temperature thermometer, $0.6 \mathrm{~g}$ of CuI $(0.003 \mathrm{~mol})$ was taken. A solution of $1 \mathrm{~g}$ of iodide $193(0.003 \mathrm{~mol})$ dissolved in $25 \mathrm{~mL}$ of tetrahydrofuran and $25 \mathrm{~mL}$ of hexamethylphosphoramide and transferred via syringe into the reaction flask. The reaction mixture was cooled to $-10^{\circ} \mathrm{C}$. 15.5 mi ( $5 \times 0.003 \mathrm{~mol})$ of allyl magnesium bromide ( $2 \mathrm{M}$ solution in THF) was added via syringe. The mixture was brought to $23^{\circ} \mathrm{C}$ and stirred for $72 \mathrm{hr}$. At the end it was heated to reflux for $0.5 \mathrm{hr}$. The aixture was poured onto ice, dilute hydrochloric acid 
was added to adjust $\mathrm{pH}$ to 2 and extracted with ether. The water layer was made alkaline ( $\mathrm{pH} 10)$ with dilute ammonium hydorxide and extracted with chloroform. Evaporation of solvent gave unreacted 1 -iodomethyl-3B-tropanylacetate $\underline{193}$ as the sole product. 


\section{References}

1. a. J. W. Daly, I. Rarle, C. W. Myers, T. Tokuyama, J.

A. Waters and B. Witkop, Proc. Nat. Acad. Sci., U.S.A., $1971,68,1870$.

b. T. Tokuyama, R. Uenoyama, G. Brown, J. W. Daly and

B. Witkop, Helv. Chim. Acta, 1974, 57, 2597.

c. I. L. Karle, J. Am. Chem. Soc., 1973, 95, 4036.

d. J. W. Daly, T. Tokuyama, T. Fujiwara, R. J. Highet, and

I. L. Rarle, J. Am. Chem. Soc., 1980, $102,830$.

e. J. W. Daly, B. Wickop, T. Tokuyama, T. Nishikawa, and

I. L. Rarle, Helv. Chim. Acta, $1977,60,1128$.

2. J. Inubushi and I. Ibuka, Heterocycles, $1977, \underline{8}, 633$.

3. a. M. Aratani, L. V. Dunkerton, T. Fukuyama, Y. Kishi,

A. Rakoi, S. Sugiura and S. Inoue, J. Org. Chem., 1975, $40,2009$.

b. T. Fukuyama, L. V. Dunkerton, M. Aratani and Y. Rishi, J. Org. Chem., 1975, 40, 2011.

c. E. J. Corey, J. F. Arnet and G. N. Widiger, J. Am. Chem. Soc., 1975, 97, 430.

d. E. J. Corey, M. Petrzilka and Y. Ueda, Helv. Chim. Acta, $1977,60,2294$.

e. D. A. Evans, E. W. Thomas, and R. E. Cherpeck, J. Am. Chem. Soc., 1982, $104,3695$.

f. S. A. Godleski, D. J. Heacock, J. D. Meinhart and S. V. Wallendael, J. Org. Chem., 1983, 48, 2101.

g. R. Takahashi, B. Witkop, A. Brossi, M. A. Maleque and E. X. Albuquerque, Helv. Chim. Acta, 1982, 65, 252.

4. a. J. Elliott and m. A. Raftery, Biochemistry, 1979, 18, 1968.

b. A. J. Lapa, E. X. Albuquerque, M. J. Sarvey, J. Daly and

B. Witkop, Exp. Neurol., 1975, 47, 558.

c. W. Burgermeister, W. L. Klein, M. Nirenberg and

B. Witkop, Mol. Pharmacol., 1978, 14, 751 .

5. B. Tursch, J. C. Braekman, D. Daloze, C. Hootele, D. Losman,

R. Rarlsson, and J. M. Pasteels, Tetrahedron Letters, 1973, 201.

6. For total syntheses of adaline, see

a. E. Gossinget and B. Witkop, Monatsh. Chem., 1980, 111, 803.

b. R. R. Hill and L. A. Renbaum, Tetrahedron, 1982, $\underline{38}$, 1959.

c. D. H. Gnecco Medina, D. S. Grierson and H. P. Husson, Tetrahedron Lett., 1983, 2099. 
7. For extensive reviews on the chemistry of tropanes, see:

a. G. Fodor, in "The Alkaloids" (R. H. F. Manske, ed.), $1960,6,145$.

b. G. Fodor, in "The Alkaloids" (R. H. F. Manske, ed.), $1967, \underline{9}, 269$.

c. G. Fodor, in "The Alkaloids" (R. H. F. Manske, ed.), $1971,13,351$.

d. G. Fodor, in "Chemistry of the Alkaloids"

(S. W. Pelletier, ed.), p. 431, Van Nostrand-Reinhold, Princeton, New Jersey, 1970.

e. R. L. Clarke, in "The Alkaloids" (R. H. F. Manske, ed.), $1977,16,84$.

f. G. Fodor, in "The Alkaloids" (M. F. Grundon, ed.), Specialist Periodical Reports, The Royal Society of Chemistry, London, 1978,8 .

g. G. Fodor, in "The Alkaloids" (M. F. Grundon, ed.), Specialist Periodical Reports, The Royal Society of Chemistry, London, $1979, \underline{9}$.

h. G. Fodor and J. Butterick, in "The Alkaloids" (M. F. Grundon, ed.), Specialist Periodical Reports, The Royal Society of Chemistry, London, 1980, 10.

i. G. Fodor and R. Dharanipragada, in "The Alkaloids" (M. F. Grundon, ed.), Specialist Periodical Reports, The Royal Society of Chemistry, London, 1981, 11, 36.

j. G. Fodor and R. Dharanipragada, in "The Alkaloids" (M. F. Grundon, ed.), Specialist Periodical Reports, The Royal Society of Chemistry, London, 1982, 12, 45.

k. G. Fodor and R. Dharanipragada, in "The Alkaloids" (M. F. Grundon, ed.), Specialist Periodical Reports, The Royal Society of Chemistry, London, 1983, 13, 55.

1. G. Fodor and R. Dharanipragada, in "The Alkaloids" (M. F. Grundon, ed.), Natural Product Reports, The Royal Society of Chemistry, London, 1984, 1, 231.

m. G. Fodor and R. Dharanipragada, in "The Alkaloids" (M. F. Grundon, ed.), Natural Product Reports, The Royal Society of Chemistry, London, 2 , manuscript in print.

8. a. R. Robinson, J. Chem. Soc., 1917, 762 .

b. B. K. Blount and R. Robinson, J. Chem. Soc., 1933, 1511.

9. J. Case, unpublished results.

10. J. Kebrle and P. Karrer, Helv. Chim. Acta, 1954, 37, 484.

11. a. N. Clauson-Kaas and F. Limborg, Acta Chem. Scand., $1952, \underline{6}, 551$.

b. R. Mozingo, Org. Syn. Coll. Vol. III, 1955, 181.

12. L. Wesse11 and B. Tollens, Ann,, 1892, 272, 291.

13. D. M. Burness, Orz. Syn. Coll. Vo1. V, 1973, 403.

14. N. Clauson-Kaas, F. Limborg and J. Fakstorp, Acta Chem. Scand., $1948, \underline{2}, 109$. 
15. J. Fakstorp, D. Raleigh and L. E. Schniepp,

J. Am. Chem. Soc., 1950, 72, 869 .

16. G. Gal, I. Simonyi and G. Tokar, Acta. Chem. Acad. Sci. Hung., $1955, \underline{6}, 365$.

17. L. Paquette and J. Heimaster, J. Am. Chem. Soc., 1966, 88, 763.

18. A. H. Beckett, N. J. Harper, A. D. J. Balon, and

T. H. E. Watts, Tetrahedron, 1959, $\underline{6}, 319$.

19. A. Nickon and L. Fieser, J. Am. Chem. Soc., 1952, 74, 5566.

20. R. J. Bishop, G. Fodor, A. R. Ratrizsky, F. Soti, L. E. Sutton, and F. J. Swinbourne, J. Chem. Soc. (C), $1966,74$.

21. For an elaborate discussion of PMR studies on tropanes, see A. F. Casy, "PMR Spectroscopy in Medicinal and Biological Chemistry", 1971 , p. 240.

22. N. Sperber, M. Sherlock and D. Papa, J. Am. Chem. Soc., $1953,75,1122$.

23. A. W. Nineham, J. Chem. Soc., 1953, 2601.

24. G. Fodor, S. Riss and J. Rakoczi, Chim \& Ind. (Paris), 1963,90 , No. $36,225$.

25. G. Fodor and O. Kovacs, J. Chem. Soc., 1953, 724.

26. W. Steglich and G. Hofle, Angew. Chem. Int. Ed. (Engl.), 1969,8 , 981 .

27. G. Hofle and W. Steglich, Synthesis, 1972, 619.

28. G. Hofle, W. Steglich and H. Vorbruggen, Angew. Chem. Int. Ed. (Engl.) $, 1978,17,569$.

29. E. F. V. Scriven, Chemical Society Reviews, 1983, 12, 129.

30. E. J. Corey and K. Shimoji, J. Am. Chem. Soc., 1983, 105, 1662 . 31. A. Brossi, F. Hsu and K. Rice, J. Org. Chem., 1982, 47 ,
5214 .

32. E. J. Corey, N. M. Weinsheker, T. K. Schaaf, W. Huber, J. Am. Chem. Soc., $1969,91,5676$.

33. T. G. Bonner, E. J. Bourne and S. MeNally, J. Chem. Soc., $1960,2929$. 
34. E. J. Corey and J. W. Suggs, Tetrahedron Lett., 1975, 2647.

35. G. Piancatel1i, A. Scettri and M. D'Auria, Synthesis, 1982, 245.

36. E. J. Corey and G. Schmidt, Tetrahedron Lett., 1979, 399.

37. J. Herscovici and K. Antonakis, J. Chem. Soc. Chem. Commun., $1980,561$.

38. Y. S. Cheng, W. I. Liu and S. Chen, Synthesis, 1980, 223.

39. G. Melvyn and R. W. Rickards, J. Chem. Soc. Perkin Trans. I, $1981,599$.

40. J. C. Collins and W. W. Hess, Org. Syn., 1972, 22, 5.

41. R. Ratcliffe and R. Rodehorst, J. Org. Chem., 1970, 35, 4000 .

42. J. Attenburrow, A. F. B. Cameron, J. H. Chapman, R. M. Evans, B. A. Hems, A. B. A. Janesen and T. Walker, J. Chem. Soc., 1952, 1094.

43. The activated manganese dioxide used in these experiments has been kindly provided by Dr. K. Fang.

44. E. J. Corey and R. D. Balanson, J. Am. Chem. Soc., 1974, $\underline{96}, 6516$.

45. A. Cave, C. Kan-Fan, P. Potier, J. Le Men and M. M. Janot, Tetrahedron, $1967, \underline{23}, 4691$.

46. J. G. Moffatt in "Oxidation", Vol. 2, R. L. Augustine and

D. L. Trecker (eds.), Marcel Dekker Inc., New York (1971).

47. a. R. E. Pfitzner and J. G. Moffatt, J. Am. Chem. Soc., $1965,87,5661,(1965)$.

b. K. E. Pfitzner and J. G. Moffatt, J. Am. Chem. Soc., $1965,87,5670$.

48. G. Büchi, D. L. Coffen, K. Kocsis, P. E. Sonnet and

F. E. Ziegler, J. Am. Chem. Soc., 1966, 88, 3099.

49. J. Karliner and C. Djerassi, J. Org. Chem., 1966, 31, 1945.

50. K. Wiesner, A. Phillip and P. T. Ho, Tetrahedron Letr., $1968,1209$.

51. J. Meinwald and R. A. Schneider, J. Am. Chem. Soc., 1967, 89, 2023.

52. J. G. Moffatt, J. Org. Chem., 1971, 36, 1909.

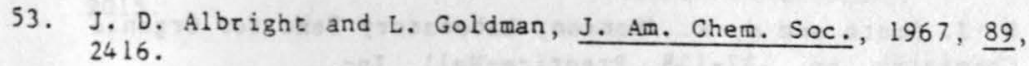


54. R. T. Joseph and C. S. Krishna Rao, Tetrahedron, 1967, 23, 3215 .

55. G. Eggart, C. Pascual and H. Wehrli, Helv. Chim. Acta, 1967, 50, 985 .

56. E. Houghton and J. E. Saxton, J. Chem. Soc. (C), 1969, 595.

57. J. R. Parikh and w. von E. Doering, J. Am. Chem. Soc., $1967,89,5505$.

58. L. Fieser and M. Fieser, "Reagents for Organic Synthesis", John Wiley and Sons, Inc., New York, NY, Vol. I, 1967, p. 1127 .

59. R. Onodera, S. Hirano and N. Kashimura, Carbohyd. Res., $1968,6,276$.

60. R. Omura and D. Swern, Tetrahedron, 1978, 34, 1651.

61. S. L. Huang, K. Omura and D. Swern, Synthesis, 1978, 297.

62. S. L. Huang, K. Omura and S. Swern, J. Org. Chem., 1976, 41, 3329 .

63. A. J. Mancuso, S. L. Huang and D. Swern, J. Org. Chem., $1978,43,2480$.

64. A. J. Mancuso and D. Swern, Synthesis, 1981, 165.

65. C. R. Johnson, J. C. Sharp and W. G. Phillips, Tetrahedron Lett., $1967,5299$.

66. C. R. Johnson and W. G. Phillips, J. Am. Chem. Soc., 1969, 91, 682 .

67. A. Maercker, Org. React., 1965, 14, 270.

68. H. J. Bestmann and 0 . Vostrowsky, Topics in Current Chemistry, 1983, 109, 86.

69. I. Gosney and A. G. Rowley in "Organophosphorus Reagents in Organic Synthesis", Ch. 2, J. G. Cadogan (ed.), Academic Press (1979), p. 17.

70. G. Wittig and G. Geissler, Ann., 1953, 580, 44 .

71. H. Rapoport and M. S. Chadha, J. Am. Chem. Soc., 1957, 79, 5730 .

72. R. Mechoulam and F. Sondheimer, J. Am. Chem. Soc., 1958, 80, 4386 .

73. D. J. Pasto and C. R. Jhonson, Laboratory Text for Organic Chemistry, pp. 137-138, Prentice-Hall, Inc., Englewood Cliffs, NJ (1979). 
74. E. Wenkert, J. S. Bindra, C. Chang, D. W. Cochran and

F. M. Schell, Accts. Chem. Res., 1974, 7, 46.

75. E. L. Blossey, H. Budzikiewicz, M. Ohashi, G. Fodor and C. Djerassi, Tetrahedron, 1964, 20, 585.

76. F. Sondheimer and R. Mechoulam, J. Am. Chem. Soc., 1957, 79, 5029 .

77. C. B. Reese in Protective Groups in Organic Chemistry (J. W. Mcomie, ed.) Plenum Press, New York (1973), p. 109.

78. E. Vedejs and K. A. J. Snoble, J. Am. Chem. Soc., 1973, 95, 5778.

79. W. P. Schneider, J. Chem. Soc. Chem. Commun., 1969, 785.

80. U. Axen, F. H. Lincoln, J. L. Thompson, J. Chem. Soc. Chem. Commun., $1969,303$.

81. M. Schlosser, Top. Stereochem., 1970, 5,1 .

82. E. J. Corey and E. Hamanaka, J. Am. Chem. Soc., 1967, 89, 2758.

83. R. Holler and H. Lischka, J. Am. Chem. Soc., 1980, 102, 4632 .

84. E. Vedejs, G. P. Meier and R. A. J. Snoble, J. Am. Chem. Soc., $1981,103,2823$.

85. Chemical and Engineering News, p. 30, March 26, 1984.

86. A. B. Reitz, M. S. Mutter and B. E. Maryanoff, J. Am. Chem. Soc., $1984,106,1873$.

87. J. W. Hamersma and E. I. Snyder, J. Org. Chem., 1965, 30, 3985.

88. D. C. Curry, B. C. Uff and N. D. Ward, J. Chem. Soc. (C), 1967, 1120.

89. a. Suggestion from Dr. B. Witkop of NIH to Dr. G. Fodor.

b. The unsaturated amino alcohol 14 and the saturated amine hydrochloride salt 93 have been sent to Dr. B. Witkop at NIH for biological evaluations.

90. G. Kraiss and N. Nador, Tetrahedron Lett., 1971, 57.

91. T. A. Montzka, J. D. Matiskella and R. A. Partyka, Tetrahedron Lett., $1974,1325$.

92. J. D. Hobson and J. G. McCluskey, J. Chem. Soc. (C), 1967, 2015. 
93. R. A. Olofson, R. C. Schnur, L. Bunes and J. P. Pepe, Tetrahedron Lett., $1977,1567$.

94. R. A. Olofson, J. T. Martz, J. P. Senet, M. Piteau and T. Malfroot, J. Org. Chem., 1984, 49, 2081.

95. R. D. Birkenmeyer and L. A. Dolak, Tetrahedron Lett., 1970, 5049 .

96. G. T. Davis and D. H. Rosenblatt, Tetrahedron Lett., 1968, 4085 .

97. R. C. Thomas, J. Antibiotics, 1982, 35, 1202.

98. S. F. Martin and S. K. Davidsen, J. Am. Chem. Soc., 1984, 106,6431 .

99. H. A. Hageman, Org. React., 1953, I, 198.

100. G. Fodor, S. Abidi and T. C. Carpenter, J. Org. Chem., $1974,39,1507$.

101. A. Nickon and L. F. Fieser, J. Am. Chem. Soc., 1952, 74, 5566 .

102. A. G. Fallis, M. T. W. Hearn, E. R. H. Jones, V. Thaller and J. Turner, J. Chem. Soc. Perkin Trans. I, 1973, 743.

103. M. F. Shostakovskii, A. S. Atavin and N. V. Egorov, J. Gen. Chem. (USSR), 1965, 35, 813 .

104. G. Eglinton and M. C. Whiting, J. Chem. Soc., 1950, 3650.

105. This result is in contrast to Eglinton's claim ${ }^{104}$ that the reaction proceeds only in pyridine and not in 2,6-lutidine.

106. None of the published procedures 104 of Eglinton could be reproduced by us.

107. I. Ernest, A. Main and R. Manasse, Tetrahedron Lett., 1982, 167.

108. D. Klamann and P. Weyerstahl, Chem. Ber., 1964, 97, 2534.

109. E. J. Corey, D. A. Clark, G. Goto, A. Marfat,

C. Mioskowski, B. Samuelsson and S. Hammarstrom,

J. Am. Chem. Soc., $1980,102,1436$.

110. Reference 68 , p. 130 .

111. D. Klamann and P. Weyerstahl, Angew. Chem. Int. Ed. (Engl.), $1963, \underline{2}, 43$.

112. W. G. Dauben, J. M. Gerdes and R. A. Bunce, J. Org. Chem., $1984,49,4293$. 
113. S. Chen and M. M. Joul1ie, Synth. Commun., 1984, 14, 591.

114. J. Hooz and S. Gilani, Can. J. Chem., 1968, 46, 86.

115. A. K. Bose and B. Lal, Tetrahedron Lett., 1973, 3937.

116. W. S. Johnson and T. R. Schaaf, J. Chem. Soc. Chem. Commun., $1969,611$.

117. C. Burford, F. Cooke, E. Ehlinger and P. Magnus, J. Am. Chem. Soc., 1977, 4536.

118. S. Danishefsky, R. Nagasawa and N. Wang, J. Org. Chem., $1975,40,1989$.

119. S. G. Levine, J. Am. Chem. Soc., 1958, 80, 6150 .

120. D. R. Coulson, Tetrahedron Lett., 1964, 3323.

121. J. D. Brewer and J. A. Elix, Aust. J. Chem., 1972, 25, 545.

122. G. Wittig and M. Schlosser, Chem. Ber., 1961, 94, 1373.

123. N. R. Natale, B. E. Marron, E. J. Evain and C. D. Dodson, Synth. Commun., 1984, 14, 599.

124. K. C. Nicolaou, R. L. Magolda and D. A. Claremon, J. Am. Chem. Soc., $1980,102,1404$.

125. E. J. Corey and G. H. Posner, J. Am. Chem. Soc., 1967, 89, 3911.

126. G. Posner, Org. React., 1972, 19, 1 .

127. G. Posner, Org. React., 1975, 22, 253.

128. F. Derguini-Boumechal and G. Linstrumelle, Tetrahedron Lett., $1976,3225$.

129. G. Fouquet and M. Schlosser, Angew. Chem. Int. Ed. (Eng1.), $1974, \underline{13}, 82$.

130. C. R. Johnson and G. A. Dutra, J. Am. Chem. Soc., 1973, 95, 7777.

131. C. R. Johnson and G. A. Dutra, J. Am. Chem. Soc., 1973, 95, 7783.

132. G. M. Whitesides, W. F. Fischer, Jr., J. S. Filippo, Jr., R. W. Bashe, and H. O. House, J. Am. Chem, Soc., 1969, 91, 4871 .

133. M. Tamura and J. Kochi, Synchesis, 1971, 303. 
134. F. Derguini, Y. Bessiere and G. Linstrumelle, Synth. Coumun., 1981, 11,859 .

135. M. S. Kharasch and C. F. Fuchs, J. Org. Chem., 1944, 9, 359.

136. B. H. Lipshutz, D. Parker and J. Rozlowski, J. Org. Chem., $1983,48,3334$.

137. B. H. Lipshutz, R. S. Wilhelm and J. Kozlowski, Tetrahedron, $1984,40,5005$.

138. A. G. Anderson, Jr. and F. J. Freenor, J. Am. Chem. Soc., $1964,86,5037$.

139. A. G. Anderson, Jr. and F. J. Freenor, J. Org. Chem,, 1972, 37, 626 .

140. O. Kovacs, G. Fodor, and I. Weisz, Helv. Chim. Acta, 1954, 37, 892 .

141. R. S. Tipson, J. Org. Chem., 1944, 9, 235.

142. R. K. Crossland and K. L. Servis, J. Org. Chem., 1970, 35, 3195 .

143. A. C. Cope and G. L. Woo, J. Am. Chem. Soc., 1963, 85, 3601.

144. A. Eschenmoser and A. Frey, Helv. Chin. Acta, 1952, 35, 1660 .

145. R. C. Ebersole and F. C. Chang, J. Org. Chem., 1973, 38 , 2713.

146. Compared with ${ }^{1}$ H NMR spectrum of allyl phenyl sulfone Sadtler ${ }^{l_{\text {H }}}$ NMR spectra \#20468M.

147. A. I. Meyers, A. Nabeya, H. W. Adickes and I. R. Politzer, J. Am. Chem. Soc., 1969, 91, 763.

148. It has been observed that treatment of norbornyl brosylates with strong bases yields dinorbornyl ethers. 149

149. W. Huckel, W. Toppe and G. Legutke, Ann., 1940, 543, 191.

150. P. Place, M. Roumestant and J. Gore, Bull. Chim. Soc. Fr., $1976,169$.

151. W. Kraus and H. Graf, Angew. Chem. Int. Ed. (Eng1.), 1975, 14, 824 .

152. L. Fieser and M. Fieser, "Reagents for Organic Synthesis", John Wiley and Sons, Inc., New York, NY, Vol. I, p. 1158 (1967). 
153. G. Fodor and R. Dharanipragada, Abstract MEDI 106, 188th National Meeting of the American Chemical Society, Philadelphia, PA (1984).

154. R. Dharanipragada and G. Fodor, "Search for New Membrane Active Substances: Synthesis of 3-Tropanols with Alkyl, Alkenyl and Alkenynl Group at the Bridgehead", submitted to Chem. Soc. for publication. 


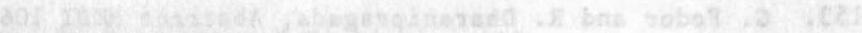

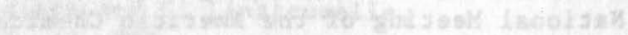

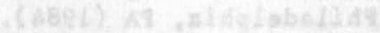

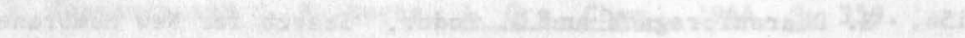

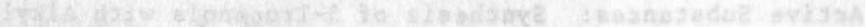
Wand

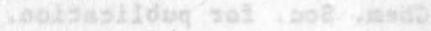

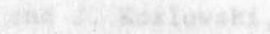

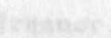

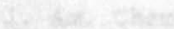

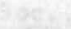

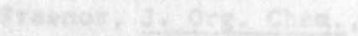

APPENDIX

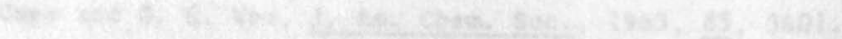


[I $\lambda_{\mathrm{CH}_{2} \mathrm{OCH}_{3}}$

31 


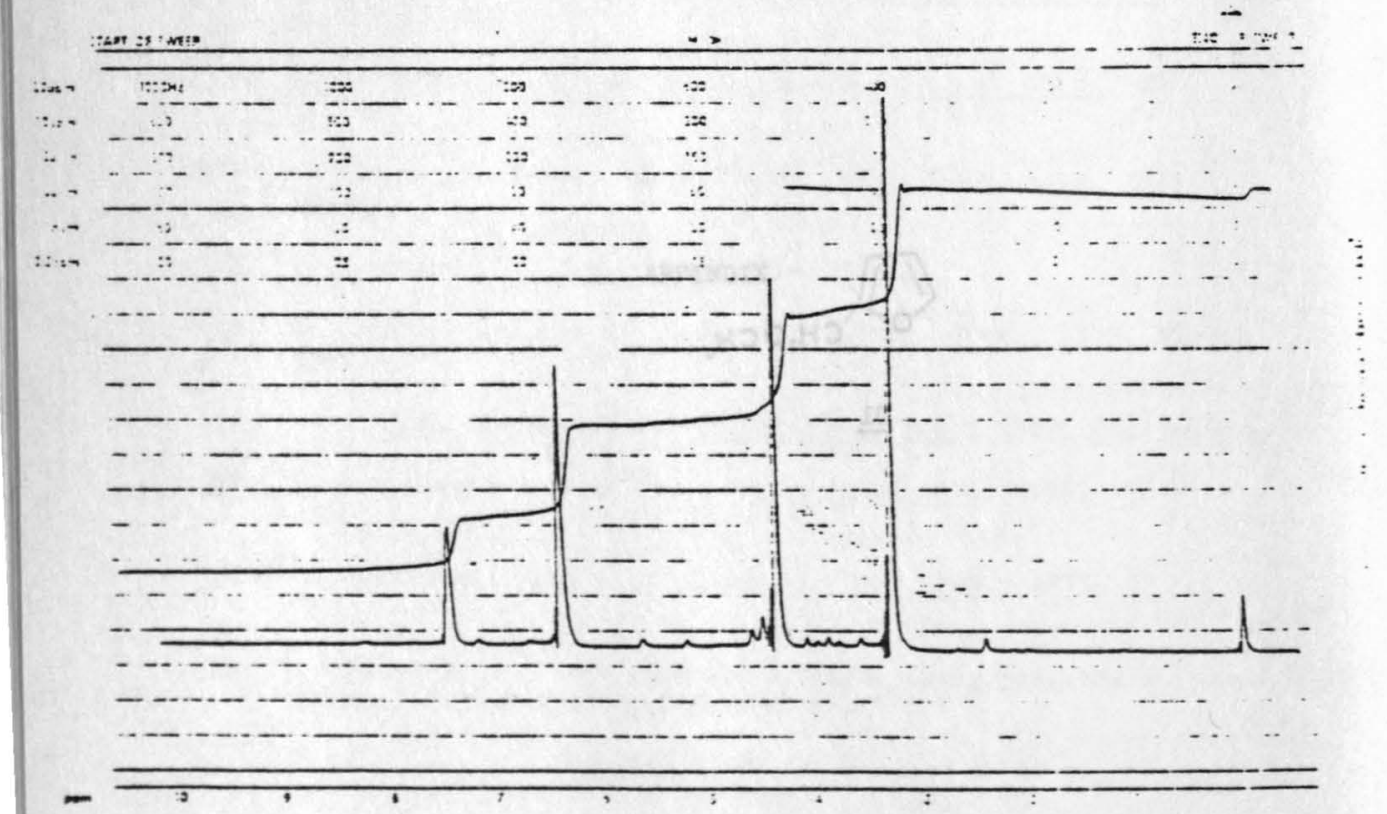

Figure 1. ${ }^{1} \mathrm{H}$ NMR spectrum of 1-methoxymethylfuran (31). 


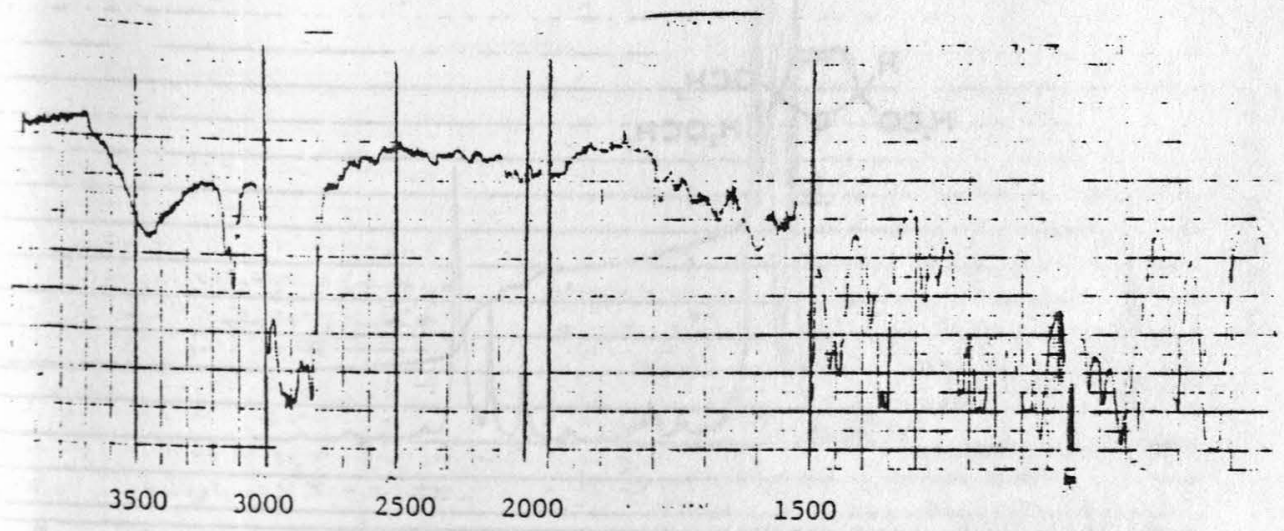

Figure 2. Infrared spectrum of 1-methoxymethyl furan (31). 


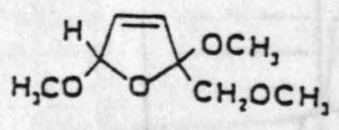

32 


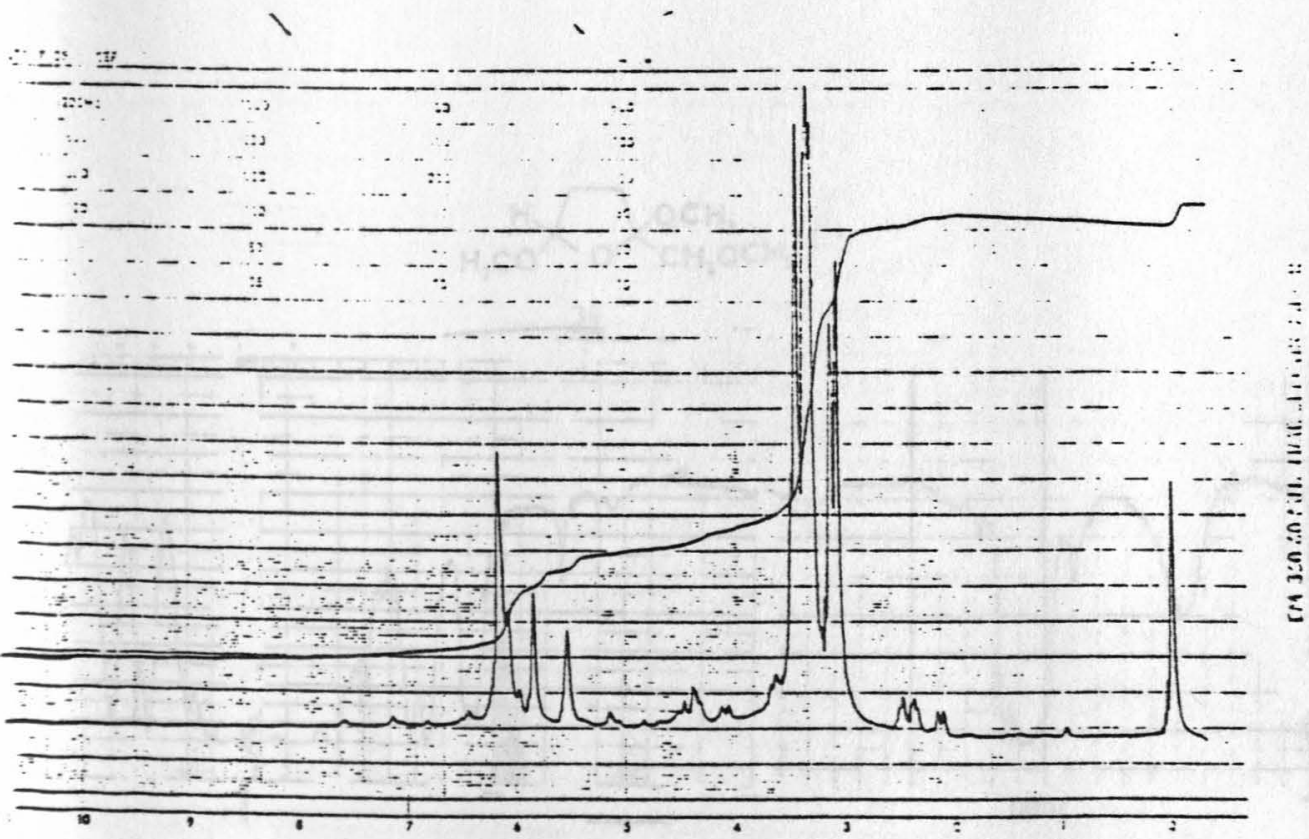

Figure 3. ${ }^{1}$ H NMR spectrum of 1-methoxymethyl-2,5-dimethoxy2,5-dihydrofuran (32). 


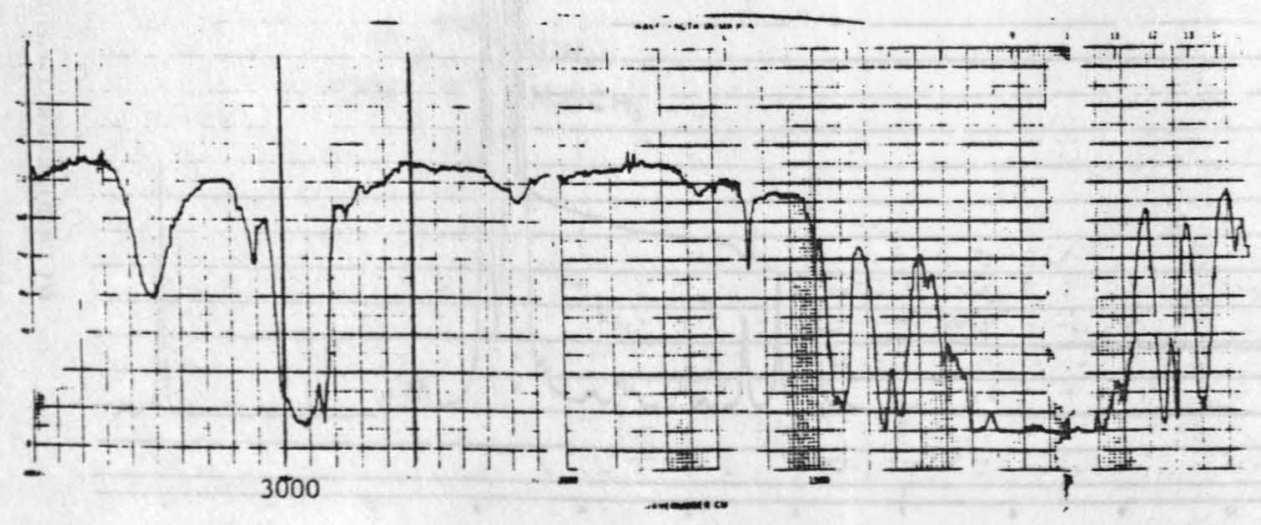

Figure 4. Infrared spectrum of 1-methoxymethyl-2,5-dimethoxy2,5-dihydrofuran (32). 


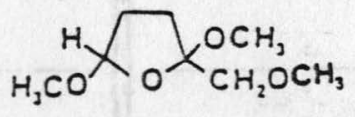

34 


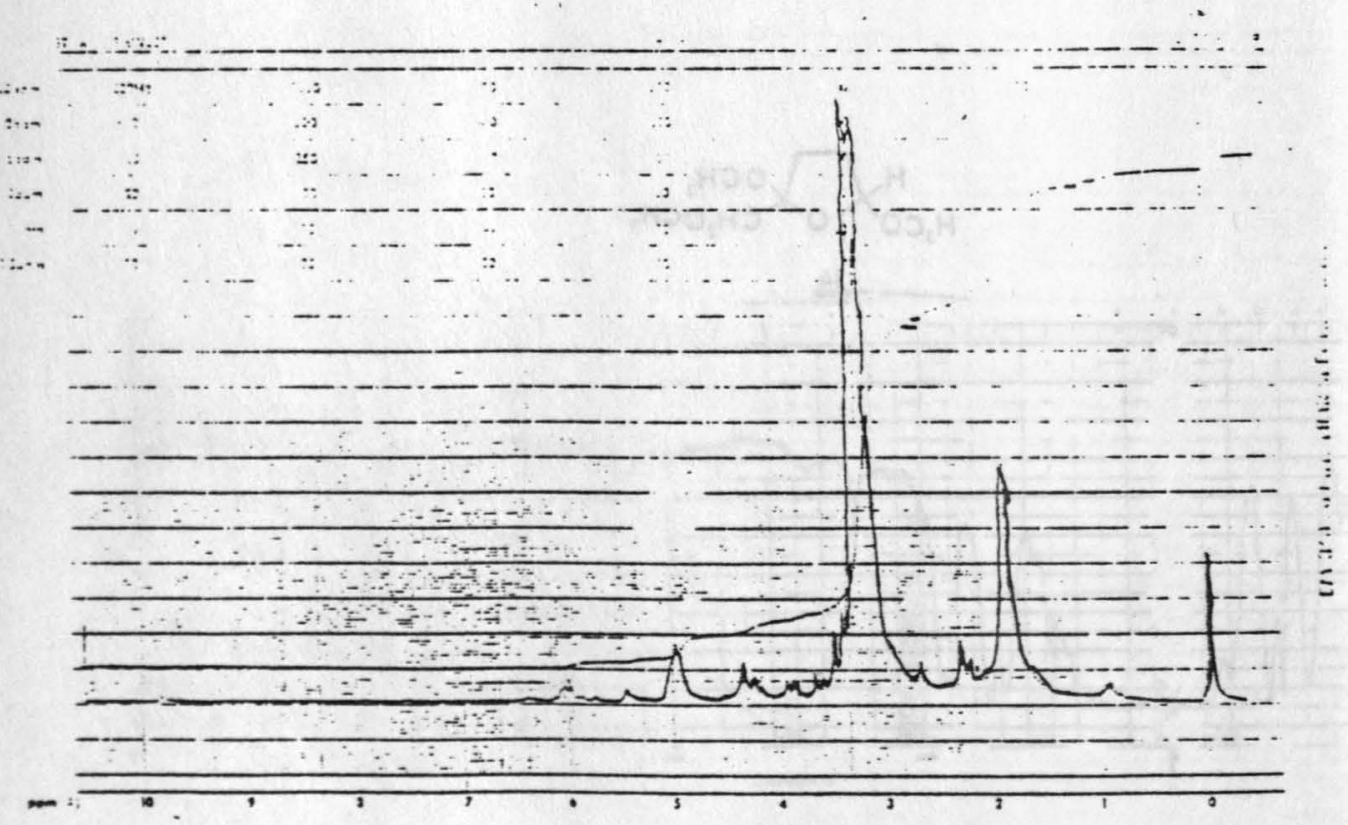

Figure 5. ${ }^{1}$ H NMR spectrum of 1-methoxymethyl 2,5-dimethoxy tetrahydrofuran (34). 


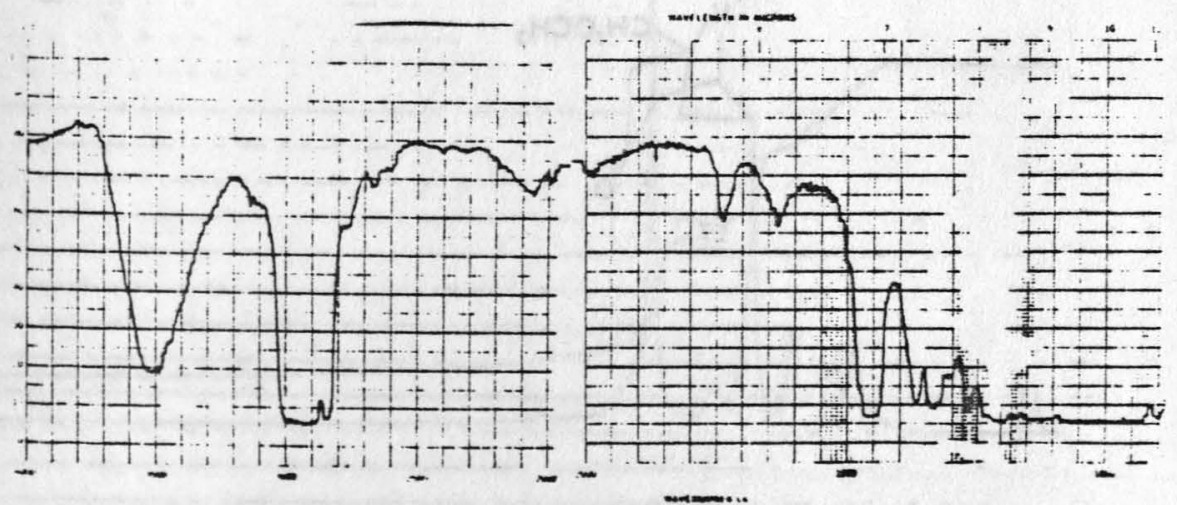

Figure 6. Infrared spectrum of 1-methoxymethy 1-2,5-dimethoxy tetrahydrofuran (34). 


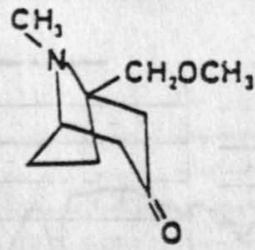

17 


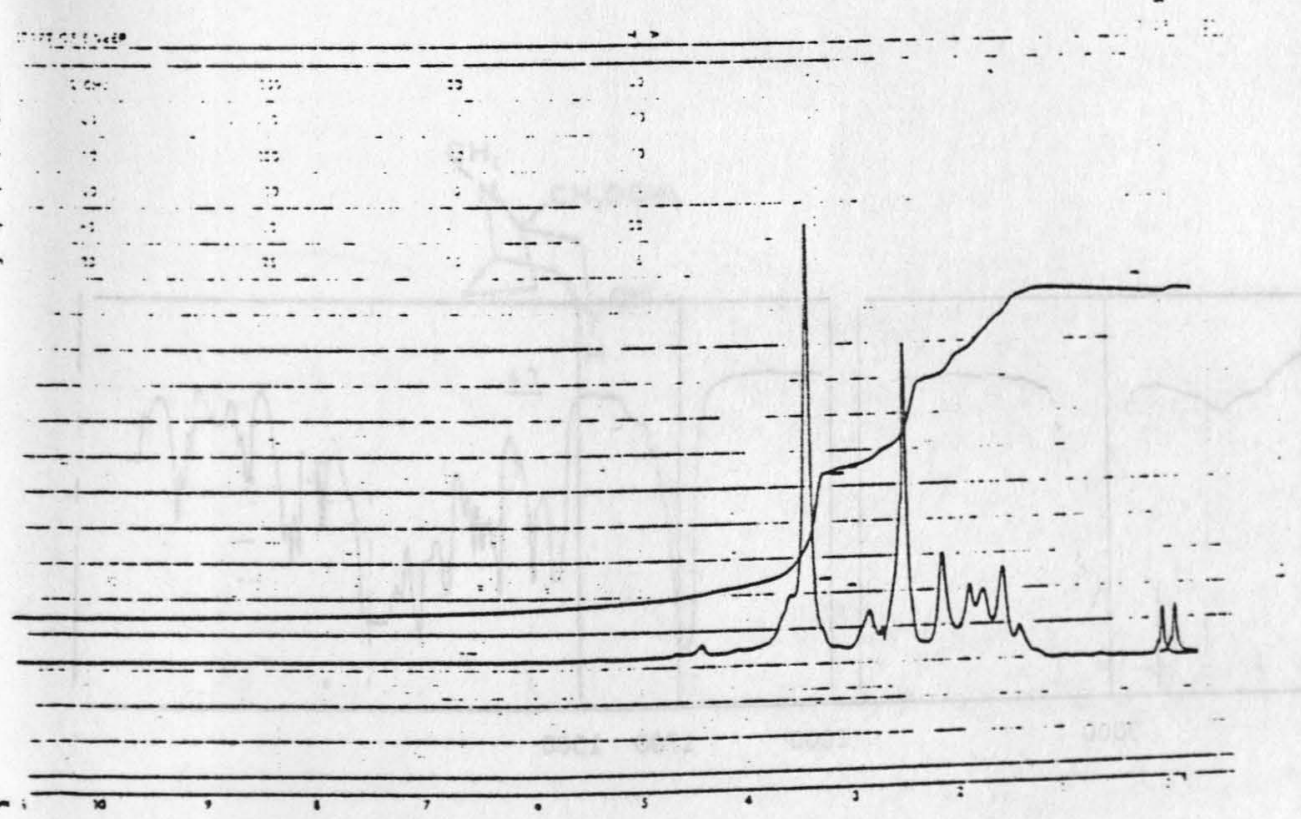

Figure 7. ${ }^{1}$ H NMR spectrum of 1-methoxymethyl tropane 3-one (17). 


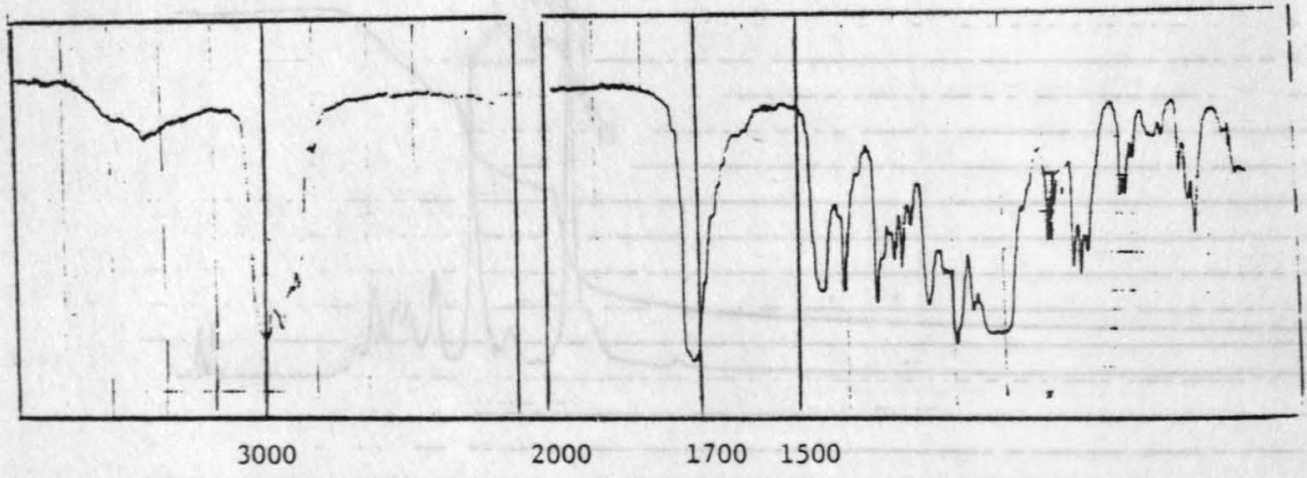

Figure 8. Infrared spectrum of 1-methoxymethyl tropane-3-one (17). 


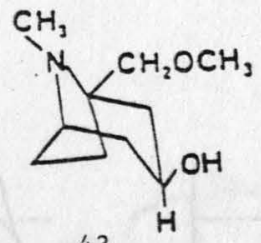

43 


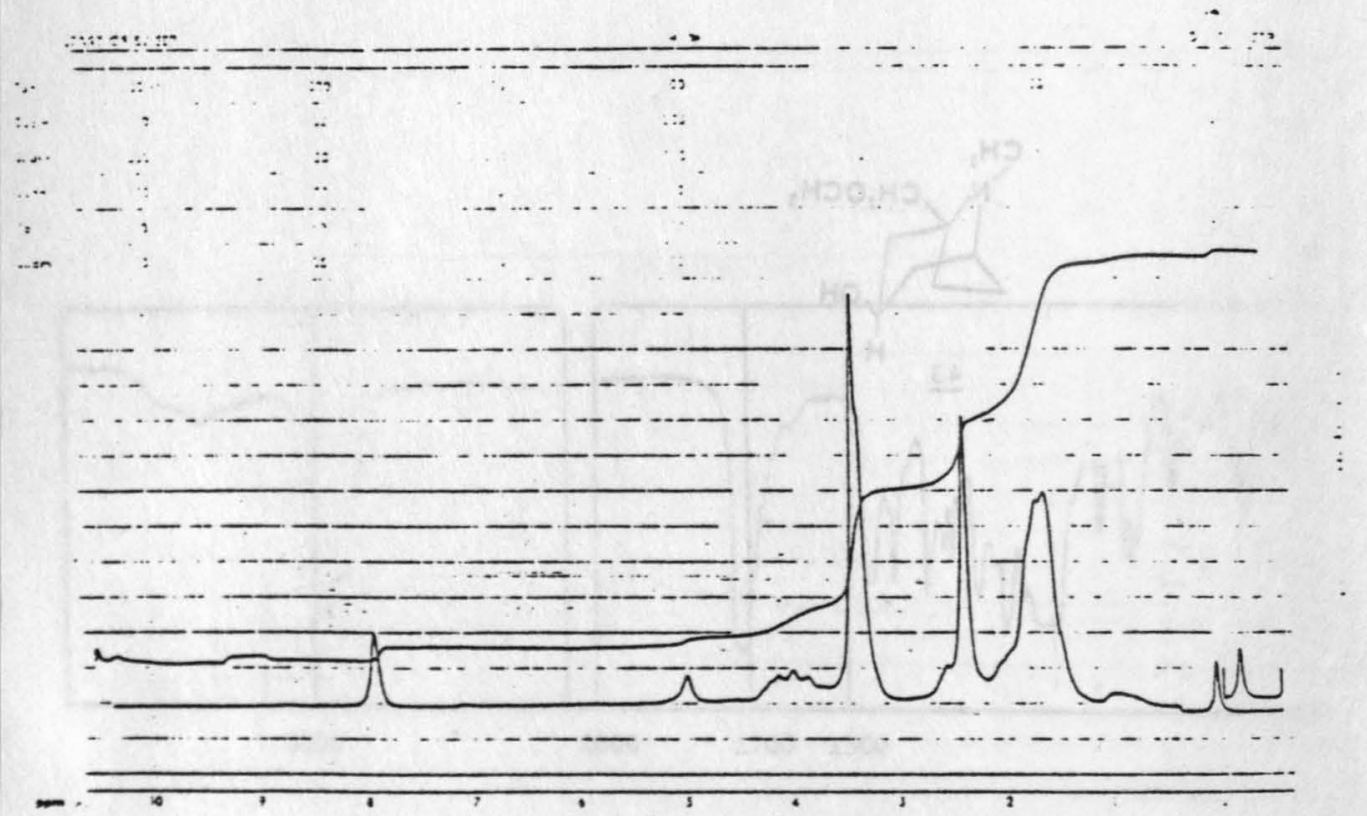

Figure 9. $1_{H}$ MMR spectrum of 1-methoxymethyl 3B-hydroxytropane (43). 

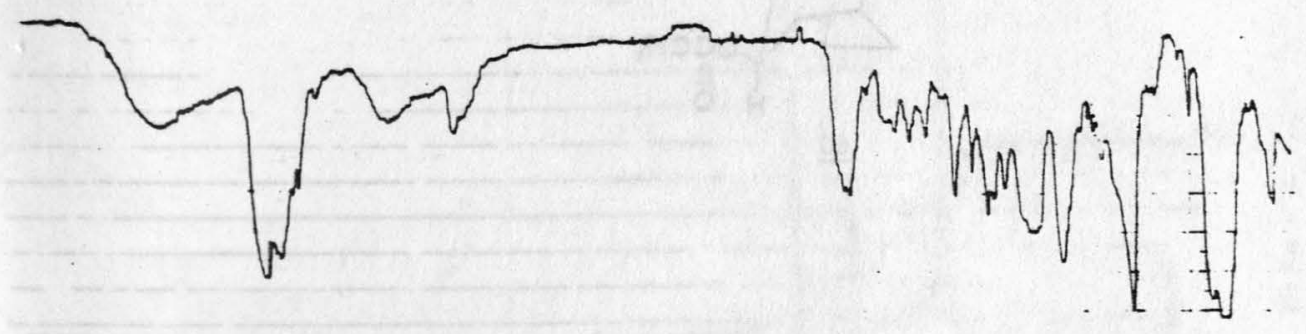

Figure 10. Infrared spectrum of 1-methoxymethyl 38 -hydroxytropane (43). 


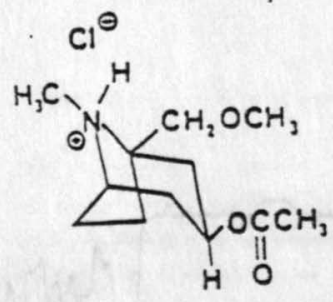

60 


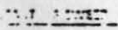

…--- - - -

.

$\because$

. $\because$
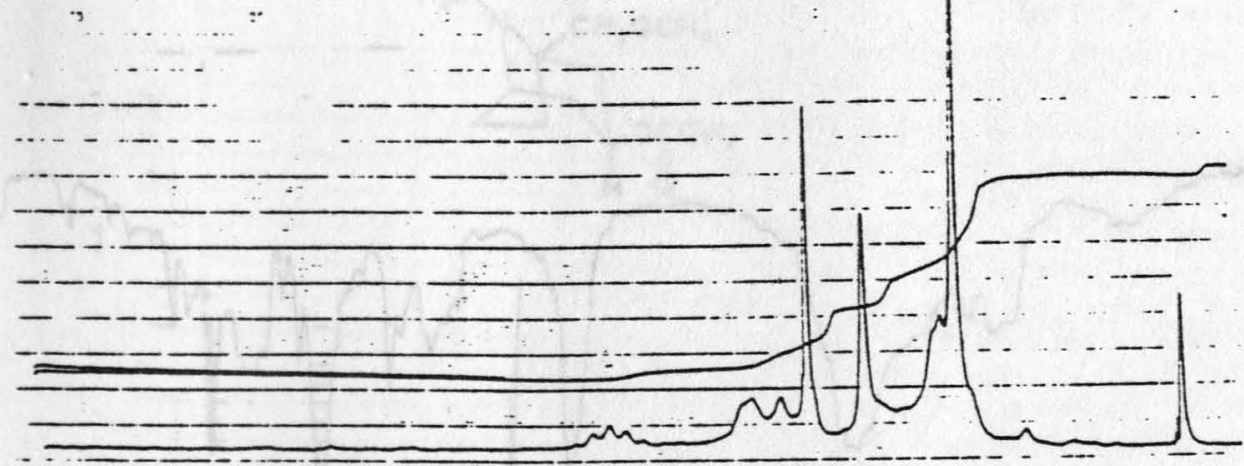

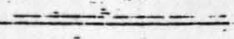
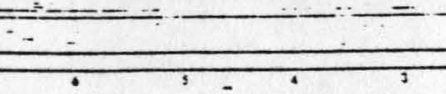

Figure 11. ${ }^{1} \mathrm{H}$ NMR spectrum of 1-methoxymethyl 3B-acetoxytropane hydrochloride $(\underline{60})$. 


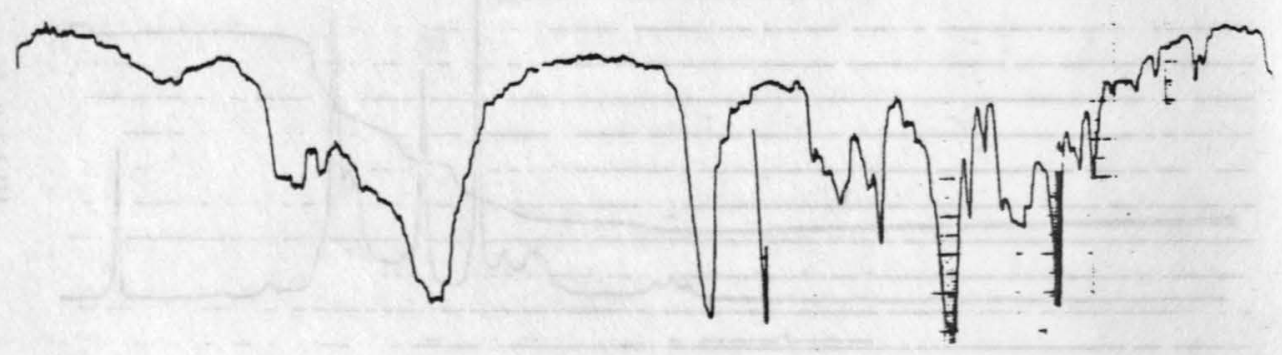

Figure 12. Infrared spectrum of 1-methoxymethyl-3B-acetoxytropane hydrochloride $(\underline{60})$. 


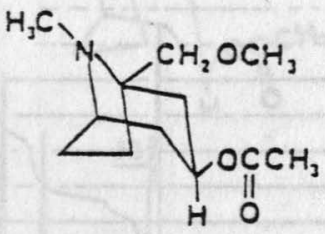




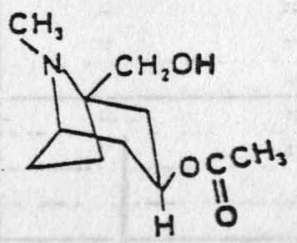




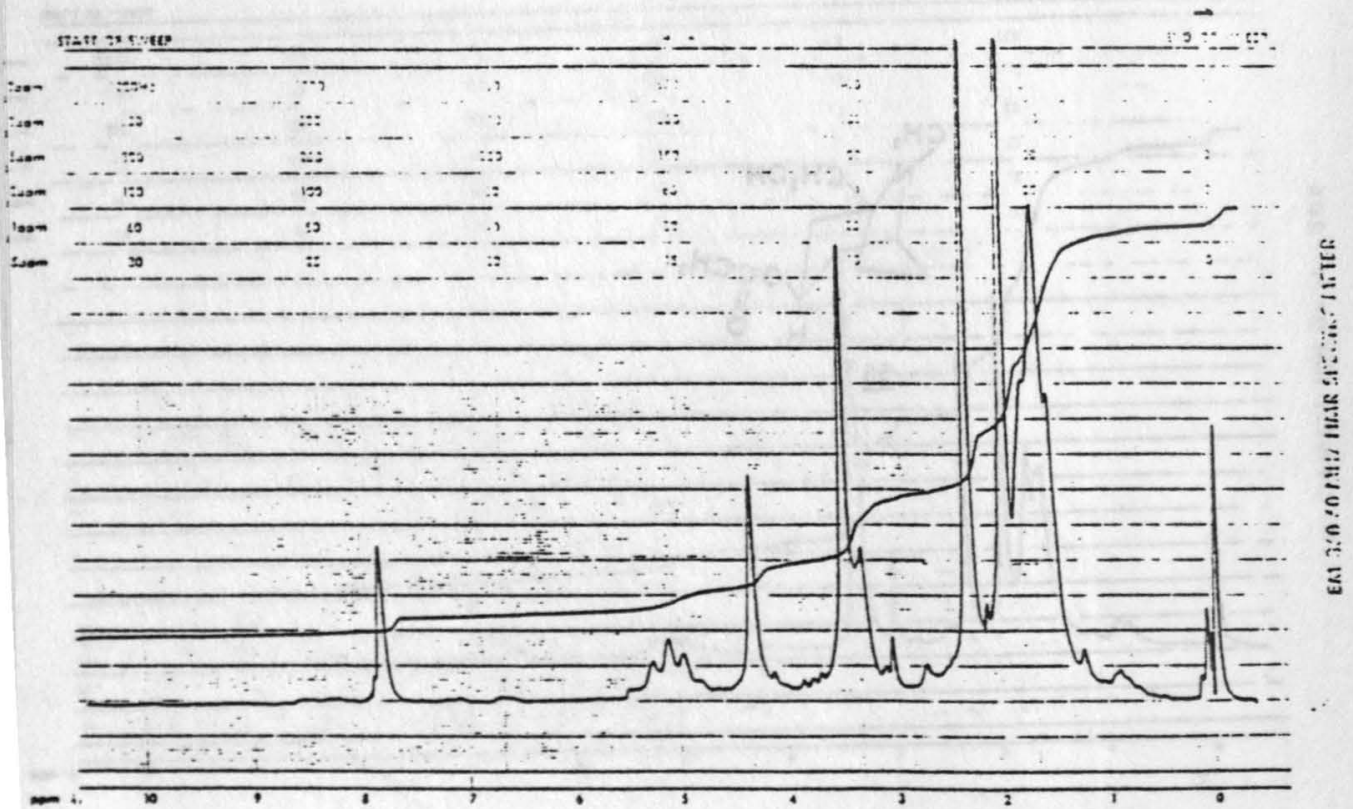

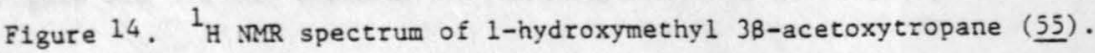




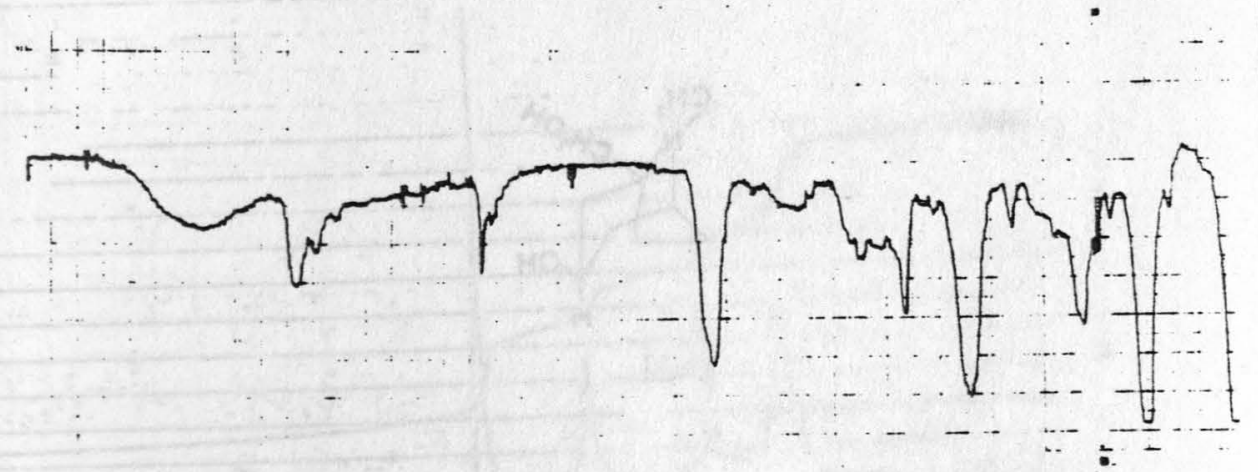

Figure 15. Infrared spectrum of 1-hydroxymethyl-3B-acetoxytropane (호). 


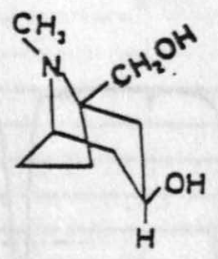

52 


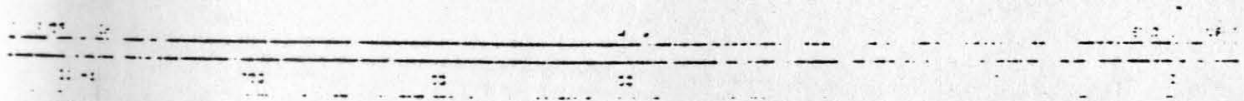

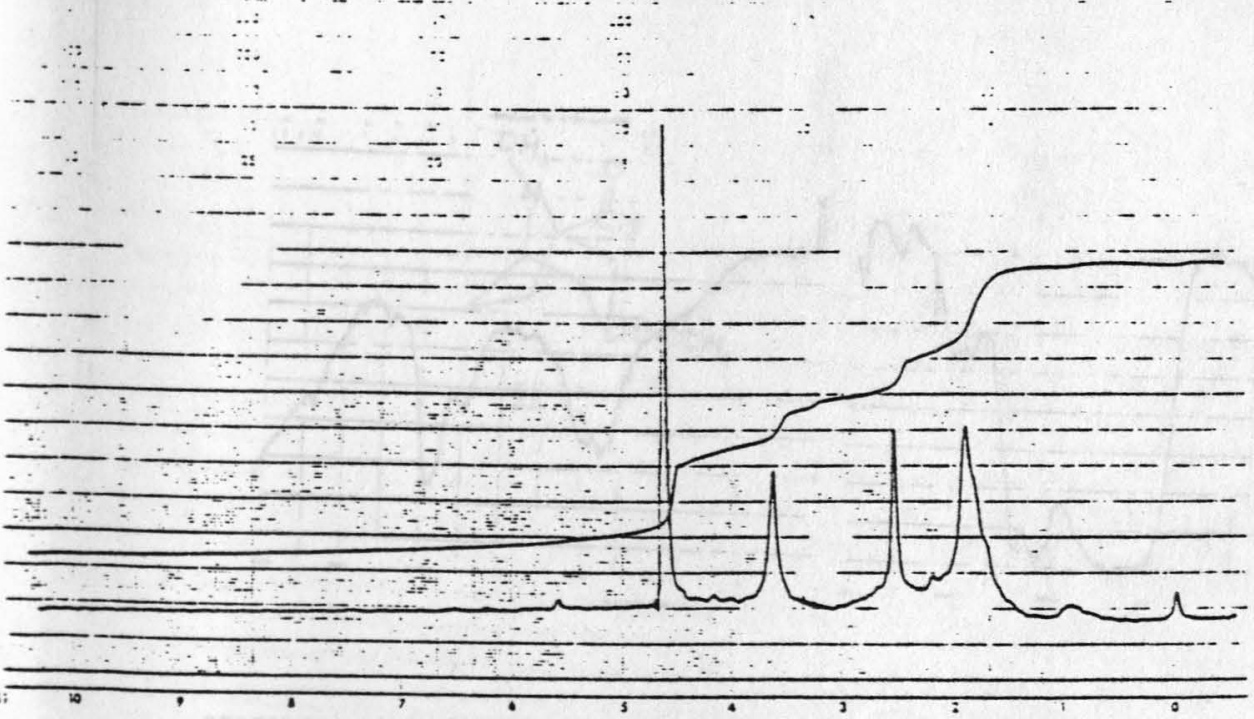

Figure 16. ${ }^{1}$ H NMR spectrum of 1-hydroxymethyl 38-hydroxytropane (2) 


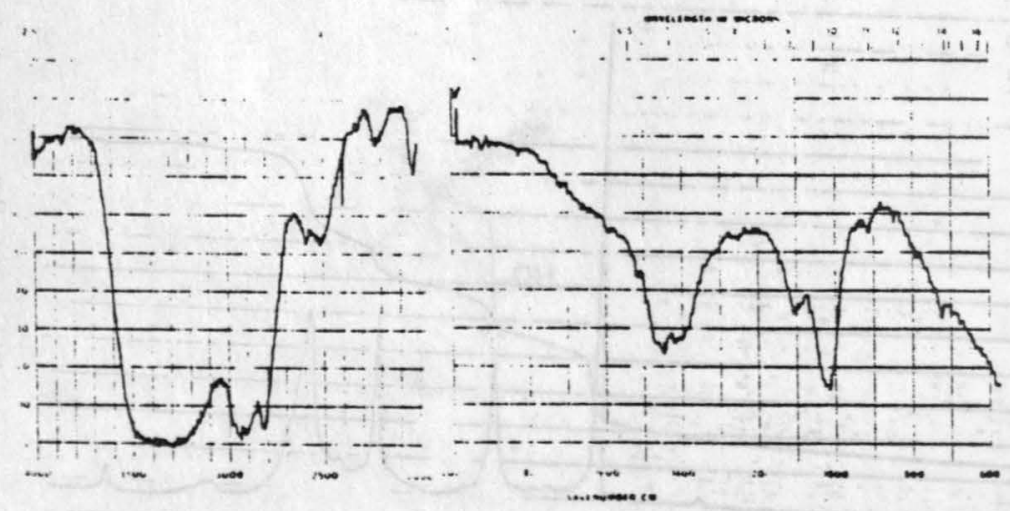

Figure 17. Infrared spectrum of 1-hydroxymethy 18 -hydroxytropane (52). 


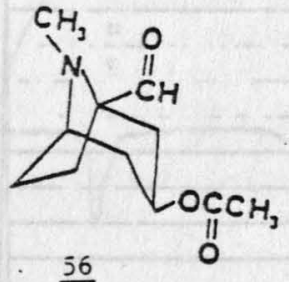




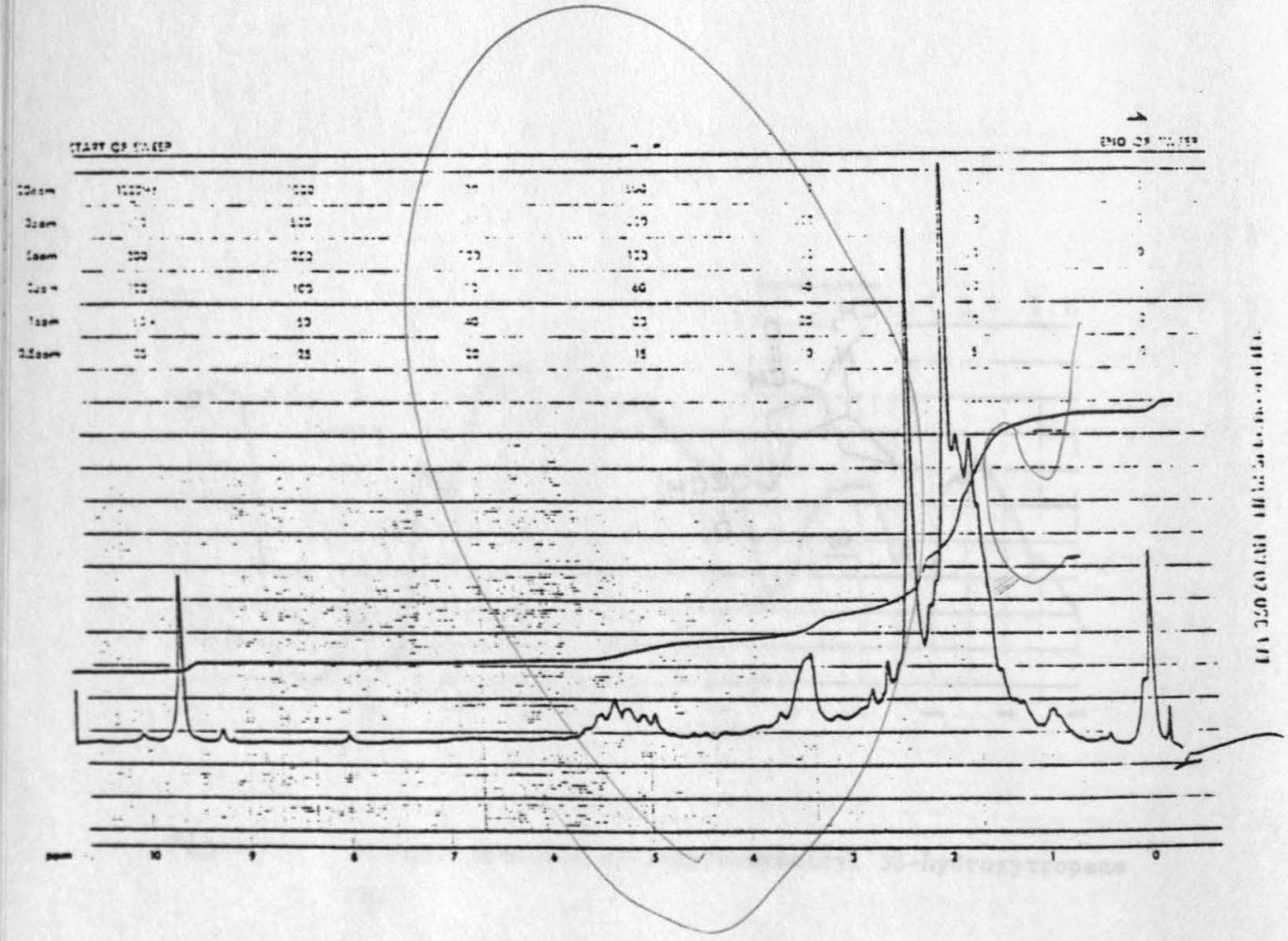

Figure 18. ${ }^{1} \mathrm{H}$ NMR spectrum of $3 B$-acetoxytropane 1-aldehyde $(\underline{56})$. 


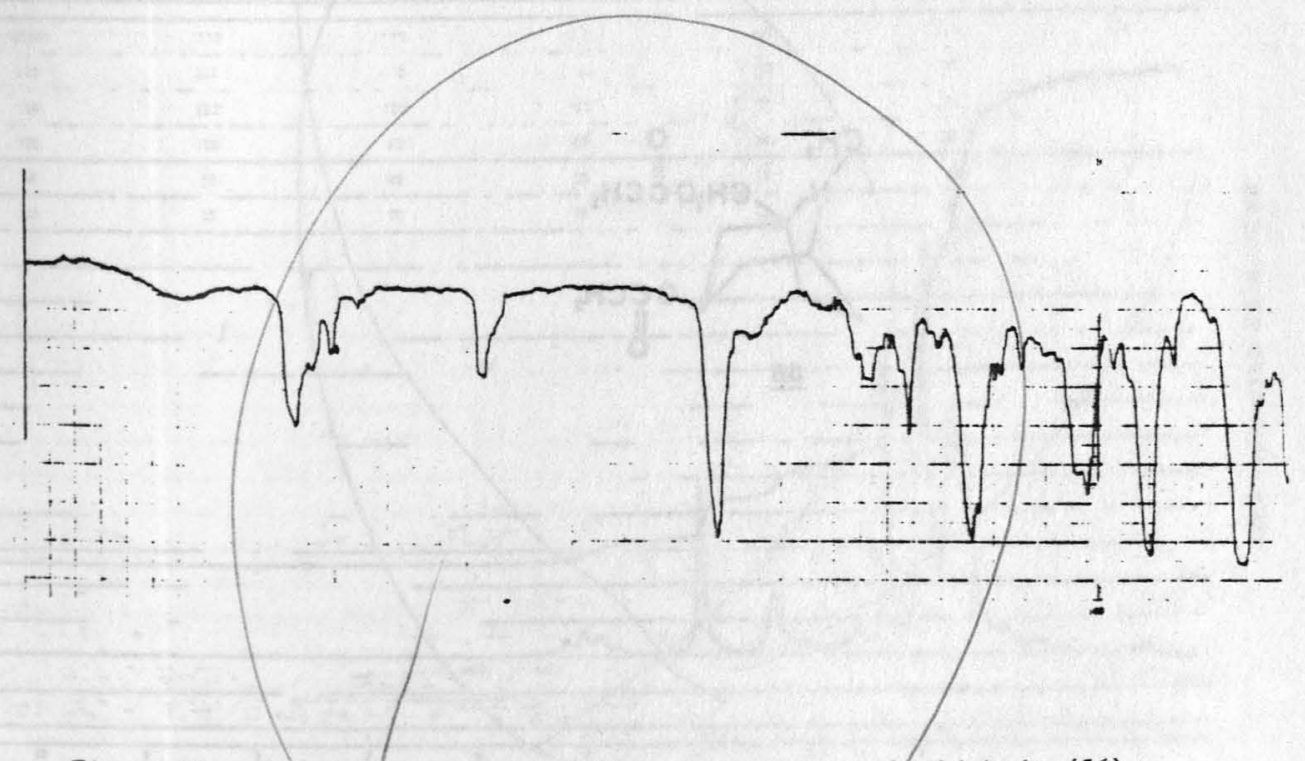

Figure 19. Infrared spectrum of 38 -acetoxytropane-1-aldehyde (56).

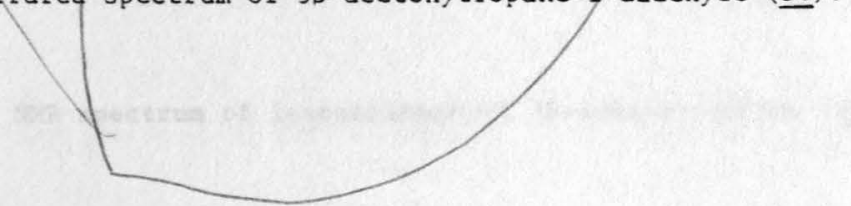




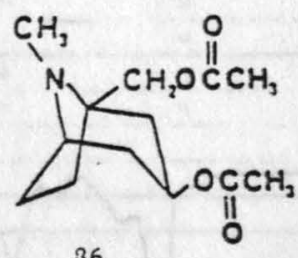




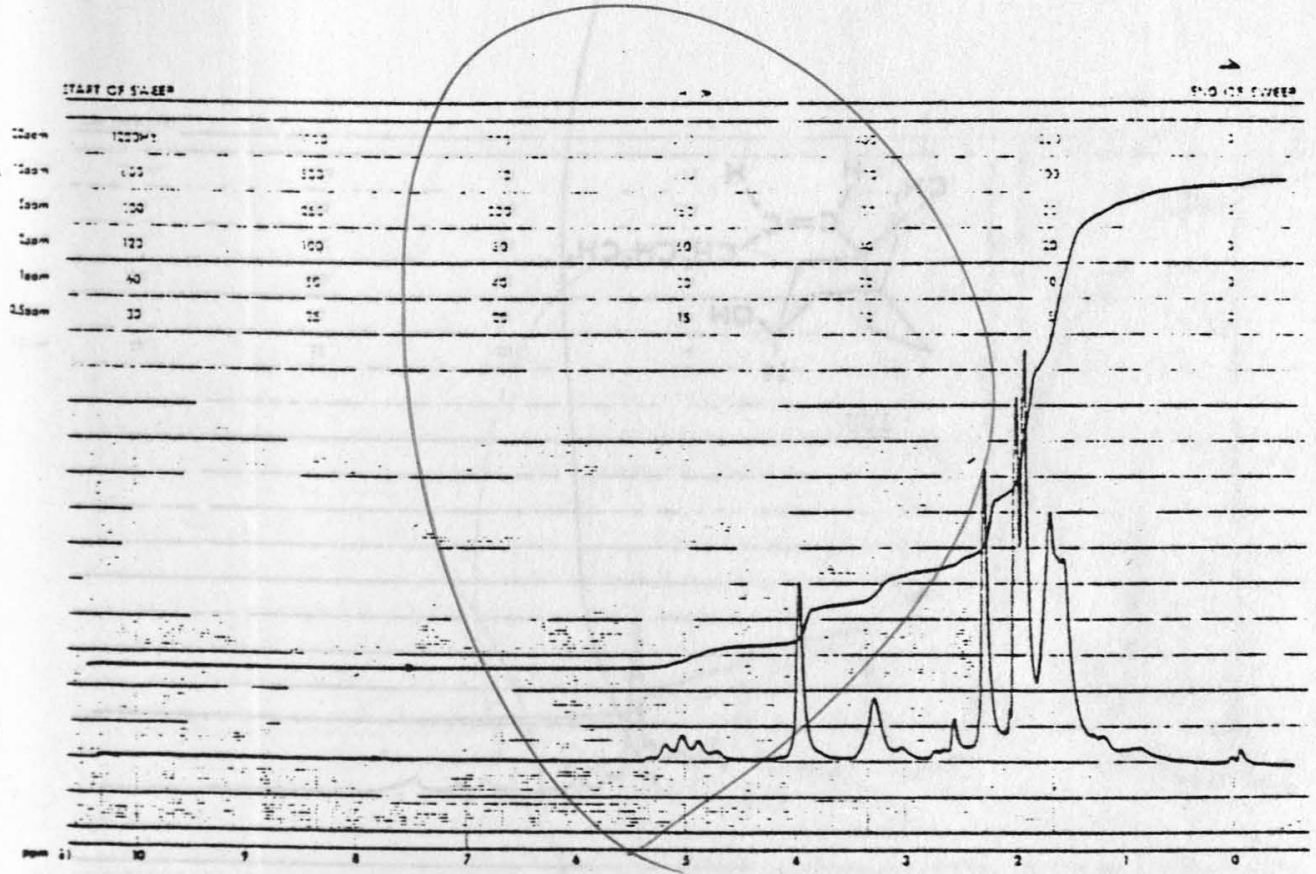

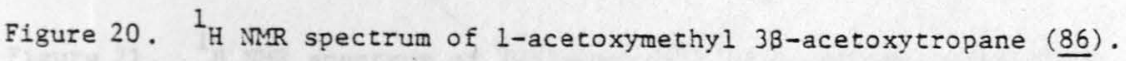




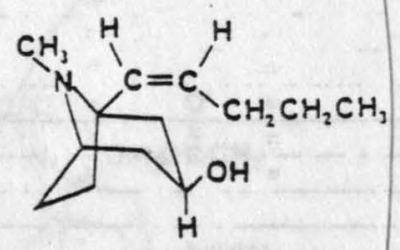

103 


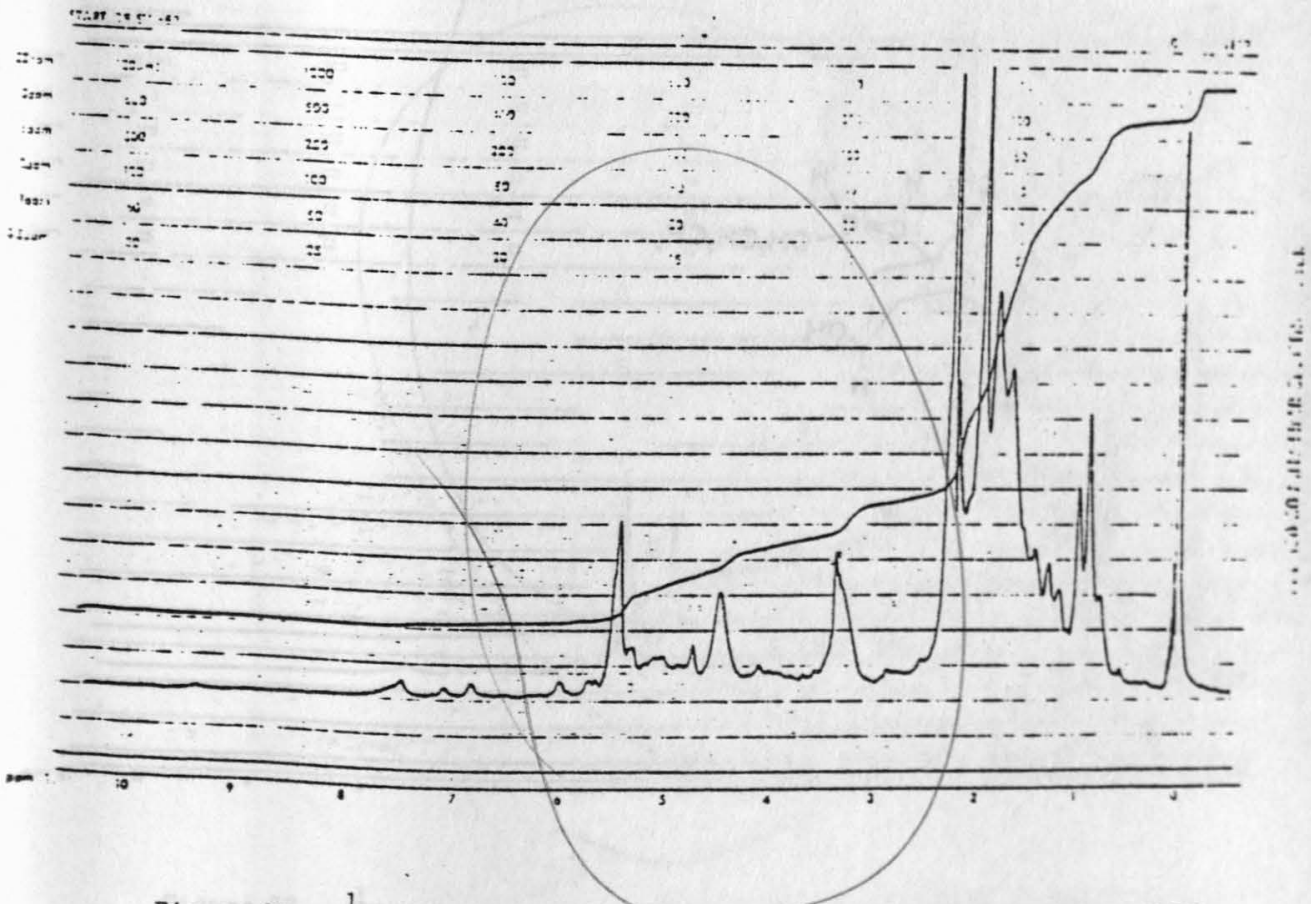

Figure 21. ${ }^{1}$ H NMR spectrum of 1-(1-penteny1)-3B-acetoxytropane (103). 


$$
230
$$




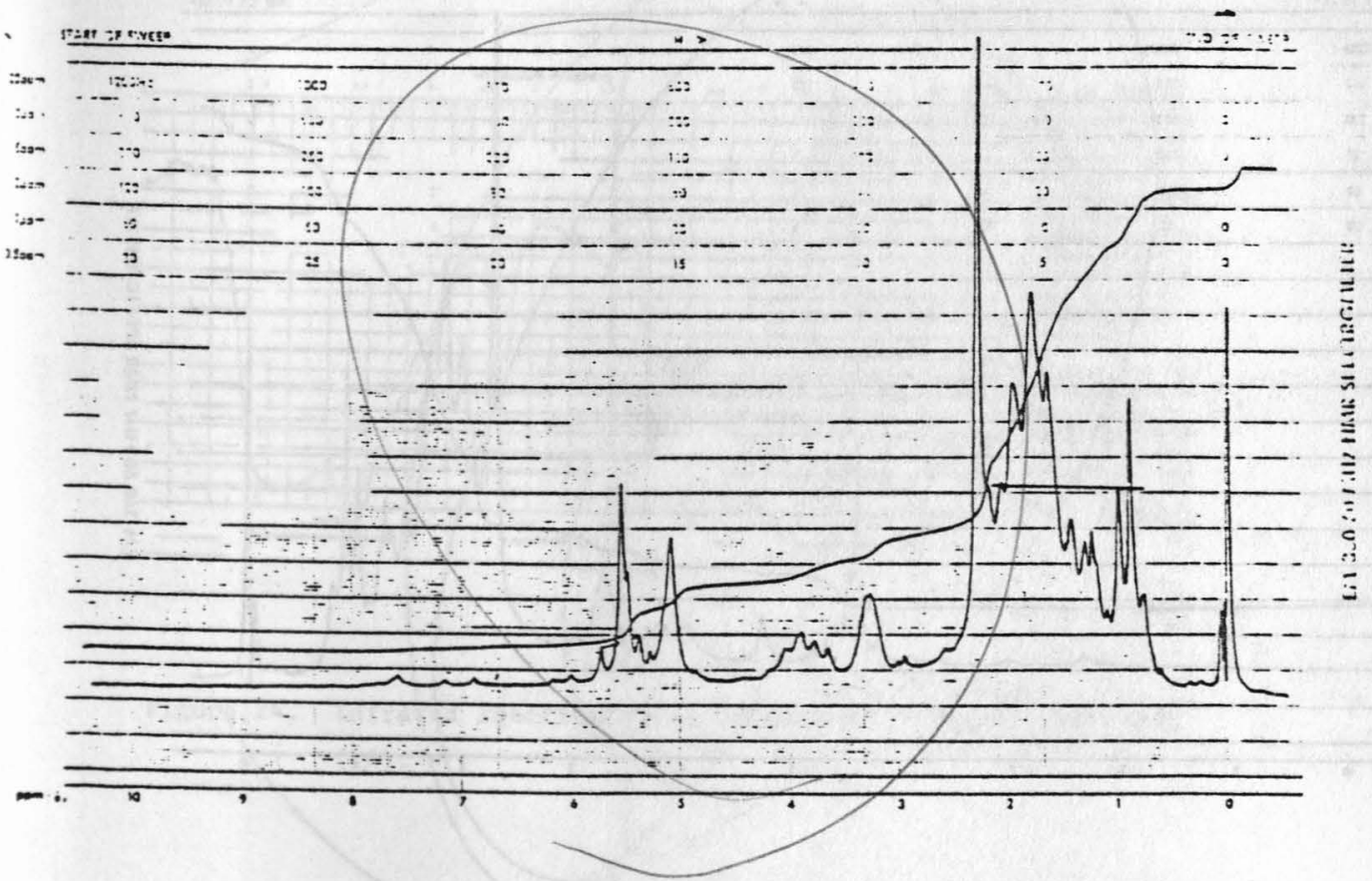

Figure 22. ${ }^{1}$ H NMR spectrum of 1-(1-penteny 1$) 38$-hydroxytropane (14). Solvent: $\mathrm{CDCl}_{3}$ 


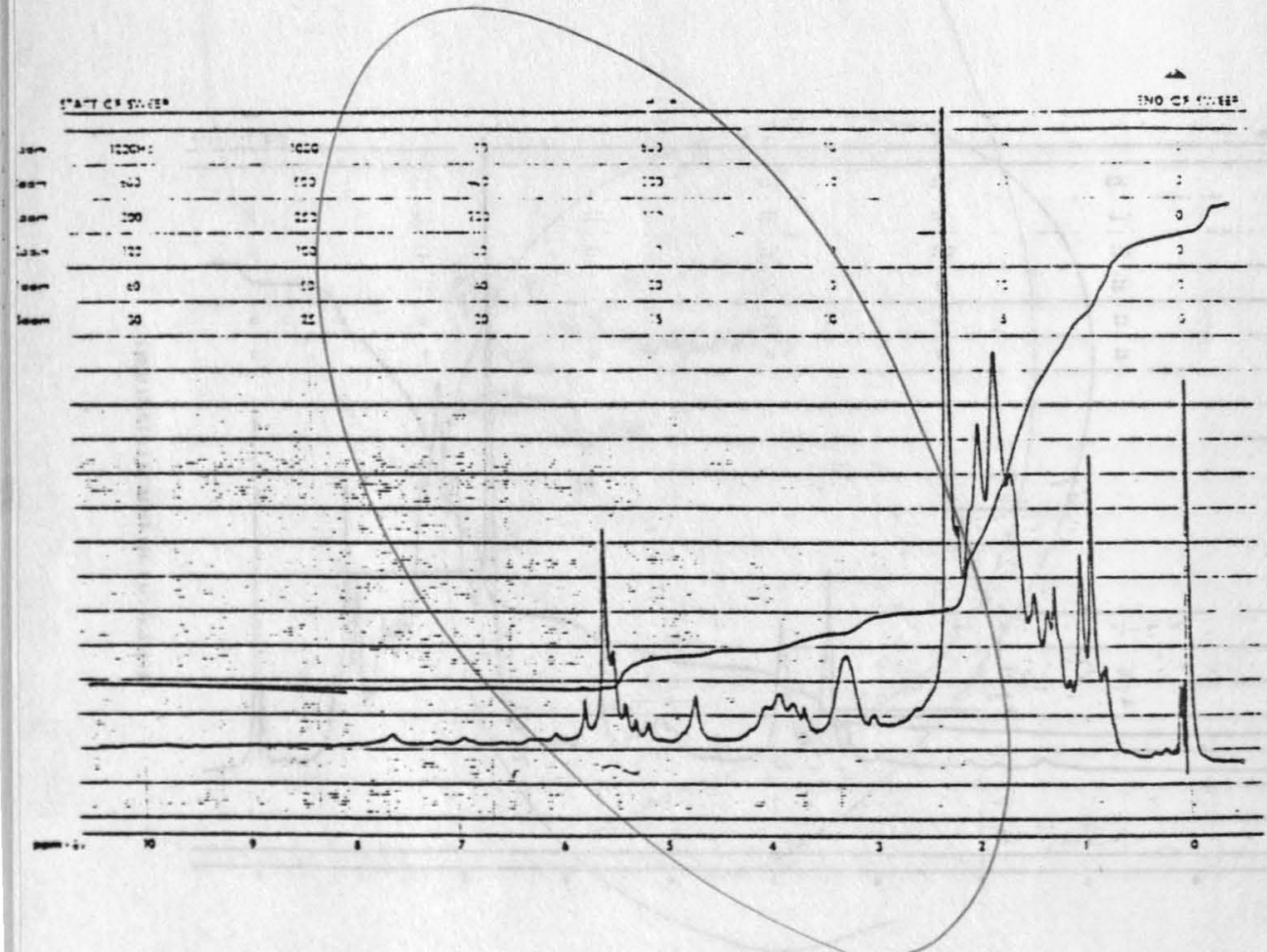

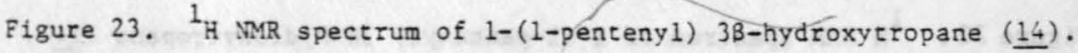
Solvent: $\mathrm{CDCl}_{3}+\mathrm{D}_{2} \mathrm{O}$ 


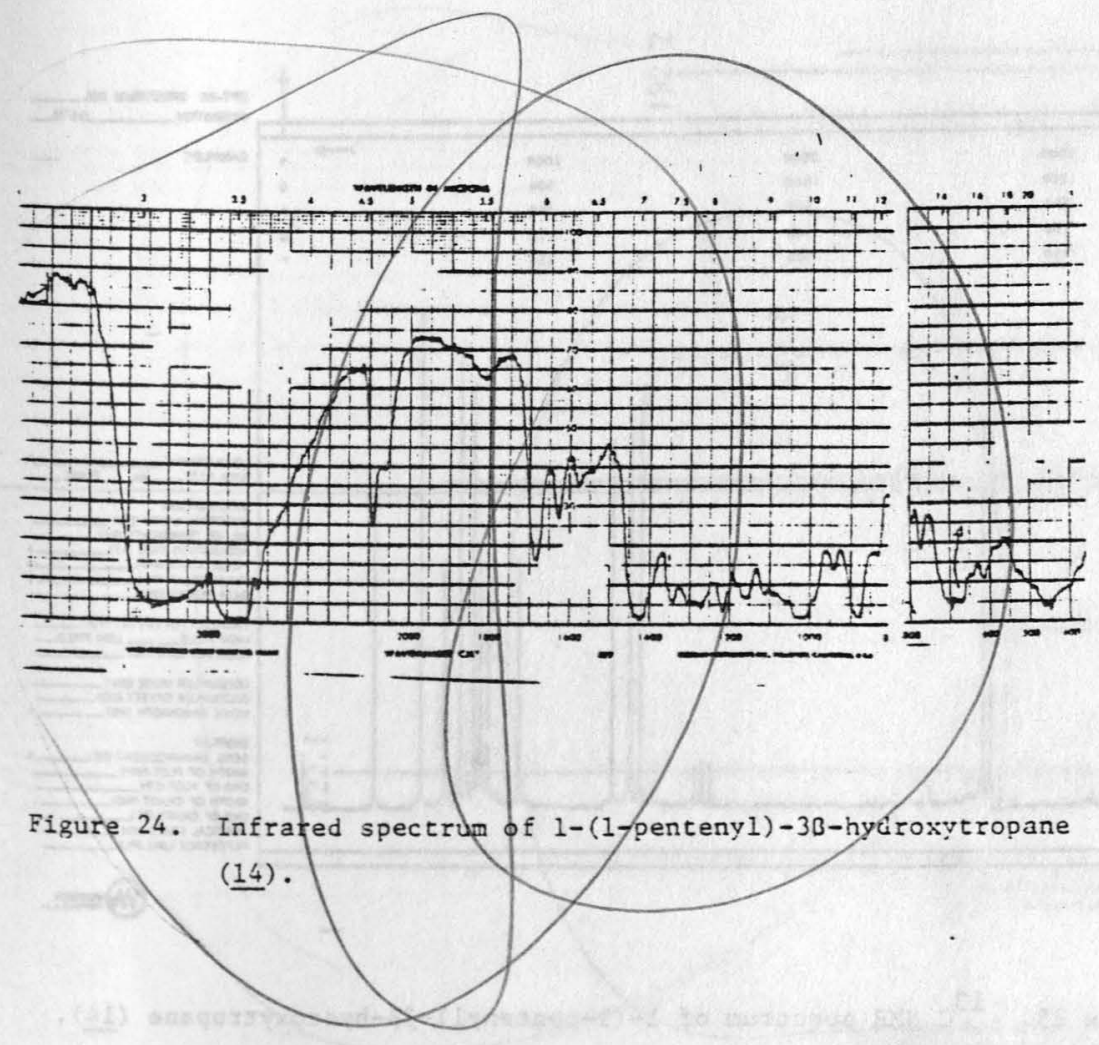




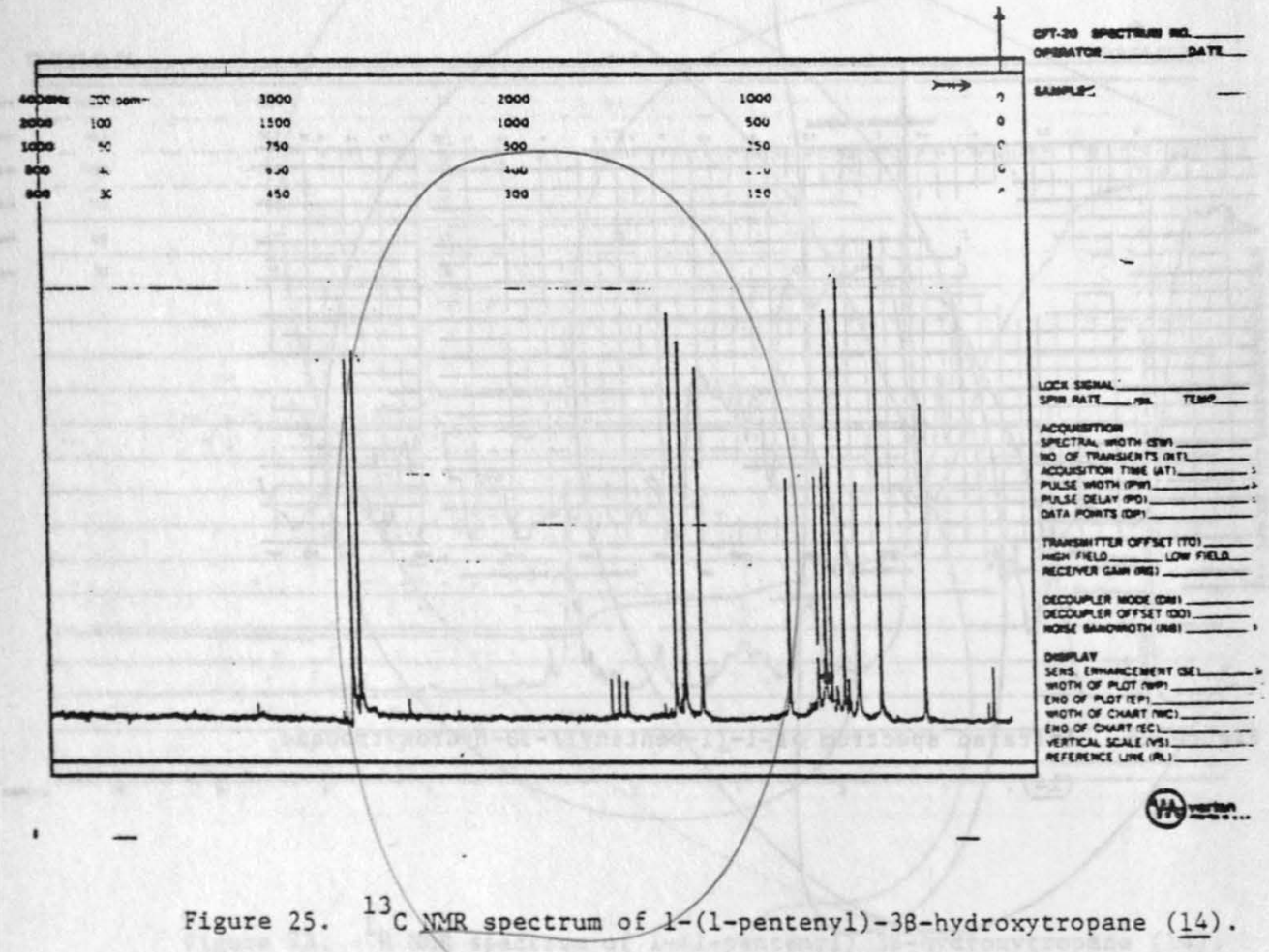


है

瓷

is

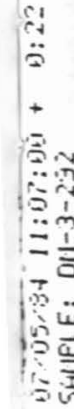
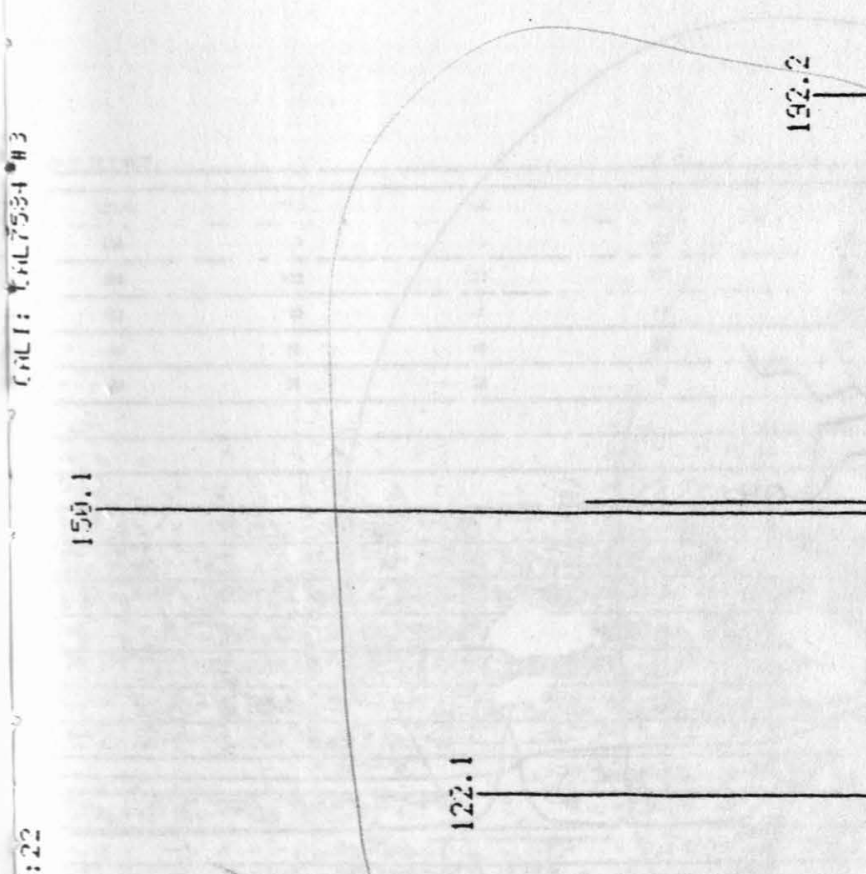


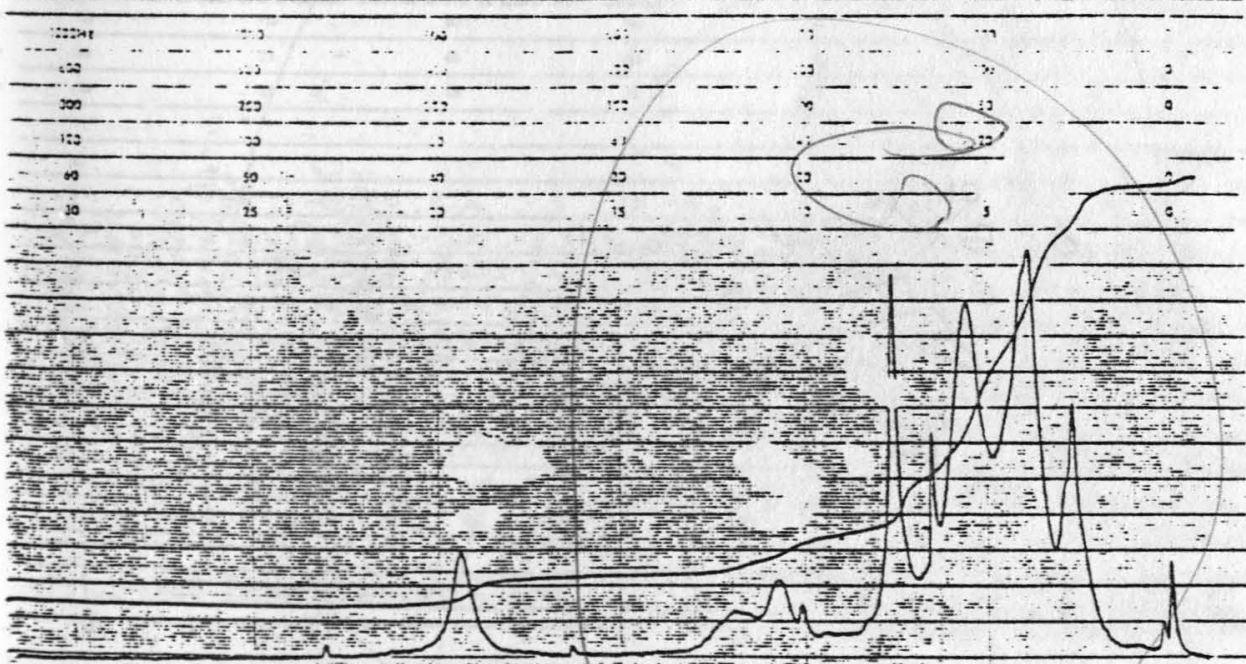

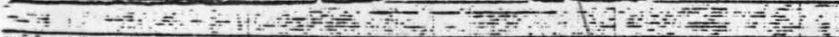

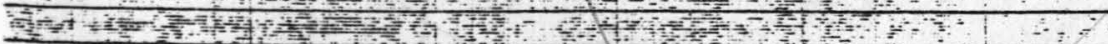

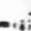
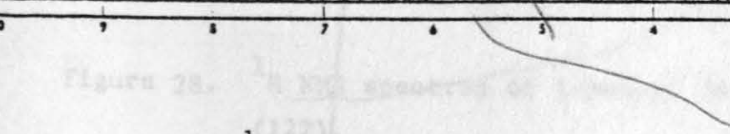

Figure 27. ${ }^{1} \mathrm{H}$ NMR spectrum of 1-pentenyl 38-hydroxytropane (15). 


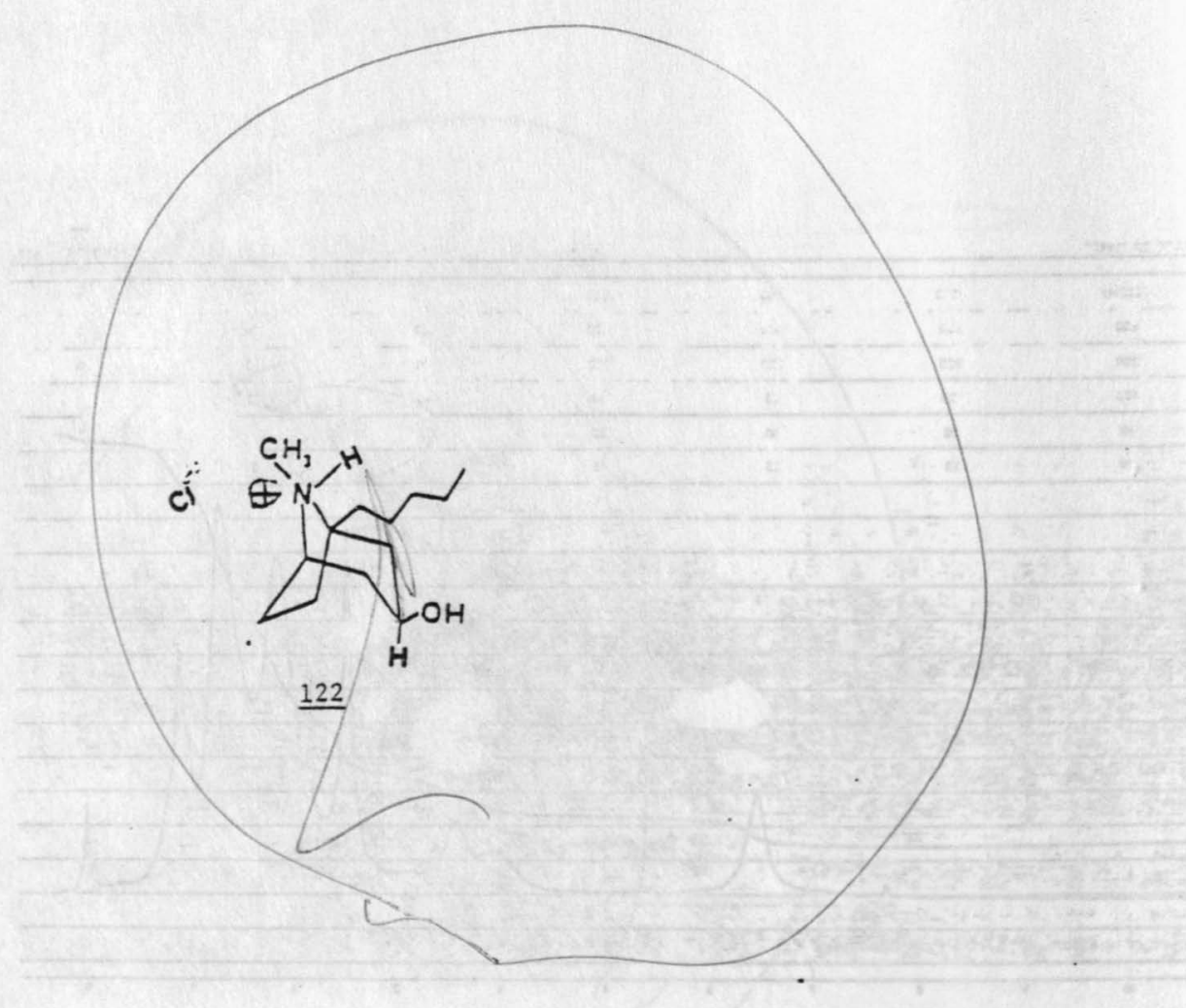




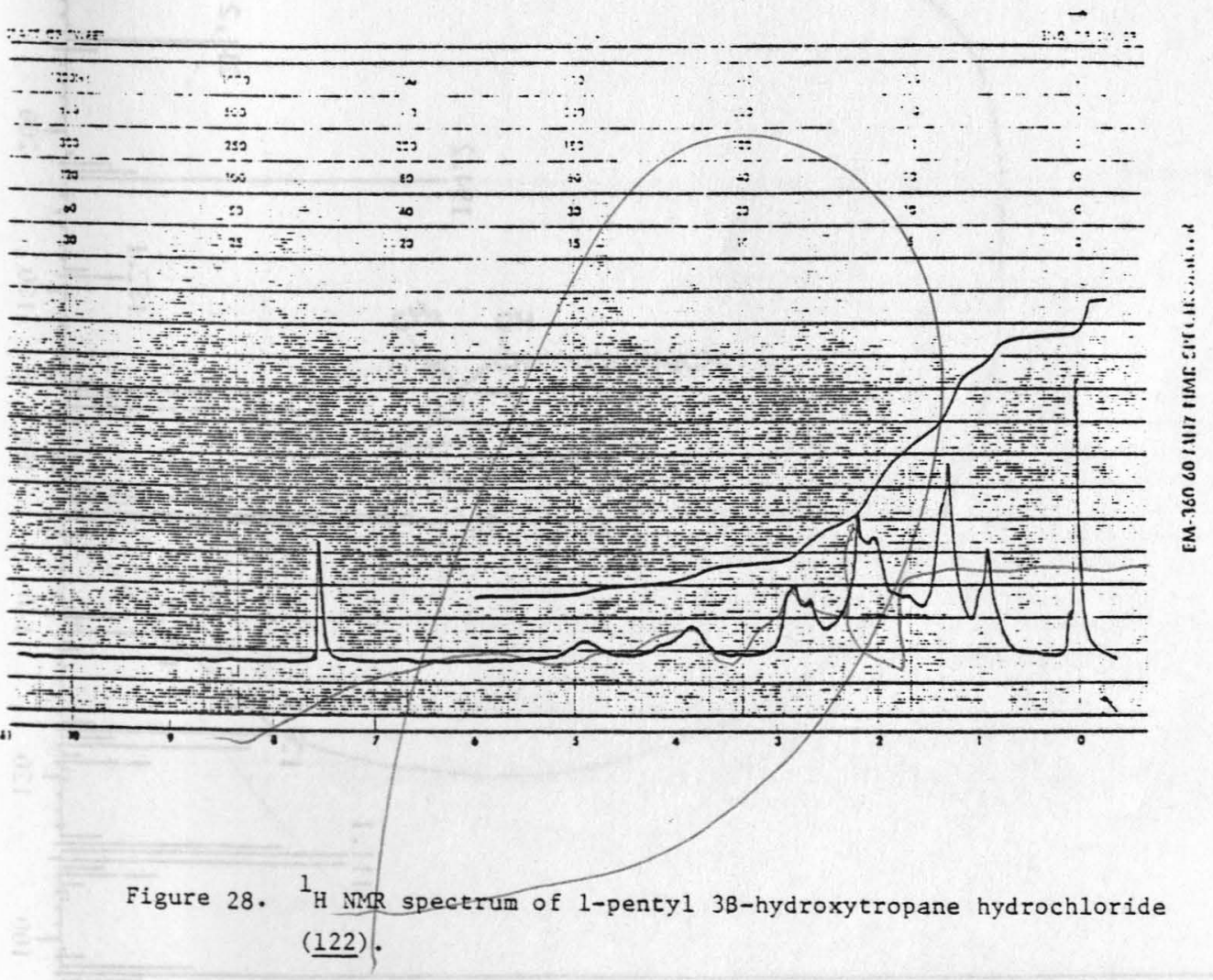




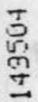

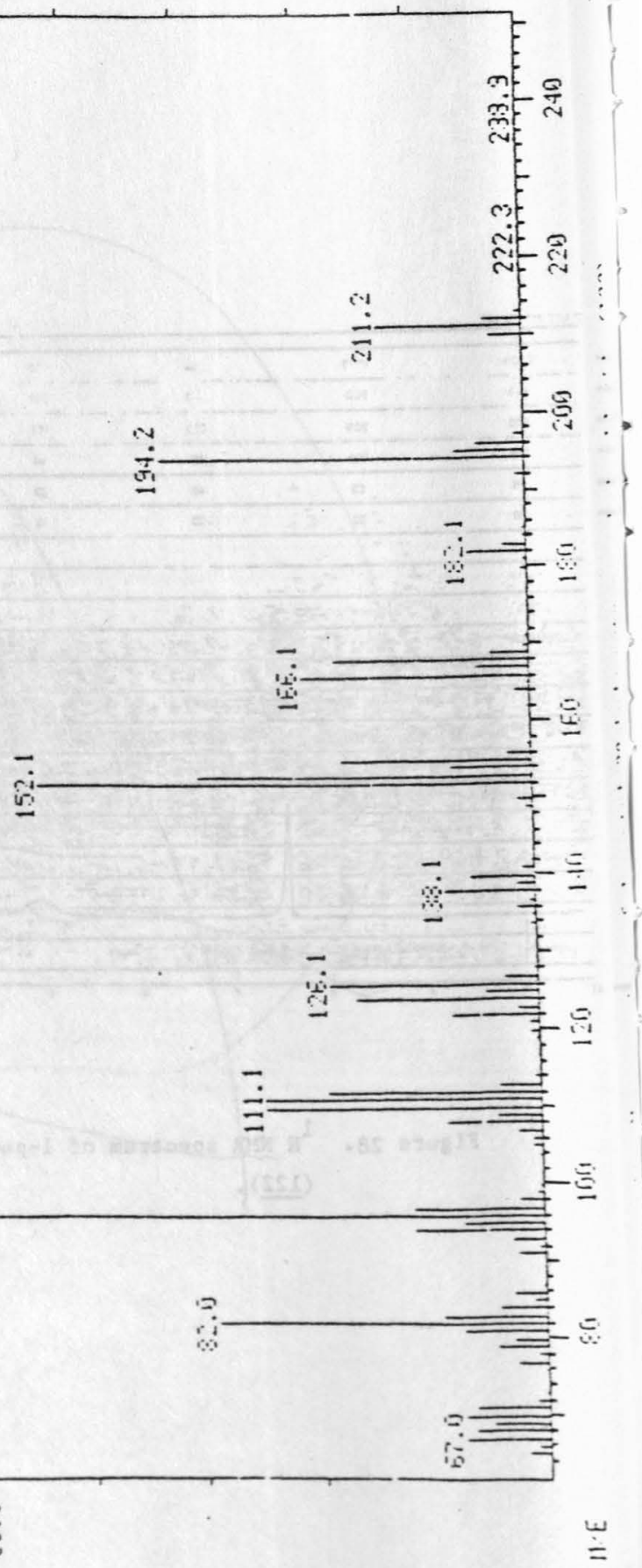




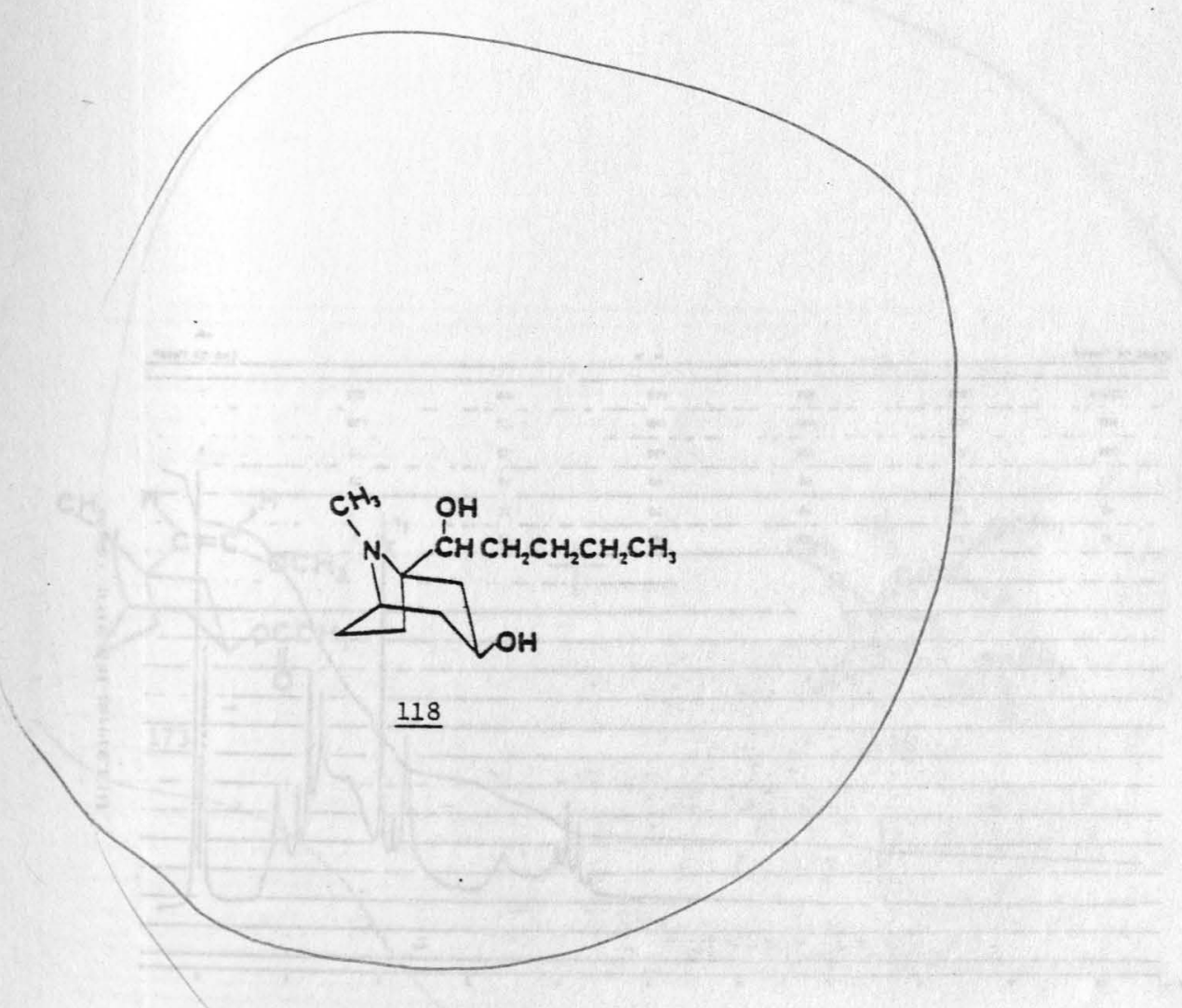




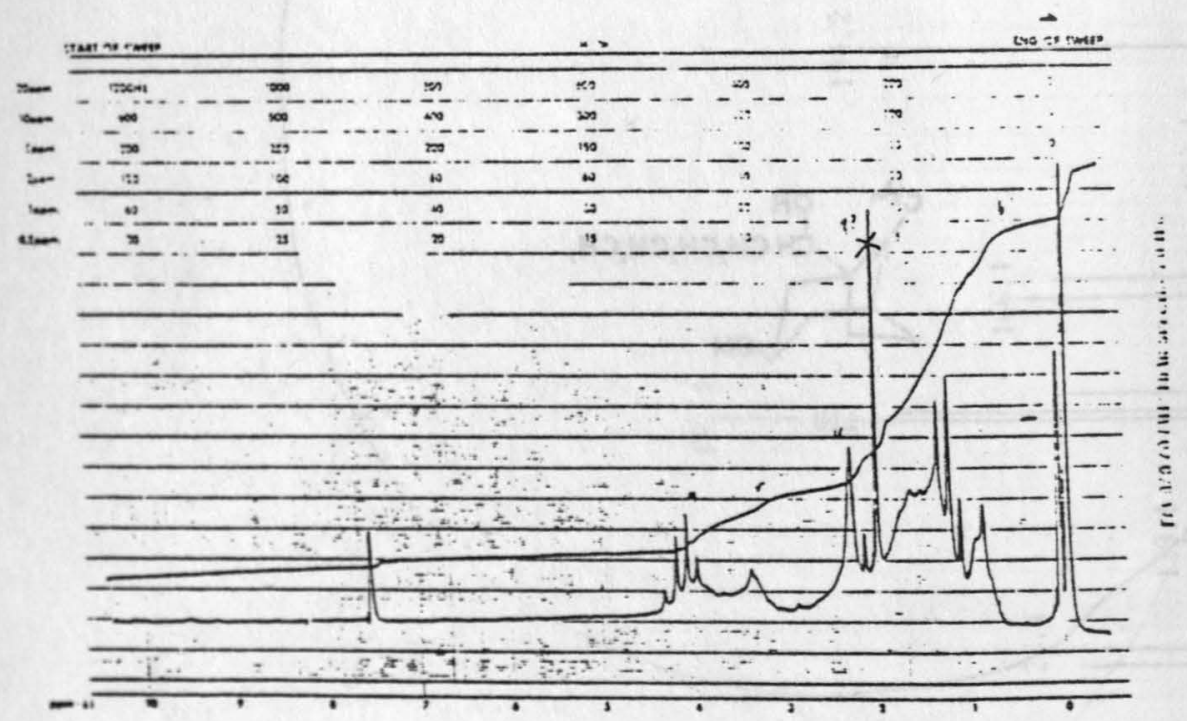

Figure 30. ${ }^{1}$ H NMR spectrum of 1-(1-hydroxypenty 1$)-3 B$-hydroxytropane (118). 


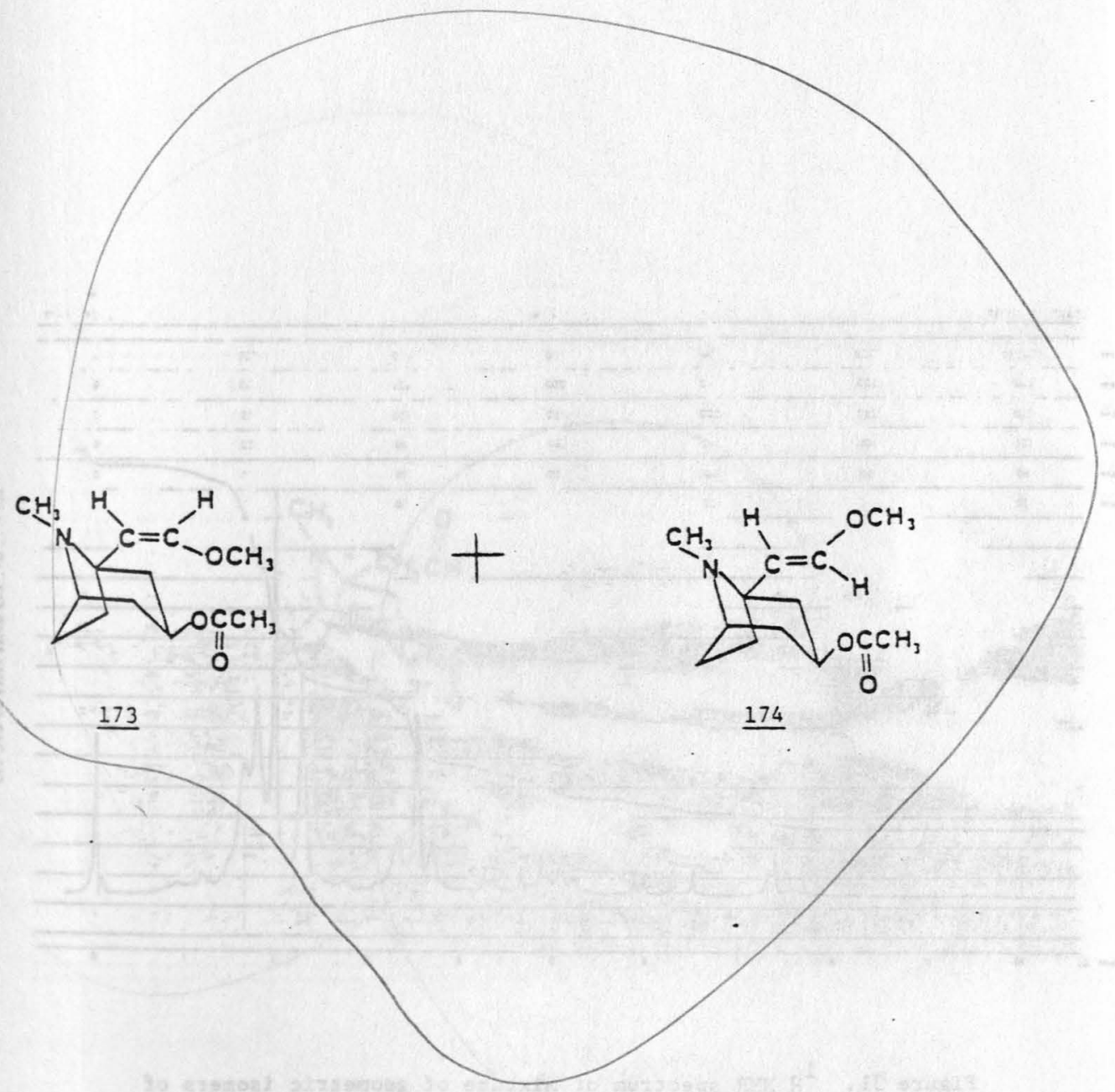




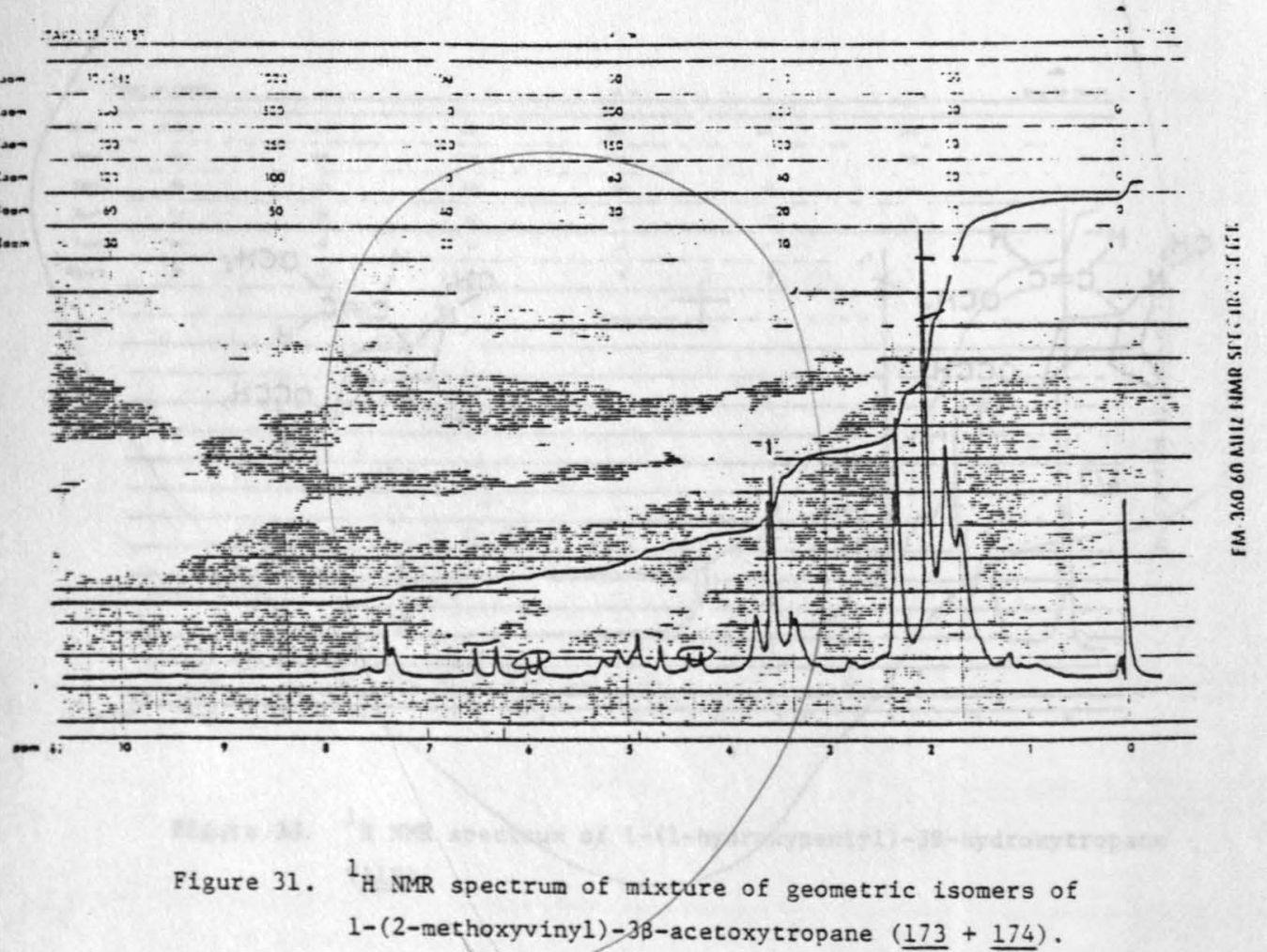




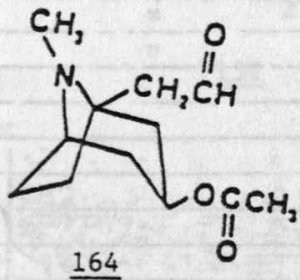




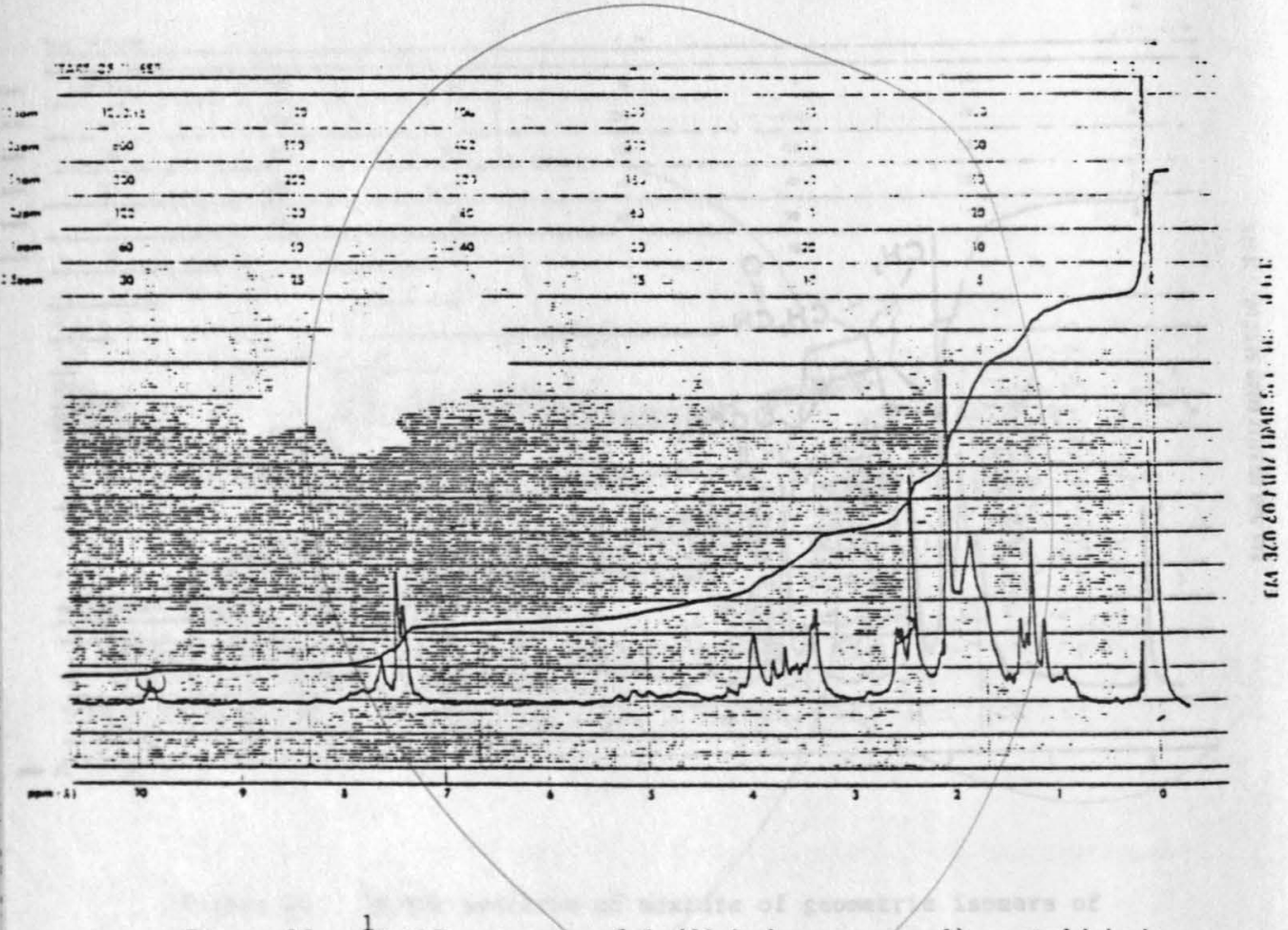

Figure 32. ${ }^{1}$ H NMR spectrum of 1-(3B-hydroxytropanyl) acetaldehyde (164). 


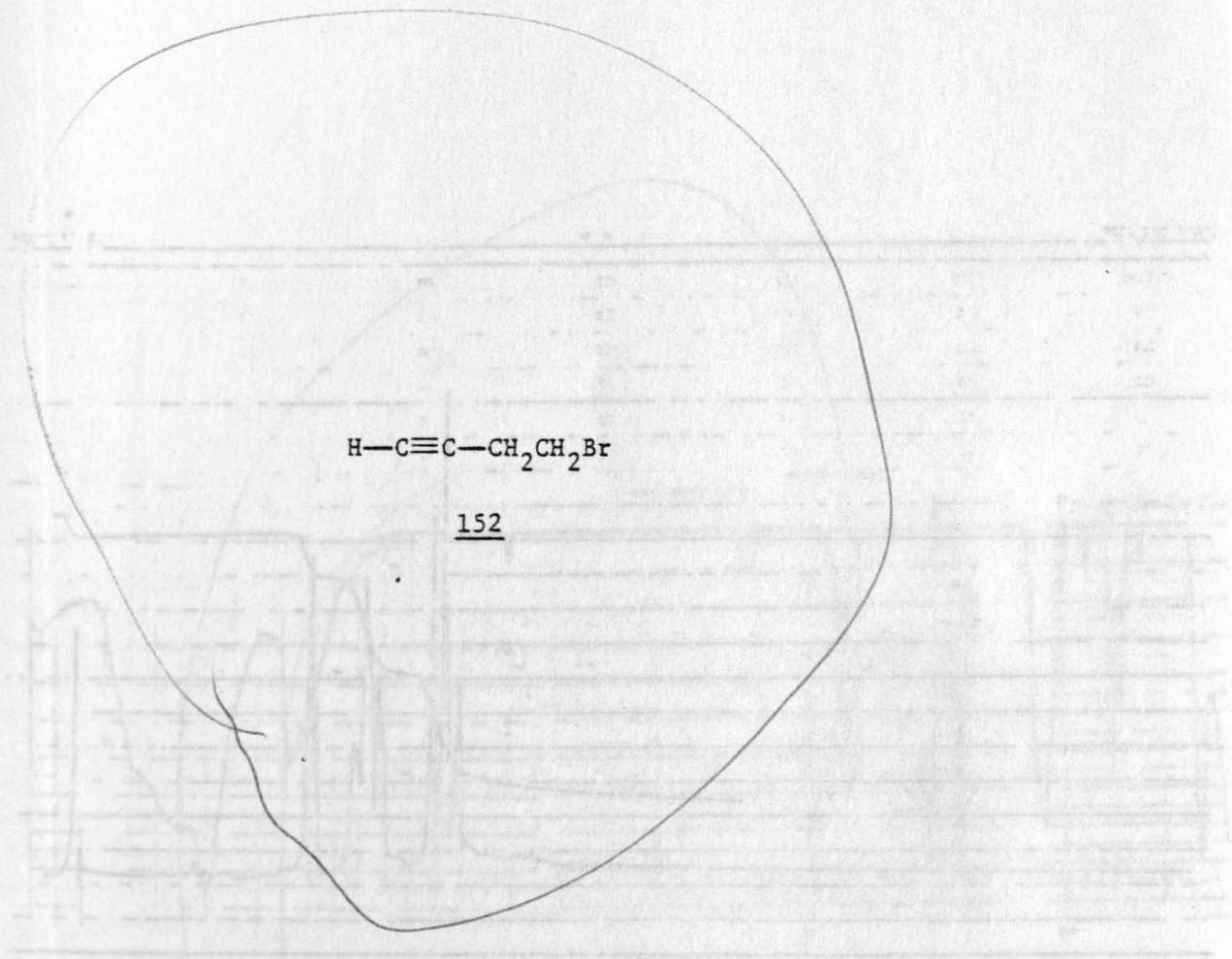




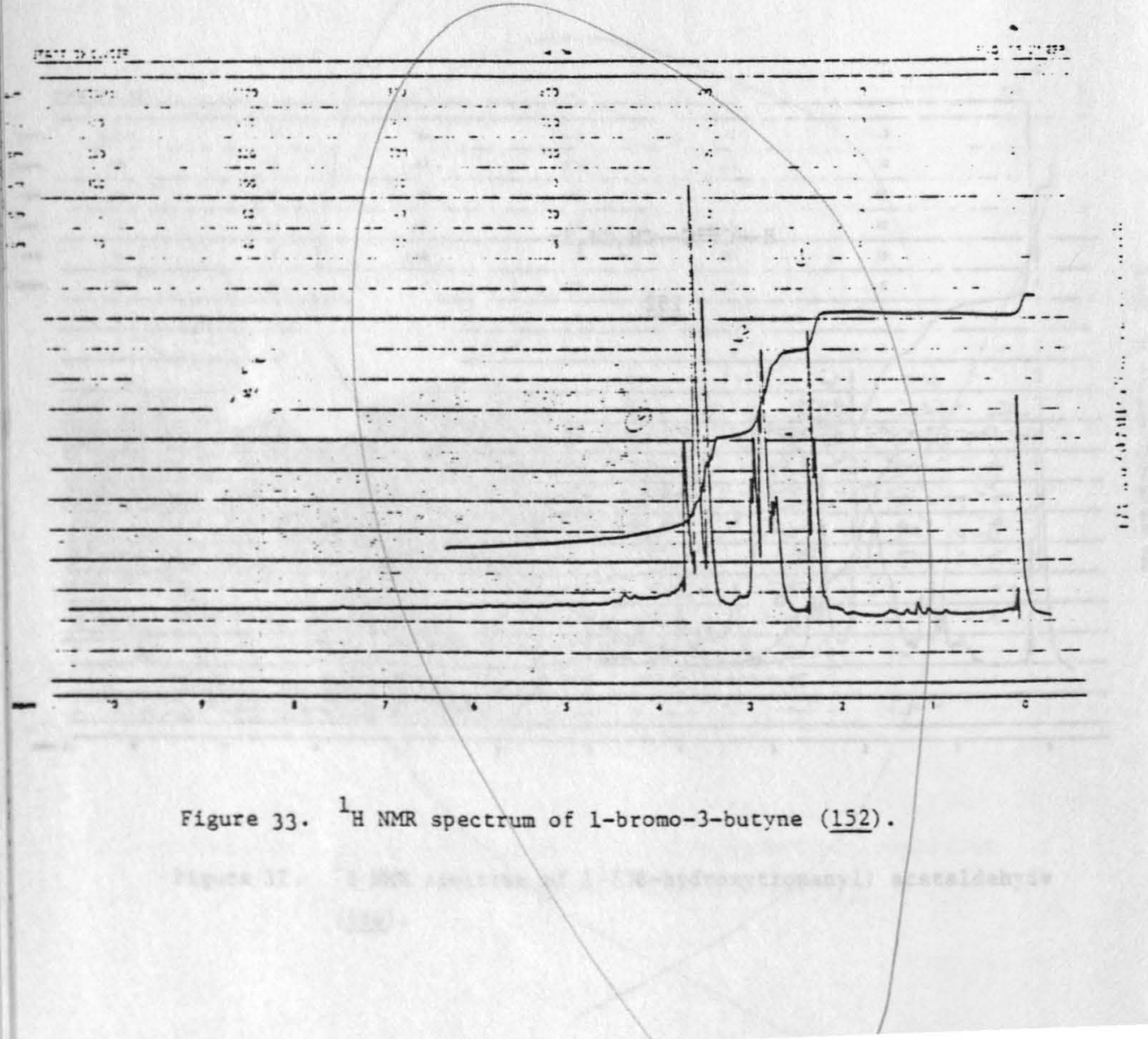




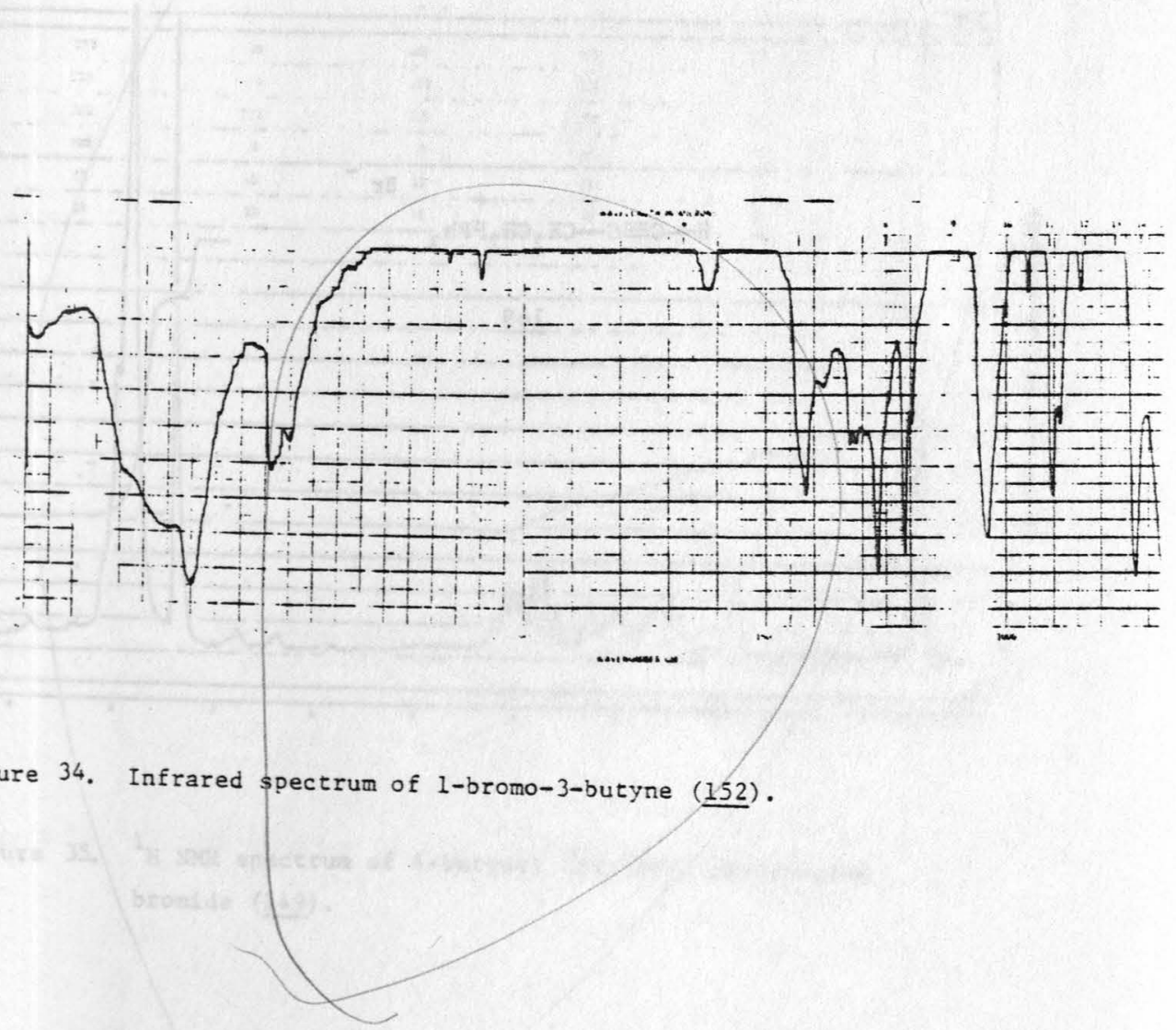


:72: : : $24: t^{3}$

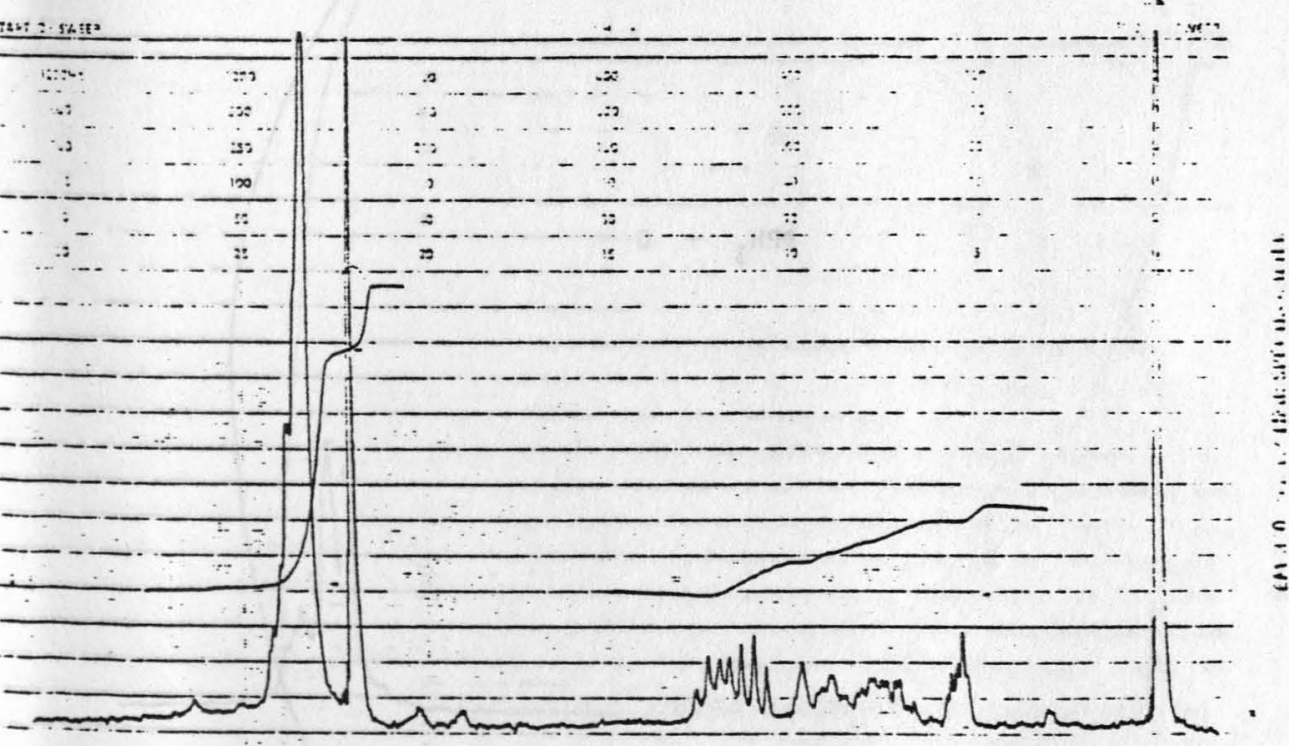

Figure 35. ${ }^{1}$ H MMR spectrum of 4-butynyl triphenyl phosphonium bromide $(\underline{149})$. 


$$
252
$$




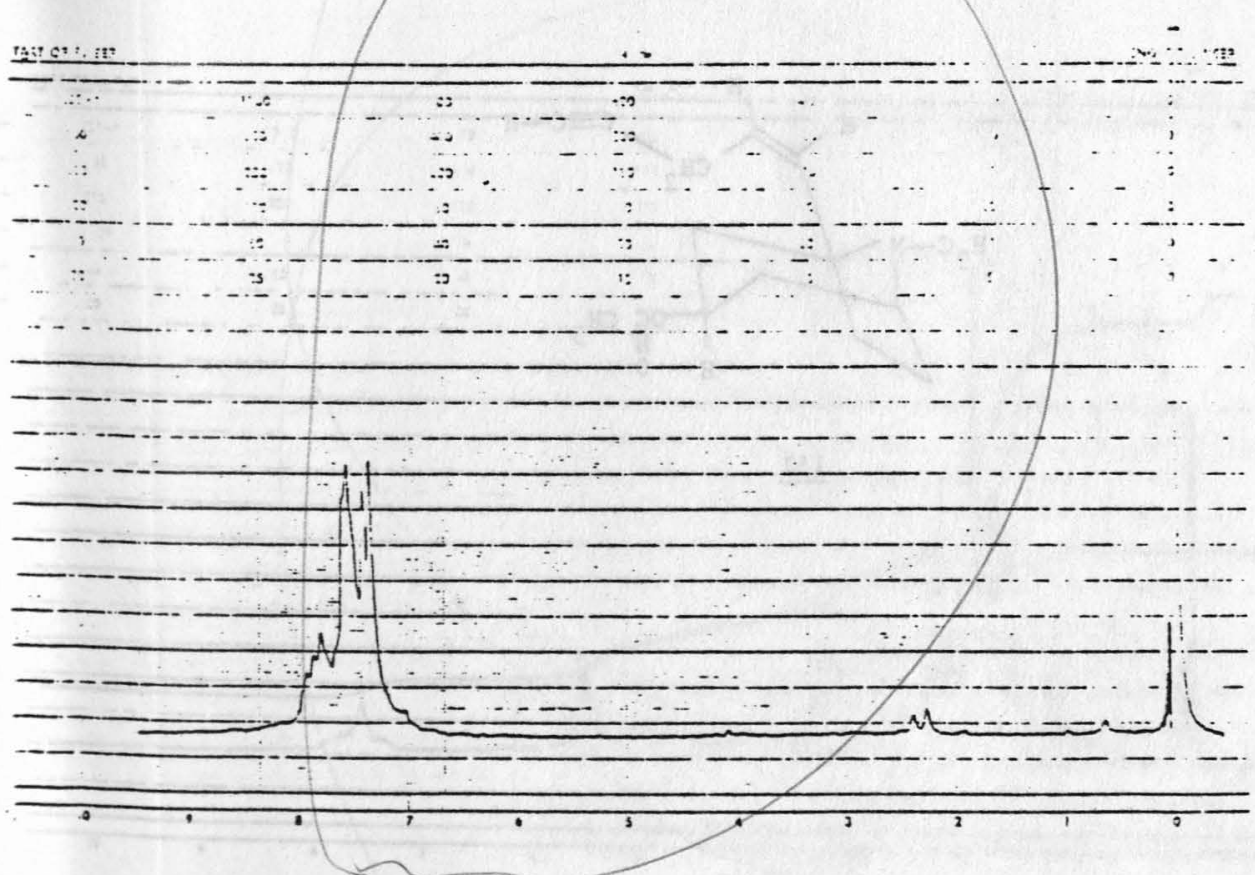

Figure $36.1_{H}$ NMR spectrum of triphenylphosphine oxide. 


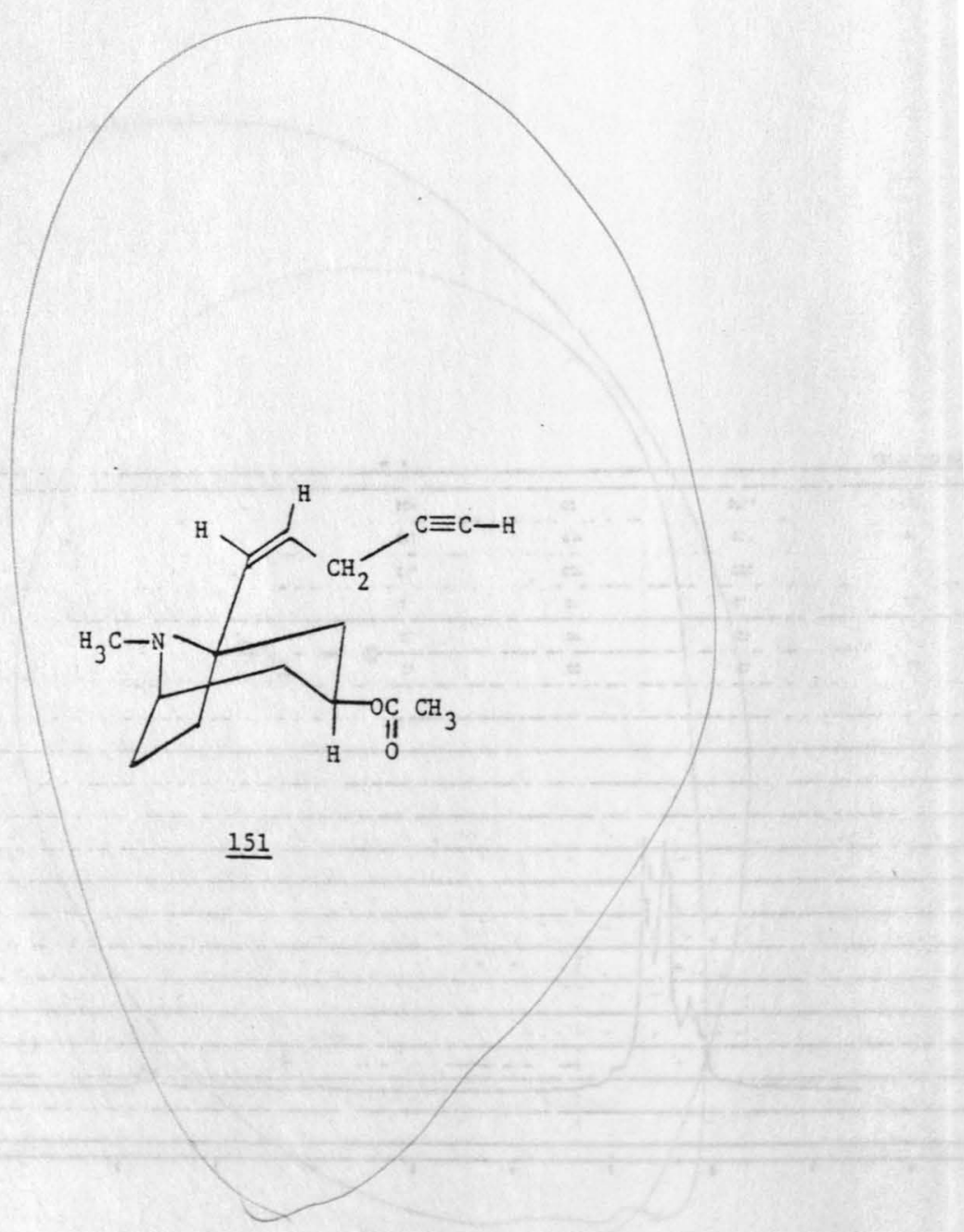




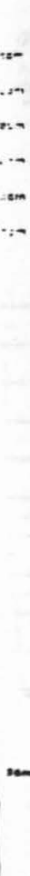

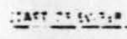
$-$

(3)

$\left.\begin{array}{ccc}\because & -: \\ \because & \vdots \\ -\because & -\cdots & -\cdots\end{array}\right]$

$:$

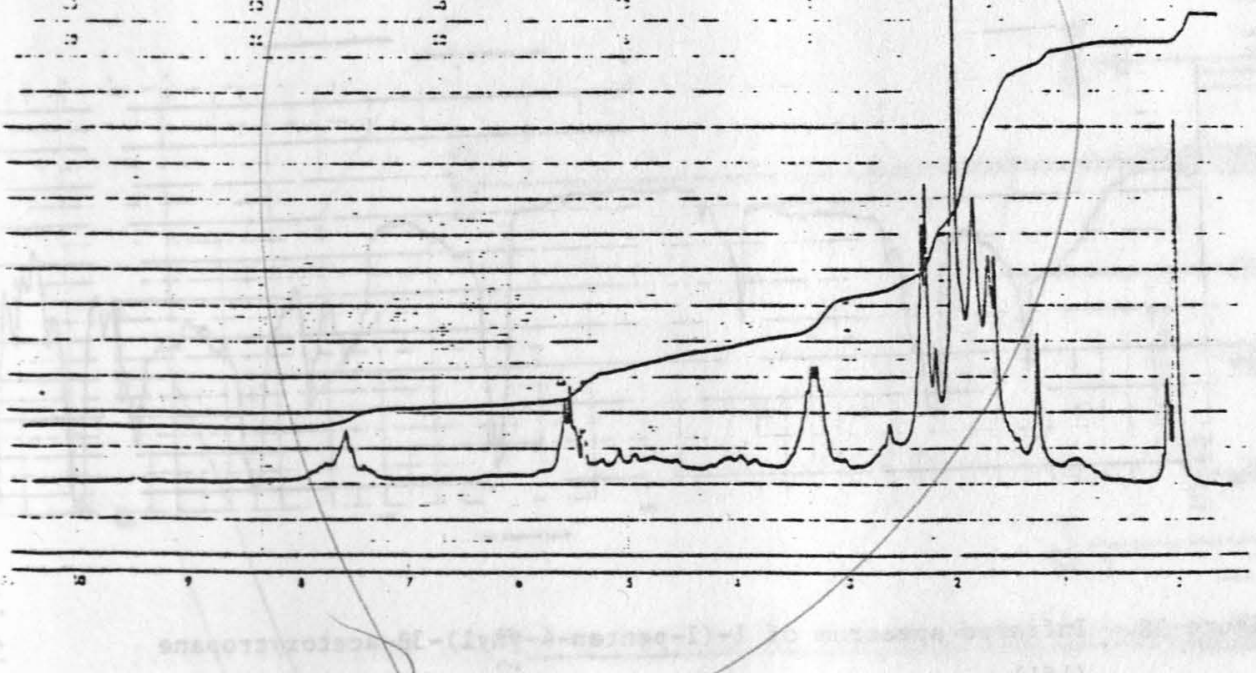

Figure 37. ${ }^{1} \mathrm{H}$ NMR spectrum of $1-(1-$ penten-4-yny 1$)-3 B$-acetoxytropane (151) 


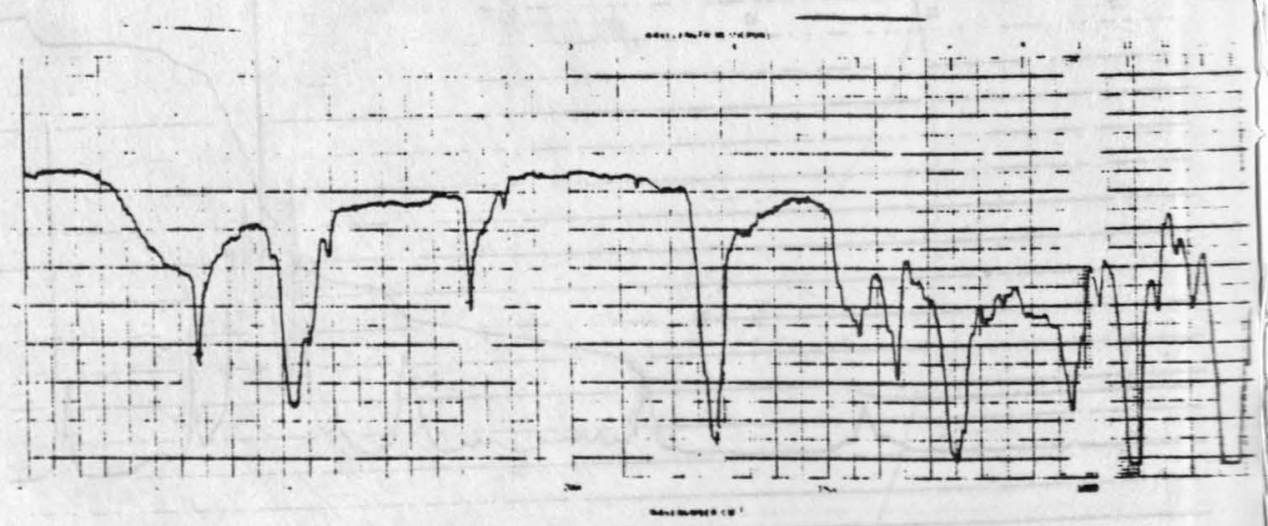

Figure 38. Infrared spectrum of 1-(1-penten-4-yny 1$)-3 \beta$-acetoxytropane (151). 


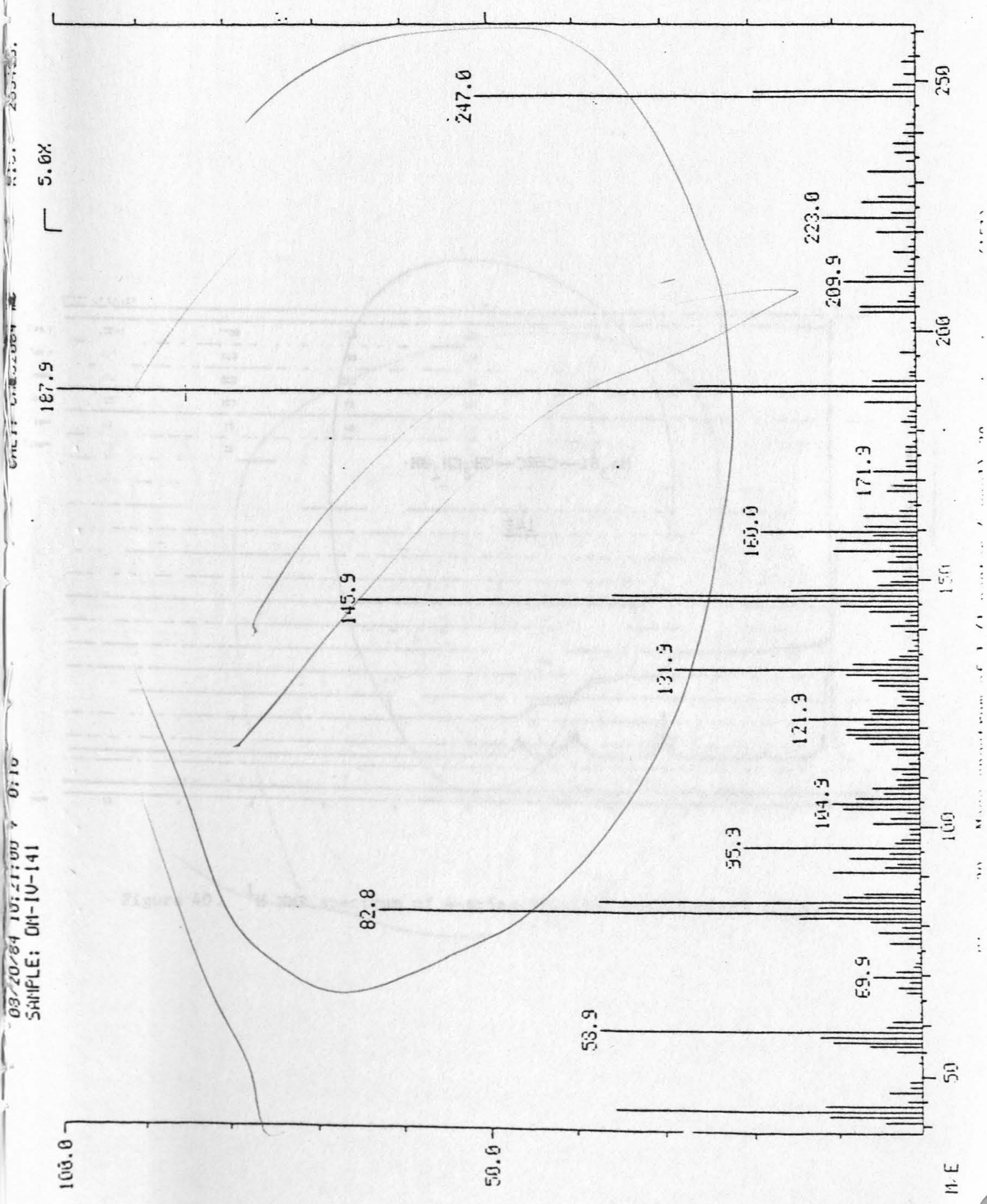




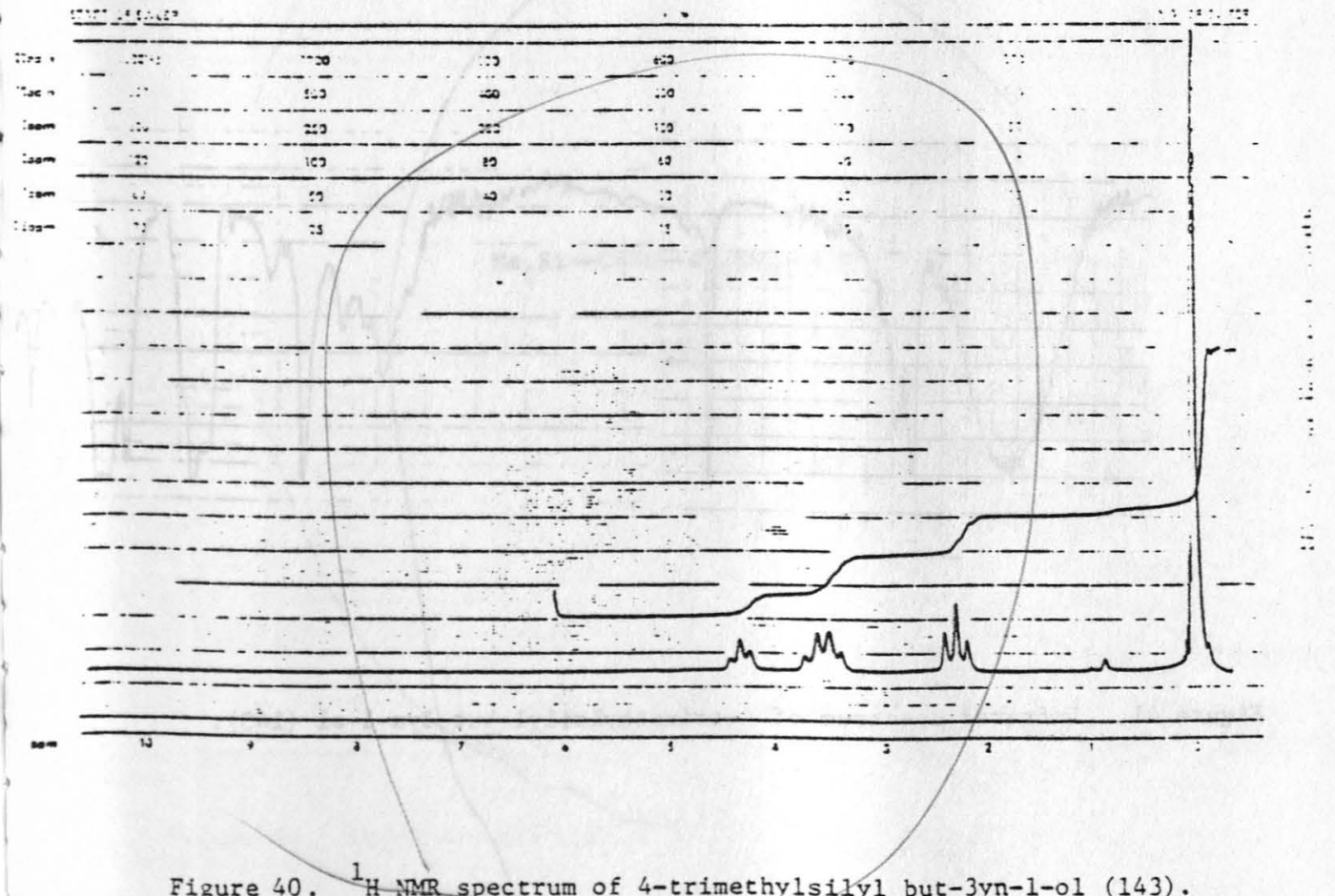




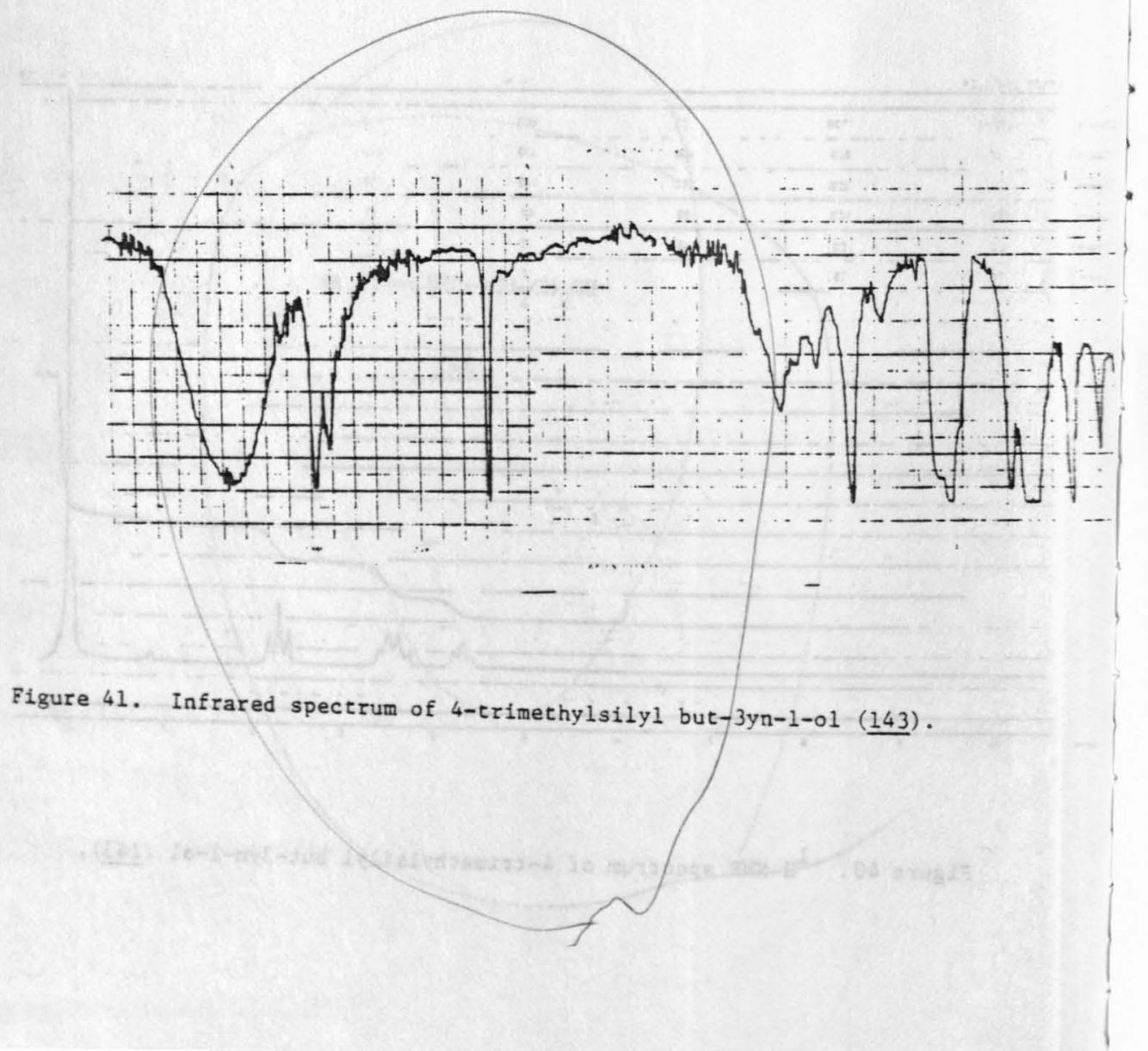




$$
\mathrm{Me}_{3} \mathrm{Si}-\mathrm{C} \equiv \mathrm{C}-\mathrm{CH}_{2} \mathrm{CH}_{2} \text {-OTS }
$$

146 


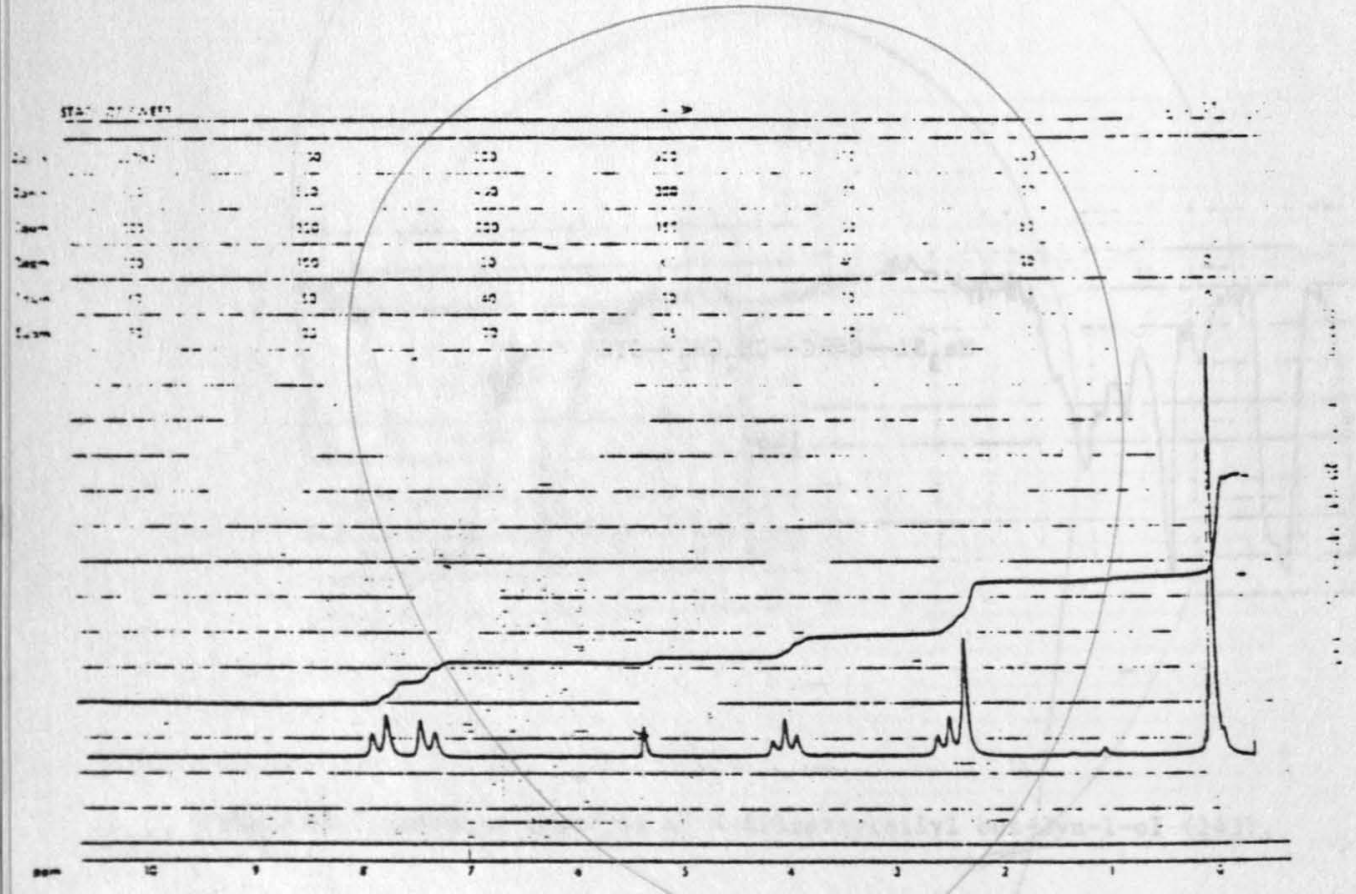

Figure 42 . $1_{H}$ NMR spectrum of 4 -trimethylsilyl but-3yn-1-tosylate (146). 


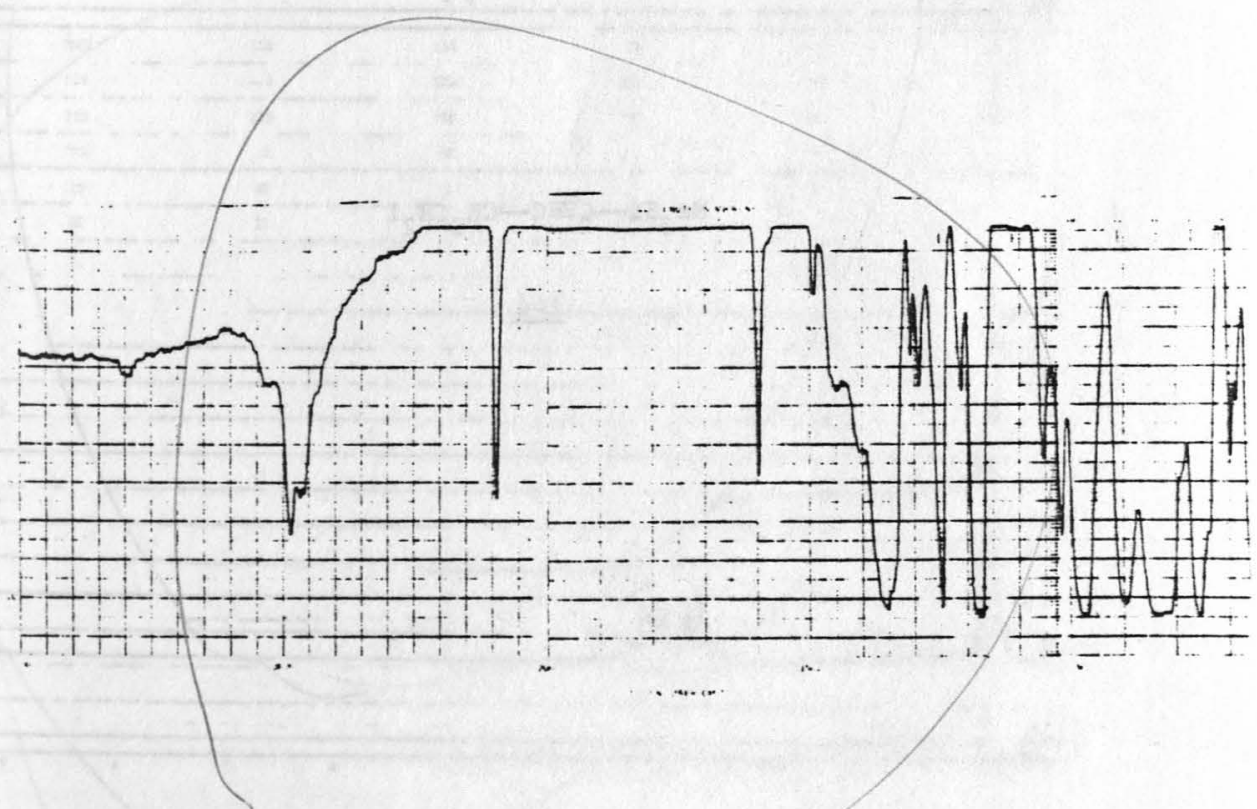

Figure 43. Infrared spectrum of 4-trimethylsilyl but-3yn-1-tosylate (146). 


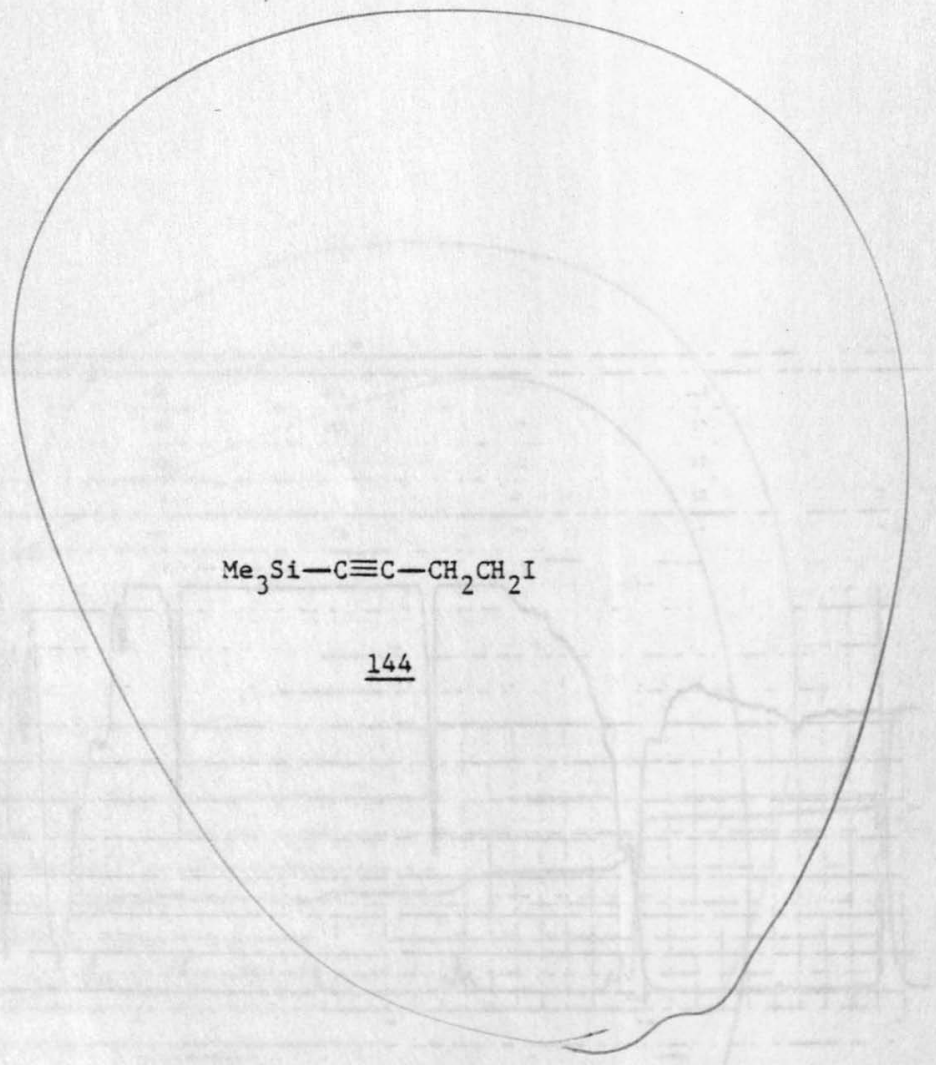




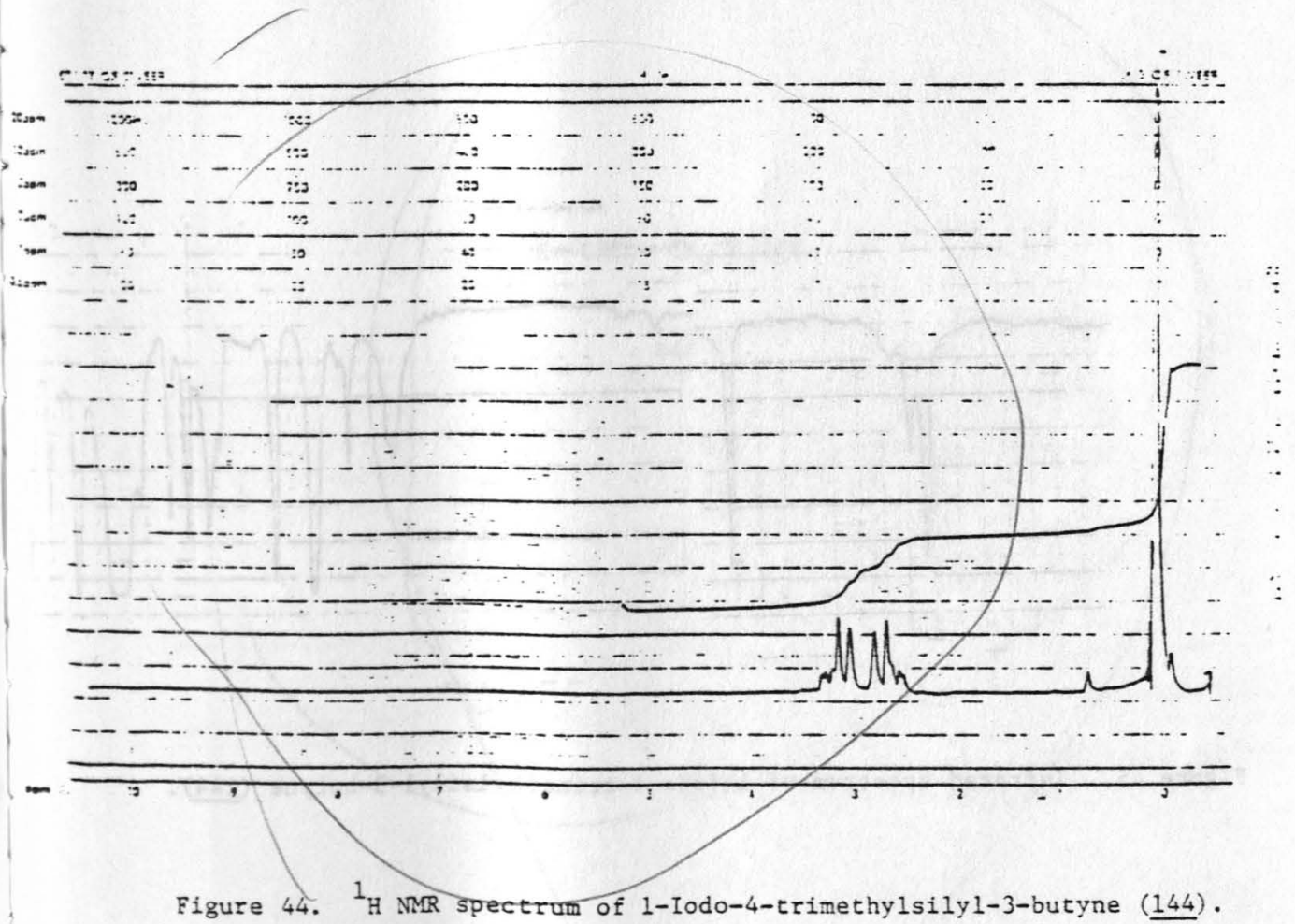




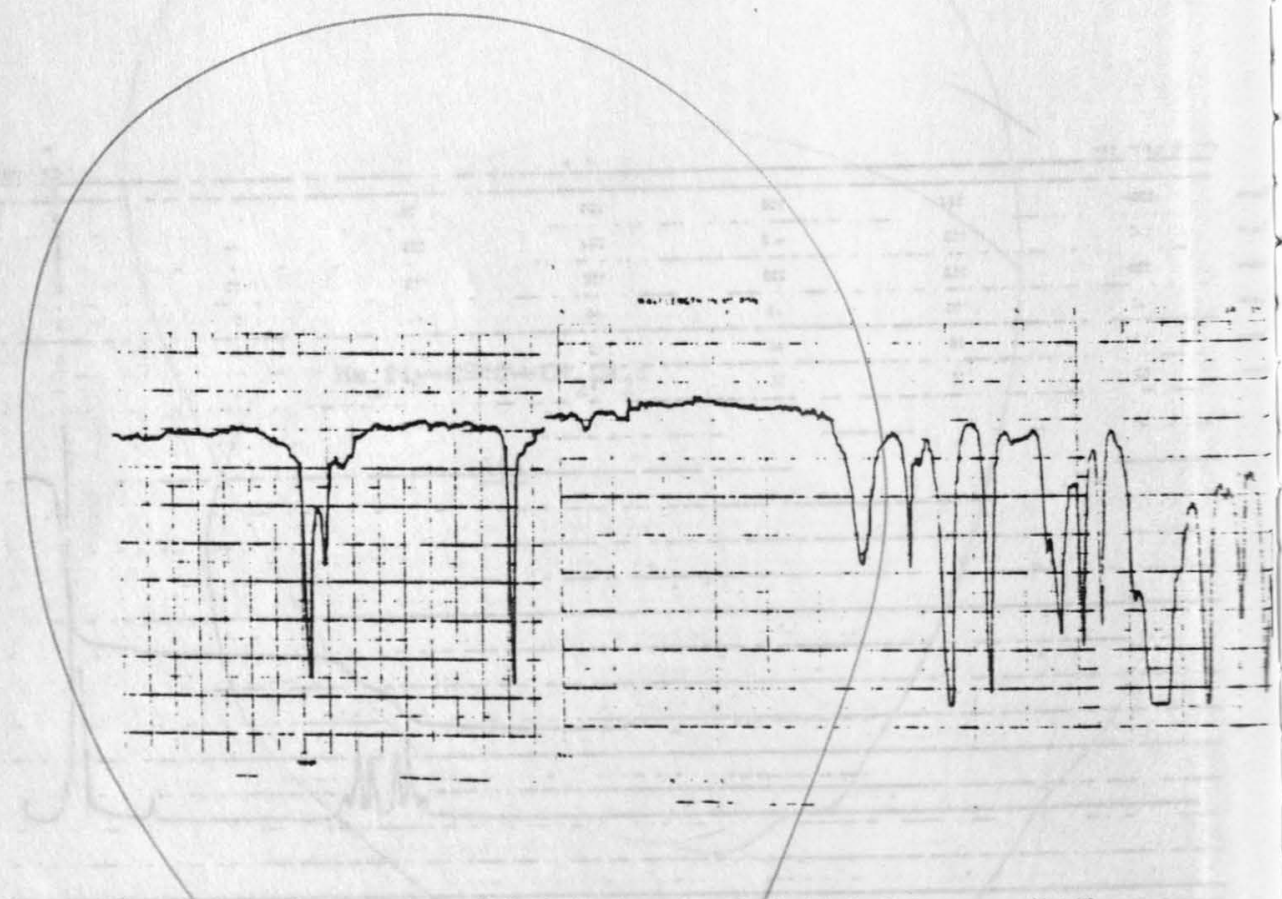

Figure 45. Infrared spectrum of 1-Iodo-4-trimethylsilyl-3-butyne (144). 


$$
267
$$




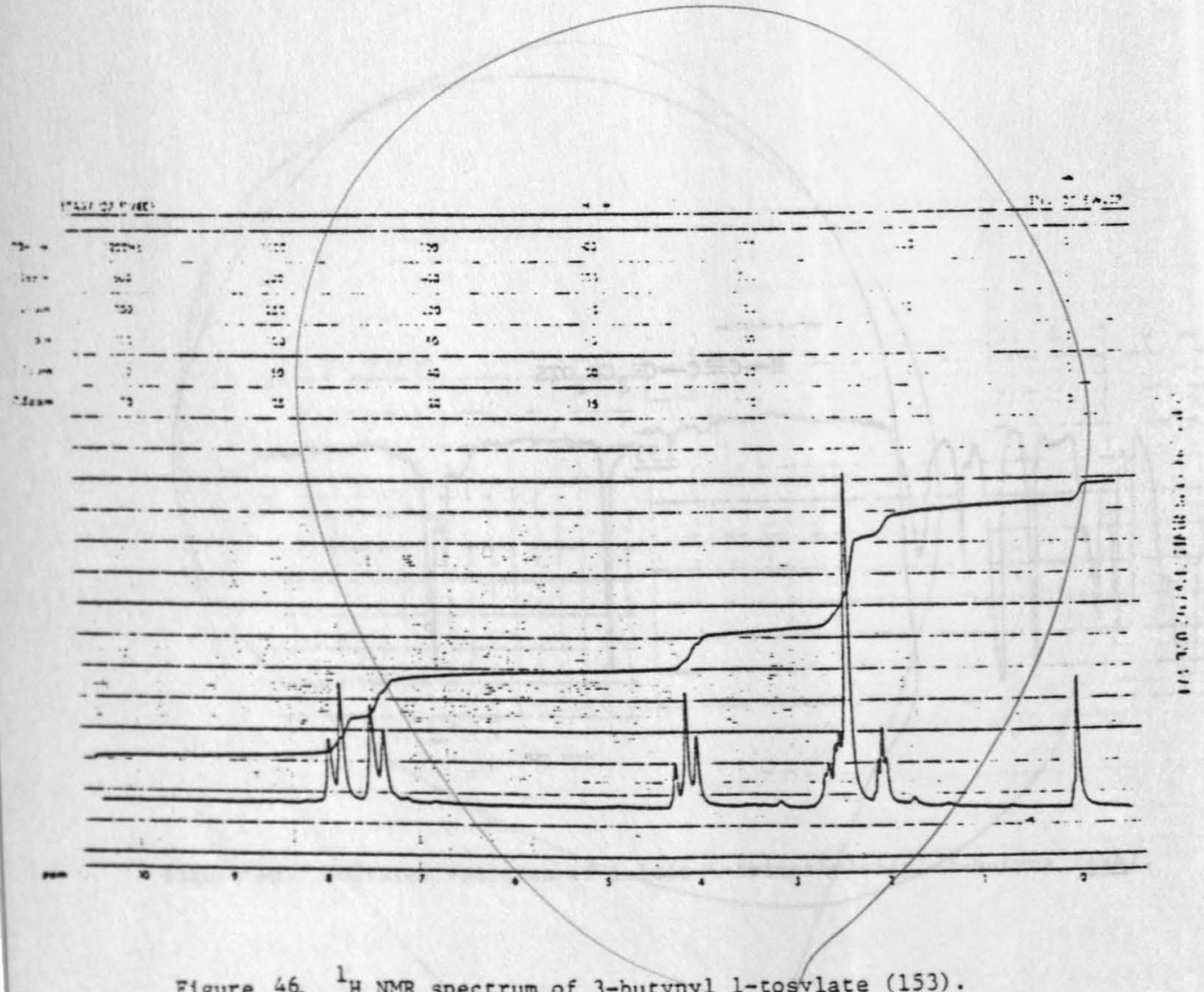

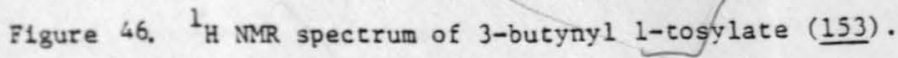




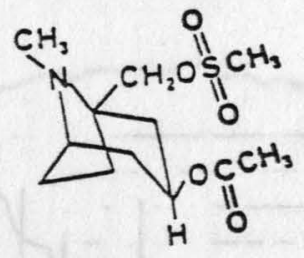

180 


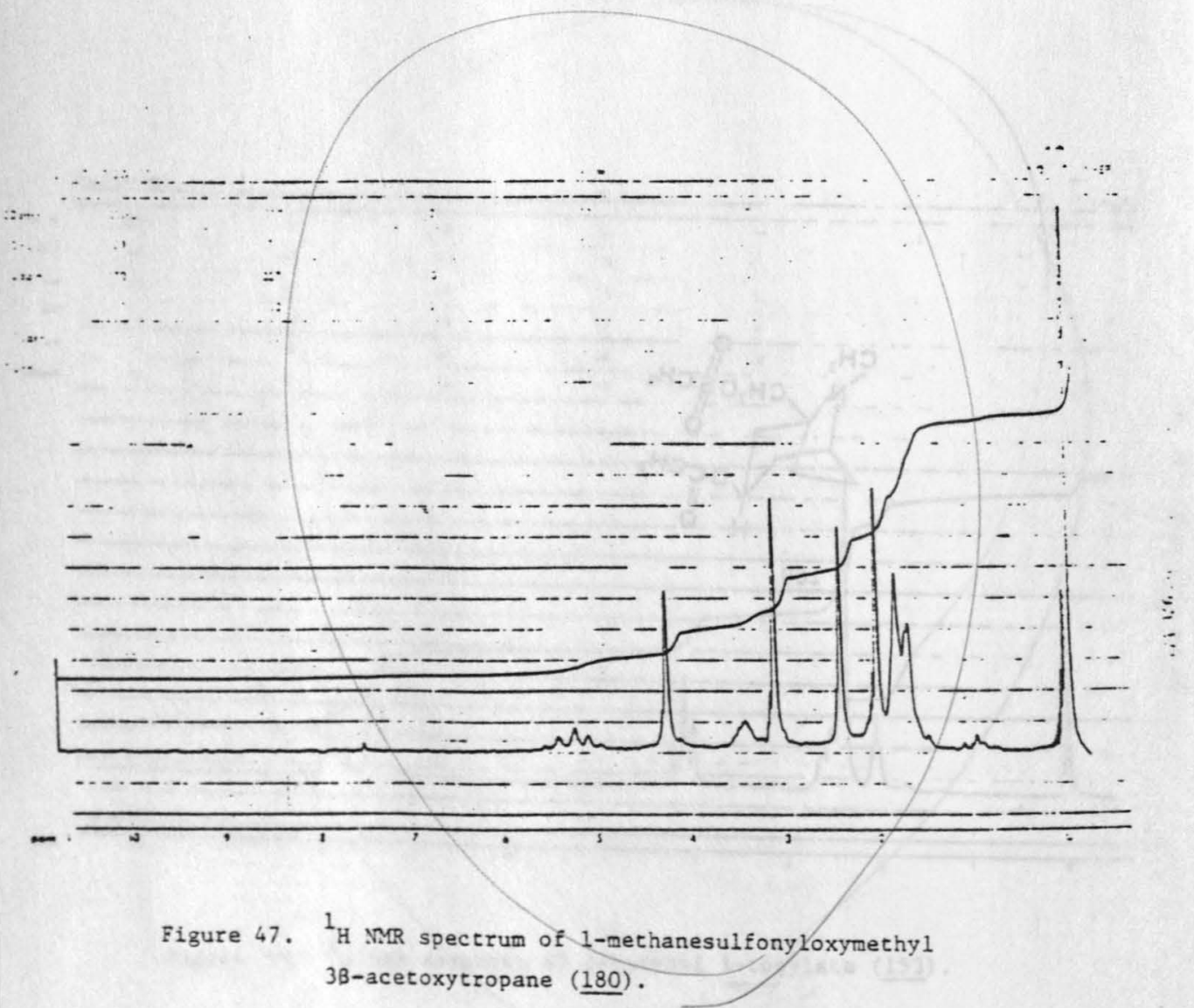




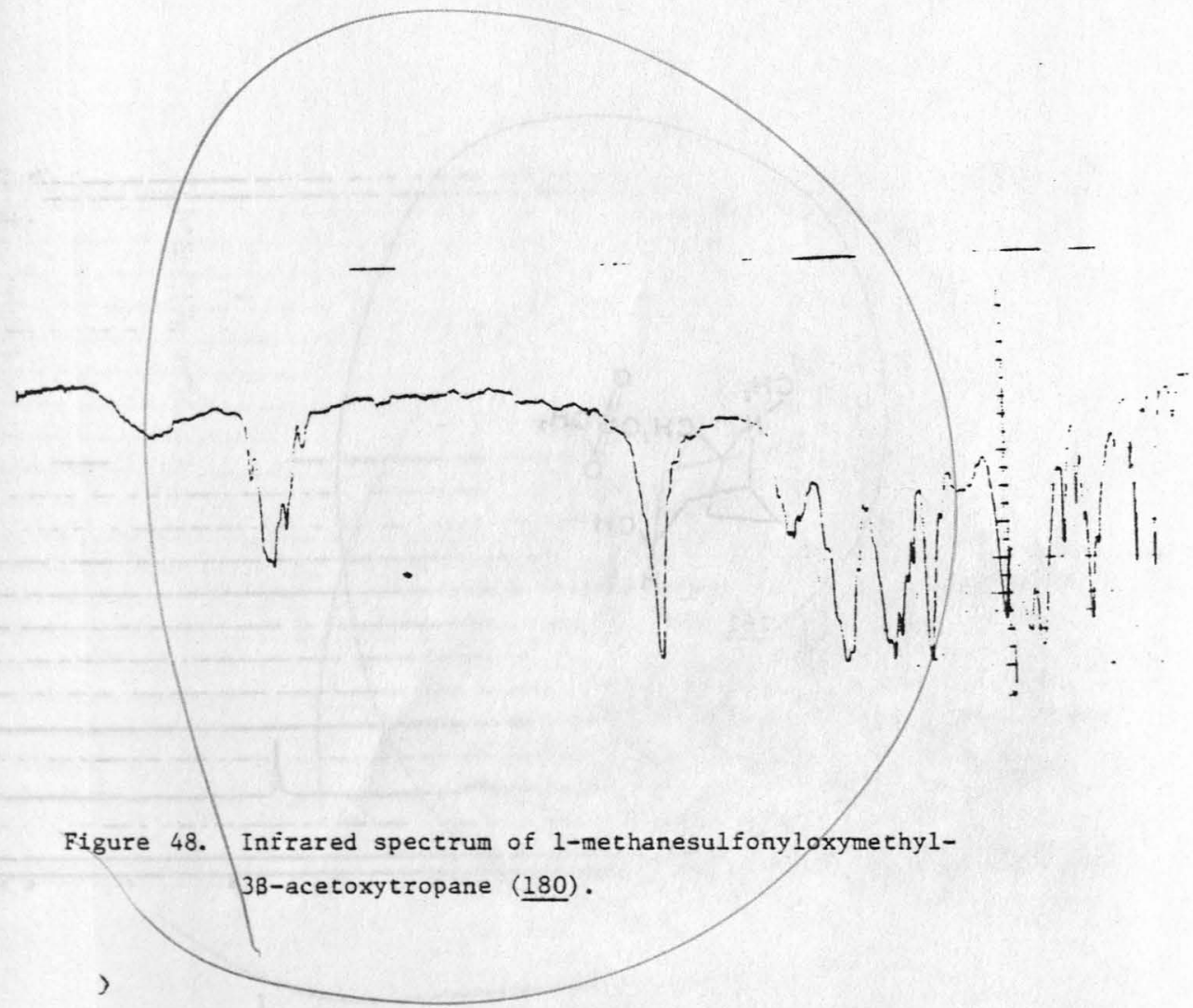




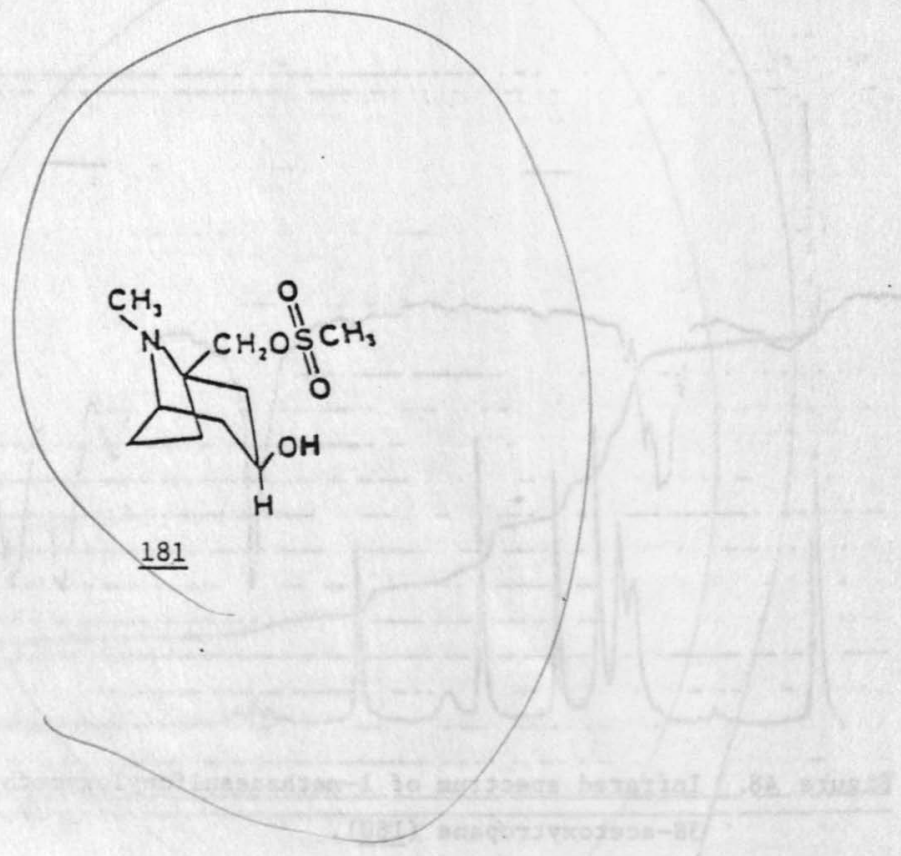




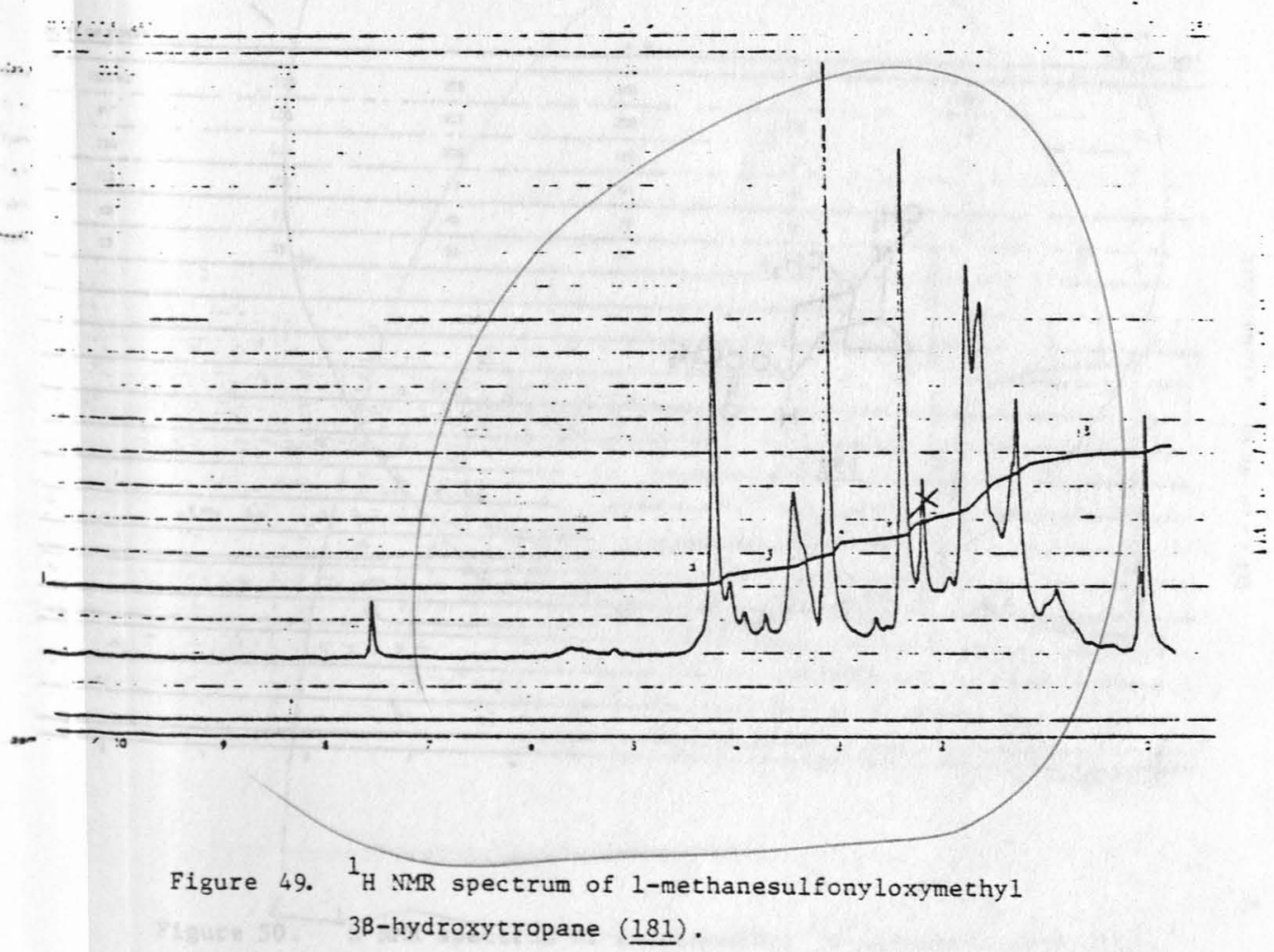




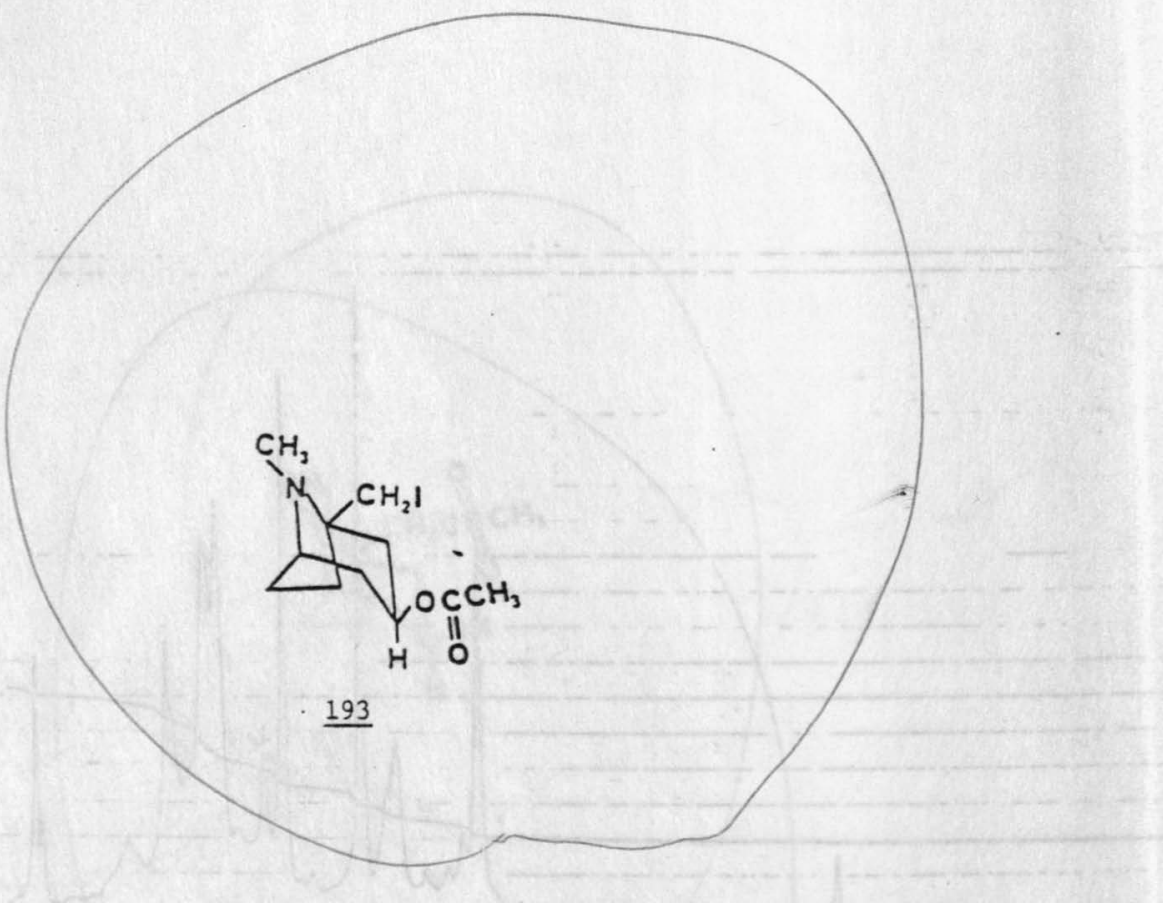




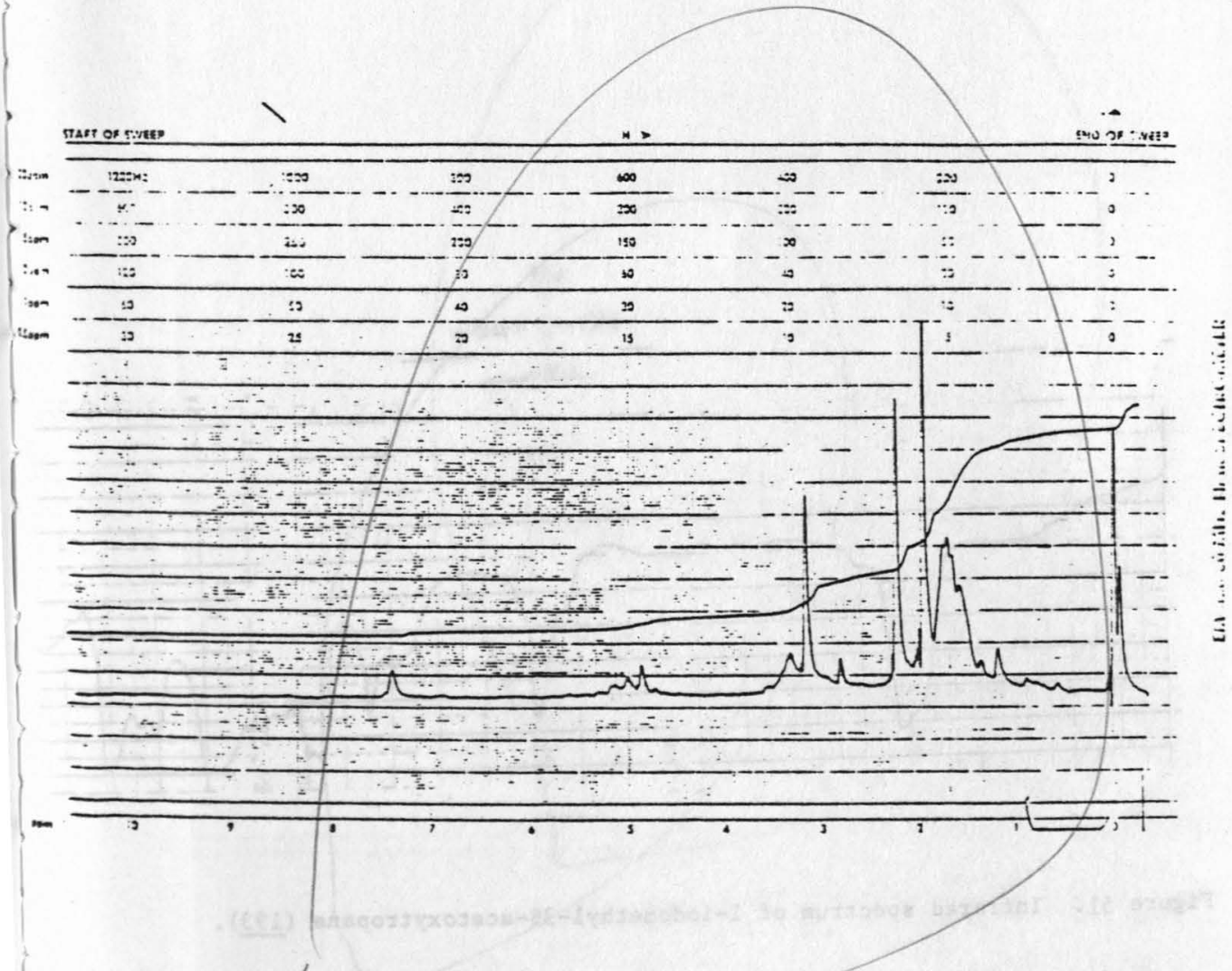

Figure $50 .{ }^{1}$ H NMR spectrum of 1-iodomethyl 3B-acetoxytropane (193). 


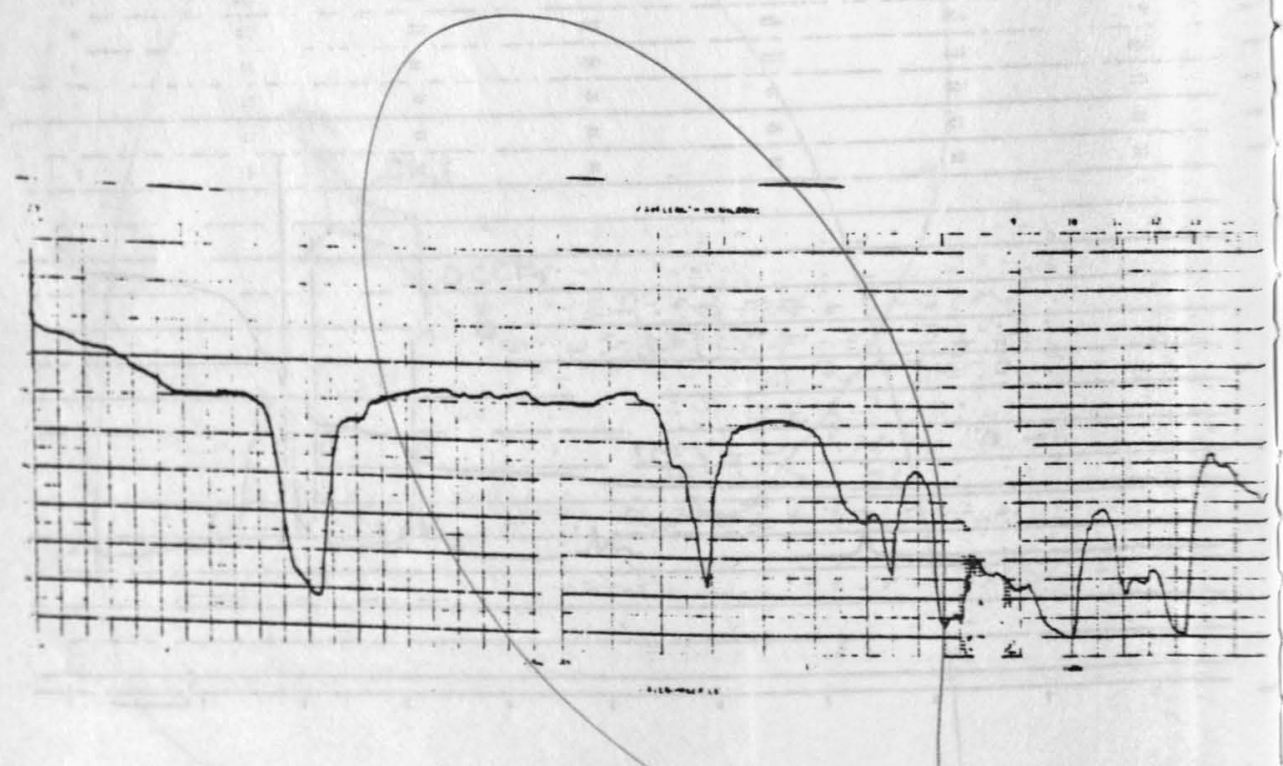

Figure 51. Infrared spectrum of 1 -iodomethyl-38-acetoxytropane (193). 


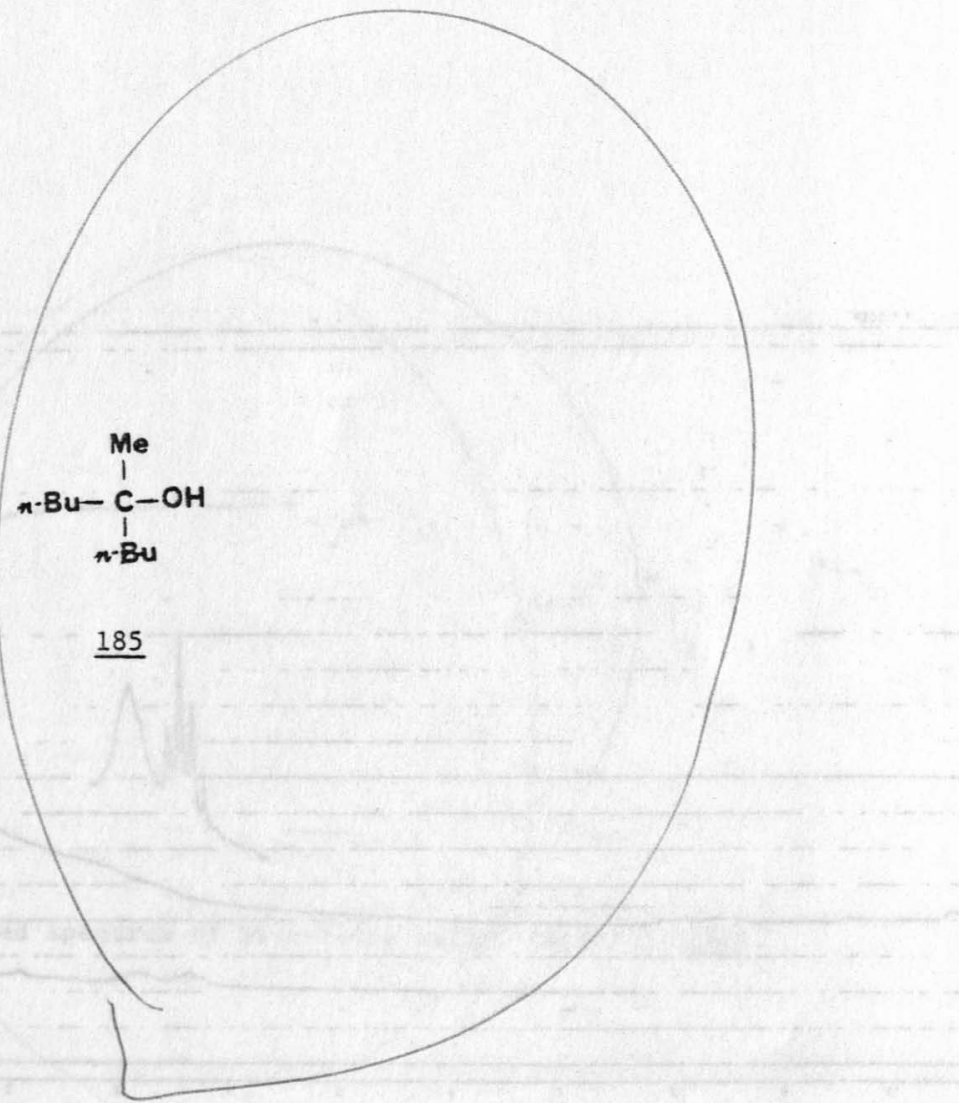




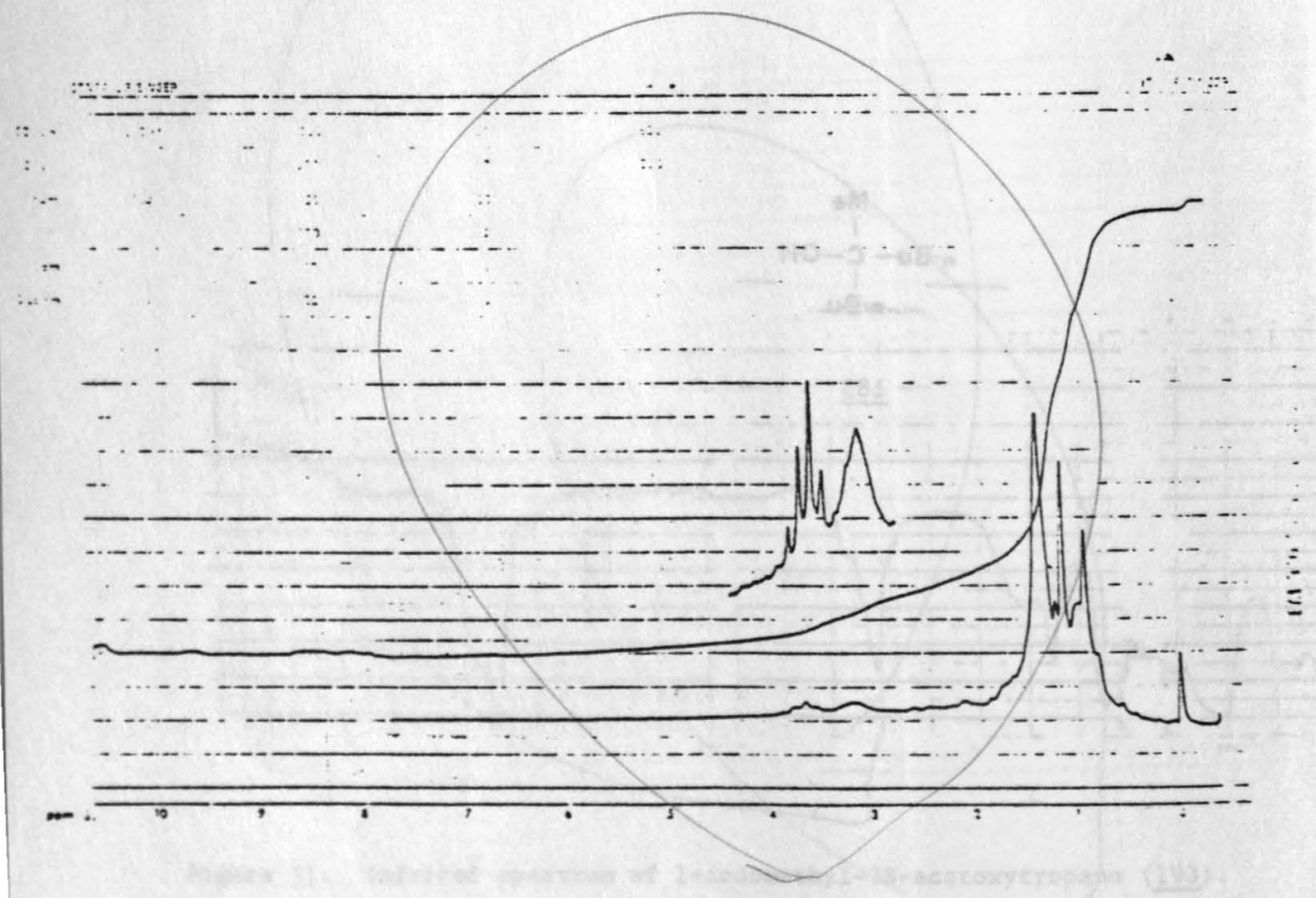

Figure 52. ${ }^{1}$ H NMR spectrum of Di-n-butyl methyl carbinol (185). 


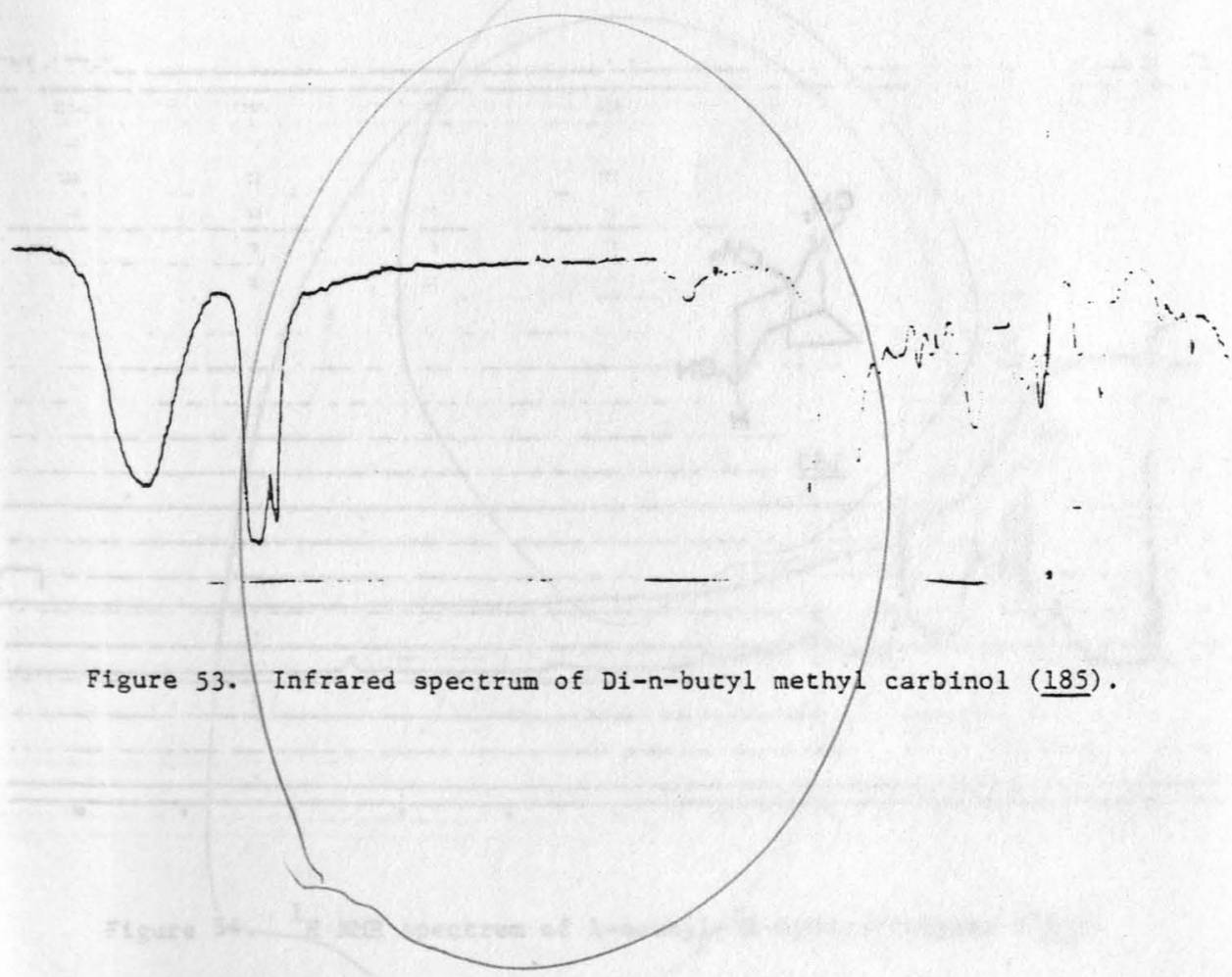


280

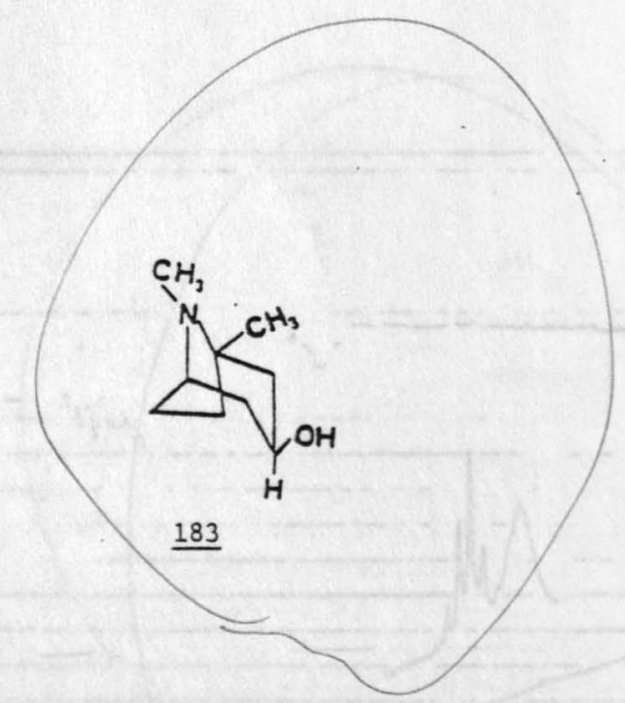




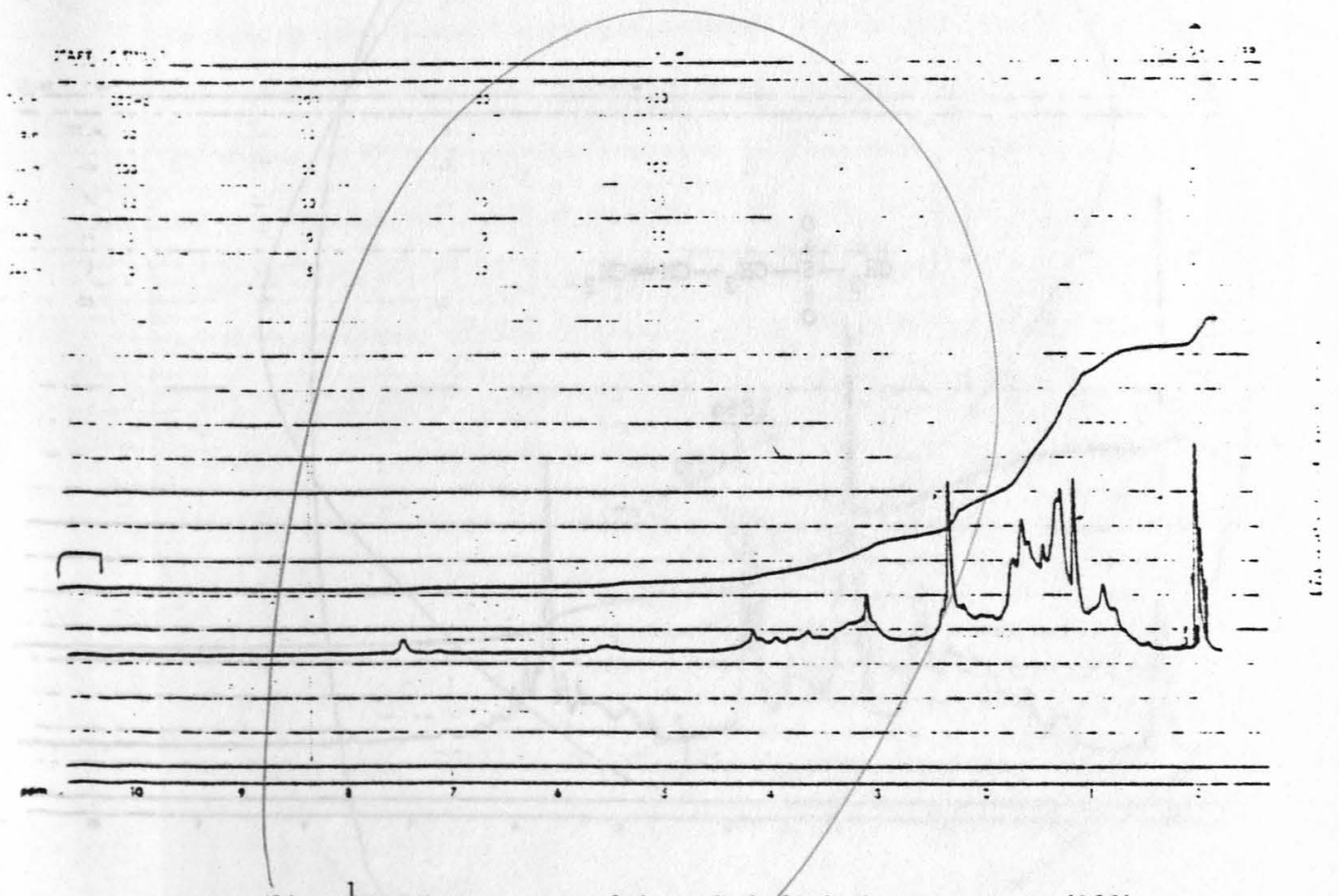

Figure $54.1_{H}$ NMR spectrum of 1-methyl-3B-hydroxytropane (183). 


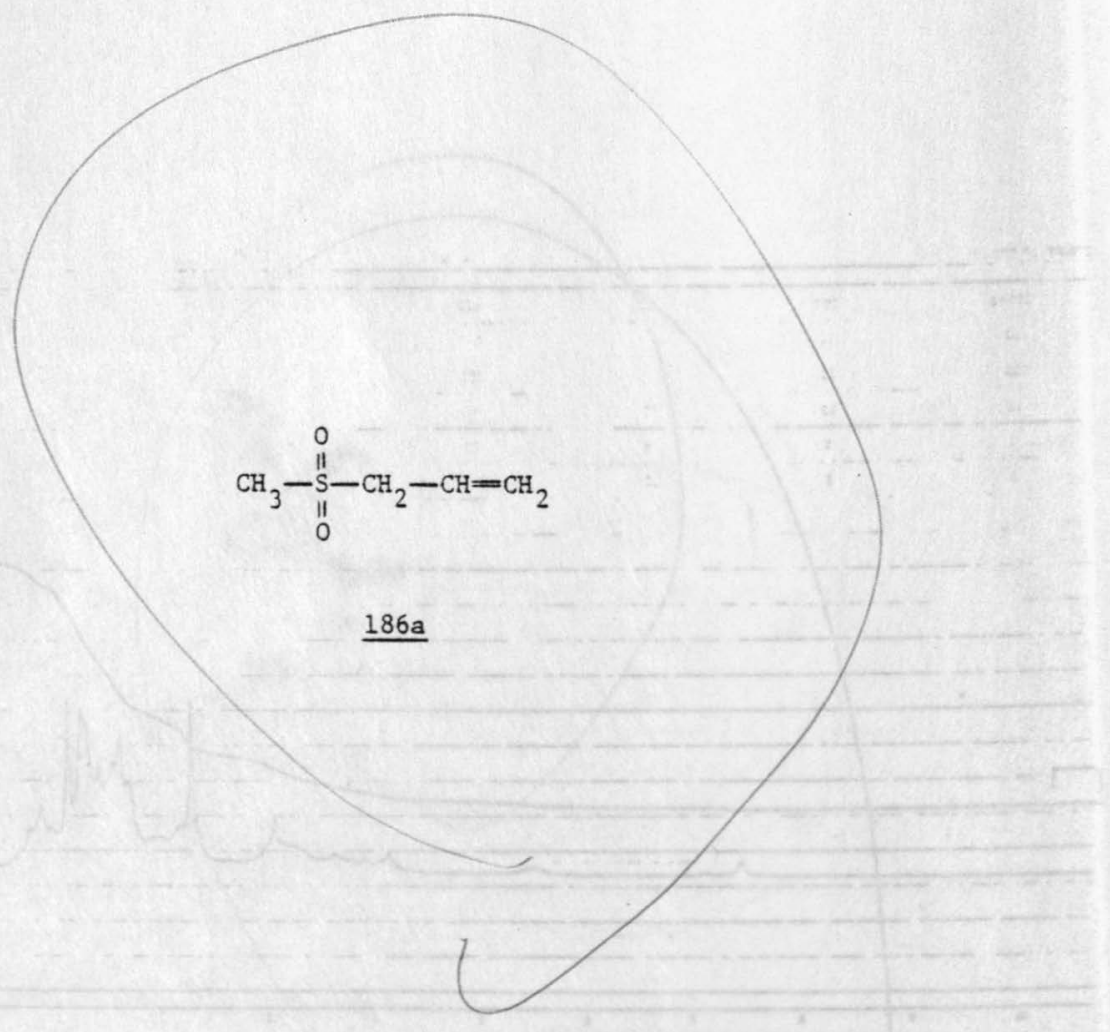




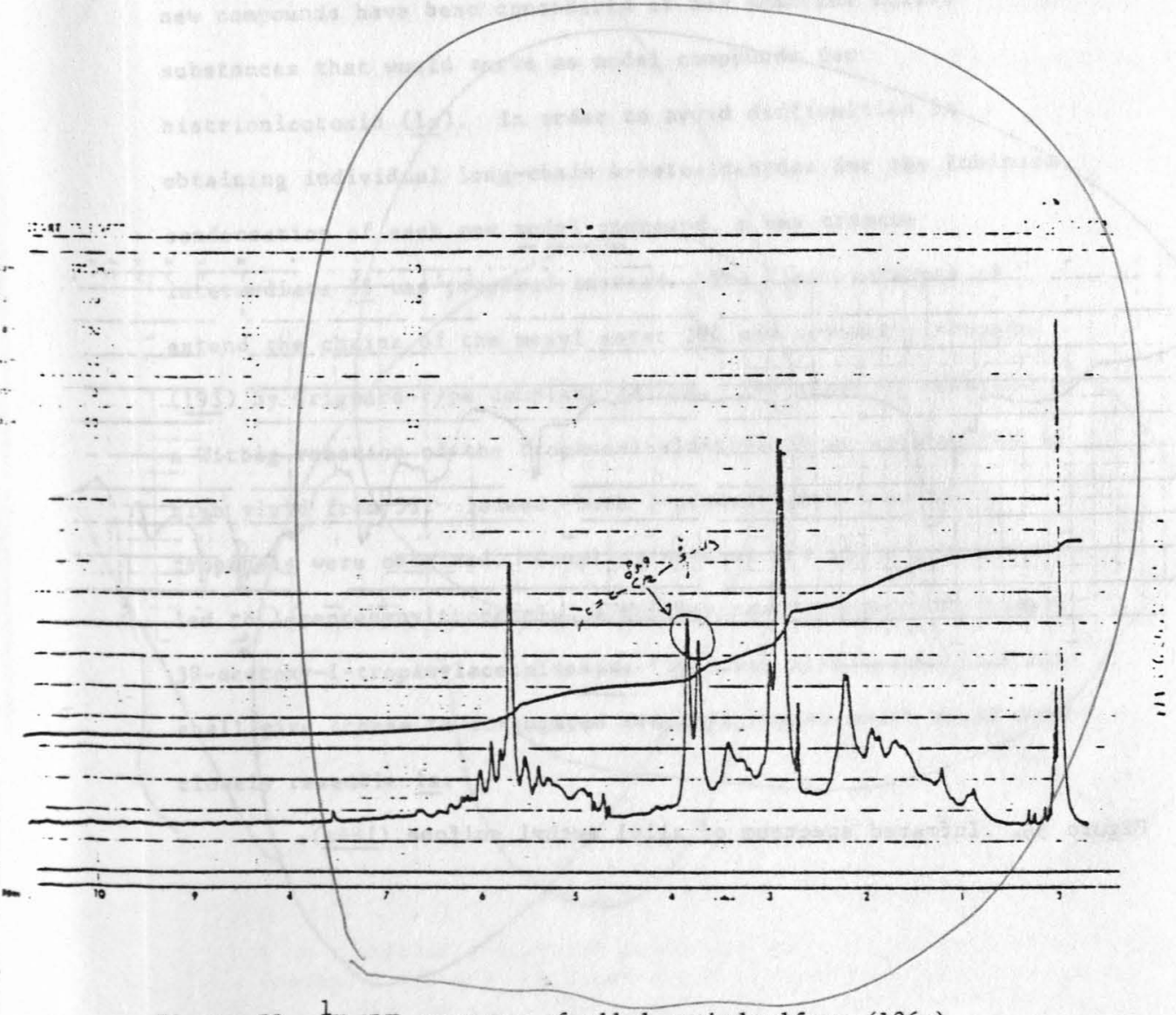

Figure 55. ${ }^{1}$ H IMR spectrum of allyl methylsulfone (186a). 


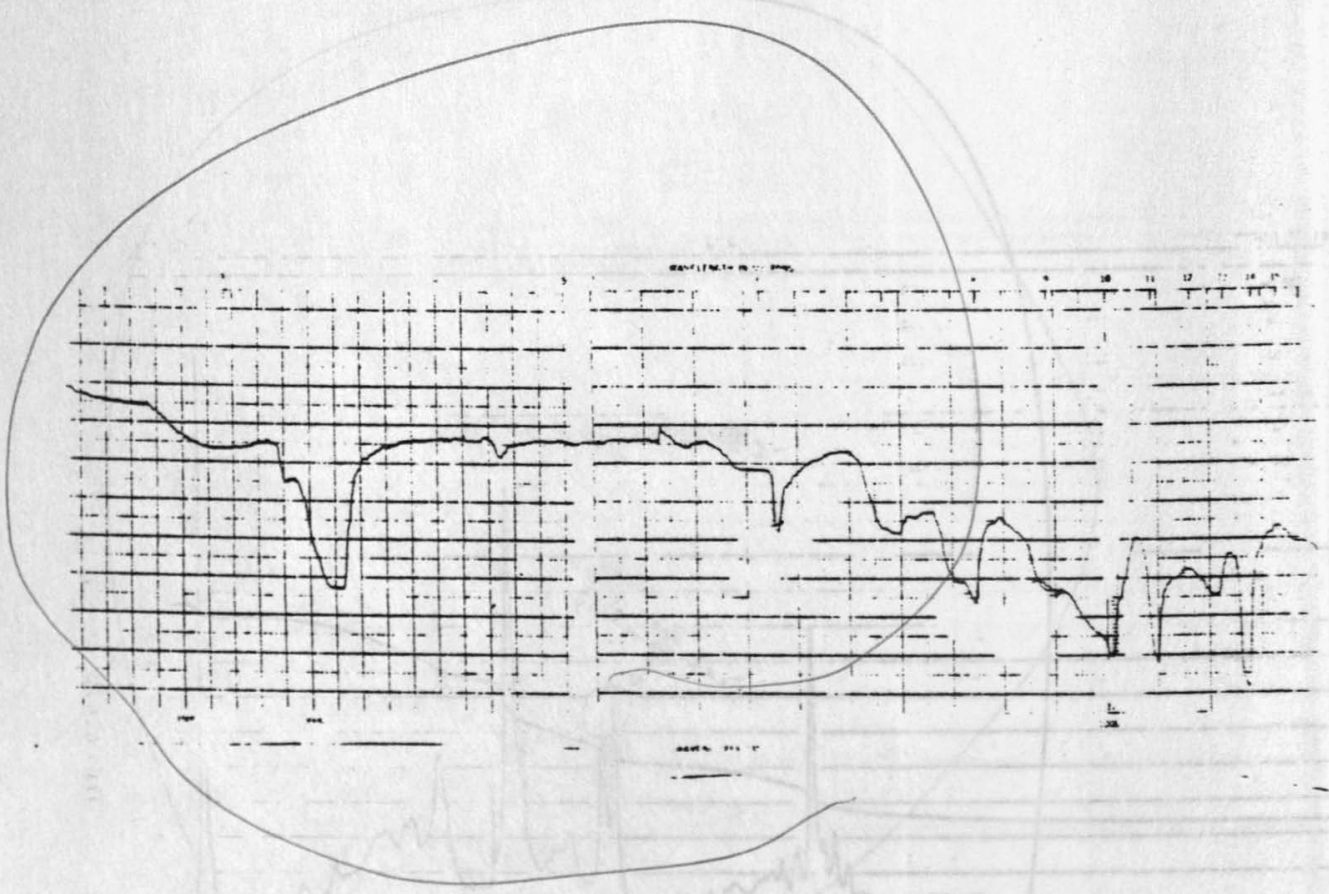

Figure 56. Infrared spectrum of allyl methyl sulfone (186a). 


\section{ABSTRACT}

The synthesis of 3-tropanols and nortropanols, with alkyl, alkenyl and alkynyl groups at the bridgehead was elaborated. The new compounds have been considered as new membrane active substances that would serve as model compounds for histrionicotoxin (1a). In order to avoid difficulties in obtaining individual long-chain 4-ketoaldehydes for the Robinson condensation of each new model compound, a key tropane intermediate 55 was prepared instead. The first attempts to extend the chains of the mesyl ester 180 and iodomethyltropanol (193) by Grigpard-type coupling failed. Therefore we embarked on a Wittig rgaction of the tropane-1-aldehyde 56 we synthesized in high yiefd from 55. Indeed, both 1-pentenyl and 1-pentyltropanofs were obtained. Coupling with an acetylenic phosphorane led to 1-pentenynyltropanol. A further/new/key compound, namely 3B-acetoxy-1-tropanylacetaldehyde ( 164 ) was also synthesized that shall give access to conjugated tropanyl/enynes which would more closely resemble la. 
VITA

Ramalinga Murty Dharanipragada was born in Vijayawada, India on November 9, 1956. He received his early education at Vivekananda Centenary High School. He graduated from Andhra Loyola College in 1975. He obtained his Master's degree in chemistry from the Indian Institute of Technology, Bombay in 1977. After working as a research scholar for a year at the same school, he came to the United States to pursue reseapch in synthetic organic chemistry under the direction of Dr. Gabor Fodor at West Virginia University. He is curtently a candidare

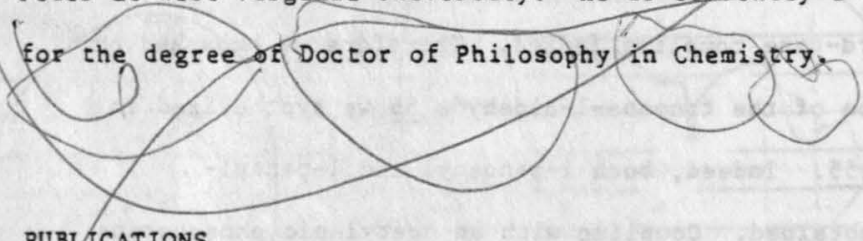

PUBLICATIONS

G. Fodor and R. Dharanipragada in "Tropane Alkaloids", M. F. Grundon, Ed. (Specialist Periodical Reports), The Royal Society of Chemistry, London, 1981, Vol. 11, p. 36-43.

2. G. Fodor and R. Dharanipragada in "Tropane Alkaloids", M. F. Grundon, Ed. (Specialist Periodical Reports), The Royal Society of Chemistry, London, 1982, Vol. 12, p. 45-52.

3. G. Fodor and R. Dharanipragada in "Tropane Alkaloids", M. F. Grundon, Ed. (Specialist Periodical Reports), The Royal Society of Chemistry, London, 1983, Vol. 13, p. 55-64.

4. G. Fodor and R. Dharanipragada in "Tropane Alkaloids", M. F. Grundon, Ed. (Natural Products Reports), The Royal Society of Chemistry, London, 1984, Vol. 1 (\$3), pp. 231-234.

5. G. Fodor and R. Dharanipragada in "Tropane Alkaloids", M. F. Grundon, Ed. (Natural Products Reports), The Royal Society of Chemistry, London, 1985, Vol. 2, manuscript in print.

6. G. Fodor and R. Dharanipragada in "Tropane Alkaloids", M. F. Grundon, Ed. (Natural Products Reports), The Royal Society of Chemistry, London, 1986, Vol. 3, manuscript in preparation. 
7. G. Fodor and R. Dharanipragada, Abstract MEDI 106, 188th National Meeting of the American Chemical Society, Philadelphia, PA (1984).

8. R. Dharanipragada and G. Fodor, "Search for New Membrane Active Substances: Synthesis of 3-Tropanols with Alkyl, Alkenyl and Alkenynl Group at the Bridgehead", submitted to Chem. Soc. for publication. 
288

APPROVAL OF THE EXAMINING COMMITTEE
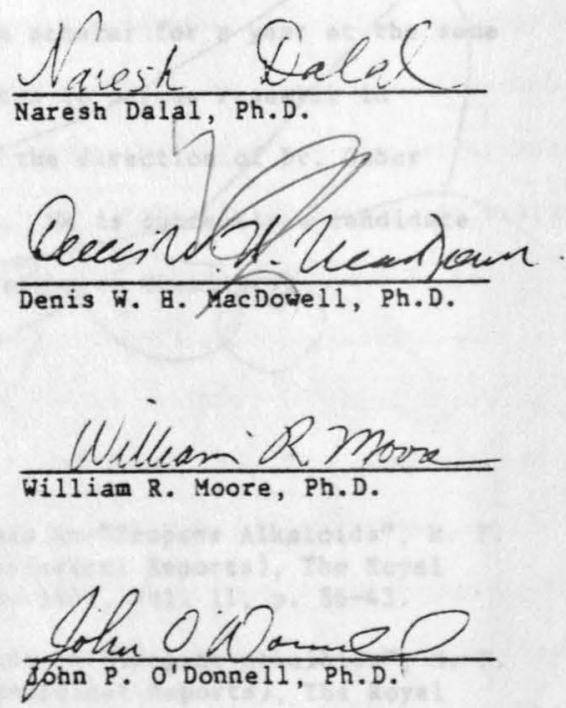

$\frac{\text { Ap in } 16,1985}{\text { Date }}$

$\frac{\frac{3}{4}, 42}{\text { Gabor B. Fodor, PhD., Chairman }}$ 